Portland State University

PDXScholar

Winter 3-14-2018

\title{
Benevolent Sexism and Racial Stereotypes: Targets, Functions, and Consequences
}

Jean Marie McMahon

Portland State University

Follow this and additional works at: https://pdxscholar.library.pdx.edu/open_access_etds

Part of the Social Psychology Commons

Let us know how access to this document benefits you.

\section{Recommended Citation}

McMahon, Jean Marie, "Benevolent Sexism and Racial Stereotypes: Targets, Functions, and Consequences" (2018). Dissertations and Theses. Paper 4227.

https://doi.org/10.15760/etd.6111

This Dissertation is brought to you for free and open access. It has been accepted for inclusion in Dissertations and Theses by an authorized administrator of PDXScholar. Please contact us if we can make this document more accessible: pdxscholar@pdx.edu. 
Benevolent Sexism and Racial Stereotypes:

Targets, Functions, and Consequences

by

Jean Marie McMahon

A dissertation submitted in partial fulfillment of the requirements for the degree of

\author{
Doctor of Philosophy \\ in \\ Applied Psychology
}

Dissertation Committee:

Kimberly Barsamian Kahn, Chair

Cynthia Mohr

Eric Mankowski

Kris Henning

Portland State University

2018 
(C) 2018 Jean Marie McMahon 


\begin{abstract}
In this dissertation, I present three manuscripts in which I integrate race into an ambivalent sexism framework using experimental, correlational, and cross-sectional methods. The first paper (McMahon \& Kahn, 2016; chapter II) tests whether a female's race acts as a subtype to differentially elicit benevolent sexism (BS). Two experiments demonstrated that BS is more strongly associated with White women than Black women. The second paper (McMahon \& Kahn, 2017; chapter III) explores the relationship between protective paternalism (a subcomponent of BS), anti-minority attitudes, and threat. Threat was associated with stronger endorsement of protective paternalism and a corresponding increase in anti-minority attitudes, particularly for White men, implicating BS in the maintenance of racial inequality. Finally, my third study (chapter IV) investigated potential real-world consequences of the differential application of BS to Black and White women in the context of police responses to intimate partner violence (IPV). Officers were more likely to file supplemental paperwork for White victims than Black victims, and were most likely to do so when encountering a White victim and a Black suspect. White victims were also written about with a greater "risk focus", consistent with BS. In sum, chapter II (McMahon \& Kahn, 2016) establishes racial differences in who receives BS, chapter III (McMahon \& Kahn, 2017) demonstrates how paternalistic protections of White women are racialized, and chapter IV reveals how the intersection of BS with racial stereotypes may impact women seeking help from police. This dissertation is the first investigation in the social psychological literature of how race informs the targets, function, and consequences of BS.
\end{abstract}




\section{Acknowledgements}

I want to extend my appreciation to my dissertation committee for their expertise and enthusiasm throughout this process. I'm also grateful to Sgt. Greg Stewart for his unwavering generosity and interest, which made my third study possible. Kim - six years ago you picked your first graduate student and I am so gratified that you picked me. Thank you for your unfailing patience, guidance, and encouragement during our many meetings and collaborations. I have watched your career take off, and I'm excited to see what comes next for the both of us.

I also wish to thank my past psychology instructors for setting me on this course, especially Dr. Joseph “it’s a great day to be alive!” Bogan at Paschal High School and Kathy Oleson, Jennifer Henderlong Corpus, and Kris Anderson at Reed College. And special thanks to my very first teacher, Gracie, who called me her "little scientist."

I'm grateful to my friends and peers for their encouragement throughout graduate school, including the past and present members of the GRASP lab, my Reed family, the PSU social track, and my 2012 cohort. And thank you, Stephanie and Jonathan, my oldest and dearest friends.

And finally, to Dr. Edward J. McMahon II and Dr. Nadia M. Lahutsky, my wonderful parents: I could never have done any of this without you. Thank you. 


\section{Table of Contents}

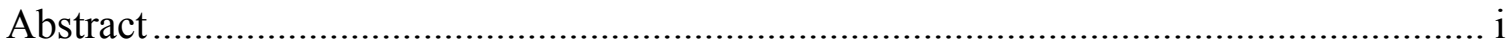

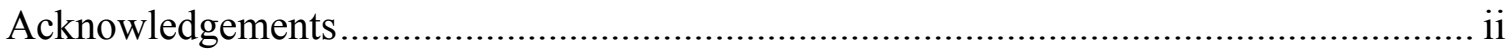

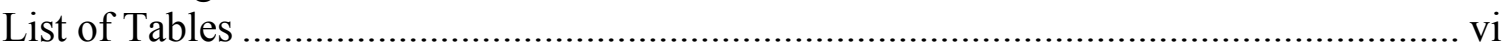

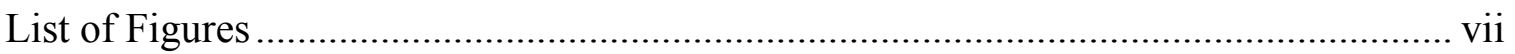

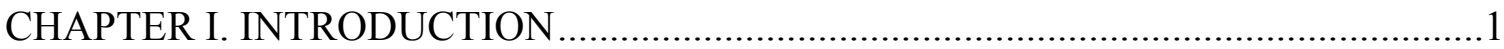

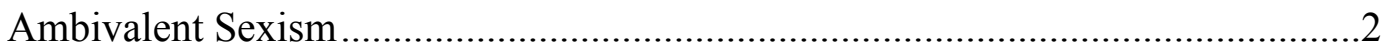

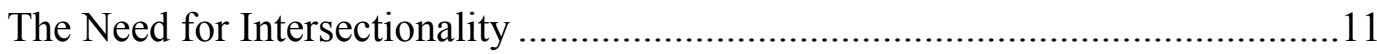

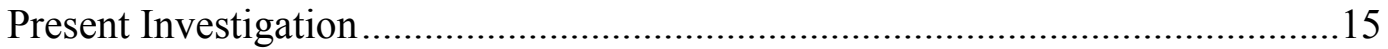

Chapter II Overview: Benevolent racism? The impact of target race on

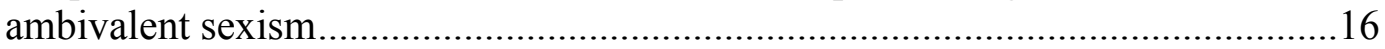

Chapter III Overview: When sexism leads to racism: Experiencing threat, protecting women, and racial bias ................................................................ 17

Chapter IV Overview: To protect and serve: Police responses to Black and White female victims of intimate partner violence..........................................19

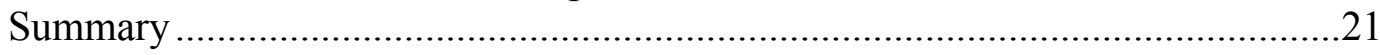

\section{CHAPTER II. MANUSCRIPT I. BENEVOLENT RACISM? THE IMPACT OF}

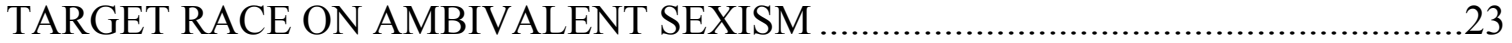

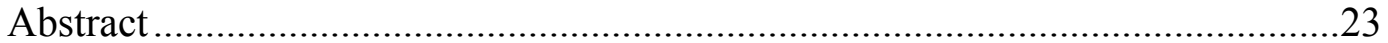

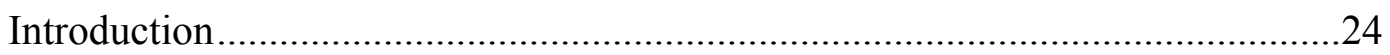

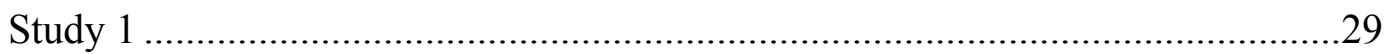

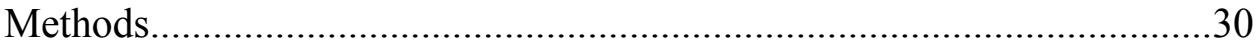

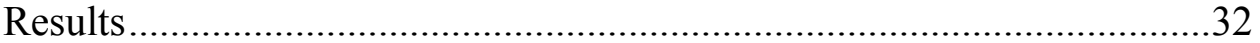

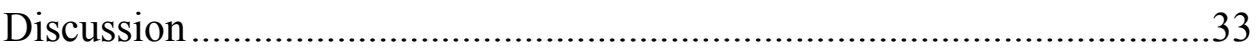

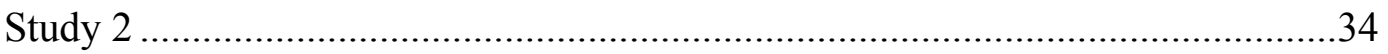

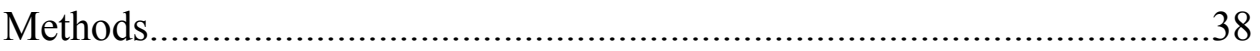



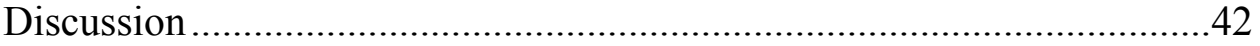

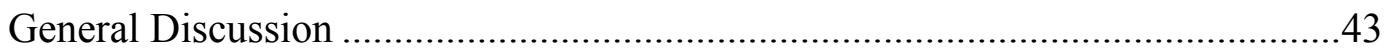

\section{CHAPTER III. MANUSCRIPT II. WHEN SEXISM LEADS TO RACISM:}

EXPERIENCING THREAT, PROTECTING WOMEN, AND RACIAL BIAS.............51



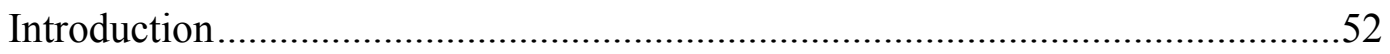



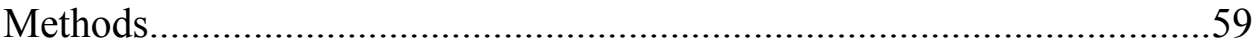

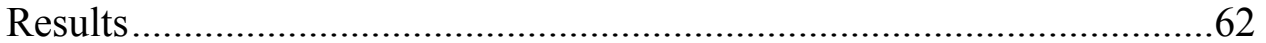

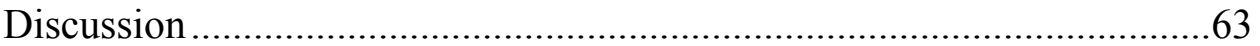

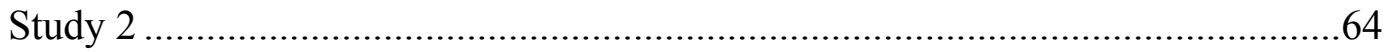

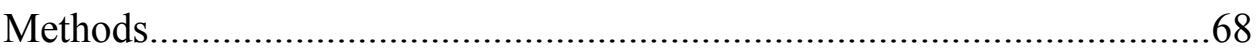

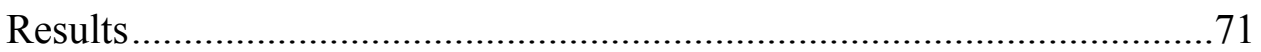

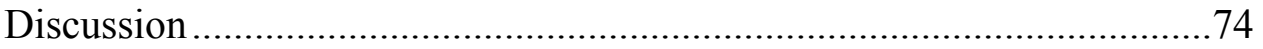




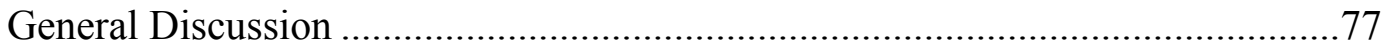

Limitations and Future Research Directions..............................................79

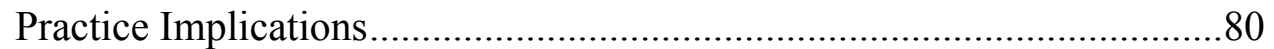

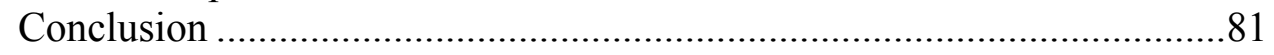

\section{CHAPTER IV. MANUSCRIPT III. TO PROTECT AND SERVE: POLICE} RESPONSES TO BLACK AND WHITE FEMALE VICTIMS OF INTIMATE

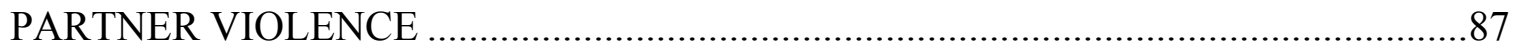

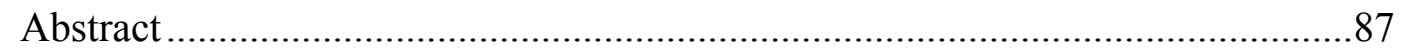

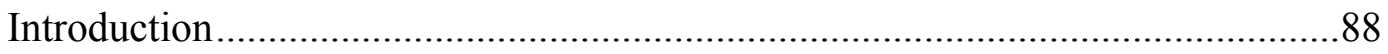

Intimate Partner Violence ………………………………...................... 89

Social Psychology, Police, and IPV ......................................................97

The Current Study …………………….........................................................105

Study Development and Data Sources....................................................105

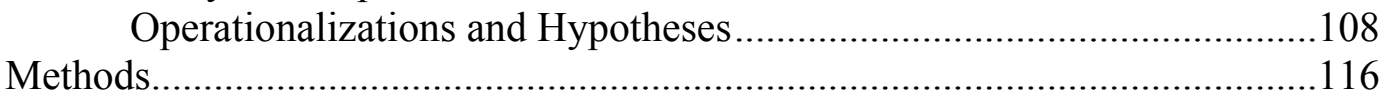

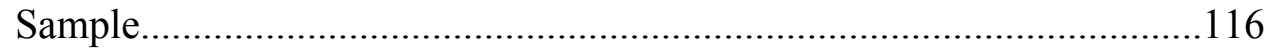

Data Preparation and Coding .............................................................117

Control Variables ............................................................................... 118

Paternalism Dictionary ....................................................................120

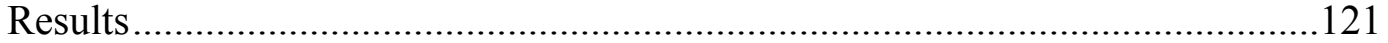

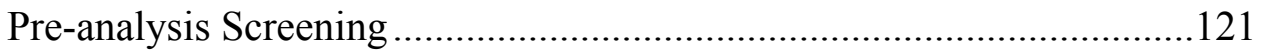

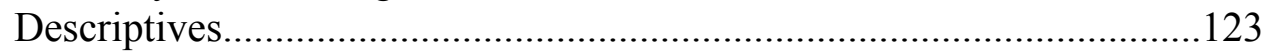

Basic Reporting Hypotheses ................................................................124

Discretionary Effort Hypotheses...........................................................127

Linguistic Hypothesis ..........................................................................131

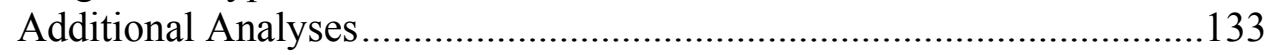

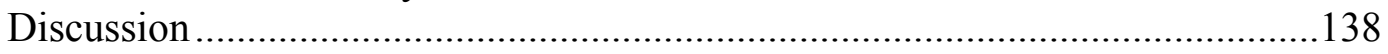

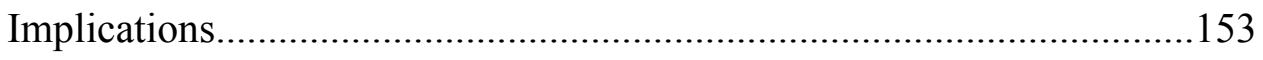

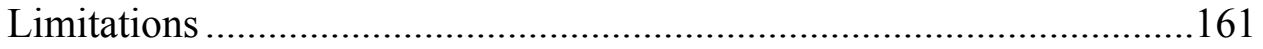

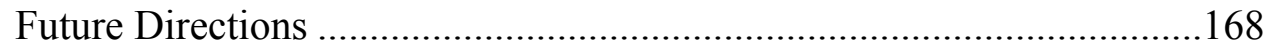

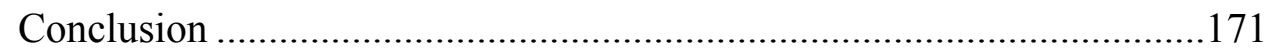

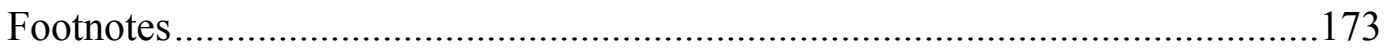

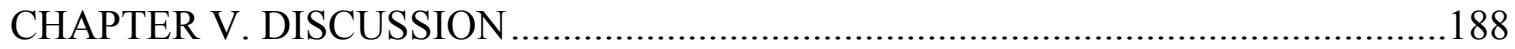

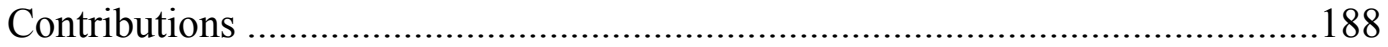

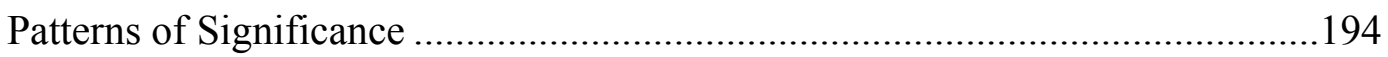

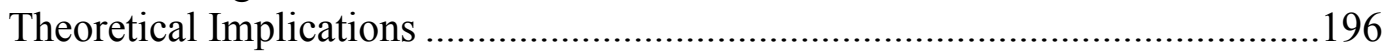

Applied Implications ..................................................................................199

Limitations and Future Directions .............................................................201

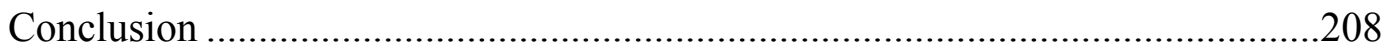

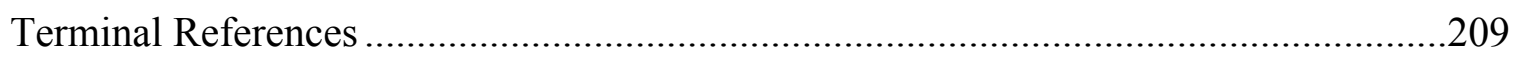

Appendix A: Narrative Coding Instructions …………….........................................229

Appendix B: Narrative Examples ..........................................................................231 


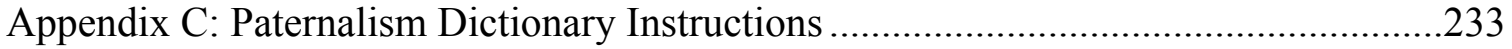

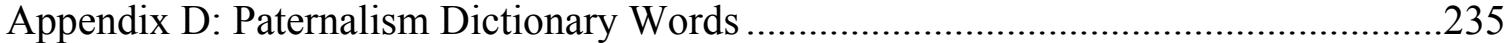

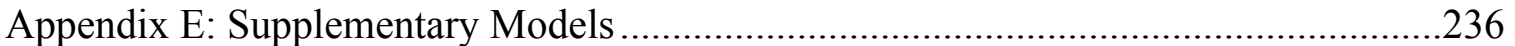




\section{List of Tables}

\section{Chapter III}

Table 1.0: Descriptive Statistics and Correlations for Study Variables,

Studies 1 and 2

Table 1.1: Moderation by Participants' Race and Gender for the Relation

Between Protective Paternalism and Three Racial Bias Outcomes, Study 1 ........83

Table 1.2: Moderated Mediation Results, Study 2

\section{Chapter IV}

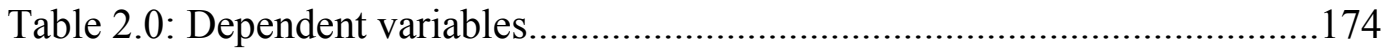

Table 2.1: Control and independent variables ...............................................175

Table 2.2. Descriptive frequencies for control and outcome variables................176

Table 2.3. Descriptive statistics for control and outcome variables ....................177

Table 2.4. Results of sequential logistic regression predicting filing of the

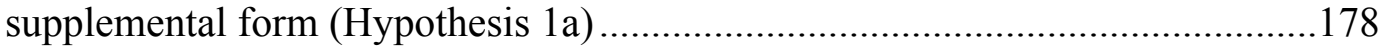

Table 2.5. Exploratory results of sequential logistic regression predicting filing of the supplemental form.

Table 2.6. Testing the moderating effect of suspect race on the relation between victim race and filing the supplemental form

Table 2.7. Results of sequential logistic regression predicting completed incident details (Hypothesis 1b)....

Table 2.8. Results of sequential multiple regression predicting number of victim interview questions answered (Hypothesis 2a).

Table 2.9. Results of sequential logistic regression predicting a completed victim interview (Hypothesis 2a).

Table 2.10. Results of sequential multiple regression predicting narrative length (in word count) (Hypothesis 2b)....

Table 2.11. Results of sequential logistic regression predicting officers taking photographic evidence (Hypothesis 2c).

Table 2.12. Results of sequential logistic regression predicting child interview (Hypothesis 2d).

Table 2.13. Results of sequential logistic regression predicting the giving of informational resources to the victim (Hypothesis 2e).

Table 2.14. Results of sequential logistic regression predicting the offering of a DV advocate (Hypothesis 2f)

Table 2.15. Results of multiple linear regression predicting risk focus in the narrative reports (Hypothesis 3)

Table 2.16. Results of sequential multiple regression predicting protective paternalism in the narrative reports (Hypothesis 4).....

Table 2.17. Results of supplemental sequential multiple regression predicting number of discretionary behaviors at the scene.

Table 2.18. Results summary. 


\section{Chapter II}

\section{List of Figures}

Figure 1.0: Ratings for Black and White females in Study 1

Figure 1.1: Benevolent evaluations of women in Study 2

Figure 1.2: Hostile evaluations of women in Study 2 ......................................50 Chapter III

Figure 2.0: Moderated mediation for beliefs that racial bias is a problem in policing.

Figure 2.1: Moderated mediation for beliefs that immigration

will have negative consequences .85

Figure 2.2: Moderated mediation for support for policies

that target racial minorities

\section{Chapter IV}

Figure 3.0. Mediation model (Hypothesis 5) 


\section{CHAPTER I. INTRODUCTION}

Despite the significant strides toward equality that have been achieved in the last century, sexism remains a pressing social issue. Sexism refers to the "subordination of women's social, cultural, political, and educational rights as human beings and the unequal distribution of power and resources between men and women based on gender" (Marable, 2004, p. 162). Differences in outcomes for men and women can be found across domains. Compared to men, women earn less (Patten, 2015), are less likely to be hired in male-dominated fields (Goldin \& Rouse, 2000; Lyness \& Heilman, 2006; Reuben, Sapienza, \& Zingales, 2014), shoulder more domestic responsibilities (Bureau of Labor Statistics, 2008), and are more likely to live in poverty (National Women's Law Center, 2016a). They are also underrepresented at the highest levels of government (U.N. Women, 2016) and business (Taube, 2014), and more likely to experience rape, stalking, and intimate partner violence (Breiding, 2014). The systematic subordination of women is partially sustained by discriminatory laws and practices (U.N. Women, 2017), but also through individuals' sexist attitudes and beliefs. Gender-related beliefs are often socialized from parent to child (Tenenbaum \& Leaper, 2002), further perpetuating them. Benevolent sexism (Glick \& Fiske, 1996) is an especially pernicious ideology that justifies and maintains the status quo (Jost \& Kay, 2005).

The goal of this dissertation is to integrate race into the study of benevolent sexism (BS). Across three manuscripts and five studies, I examine how race impacts the targets, functions, and consequences of benevolent sexism. The first paper (McMahon \& Kahn, 2016; chapter II) tests for racial differences in who receives benevolent sexism 
(White vs. Black women), establishing White women as the primary targets. The second paper (McMahon \& Kahn, 2017; chapter III) examines how, for White men, paternalistic protections of women are related to anti-minority attitudes, illuminating benevolent sexism's function in the maintenance of racial inequality. The final study (chapter IV) tests for evidence of the differential application of benevolent sexism to Black and White women in the records of police officers responding to intimate partner violence, thereby demonstrating consequences of my previous studies in an applied context.

\section{Ambivalent Sexism}

Early social psychological definitions of prejudice viewed it as antipathy or contempt toward an outgroup (Allport, 1954). Measures of sexism similarly focused on negative beliefs about women (Spence, Helmreich, \& Stapp, 1973; Swim, Aiken, Hall, \& Hunter, 1995). However, this definition is insufficient to explain why women, who have historically been subordinate to men, are also stereotyped more positively than they are (Swim, 1994) and assigned numerous favorable traits, such as warmth and nurturance (Eagly \& Mladinic, 1994). Ambivalent sexism theory (AST; Glick \& Fiske, 1996) was one of the earliest challenges to the predominant view that prejudice was solely a negative attitude.

At the core of ambivalent sexism theory is the premise that relations between men and women are characterized by the coexistence of both power differences and intimate interdependence. Men possess structural control of political, economic, religious, and legal institutions across cultures and time (Harris, 1991), but the biological realities of sex and procreation create a unique situation in which men (the dominant group) are also 
didactically dependent on women as mothers and intimate partners. Women are thereby afforded an honored place in patriarchal society in which they may be revered in their roles as wives and mothers and idealized as romantic objects (Guttentag \& Secord, 1983). However, men's social dominance also fosters hostility toward women who challenge the gender-stratified status quo. Rather than uniformly negative or overwhelmingly positive, sexism is better characterized as, "a special case of prejudice marked by a deep ambivalence", whereby women as a whole are at once condemned and adored (Glick \& Fiske, 1996, p. 491).

Components. Ambivalent sexism theory (Glick \& Fiske, 1996) posits that sexism has two distinct yet related components. Hostile sexism (HS) embodies the antipathy usually seen in prejudices, featuring derogatory characterizations of women as manipulative with their sexuality, unappreciative of and seeking to gain power over men, and too easily offended. Benevolent sexism takes a more positive tone by portraying women as pure, defenseless, and necessary for men to be complete. This set of beliefs is rooted in three subfactors: paternalism, gender differentiation, and heterosexuality. Protective paternalism argues that men possess superior strength and authority and ought to protect and provide for their wives and families. It is ideologically akin to the "White Man's Burden", where the dominant group has a sacred duty to care for the helpless and childlike subordinate group. Gender differentiation, rooted in biological essentialism, suggests that women have positive qualities that complement those of men, such as sensitivity and nurturance, which make them uniquely suited for domesticity and being a male partner's "better half." Finally, needs for heterosexual intimacy create a context in 
which the dominant group (men) depends upon the subordinate group (women).

Both hostile and benevolent sexism are related to various facets of conservative ideology, which consists of a set of interrelated beliefs including social dominance orientation (SDO), right-wing authoritarianism (RWA), and the Protestant work ethic (PWE) (Christopher \& Mull, 2006). Specifically, support for maintaining the social hierarchy (i.e. high SDO) and distain for those trying to gain resources they do not deserve (i.e. high PWE) predicts greater endorsement of HS, while the desire to preserve social traditions (i.e. high RWA) predicts greater endorsement of BS. These relationships hold over time, with SDO predicting increases in HS (but not BS), and RWA predicting increases in BS (but not HS) (Sibley, Wilson, \& Duckitt, 2007). Ambivalent sexism is thus a prejudicial attitude (concerning women in particular) that, like biases toward other social groups (e.g. Ekehammar, Akrami, Gylje, \& Zakrisson, 2004), is predicted by conservative ideologies.

Positive prejudices. AST was unique for its time in that it emphasized the positive and negative components of prejudice rather than focusing solely on hostility. From this paradigm shift emerged a more nuanced understanding of the mixed nature of stereotyping and prejudice. The originators of the ASI, Peter Glick and Susan Fiske, went on to incorporate this idea into their Stereotype Content Model (Fiske, Cuddy, Glick, \& Xu, 2002), which holds that stereotypes are captured by two separate dimensions warmth and competence. While some groups are stereotyped in ways that are wholly negative (not warm and not competent, e.g. welfare recipients, poor people) or positive (both warm and competent, e.g. Whites, the middle class, Christians), many group 
stereotypes have both positive and negative components. Groups that are stereotyped as warm but incompetent include housewives, the elderly, and the disabled; groups seen as competent but not warm include feminists, businesswomen, Asians, and Jews. These stereotypes are rooted in the relative status and competition between groups and serve to explain and justify their positions within society. For groups that are high-status and competitive, such as Asians or businesswomen, stereotypes of their competence justify the meritocratic system that benefits the dominant ingroup, but stereotypes of low warmth support the ingroup's resentment of their success. For subordinate, cooperative groups, such as the elderly or housewives, stereotypes of low competence justify their subordination while stereotypes of warmth encourage their compliance.

Not surprisingly, ambivalent sexism aligns with this model of ambivalent stereotypes. Warm but incompetent women include traditional subtypes like housewives (who receive BS), while non-traditional women (who receive HS) are recognized as competent but lacking in warmth (Cuddy, Fiske, \& Glick, 2008). Hostile and benevolent sexism therefore serve the same system-justifying function as positive and negative stereotypes of other groups, such as Asians (who are seen by the dominant group as competent, and therefore deserving of their high status, yet cold, justifying feelings of mistrust).

If ambivalent sexism differs from other forms of bias, it would be in the degree of interdependence between the two groups (i.e. men and women), which is qualitatively different from the relations between racial, national, religious, or other social groups (Glick \& Fiske, 1996; Glick \& Fiske, 2011). “Unlike most intergroup relations, in which 
'we' not only can but often prefer to live without 'them', heterosexual men could not imagine living completely without women" (Glick \& Fiske, 2011, p. 532). The power differential between men and women coincides with sexual drives, familial bonds, and feelings of sincere affection and love. No other intergroup context (e.g. Black and White, heterosexual and homosexual, Protestant and Catholic) is characterized by such didactic dependence and genuine intimacy. Positive stereotypes do exist about other outgroups (e.g. Asians, the rich), but they are not rooted in the same biological necessities and romantic ties that characterize sexism, "the oldest form of prejudice" (Cuddy et al., 2008, p. 76). Notably, while groups about whom there are positive stereotypes can still be viciously turned on during times of societal breakdown (e.g. Jews in Europe, Tutsis in Rwanda), it is difficult to imagine a scenario in which women as a group are wholly rejected (Cuddy et al., 2008).

Measurement. Endorsement of HS and BS are measured on a 0-5 Likert scale with the 22-item Ambivalent Sexism Inventory (ASI; Glick \& Fiske, 1996). Eleven items assess hostile sexism (e.g. "Most women interpret innocent remarks or acts as being sexist"; "Women seek to gain power by getting control over men.") For benevolent sexism, four items measure the heterosexual intimacy subcomponent (e.g. "No matter how accomplished he is, a man is not truly complete as a person unless he has the love of a woman"), four items measure the protective paternalism subcomponent (e.g. "Men should be willing to sacrifice their own well being in order to provide financially for the women in their lives"), and three items assess the gender differentiation subcomponent (e.g. "women, compared to men, tend to have a more refined sense of culture and good 
taste.")

While a shorter version of the ASI containing only twelve of these items has been created (Rollero, Glick, \& Taraglia, 2014), the original ASI is the most widely used. Much of ambivalent sexism research is concerned with correlating the original ASI with other variables (Lee, Fiske, \& Glick, 2010) or using endorsement of HS and BS to predict perceptions of targets (e.g. rape victims, Abrams, Tenyadi Viki, Masser, \& Bohner, 2003).

The ASI has been tested on student and community samples in 19 countries on six continents (Glick et al., 2000), with high correlations and consistent factor structures across nations, suggesting that ambivalent sexism is a coherent ideological construct at the societal level. However, the ASI scale itself has been critiqued for being culturespecific, as it was developed using majority White middle-class American student samples (Glick \& Fiske, 1996) and specific items, even when translated directly into other languages, may not tap into the same construct in a different cultural context (Gibbons, Hamby, \& Dennis, 1997). For instance, the belief that women have a "more refined sense of culture and good taste" may not be present in China, where men are considered superior in this domain (Gibbons et al., 1997). A comparison of African, Asian, Latinx, and European Americans' responses to the ASI (Hayes \& Swim, 2013) revealed that the BS subscale had low internal reliability for the African and Latinx participants $(<.6 \alpha<.7)$. The authors concluded that the ASI could, for the most part, be used to validly and reliably assess different ethnic populations within the United States, but that the BS subscale items may have different meanings for ethnic minority groups. The subjectively positive tone and evaluations of women suggested by benevolent 
sexism belie the harm it does to individuals and gender equality as a whole. The typical targets of benevolent sexism, its function in the maintenance of women's subordination at the societal level, and the consequences it has for individual women are detailed below.

Targets of benevolent sexism. When compared side by side, hostile and benevolent ideologies appear in conflict. HS suggests that women deserve men's mistrust and distain, while BS depicts a much more positive image of women rooted, oftentimes, in feelings of genuine affection; the latter places women on the proverbial pedestal, the former, in the gutter (Tavris \& Wade, 1984). Rather than being perceived as one cohesive group, women are separated into distinct subtypes based on their behavior that characterizes them as good or bad. "Good women" are those who conform to traditional gender norms by being adoring wives, nurturing mothers, and chaste, while "bad women" are those who reject these traditional expectations by being feminists, career-oriented, lesbians, or sexually promiscuous (Glick, Diebold, Bailey-Werner, \& Zhu, 1997; Sibley \& Wilson, 2004). Benevolent sexism, in the form of romantic adoration, societal approval, and personal protection, is rewarded to these "good women" who remain in traditional gender roles characterized by domesticity, chastity, and motherhood (Glick \& Fiske, 2001a). Women who do not conform to these roles are rejected and punished with hostile sexism (Glick \& Fiske, 2001a).

Function of benevolent sexism at the societal level. Hostile and benevolent sexism are mutually reinforcing and work in tandem to maintain patriarchal hegemony. Benevolent sexism, with its warm and romantic tone, is easier for women to accept than the outright subjugation suggested by hostile sexism. While HS is more easily identified 
as prejudicial, BS functions as a "velvet glove" (Jackman, 1994) that promises affection and security for those willing to forego their independent status and accept male dominance (Glick \& Fiske, 2001a). For members of the dominant group (men), hostile sexist beliefs about women's incompetence and malevolence justify their exclusion from positions of power, while benevolent rationalizations for confining women to domestic roles allow them to view themselves as non-exploitative.

Benevolent sexism has been linked to societal level outcomes. In a cross-cultural examination of the ASI in 19 nations, levels of BS and HS within a given country were negatively correlated with indices of gender equality that assess women's presence in high status jobs as well as levels of education, longevity, and standard of living (Glick et al., 2000), suggesting that BS and HS predict gender equality at the national level. Women reminded of benevolent stereotypes concerning their group increase their support for both traditional gender arrangements and the social system in general (Jost \& Kay, 2005) and show less motivation to engage in social activism that challenges these norms (Becker \& Wright, 2011), demonstrating BS's role in justifying patriarchal systems and dismantling opposition. Women's initial endorsement of BS also predicts greater endorsement of HS later in life, presumably because the "disarming" effects of BS make widespread gender inequality more agreeable over time (Sibley, Overall, \& Duckitt, 2007).

The subjectively positive valence of BS is especially pernicious because it makes it harder to detect and reject than its more explicitly negative counterpart, HS (Kilianski \& Rudman, 1998; Swim, Hyers, Cohen, \& Ferguson, 2001). Benevolent sexists are 
generally not perceived as actually being sexist (Barreto \& Ellemers, 2005) and are evaluated positively, such that men described as benevolent (but not hostile) sexists are viewed as the ideal romantic partners (Kilianski \& Rudman, 1998). Women generally reject HS while still endorsing BS (Glick \& Fiske, 2001a), allowing it to perpetuate.

Consequences of benevolent sexism at the individual level. The insidious effects of BS are also evident at the individual level. Compared to a hostile comment, women tend to underestimate the intensity and duration of the negative emotional impact of a benevolently sexist comment (Bosson, Pinel, \& Vandello, 2010). Exposure to benevolent sexism impedes cognitive performance by undermining women's feelings of competence (Dardenne, Dumont, \& Bollier, 2007; Dardenne et al., 2013), increases body shame (Shepherd et al., 2011), and decreases help seeking (Wakefield, Hopkins, \& Greenwood, 2012). BS is socialized from mother to daughter, with negative consequences for the daughters' academic performance and goals (Montañés, et al., 2012). As benevolent sexists highly value motherhood, they express opposition to both traumatic and elective abortion (Huang, Osborne, Sibley, \& Davies, 2014) and react more negatively toward women who harm children (Viki, Massey, \& Masser, 2004). Women who violate chastity norms, whether by consensual premarital sex (Sakalh-Uğurlu \& Glick, 2003) or acquaintance rape (Abrams, et al., 2003), or who confront sexism (Kahn, Barreto, \& Kaiser, 2012), are also rejected.

Omissions in the benevolent sexism literature. While benevolent sexism as a construct has been traced to antiquity (Pomeroy, 1975) and has been part of the psychological parlance for over 20 years at the time of this dissertation, there is no 
substantive body of work (to my knowledge) in the social psychological literature that explores the ways in which this subtle, subjectively positive form of sexism is also racialized. That is, what is the role of race in understanding the targets, function, and consequences of benevolent sexism?

\section{The Need for Intersectionality}

Stereotyping and prejudice is one of the dominant areas of research in social psychology (Ross, Lepper, \& Ward, 2010). However, psychological science has largely neglected how race and gender mutually construct each other and influence individuals' experiences with and vulnerabilities to discrimination (Cole, 2009; Goff \& Kahn, 2013). Instead, racial bias and gender bias are often examined in isolation. The result has been an androcentric view of racism (primarily concerned with the experiences of Black men) and a Eurocentric view of sexism (dominated by the experiences of White women) (Goff \& Kahn, 2013), producing an "intersectional invisibility" that neglects those who are not the prototypical group members, such as Black women (Purdie-Vaughns \& Eibach, 2008). Studies of the stereotypes of African Americans sometimes conflate Black men and women, overlooking how the perceptions of stereotypes of the sexes might differ based on racial categories (Devine \& Baker, 1991; Madon et al., 2001).

Kimberle Crenshaw (1993), a legal scholar and critical race theorist, is credited with coining the term "intersectionality" to describe analytic approaches that consider the meaning and consequences of multiple categories of social group membership, such as race, gender, class, sexual orientation, and other social identity categories. Unfortunately, the tendency to ignore the experiences of those living with multiple marginalized 
identities is not unique to the field of psychology. Major U.S. social movements organized on the basis of class, race, or gender have also failed to acknowledge the intersections of these categories among their members (King, 1988). This includes the feminist movement, which has long focused primarily on the struggles of White women and neglected the many unique challenges faced by women of color (Davis, 1983; hooks, 1981; Hull, Bell Scott, \& Smith, 1982).

Due to their intersectional identity, Black women face discrimination on the basis of their race as well as their gender. Black women commonly report experiences of both racial discrimination and sexual harassment in the work place (Buchanan, Settles, \& Woods, 2008; Krieger, et al., 2006). The wage gap between Black women and White men (60 cents to the dollar) is greater than that between White women and White men (79 cents to the dollar) (National Women's Law Center, 2016b). White female names are more likely to receive callbacks from real employers than the same resume bearing a Black name (Bertrand \& Mullainathan, 2003). Black shoppers may wait twice as long for service (Ainscough \& Motley, 2000) or be charged more (Ayres \& Siegelman, 1995) than their White counterparts. Over time these experiences can have serious negative health consequences for Black women, as perceptions of discrimination by police, at work, in housing, and in everyday life have been associated with increased incidence of breast cancer (Taylor, et al., 2007), hypertension (Cozier, et al., 2006), and obesity (Cozier, et al, 2014).

Clearly, an understanding of prejudice toward women cannot fall into the trap of assuming that all women are perceived or treated in the same way, as psychological 
science has done in its Eurocentric conceptualizations of sexism. The overarching goal of this dissertation is to explore how race fits in to Ambivalent Sexism Theory (Glick \& Fiske, 1996). Specifically, this dissertation explores how race impacts the targets, functions, and consequences of benevolent sexism across three papers.

Race and the targets of benevolent sexism. As an antidote to the lack of intersectional approaches within psychology, Cole (2009) recommends researchers begin by asking, "Who is included within this category?" Ambivalent sexism theory posits that women are subtyped into smaller categories based on their adherence to traditional gender roles (e.g., homemaker, mother, whore, bitch; Glick et al., 1997), but has so far neglected to explicitly examine how a woman's race would directly impact the benevolent sexism attributed her. Benevolent sexism characterizes women as inherently fragile, domestic, and pure (Glick \& Fiske, 1996), yet these qualities have traditionally been associated with upper class White women (Morton, 1991; Schloesser, 2002). These traits also contradict stereotypes of Black women, which paint them as antagonistic (Niemann, Jennings, Rozelle, Baxter, \& Sullivan, 1994) and promiscuous (Davis \& Cross, 1979). Historically, femininity has been associated with Whiteness and masculinity has been associated with Blackness (Hull, et al., 1982), suggesting that, in the absence of other information about adherence to gender roles, benevolent sexism might be more strongly associated with White women than Black women. This research question is explored in Chapter II (the first manuscript) of this dissertation.

Race and the function of benevolent sexism at the societal level. Benevolent sexism has been implicated in the maintenance of gender inequality (Glick et al., 2000; 
Glick \& Fiske, 2001a; Jost \& Kay, 2005), but historical evidence suggests that it has long been used to support racial inequality as well. The sacred duty men have to defend their women, as espoused by the protective paternalism subcomponent of BS (Glick \& Fiske, 1996), requires the existence of a dangerous other (Young, 2003) which often takes the form of a man from a racial minority group. Social psychological examinations have revealed that the dominant social group (here, White males) view men belonging to an outgroup, such as a racial minority, as more of a sexual danger to ingroup (i.e. White) women than other ingroup men (Nagel, 2001; Navarette, McDonald, Molia, \& Sidanius, 2010). Indeed, the stated goal of protecting White women from minority men is a common pretext for racial discrimination and violence (Davis, 1981). Following the Civil War, the myth of the ruthless Black rapist emerged as a common justification for the lynching of thousands of African Americans (Apel, 2004; Davis, 1981). Depictions of Black men as sexual threats to White womanhood persist in modern media (Dines, 2006, Guerrero, 1993), propaganda (Difendila, 1944), and politics (Bump, 2016). The pretext of defending White women has also been linked to discrimination against whichever group is contextually relevant, including Latinos (Edwards, 2014), Arab refugees (Yardley, 2016), and Chinese immigrants (Tchen \& Yeats, 2014). This suggests that not only might benevolent sexism favor White women relative to Black women, but it may also play a role in the subordination of racial minorities in general. This idea is tested in Chapter III (the second manuscript) of this dissertation.

\section{Race and the consequences of benevolent sexism at the individual level.}

Research has examined how exposure to benevolent sexism affects women directly in the 
lab (Dardenne et al., 2007; Shepherd et al., 2011; Wakefield et al., 2012), in school (Montañés, et al., 2012), and in the workplace (King, et al., 2012). Others have demonstrated how endorsement of BS predicts perceptions of women's behavior, including breast-feeding (Forbes, Adams-Curtis; Hamm, \& White, 2003), getting abortions (Huang, et al., 2014), and confronting sexism (Kahn et al., 2012). However, if benevolent sexism is directed more toward White women and less toward Black women, what might be a broader consequence of this disparity? In a situation in which women truly need assistance, stereotypes about who is more deserving of help or requiring protection might influence who receives it. Chapter IV explores this possibility in the context of policing.

\section{Present Investigation}

In this dissertation, I use a multi-study, multi-method approach to make the current benevolent sexism literature more intersectional by incorporating race. No other study, to my knowledge, has examined race in the context of ambivalent sexism theory. As the sole exception, Hayes and Swim (2013) examined the internal consistency, factor structure, average endorsement, and intercorrelations of the ASI and other measures of sexism with European, African, Latino/a, and Asian American respondents (i.e. how does BS psychometrically function across the race of perceivers, versus its application to targets, as Chapter II explores). I use both experimental and non-experimental methods to investigate how race informs the targets, function, and consequences of benevolent sexism. This use of the full-cycle model (Mortenson \& Cialdini, 2010) contributes to a more ecologically valid understanding of the intersection of benevolent sexism and race 
by using laboratory experiments to corroborate theory, then returning to the field to verify these findings in the real world. In the following sections, I provide a brief introduction of the first two completed manuscripts of this dissertation and an overview of the proposed third study.

\section{Chapter II Overview: Benevolent racism?}

\section{The impact of target race on ambivalent sexism \\ Published in Group Process and Intergroup Relations}

Chapter II examines whether benevolent sexism is differentially applied based on a woman's race, with an emphasis on establishing causality. This use of experiments to test theory represents a key step in the full cycle model. In the first paper of my dissertation (McMahon \& Kahn, 2016), I experimentally investigated the role of a woman's race in whether she would be a target of benevolent sexism. Specifically, I was interested in how benevolent sexism was directed at White and Black women, both when the perceiver lacked any knowledge of the woman's adherence to traditional gender roles (Study 1) and when they were given information about her sexual behavior (Study 2).

This was the first study to test how a woman's race might act as a subtype to elicit benevolent sexism.

Given that the stereotypes of Black women as aggressive (Weitz \& Gordon, 1993) and promiscuous (Davis \& Cross, 1979) are at odds with benevolently sexist ideals of purity and defenselessness (Glick \& Fiske, 1996), I predicted in Study 1 that more benevolent sexism would be directed at White women than Black women. Study 2 used a 2 (Black vs. White) X 2 (promiscuous vs. chaste) factorial design to test how race 
interacted with sexual subtypes (Sibley \& Wilson, 2004) to produce different outcomes. I anticipated more benevolent sexism would be directed at chaste Black women than chaste White women, as negative stereotypes of Black women's sexual behavior should produce patronizing surprise (in the form of benevolent sexism) when surpassed, consistent with shifting standards theory (Biernat, 2003). Participants' endorsement of HS, BS, and modern racism (McConahay, 1986) were examined as possible moderators. Having established that benevolent sexism is directed more at White than Black female targets, I next examined what this desire to cherish and protect certain types of women over others meant for not just women, but men.

\section{Chapter III Overview: When sexism leads to racism:}

\section{Experiencing threat, protecting women, and racial bias}

\section{Published in Sex Roles}

Chapter III investigates the role that benevolent sexism plays beyond perceptions of Black and White women, but of racial minorities in general. The second paper of this dissertation (McMahon \& Kahn, 2017) tested another pernicious function that benevolent sexism may serve in society: the maintenance of racial inequality. Across two studies, I explored the relationship between protective paternalism (the subcomponent of BS espousing the defense of women) and racial bias. While previous research has shown that sexist and racist attitudes are correlated (Glick \& Fiske, 1996; Sidanius \& Pratto, 1999), the protective paternalism subscale has not been singled out for this analysis in the extant literature, nor has it been conceptualized as a form of motivated social cognition that might change as a response to threat (Jost, Glaser, Kruglanski, \& Sulloway, 2003). 
Further, it has also not been connected, on its own, to attitudes about real-world issues or policy support.

In this paper, Study 1 examined the relationships between paternalism and racism in an existing data set, while Study 2 combined an experiment with moderated mediations to test the relationship between threat, protective paternalism, and anti-minority attitudes. Based on the known relation between racist and sexist attitudes (Glick \& Fiske, 1996; Sidanius \& Pratto, 1999), I anticipated in Study 1 that protective paternalism would also be correlated with various measures of racial bias that tap contemporary issues from a pre-existing data set, including modern racism (McConahay, 1986), support for the Black Lives Matter movement, and attributions of blame in the shooting death of Michael Brown (an African American teenager) by Officer Darren Wilson (a White male) in Ferguson, Missouri. Participant gender and racial group were tested as moderators. Study 2 tested whether the threat of violent crime would bolster endorsement of protective paternalism, resulting in a corresponding increase of various anti-minority attitudes, including less support for policies that benefit racial minorities, denying that suspect race plays a role in policing outcomes, and a more negative view of immigration. Participant gender and racial group were added as moderators of the mediation model. Using a motivated social cognition approach (Jost et al., 2003) to interpret findings, I discuss how protective paternalism is implicated in the maintenance of both patriarchal and White hegemony. Experimentally manipulating threats allowed me to test whether they caused changes in endorsement of protected paternalism, while moderated mediations enabled the testing how participants' race and gender affected their subsequent reactions to threat. 
These findings demonstrated, as in chapter II (McMahon \& Kahn, 2016), that benevolent sexism is also racialized, affecting perceptions of both men and women.

\section{Chapter IV Overview: To protect and serve:}

\section{Police responses to Black and White female victims of IPV}

The first study (chapter II) demonstrated that White women, relative to Black women, are the traditional targets of benevolent sexism, while the second (chapter III) showed that paternalistic protections for White women are bolstered by threat and promote racial bias. For the third chapter, I tested for potential consequences of the racial differences in chapter II and protections in chapter III in an applied context. I performed a cross-sectional study to compare the treatment of Black and White women by police in a relevant context where assistance is needed and protections are provided. Specifically, I examined incident and supplemental reports of intimate partner violence (IPV) from a local police department. Police officers routinely encounter women who need their help, but stereotypes about which "types" of women are worthy of protection may, however unintentionally, affect the treatment victims receive. IPV presents such a context, and the corresponding paperwork presents an opportunity to test for differences in how police respond to victims. If White women are afforded more benevolent sexism than Black women (McMahon \& Kahn, 2016), they may also receive more help from police. While others have noted that Black women are not afforded chivalrous treatment by the criminal justice system (Chesney-Lind \& Pasko, 2012; Gabbidon, Higgins, \& Potter, 2010), this study would be the first to propose a benevolent sexism framework to account for these racial differences. 
Consistent with both aversive racism and shifting standards theory (Biernat, 2003; Gaertner \& Dovidio, 1986), I predicted that while officers were as likely to fulfill basic job requirements (i.e. filing supplemental forms and gathering incident details) when responding to Black and White victims, it would be in their "extra effort" discretionary behaviors at the scene (e.g. collecting photographic evidence, completing the victim interview, providing information to victims) that evidence of racial bias would emerge to favor White women, due in part to the stereotypes of White women as more deserving of paternalistic protections. I also examined the first-person narrative reports written by officers to test for linguistic choices that may illuminate officers' focus of risk and protective paternalism at the scene. Taking a cross-sectional approach allowed me to describe and test for differences between groups (particularly when random assignment is not possible, as in the case of race), while a textual analysis can quantify what officers are thinking about, feeling, avoiding, or attending to (Tausczik \& Pennebaker, 2010).

This study extended my existing program of research by examining a potential real-world consequence of the differential application of benevolent sexism to Black women and White women. Though a secondary analysis of police records prohibits the direct manipulation of variables or measurement of attitudes, this effort to corroborate experimental findings in a natural setting is consistent with both the full-cycle model's approach to research (Mortenson \& Cialdini, 2010) and the goals of our applied psychology program at Portland State University. This study also contributes to the existing research about police responses to IPV by operationalizing "effort" at the scene in multiple ways and testing for racial differences using police records rather than victim 
interviews. As the most novel example, I used victim race to predict the presence of missing data on the supplemental forms, whereas other studies have only used complete records (Shernock \& Russel, 2012) or merely acknowledged its presence (Rauma, 1984; Robinson \& Chandek, 2000). My analysis of the linguistic choices in officers' narrative reports to assess their perceptions of risk at the scene and protective paternalism also makes a novel contribution to the literature.

\section{Summary}

In summation, this dissertation consists of three manuscripts in which I examine the intersection of benevolent sexism and race. Specifically, I use a combination of experimental and non-experimental methods to investigate how race informs the targets, function, and consequences of benevolent sexism. In the first paper, I use experimentation to test whether benevolent sexism is differentially applied to Black and White women, indicating whether race acts as a subtype to elicit benevolent sexism. The second paper explores how benevolent sexism maintains racial inequality by looking at the relationship between protective paternalism, anti-minority attitudes, and feelings of threat using correlational and experimental methods. The third study investigates consequences of the differential application of benevolent sexism to Black and White women in the context of police responses to IPV using cross-sectional and text analysis methods.

This dissertation contributes to the current social psychological understanding of benevolent sexism. This is the first set of studies to directly examine target race in the context of ambivalent sexism theory (Glick \& Fiske, 1996). This long overdue addition 
addresses the need to examine how race and gender mutually construct each other, thereby taking a more intersectional approach to the study of prejudice (Goff \& Kahn, 2013). This helps to reduce the "intersectional invisibility" (Purdie-Vaughns \& Eibach, 2008) that results from focusing exclusively on sexism as it pertains to White women and racism as it affects Black men. In doing so, I demonstrate how a subjectively positive yet pernicious form of sexism is also racist in its perceptions and treatment of Black women in particular and racial minorities in general. I do this by expanding on the extant literature concerning the targets, function, and consequences of benevolent sexism. 


\title{
CHAPTER II. MANUSCRIPT I. BENEVOLENT RACISM? THE IMPACT OF TARGET RACE ON AMBIVALENT SEXISM
}

\begin{abstract}
Two studies investigated whether benevolent sexism is differentially applied based on a woman's race. Study 1 demonstrated that participants expressed more benevolent sexism to White females than Black females when given no other information besides race. Study 2 introduced positive (chaste) and negative (promiscuous) sexually subtyped behaviors in addition to female race. Under these conditions, participants directed more benevolent sexism at chaste Black women rather than chaste White women, consistent with shifting standards theory. Despite receiving more benevolent sexism, chaste Black women did not receive more positive evaluations overall. Across both studies, expressions of hostile sexism did not differ by race. Results suggest that race may function as a subtype to elicit benevolent sexism contingent on behavior. Black women who follow traditional gender norms may be overcompensated for their conformity through benevolent sexism, but not receive more tangible positive benefits.
\end{abstract}




\section{Introduction}

"That man over there says that women need to be helped into carriages, and lifted over ditches, and to have the best place everywhere. Nobody ever helps me into carriages, or over mud-puddles, or gives me any best place! And ain't I a woman?" -Sojourner Truth

In her extemporaneous speech at the Women's Convention (as transcribed by Frances Gage in Stanton et al., 1881), Sojourner Truth remarked how her dark skin prevented men from affording her the same treatment as White women. Unfortunately, both mainstream feminism (hooks, 1981; Hull, Bell Scott, \& Smith, 1982) and psychological research have long neglected how gender and race mutually construct each other and influence individuals' experiences with discrimination (Goff \& Kahn, 2013). The result is an androcentric conception of racism and an ethnocentric understanding of sexism, wherein the default target of racism is a Black man and the default target of sexism is a White woman (Goff \& Kahn, 2013). This shortcoming has resulted in an "intersectional invisibility" that ignores the unique experiences of those who are not the prototypical members of their already subordinate groups, such as Black women (PurdieVaughns \& Eibach, 2008). In light of this dearth of intersectional research, the current study examines how race and gender stereotypes intersect within an ambivalent sexism framework.

\section{Ambivalent Sexism Theory}

Ambivalent Sexism Theory (Glick \& Fiske, 1996) distinguishes sexism on two complementary and mutually reinforcing dimensions: hostile and benevolent. Hostile sexism (HS) characterizes women as easily offended, unappreciative of and seeking to gain power over men, and manipulative with their sexuality. Benevolent sexism (BS) 
places women on a pedestal and affirms their inherent purity, morality, and defenselessness. These attitudes arise from a desire to protect the beloved and weak (protective paternalism), a need for complementary gender differentiation, and a drive for heterosexual intimacy. Women who reject traditional gender roles by being feminists or career-oriented are the targets of hostile sexism, while those who adhere to the domestic norms for their gender by being homemakers and mothers are the recipients of benevolent sexism (Glick, Diebold, Bailey-Werner, \& Zhu, 1997). Women are also subtyped on the basis of their sexual behavior (Sibley \& Wilson, 2004): HS is expressed towards those who are promiscuous (the negative sexual subtype) and BS towards those who are chaste (the positive sexual subtype). The two ideologies thus act as a system of rewards and punishments that impede gender equality (Glick \& Fiske, 2001a).

Hostile and benevolent sexism are measured with Glick and Fiske's (1996) 22item Ambivalent Sexism Inventory (ASI). While men consistently endorse HS more strongly than women do, women tend to reject HS while still endorsing BS. High correlations between mean levels of HS and BS and replicated factor structures across 19 nations on six continents (Glick, Fiske, Mladinic...\& Lopez, 2000) indicate that ambivalent sexism is a coherent ideology at the societal level across cultural contexts.

Though subjectively positive in nature, benevolent sexism is a subtle and pernicious form of bias that shares the same ideological underpinnings as more blatantly hostile forms of sexism. A growing body of work suggests that it produces a variety of insidious effects. Women exposed to benevolent sexism in a controlled setting show decreased cognitive performance (Dardenne, Dumont, \& Bollier, 2007), less motivation 
to engage in social activism that could benefit them (Becker \& Wright, 2011), increased levels of body surveillance and shame (Shepherd et al., 2011), and greater system justification for the patriarchal status quo (Jost \& Kay, 2005). BS can even affect women who strongly identify as feminists, such that they are more likely to report that they will initiate condom use after exposure to HS, but not to BS (Fitz \& Zucker, 2014). Benevolent sexists react negatively towards women who violate norms of chastity, be it by willingly engaging in premarital sex (Sakalh-Uğurlu \& Glick, 2003) or being raped by an acquaintance (Abrams, Viki, Masser, \& Bohner, 2003), and norms of motherhood, by seeking an abortion (Obsorne \& Davies, 2012) or defying the stereotype of nurturing behavior towards children (Viki, Massey, \& Masser, 2004).

While ambivalent sexism has been studied for nearly 20 years now, the literature lacks a systematic investigation into how hostile or benevolent attitudes may be shaped by the race of women. While research has shown that individuals with sexist attitudes also tend to have racist attitudes (Glick \& Fiske, 1996; Sidanius \& Pratto, 1999), an examination of the impact of race on ambivalent sexism, particularly benevolent sexism, is essential to understand the subtle ways that sexism and racism interact.

\section{Race as a Subtype of Benevolent Sexism}

In the absence of information about a particular woman's adherence to traditional gender roles, her race may function as a subtype that directs evaluators' expression of ambivalent sexism. That is, the stereotypes and perceptions associated with a racial group may lead to the differential application of hostile and benevolent sexism by perceivers. Though ambivalent sexism theory makes no direct assumptions about race, we argue that 
White women may be the primary recipients of benevolent sexism.

One key component of BS, protective paternalism, may be expressed more toward White women than to Black women. The notion that women are defenseless and require male relatives and social institutions to safeguard their chastity and well-being (Young, 2003) has often been used to justify the mistreatment of racially stigmatized groups. In the United States, the need to protect White women from "hypersexual" and "ruthless" minority men has been used to justify violence against the Black community (Davis, 1983), both in the post-Reconstruction South (Hodes, 1993) and in modern organized racist movements (Blee, 2002). In the criminal justice system, the paternalism hypothesis has been offered to explain why female offenders are given more lenient sentences than male offenders (Visher, 1983); however, this leniency is not extended to minority women (Young, 1986; Chesney-Lind \& Pasko, 2012). This protective bias may also help to explain why White women who experience domestic violence are seen as less culpable (Esqueda \& Harrison, 2005) and are more likely to experience police intervention when victimized (Ferraro, 1989) compared to Black women. Protective paternalism, it appears then, has a history of being more closely tied to White women rather than Black women.

Black women and White women are also perceived and stereotyped differently, such that White women are stereotyped in ways consistent with BS, while Black female stereotypes stand in opposition to BS. Although both are stereotyped as childlike and emotional (Ehrenreich \& English, 1978), White women have historically been characterized as angelic (Stephens, 1992) while Black women are more often seen as antagonistic, unmannerly, loud (Niemann, Jennings, Rozelle, Baxter, \& Sullivan, 1994), 
aggressive, stubborn, bitchy (Weitz \& Gordon, 1993) and hypersexual (Davis \& Cross, 1979). The archetypal promiscuous Black woman, the Jezebel, can be traced back to the antebellum South and depicts a seductive temptress who uses her sexuality to exploit men's weaknesses (Jewell, 1993). This characterization of Black women as innately licentious was used as justification for their sexual exploitation at the hands of White slave-owners (Pilgrim, 2002). This and other negative stereotypes remain pervasive in modern depictions of Black women in television, films, music videos, and social media (Thompson, 2013). While there do exist more seemingly positive stereotypes of Black women, such as the "Strong Black Woman", they remain at odds with the benevolent ideals of submissiveness and inherent fragility (Wyatt, 2008). Black women's sexuality has never been depicted as moral or demure (Davis, 1983), in stark contrast to White women's. Indeed, the ideal virgin in the public consciousness and mass media is young and White—she is never a woman of color (Valenti, 2009).

In addition to the negative stereotypes, it has been suggested that Black women are often seen as less "appropriately feminine" (Goff, Eberhardt, Williams, \& Jackson, 2008), whereas femininity is a central component of BS. In an examination of how race and gender affect person perception, Black men and women were both judged as more masculine than their White counterparts, and the conflation of "Blackness" with "maleness" resulted in Black women being rated as less physically attractive (Goff, Thomas, \& Jackson, 2008). Participants also mistakenly categorized Black women as men more frequently than they mis-categorized other groups by gender. These findings reflect a larger societal context in which femininity is associated with Whiteness and 
masculinity is associated with Blackness (Hull et al., 1982). Due to this association of femininity with White women, we argue that BS should be more closely associated with White females than Black females.

We designed the present studies to integrate race into ambivalent sexism theory, with a focus on the differential application of BS based on female race. Study 1 tested whether a woman's race could act as a subtype to impact hostile and benevolent evaluations of her. Study 2 examined how sexually subtyped behaviors interact with race to influence hostile and benevolent evaluations of women.

\section{Study 1}

Divergent racial stereotypes regarding behavior suggest that ambivalent sexism is differentially directed at Black women and White women. Our primary hypothesis posits that benevolent sexism should be directed more at White women, since they are stereotyped to match benevolent sexism ideals of purity and defenselessness (Hypothesis 1a). Though hostile sexism is not our primary outcome of interest, hostile sexism may be directed more at Black women, whose stereotypes of aggression and sexual availability contradict these ideals (Hypothesis 1b). Given the more negative stereotypes of Black women, we expected that they would also be rated less positively overall than White women (Hypothesis 1c).

To test these hypotheses, we presented participants with images of Black or White women and had them report their hostile and benevolent attitudes about her. Participants also rated the woman on several positive personality traits, which allowed for the differentiation between subjectively positive benevolent sexism and more positive 
evaluations overall. In order to better understand the process by which race impacts expressions of HS and BS, we examined participants' own endorsement of HS and BS, as well as their racial attitudes, as possible moderators.

\section{Methods}

Participants and Design

We recruited 152 participants ( 87 female, 65 male; 110 White, 17 African American, 10 Asian, 13 Hispanic; mean age 35.7 years) from Amazon Mechanical Turk and randomly assigned them to the White or the Black female condition in a one way design.

\section{Measures and Procedure}

After providing basic demographic information, participants were given the 22item Ambivalent Sexism Inventory (Glick \& Fiske, 1996) to assess their baseline levels of hostile $(\alpha=.92)$ and benevolent sexism $(\alpha=.87)$. Items are rated on a 6-point Likert scale from 0 (strongly disagree) to 5 (strongly agree). This was followed by the six-item Modern Racism Scale (McConahay, 1986) in order to evaluate their attitudes about African Americans, $(\alpha=.89)$. Questions such as, "Blacks should not push themselves where they are not wanted" are rated on a 5-point Likert scale from 1 (strongly disagree) to 5 (strongly agree).

Next, participants viewed a single randomly-selected photograph of either a Black or White woman. The photograph featured a headshot of a woman in her late teens-early twenties with neutral facial expressions against a white background, selected from a commonly used database of photographs (Minear \& Park, 2004). There were a total of 
four photographs, with two in each race condition. We paired each photograph with a racially-indicative name: White: Emily Walsh, Lauren Reilly versus Black: Lakisha Washington, Shavonn Jefferson (Bertrand \& Mullainathan, 2003; U.S. Census 2000; Greenwald et al., 1998).

After viewing the photograph, participants reported their impressions of the woman. Hostile and benevolent attitudes about the woman were assessed using shortened six-item versions (Sibley \& Wilson, 2004) of the hostile and benevolent subscales of the ASI (Glick \& Fiske, 1996). As with the original ASI, these items were rated on a 6-point Likert scale from 0 (strongly disagree) to 5 (strongly agree). This 6-point Likert scale is consistent with how the ASI was originally written by Glick and Fiske (1996) and has been validated in 19 countries (Glick et al., 2000). Expressions of hostile sexism were measured by rewording the hostile sexism subscale items of the ASI $(\alpha=.86)$ to be specifically about the woman in the picture, e.g., "Once a woman like Emily/Lakisha gets a man to commit to her, she will usually try to put him on a tight leash." Expressions of benevolent sexism were assessed by rewording the benevolent sexism subscale items of the ASI $(\alpha=.76)$, e.g., "Women like Lauren/Shavonn have a quality of purity that few men possess."

Participants then rated the woman on eight different personality traits designed to assess her warmth (sincere, good-natured, friendly, warm) and competence (intelligent, competent, confident, and capable), which were combined into a measure of overall positivity $(\alpha=.92)$. Warmth and competence were selected based on their inclusion in the stereotype content model (Fiske, Cuddy, Glick, \& Xu, 2002). Participants rated how 
appropriate each term was to describe the woman on a scale from 1 (very inappropriate) to 5 (very appropriate).

In order to isolate the effect of race on expressions of HS and BS, we controlled for the femininity and attractiveness of the photographs in the analyses. As previously noted, Black women are perceived as less feminine and less physically attractive than White women (Goff et al., 2008). Physical attractiveness, under certain conditions, can also lead to more positive evaluations of various attributes (Eagly, Ashmore, Makhijani, \& Longo, 1991). Participants rated the femininity and attractiveness of the woman on a thermometer scale from 0 (not at all) to 100 (extremely). Finally, participants answered a manipulation check question about the race of the woman in the photograph before debriefing.

\section{Results}

The responses of participants who failed the manipulation check $(N=5)$ were excluded from further analyses.

A MANCOVA ${ }^{1}$ [between-subjects factor: race (Black, White); covariate: feminine, attractive ratings; outcome: $\mathrm{HS}, \mathrm{BS}$, positive evaluations] revealed a significant main effect of the race condition, Wilks' $\Lambda=.90, F(3,121)=4.30, p=.006$, partial $\eta^{2}$ $=.10$. There was no main effect of femininity, Wilks' $\Lambda=1.00, F(3,121)=1.45, p=.23$, partial $\eta^{2}=.04$, or attractiveness, Wilks' $\Lambda=.96, F(3,121)=1.83, p=.15$, partial $\eta^{2}=.04$, ratings of the photos.

\footnotetext{
${ }^{1}$ When the feminine and attractiveness ratings of the photographs were not controlled for, the same pattern of results emerged in the MANOVA with marginal significance.
} 
Consistent with Hypothesis 1a, more benevolent sexism was expressed to the White faces, $(M=3.65, S D=.67)$ than the Black faces, $(M=3.42, S D=.68), F(1,123)=$ $4.61, p=.03$, partial $\eta^{2}=.04$. However, there was no significant difference between the hostile sexism directed at the White $(M=3.18, S D=.81)$ and Black $(M=3.01, S D=.98)$ faces, $F(1,123)=.48, p=.49$, partial $\eta^{2}=.004$, suggesting Hypothesis $1 \mathrm{~b}$ is not supported. White faces were also assigned more positive trait evaluations $(M=3.72, S D$ $=.56)$ than Black faces $(M=3.50, S D=.57), F(1,123)=11.33, p=.001$, partial $\eta^{2}=.08$, indicating support for Hypothesis 1c (Figure 1.0).

Moderation. We examined participants' baseline HS, BS, and their modern racism score as possible moderators of the HS, BS, and positive trait evaluations directed at Black and White women. Only participants' levels of modern racism approached significance as a moderator, such that individuals with higher modern racism scores expressed marginally more hostile sexism to the Black faces than those with lower modern racism scores, $B=.32, S E=.18, t=1.80, p=.07$, adjusted $R^{2}=.21$.

\section{Discussion}

Consistent with our hypotheses, when only racial category information is present, more benevolent sexism was expressed toward White females than Black females. The implicit assumption is that the White female is more closely aligned with BS ideals of fragility, purity, and need for protection, while the Black female violates these ideals. This finding suggests that subtypes based on gender roles or sexual behaviors are not always necessary for the application of benevolent sexism toward individual women; in the absence of information about a woman's behavior, being White may be enough to 
elicit increases in benevolent sexism on this measure. While there was a statistically significant difference between these two groups, the effect size was relatively small (Cohen, 1988) and we cannot yet predict how it would impact behavior toward real women.

White females were also assigned more positive traits than the Black females, suggesting that participants perceived the White females more positively overall. In this case, perceptions of BS and overall impressions were in line with each other, as "positive" evaluations of BS went along with more positive impressions of the female target overall. However, there was no difference between the amounts of hostile sexism directed at Black and White women. This is somewhat unexpected given the stereotypes of Black women as promiscuous and antagonistic, which violate traditional gender norms and should increase HS. Marginally more HS to the Black females was observed among participants with higher Modern Racism Scores. It could be that HS, unlike BS, requires explicit subtyping, such that women need to be identified as career-oriented or promiscuous before HS is expressed.

\section{Study 2}

Study 1 demonstrated that females' race alone could act as a subtype to elicit differential rates of benevolent sexism. However, it is unclear how race would impact the HS and BS evaluations of a woman whose adherence to or rejection of traditional gender roles is known. That is, how does race interact with the application of BS when the target's behavior conforms or violates BS ideals? Following a procedure by Sibley and Wilson (2004), Study 2 tests how manipulating race influences the hostile and benevolent 
evaluations of women who are chaste (positive sexual subtype) or promiscuous (negative sexual subtype).

When asking participants to judge the behavior of stereotyped individuals, shifting standards (Biernat, Manis, \& Nelson, 1991; Biernat, 2003) are likely to occur. According to the shifting standards model, judgments of members of stereotyped groups are made with reference to within-category standards. That is, stereotypes of a group will determine evaluations of individuals within that group. For instance, given the stereotype that men are more naturally skilled at math than women, one is likely to judge the performance of a particular woman in a computational physics class against the relatively lower standard for women and the performance of a man against the relatively higher standard for men. Because subjective judgments such as "tall," "athletic," or "intelligent" are not anchored to any consistent objective scale, these labels mean different things when they are directed at different targets. As a result, "good at math" does not mean the same thing for a woman as it does for a man: when directed at a male student, the phrase indicates an assessment of skill, but when directed at a female student, there is a subtextual, implicit comparison to other members of the stereotyped group, such that she is only "good at math for a woman."

Another assumption of the shifting standards model is that evidentiary standards are lower for individuals who are members of groups that are stereotyped as lacking in some domain. When asked what level of performance was required to meet minimum standards for a job, women were held to lower minimum standards than men, and Black men were held to lower minimum standards than White men (Biernat \& Kobrynowicz, 
1997). When expectations for a group are low (i.e., when stereotypes of the group are negative), individuals who surpass them are rewarded with non-zero sum behaviors or outcomes (Biernat, 2003). These include actions that can be bestowed upon many individuals without resource depletion, such as nonverbal responses or expressions of praise. That is, they are unlimited in nature and thus can be applied toward many targets without restriction. For the woman in the physics class, an A on an exam would elicit more praise for her performance compared to a male peer with the same score. In addition, female softball players who perform well receive more cheers and verbal praise than male players (Biernat \& Vescio, 2002), and female supervisors in the workplace are described as more supportive than male supervisors (Gupta, Jenkins, \& Beehr, 1983). However, these more positive evaluations do not lead to zero sum rewards in which behavior toward one individual restricts options available to another, such as choice decisions or finite resources. Though highly praised, women do not receive better batting positions (Biernat \& Vescio, 2002) or promotions (Gupta, Jenkins, \& Beehr, 1983). Furthermore, those wishing to refute accusations of discrimination in hiring or promotions (or any zero sum outcome) can submit the increased praise (non-zero sum outcome) for women as evidence of their impartiality.

In both these cases, the praise (non-zero sum outcomes) for the women who succeed in the workplace or on the field, while subjectively positive, belies the lower expectations held about their competence. In the same way that benevolent sexism is subjectively positive yet predicated on notions of inferiority, the accolades bestowed upon women who exceed the lower standards set for them are the result of patronizing 
surprise rather than a sincere judgment of quality.

The expression of benevolent sexism could be characterized as a non-zero sum behavior, because these judgments can be directed at any number of recipients without resource depletion. As such, it fits into a shifting standards framework. Given the aforementioned evidence that the expectations of Black women's sexual behavior are more negative than those of White women, Black women exhibiting more positively subtyped sexual behavior (by being chaste) should be judged against the relatively lower standard for Black women and would be "rewarded" with benevolent sexism.

Ambivalence amplification (Hass, Katz, Rizzo, Bailey, \& Eisenstadt, 1991), which states that individuals with ambivalent attitudes about an out-group will rate out-group members who succeed at a task more favorably than in-group members, could also predict this outcome. Conversely, because the purity expectations for White women are so entrenched, a White woman who violates the chastity norms for her gender and race by being promiscuous may receive more scorn, in the form of hostile sexism, than a promiscuous Black woman, who would be conforming to the negative stereotypes of sexual availability for her race.

Study 1 demonstrated that when given no other information about a woman besides her race, participants expressed significantly more benevolent sexism to the White woman than to the Black woman. Study 2 builds on Study 1 by manipulating both the target's race and her sexual behavior in order to examine how HS and BS impact race and sexual subtype. In light of these theories, we predict that more benevolent sexism will be expressed towards a chaste Black woman than a chaste White woman (Hypothesis 
2a), while more hostile sexism would be expressed towards a promiscuous White woman than a promiscuous Black woman (Hypothesis 2b). Regarding the measure of overall positivity, the pattern found in Study 1 may be replicated regardless of BS or sexual behavior (with more positive evaluations of White women than Black women), or, oppositely, chaste Black women may receive more positive evaluations in addition to more BS than chaste White women. As in Study 1, we tested whether any of these effects would be moderated by participants' baseline HS, BS, and racial attitudes.

\section{Methods}

Participants and Design

One hundred eighty-eight participants (119 female, 68 male; 149 White, 13 African American, 11 Asian, 9 Hispanic; mean age 37.5 years) were recruited from MTurk and paid for their participation. The study had a 2 (target race: Black vs. White) X 2 (female subtype: positive vs. negative) between-subjects design.

\section{Measures and Procedure}

The procedure was similar to Study 1 with the following changes and additions. We replaced the photos with a vignette based on those utilized by Sibley and Wilson (2004) that manipulated subtype and race. Participants read a short story about a man meeting a woman at a bar. In the negative sexual subtype version, the female target has a history and enjoyment of casual flings. In the positive sexual subtype version of the vignette, the female target is described as having few, if any, previous sexual partners and not inclined toward casual flings. The former vignette characterizes the woman as promiscuous, the latter as chaste. To manipulate the woman's race, we changed her name 
to be more racially indicative. The original vignettes feature a woman named Kate, which we used in the White condition of the current study. The Black female target's name was Tanisha, which both children (Daniel \& Daniel, 1989) and adults (Greenwald, McGhee, \& Schwartz, 1998) recognize as more likely to belong to an African American woman.

A manipulation check occurred after reading the vignette. Ostensibly as a memory test, participants were asked, "How was Kate/Tanisha described in the story?" (Wilson \& Sibley, 2004). To ensure that the race manipulation was effective, participants provided demographic information about the woman, including her age and race, and summarized the story they had just read in 2-3 sentences.

\section{Results}

Of the 238 surveys gathered, 50 failed to correctly identify the race of the female target and were excluded from the analyses. While the race manipulation in Study 1 used pictures of female faces, this study relied on racially-indicative names in a vignette. We attribute the increase in manipulation check failures to the current study's more subtle race manipulation and excluded these participants in order to ensure that the reported findings reflect those participants who were more likely thinking specifically about Black women or White women when they made their evaluations, as these ratings correspond to the tested hypotheses. If these 50 were included, the pattern remained the same for the main variables of interest.

A 2 (race: Black vs. White) x 2 (sexual subtype: positive vs. negative) x 3 (Outcomes: BS, HS, Positive Traits) MANOVA revealed a significant interaction of subtype and race, Wilks' $\Lambda=.94, F(3,182)=3.65, p=.014$, partial $\eta^{2}=.06$. There was 
also a main effect of subtype condition, Wilks' $\Lambda=.91, F(3,182)=6.21, p<.0001$, partial $\eta^{2}=.09$, but no main effect of race condition, Wilks' $\Lambda=.99, F(3,182)=.14, p$ $=.94$, partial $\eta^{2}=.002$.

Benevolent Sexism. In order to test Hypothesis 2a, a 2 (race) x 2 (subtype)

ANOVA on benevolent evaluations of the target found a significant interaction between race and sexual subtype, $F(1,184)=7.133 p=.008$, partial $\eta^{2}=.04$. Breaking down the interaction, when examining the positive subtype, there was significantly more BS expressed to the chaste Black woman $(M=3.23, S D=.83)$ than the chaste White woman $(M=2.88, S D=.88), F(1,96)=4.11, p=.045$, partial $\eta^{2}=.04$, see Figure 1.1.

Hostile Sexism. A 2 (race) x 2 (subtype) factorial ANOVA on hostile evaluations of the target found an interaction between subtype and race that neared significance, $F(1$, $184)=3.75, p=.054$, partial $\eta^{2}=.02$. When restricted to the negative subtype, there was no difference in the amount of HS directed at the promiscuous White woman $(M=2.61$, $S D=.79)$ and the promiscuous Black woman $(M=2.41, S D=.76), F(1,88)=1.39, p$ $=.24$, partial $\eta^{2}=.02$, see Figure 1.2. Furthermore, there was no difference between the amounts of hostile sexism directed at the Black woman when she was chaste $(M=2.39$, $S D=.65)$ or promiscuous $(M=2.41, S D=.76), F(1,91)=.03, p=.86$, partial $\eta^{2}<.001$. Instead, there was a significant main effect of subtype, such that there was more HS to promiscuous women than chaste women, $F(1,184)=4.75, p=.03$, partial $\eta^{2}=.03$. This finding, while consistent with Sibley and Wilson's (2004) results, does not support Hypothesis $2 \mathrm{~b}$, which predicted more hostile sexism directed at the promiscuous White target than the promiscuous Black target. 
Positive Evaluations. Finally, 2 a (race) x 2 (subtype) factorial ANOVA with overall positive evaluations of the female targets as the outcome did not reveal a significant interaction effect, $F(1,184)=.18, p=.67$, partial $\eta^{2}=.001$. Instead, there was a main effect of subtype, such that chaste women $(M=5.62, S D=.64)$ were evaluated more positively than promiscuous women $(M=5.21, S D=.79), F(1,184)=15.19, p$ $<.0001$, partial $\eta^{2}=.08$. There was no main effect of race, $F(1,184)=.01, p=.92$, partial $\eta^{2}<.0001$, suggesting that while participants took into account both race and subtype of the target when they made their benevolent evaluations, they were not significantly influenced by race when assessing the target on other positive traits. This finding also indicates that while more BS was directed at the chaste Black woman, her behavior did not translate into more positive evaluations overall.

Moderators. Participant's baseline hostile sexism, benevolent sexism, and modern racism were all tested individually as possible moderators of their hostile, benevolent, and positive trait evaluations of the female targets.

In regression analyses testing these moderators, only the three-way interaction between participant's HS, target race, and target subtype on benevolent evaluations of the female target approached significance, $B=.586, S E=.32, t=1.82, p=.07$. Despite the marginal 3 way interaction, when examining the negative subtype, there was a significant two-way interaction between baseline HS and target race, $B=-.34, S E=.17, t(81)=$ $2.01, p=.05$. Simple slopes analyses revealed that higher baseline HS predicted less BS toward the promiscuous Black target, $B=-.270, S E=.13, t(81)=-2.20, p=.031$, but not the promiscuous White target, $B=.06, S E=.11, t(81)=.53, p=.60$. There was no 
significant two-way interaction between baseline HS and target race in the positive subtype, $B=.25, S E=.28, t(85)=.89, p=.37$.

\section{Discussion}

Study 2 extended Study 1 by testing how a woman's race and sexually subtyped behavior impact expressions of BS, HS, and overall positivity towards her. Study 1 manipulated only the woman's race and found a significant main effect, such that more BS was expressed to the White woman than the Black woman. In Study 2, we untangle this effect further by adding in sexually subtyped behaviors (promiscuous vs. chaste) to test for interactions. We found that once both race and sexual subtype were examined, the main effect of race disappeared and was replaced by a significant interaction effect.

Consistent with shifting standards theory, expressions of benevolent sexism were higher for the chaste Black woman than the chaste White woman. However, the chaste Black target was not evaluated any more positively on the trait measures than the chaste White target, suggesting that the Black woman may have been "praised" with benevolent sexism for her stereotype-inconsistent behavior, but this did not translate into more positive evaluations overall. In this case, perceptions of BS and positive impressions were incongruous, as "positive" expressions of BS favored the chaste Black woman while positive overall impressions favored chaste women over promiscuous women, regardless of their race.

While we had predicted that more HS would be directed at the promiscuous White target than the promiscuous Black target (Hypothesis 1b), we did not find that hostile sexism was differentially applied based on race. This finding is consistent with 
Study 1, which also did not find different levels of hostile sexism directed at Black faces and White faces. This suggests that the women were equally punished for violating the chastity ideals of their gender, irrespective of race. When White women violate their expected roles of purity, they are not punished any more than Black women are for this behavior. That is, they are "protected" from the overly negative evaluations that shifting standards would predict from violating their expected positive sexual behavior. These results are also contrary to ambivalence amplification (Hass et al., 1991), which would have predicted more extreme evaluations of the Black targets.

We assessed participants' endorsement of HS, BS, and their modern racism as potential moderators of these effects. Unlike Study 1, participants' modern racism did not alter how they evaluated the White and Black targets. Only baseline HS approached conventional levels of significance, such that participants with higher HS directed marginally less BS at the promiscuous Black target, but not promiscuous White target. As previously stated, HS punishes women who reject traditional gender roles (Glick \& Fiske, 2001). That in this study higher endorsement of HS led to marginally less BS for the Black woman who violated traditional norms but not her White counterpart further demonstrates how even White women who reject the purity norms of their gender may be "protected" by their Whiteness from "losing" benevolent sexism.

\section{General Discussion}

These two studies sought to integrate race into Ambivalent Sexism Theory by measuring how benevolent and hostile sexism are differentially applied to Black women and White women, thus merging this modern form of sexism with the comparatively 
larger racism literature to test for vital intergroup differences. Previous research had identified adherence to traditional gender roles as predictors of BS (Glick et al., 1997; Sibley \& Wilson, 2004). We found that more BS was directed at White faces than Black faces (Study 1), suggesting that race could function as a subtype in the absence of traditional behavioral cues. However, when Black and White women were sexually subtyped, more BS was expressed to the chaste Black woman than the chaste White woman (Study 2). Target race is therefore not the only determinate of benevolent sexism; race and behavior can interact to produce different outcomes.

Given that the BS ideals of purity and defenselessness are incompatible with stereotypes of Black women as promiscuous (Jewell, 1993) and aggressive (Weitz \& Gordon, 1993), we maintain that this finding is indicative of shifting standards, whereby individuals who exceed the lower expectations of their stereotyped group receive more praise (non-zero sum rewards) for their stereotype-inconsistent behavior. It is because expectations for Black woman's behavior were more negative that participants tended to report that she should be "cherished and protected" and "set on a pedestal by her man" when she surpassed them by being chaste, even more so than her White counterpart. While subjectively positive, it reveals the impact of negative stereotypes and only reinforces her subordinate status relative to men.

Positive impressions of the women differed across studies, with a main effect of race in Study 1 (favoring White women) and a main effect of sexual subtype in Study 2 (favoring chaste behavior.) Even though she conformed to traditional gender norms, the chaste Black woman was not viewed more positively overall, indicating that participants 
only treated her differently on the one positively-valenced sexist measure of benevolent sexism. That is, shifting standards occurred on the measure of BS but not on overall positive impressions. This result implies that the benefits for Black women who conform to traditional gender norms may not extend beyond increased BS.

Across both studies, hostile sexism was not differentially applied based on race. Here the findings both lend support to Sibley and Wilson's (2004) conclusions about ambivalent sexism and sexual subtype and qualify them by race: While more HS was directed at promiscuous women than chaste women, there was no difference in the amounts of HS directed at Black women when they were promiscuous or chaste. That we were able to demonstrate that a previously uncontested assumption might not necessarily apply to women of every race hints at the magnitude of other studies within this literature that could benefit from a more intersectional paradigm. We suspect that these comparable levels of HS to Black women, regardless of sexual subtype, reflect the influence of the other negative stereotypes of her racial group, which characterize Black women as loud, antagonistic, unmannerly (Niemann et al., 1994) and less "appropriately feminine" (Goff et al., 2008b). Alternatively, it could be that shifting standards occurs more exclusively with expressions of praise than contempt. Either way, Black women may continue to experience hostility regardless of their adherence to traditional norms of chastity.

Although we observed differences in benevolent sexism in these studies, care must be taken when interpreting the findings. While statistically significant, the observed mean differences are close to each other and to the scale midpoint. While the effect sizes across both studies were small, it is noteworthy that this effect emerged following a 
manipulation as subtle as changing the female target's race. Prentice and Miller (1992) have argued that effects can still be important even when they are statistically small when researchers demonstrate how even a minimal manipulation of the independent variable can account for some variance of the dependent variable. In Study 2, changing the chaste woman's name from Kate to Tanisha was enough to create a significant increase in BS; this finding has consequences for women in the real world insofar as it could produce differential treatment, perhaps in the form of racial and gender-based microaggressions, which are commonplace verbal or behavioral slights that communicate negative perceptions of a person or their group (Sue, 2010). For instance, Black teenagers participating in a chastity ball, dressing modestly, or delaying sexual intercourse might receive increased praise for these actions in ways that communicate to them that they do so in spite of their racial identity. These microaggressions build on each other over time to produce negative psychological consequences, such as higher stress, feelings of powerlessness, and loss of integrity (Sue, Capodilupo, \& Holder, 2008).

Future studies will want to examine how ambivalent sexism is differentially applied to Hispanic and Asian Americans, as well as other ethnic groups in other settings. As the stereotype of Black women as sexually available has its roots in slavery in the American antebellum South (Jewell, 1993), it is possible that our findings would not generalize to countries that do not share this history. Instead, results may be contingent upon the ethnic groups that exist in a particular country and the stereotypes about those groups that are specific to that time and location. As Black males are also stereotyped as hypersexual (Hall, 1995), there may be differences between perceptions of promiscuous 
White men and Black men as well. Further explorations of how ambivalent sexism is applied to women of different races may want to make use of indirect measures of implicit attitudes, especially given the social sensitivity of this topic (Greenwald, Poehlman, Uhlmann, \& Banaji, 2009).

Though the present study was unable to demonstrate shifting standards of hostile sexism toward promiscuous White women, this effect may emerge in a more applied setting. In the criminal justice domain, White women who violate expectations of their racial group by being prostitutes may receive more severe punishments upon arrest than Black prostitutes. Evidence suggests that prostitutes are seen as violating cultural values (Rosenblatt, Greenberg, Solomon, Pyszczynski, \& Lyon, 1989), but the strength of this perception and subsequent treatment of this woman might differ depending on her race. This could come in the form of a judge recommending harsher bonds or a police officer using more force or callous language. These and other experiments would help to clarify if and how reactions to women who violate traditional gender roles by being promiscuous are influenced by her race.

The paradigm used here brings a much-needed intersectionality perspective to the ambivalent sexism literature. It calls into question the generalizability of studies with the ASI that have failed to broach the subject of race. To the extent that this proves a fruitful line of inquiry, others may be encouraged to examine more constructs related to gender through the lens of race, and theories of racism in the context of gender. A more thorough and representative understanding of concurrent gender and racial prejudice will eliminate the overwhelming bias in the field that the primary targets of sexism are White women 
and the primary targets of racism are Black men, resulting in a discipline better able to address discrimination in all its contemporary forms. 
Figure 1.0: Ratings of benevolent sexism, hostile sexism, and positive trait evaluations for Black and White females.

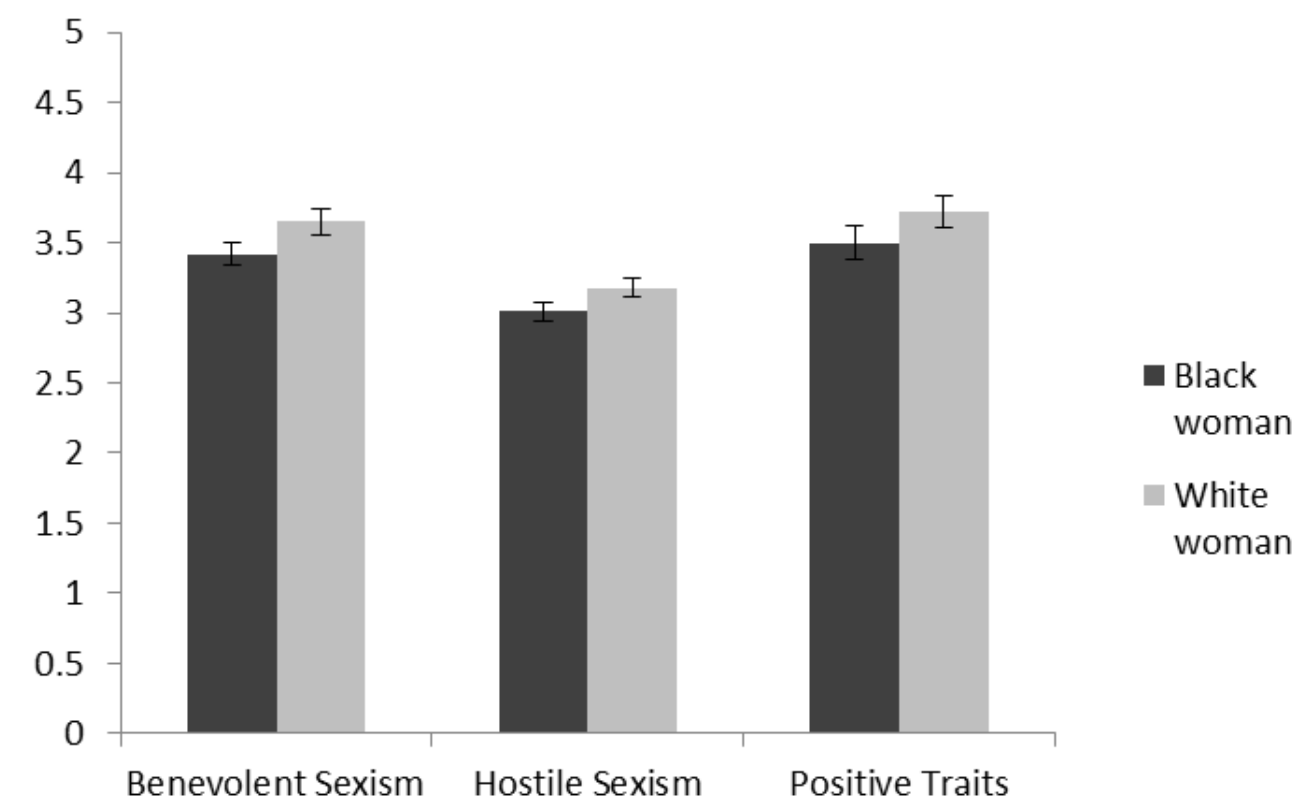

Figure 1.1: Benevolent evaluations of women as a function of their race and sexual behavior.

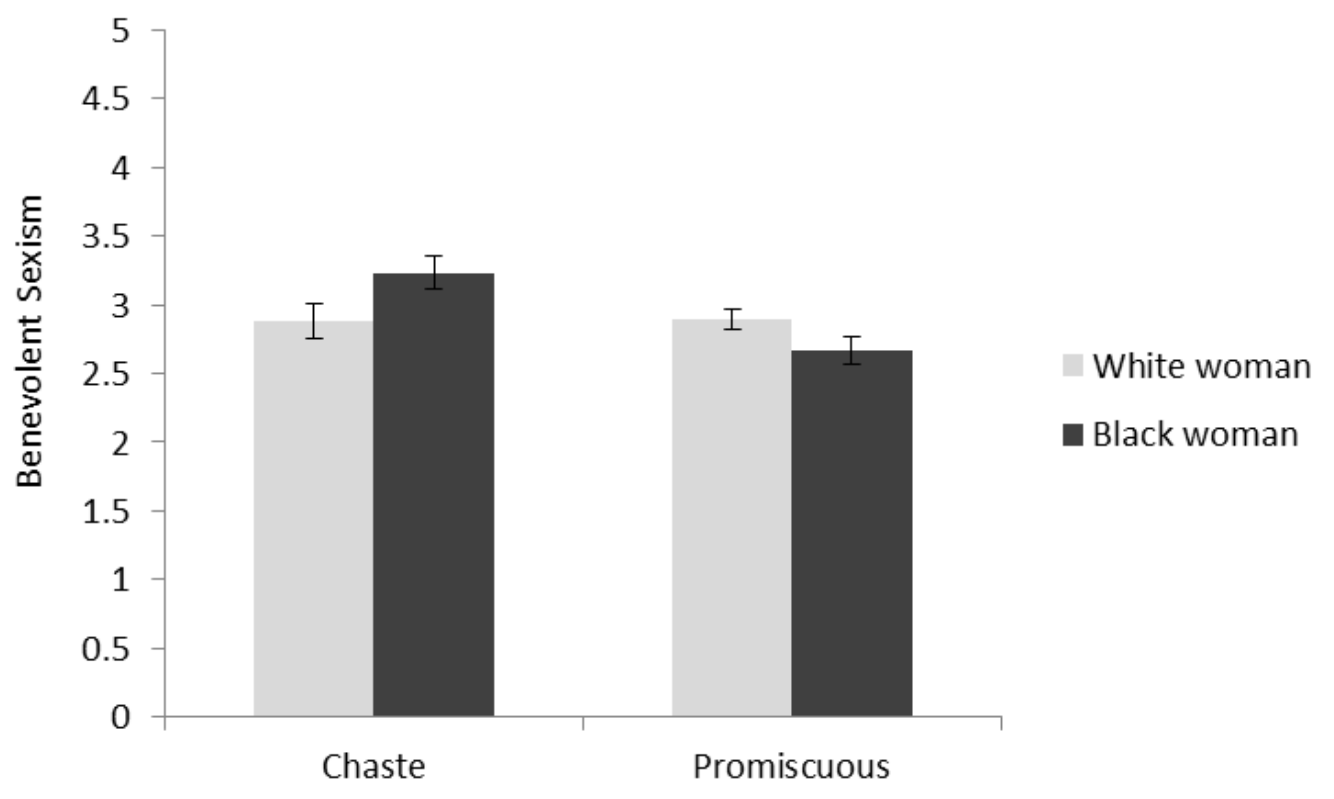


Figure 1.2: Hostile evaluations of women as a function of their race and sexual behavior.

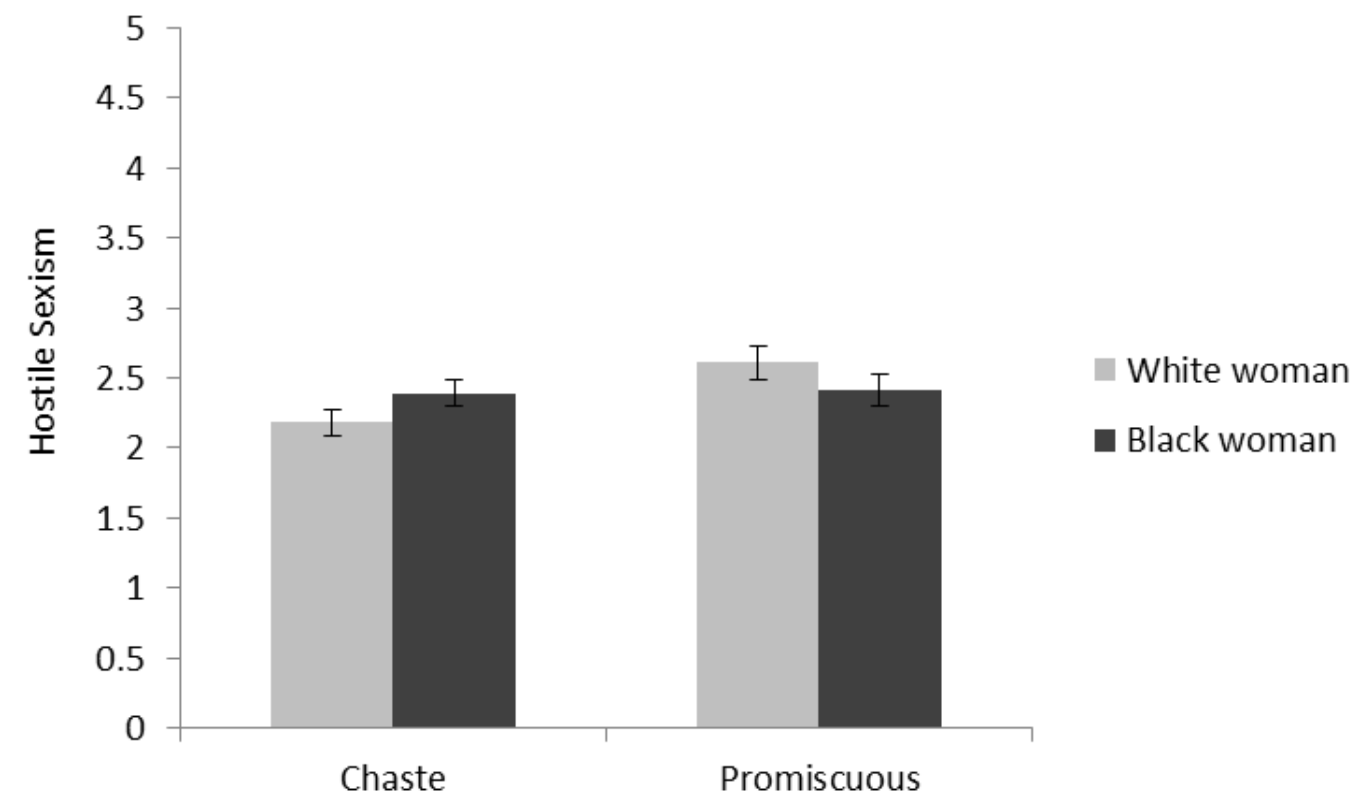




\title{
CHAPTER III. MANUSCRIPT II. WHEN SEXISM LEADS TO RACISM:
} EXPERIENCING THREAT, PROTECTING WOMEN, AND RACIAL BIAS.

\begin{abstract}
The stated goal of protecting White women from harm has been used, historically and contemporarily, as a pretext for racial violence. Two studies explored the relationship between protective paternalism (the belief that men should protect and care for womenpart of benevolent sexism; Glick \& Fiske, 1996) and anti-minority racial attitudes. In Study $1(\mathrm{~N}=474,61 \%$ women, $61 \%$ White), survey data found that protective paternalism was related to anti-Black bias, but only for White respondents. Study 2 (N=242, 52\% women, 74\% White) experimentally manipulated feelings of threat to test for increases in protective paternalism and its corresponding effect on three anti-minority racial attitudes. For male participants only, threat (i.e., reading about recent increases in violent crime) increased endorsement of protective paternalism, which was in turn associated with a more negative view of immigration, and, for White men only, less support for policies that benefit racial minority groups and greater denial of racial bias in policing. Threat did not increase protective paternalism in female participants. For White men in particular, news of crime and danger increases racial bias by first increasing the desire to protect women. Policymakers should be aware that framing policies around safety concerns or appealing to the protection of women might unintentionally bolster anti-minority racial prejudices.
\end{abstract}

\section{The final publication is available at Springer} via http://dx.doi.org/10.1007/s11199-017-0828-x 


\section{Introduction}

"You rape our women and you're taking over our country and you have to go." Dylann Roof, a White male, used these words to justify the murder of nine Black worshippers at the Emanuel African Methodist Episcopal Church in Charleston, South Carolina (Wade, 2015). As a pretext for violence, this act of White supremacy explicitly cites the need to protect White women from a racial minority group. Taken to an extreme, this justification, which has been historically used against the Black community (Davis, 1981), embodies similar beliefs as protective paternalism, a component of benevolent sexism (Glick \& Fiske, 1996). The present studies explore how this sexist ideology is linked to racial prejudice. While considering the moderating roles of participants' racial group membership and gender, our first study tests for relationships between protective paternalism and various indicators of racial bias in a survey, and our second study uses an experiment to manipulate threat to test for increases in protective paternalism and corresponding anti-minority attitudes.

\section{Benevolent Sexism}

Ambivalent sexism theory (Glick \& Fiske, 1996) suggests that although many forms of prejudice are rooted in antagonism, men's didactic dependence on women as mothers and intimate partners requires that the group not be wholly condemned. As a result, stereotypes of women must also emphasize positive traits, a duality represented by hostile and benevolent sexism. Benevolent sexism (BS) characterizes women as moral, pure, and deserving of male protection. BS is reserved for women who conform to traditional gender roles of chastity and domesticity, whereas women who reject them are 
depicted as unappreciative, overly sensitive, and sexually manipulative and are met with hostile sexism (HS) (Glick, Diebold, Bailey-Werner, \& Zhu, 1997; Sibley \& Wilson, 2004). The result is a two-pronged system of rewards and punishments that maintain patriarchal hegemony by encouraging women to remain in domestic, subordinate roles and by threatening those women who challenge them (Glick \& Fiske, 2001). BS has three subcomponents at its roots: a male need for heterosexual intimacy, the use of biological essentialism to promote complementary gender differentiation, and the sincere desire to protect and defend women from harm (protective paternalism) (Glick \& Fiske, 1996).

On the surface, motivations to protect and treasure women appear overwhelmingly positive. Although it may stem from a place of genuine affection, BS has been repeatedly shown to predict negative outcomes for women. Benevolent sexists disapprove of women who have abortions for any reason (Huang, Osborne, Sibley, \& Davies, 2014) or who engage in premarital sex, consensually or otherwise (Abrams, Tenyadi Viki, Masser, \& Bohner, 2003; Sakalh-Uğurlu \& Glick, 2003). BS increases women's body shame (Shepherd et al., 2011) and system-justifying beliefs (Jost \& Kay, 2005), impedes cognitive performance (Dardenne et al., 2013), and undermines their successes in school (Montañés, de Lemus, Bohner, Megías, Moya, \& Garcia-Retamero, 2012) and in the workplace (King et al., 2012). Benevolent sexism is thus a velvet glove (Jackman, 1994) that contributes to gender inequality by promising rewards to women who remain in a subordinate position relative to men.

Paramount among these "rewards" for women is the promise of men's protection, as defined by the protective paternalism component of BS. Enshrined in patriarchal logic 
is the role of the masculine protector whose duty it is to ensure the safety of his wife and children in exchange for their obedience and affection (Young, 2003). Just as ambivalent sexism theory distinguishes between "good women" (who receive BS) and "bad women" (who provoke HS), this conceptualization of masculinity distinguishes between the "good men" who self-sacrifice to shield their families from harm and the "bad men" who seek to claim his property and women for themselves. In this way, "virtuous masculinity depends on its relation to the presumption of evil others" (Young, 2003, p. 13). In practice, these perceived "evil others" are often racial minority men.

\section{Racism and Benevolent Sexism: Historical Roots}

At the core of BS is the inherent fragility, domesticity, and purity of women (Glick \& Fiske, 1996). However, these traits have historically been more closely associated with upper class White women in particular (Morton, 1991; Schloesser, 2002). In the absence of information about an individual woman's adherence to traditional gender roles, being White (rather than Black) is enough to elicit greater benevolent sexism toward her (McMahon \& Kahn, 2016). Historically, White women's innate purity made them sacred vessels for propagating the race (Apel, 2004), which necessitated their safeguarding by male relatives. In this way, White men's protection encompasses the defense not just of any one treasured relation or partner, but also of the purity of the White race as a whole (Wood, 2011).

The need to protect White women from racial minority men has long been used as a pretext for violence. During Reconstruction, an estimated 10,000 African Americans were killed by White mobs (Davis, 1981). News reports and lynching apologists alike 
cited the need to avenge supposed attacks on White women and children (Davis, 1981; Wood, 2011). Representations of Black men as detriments to White womanhood persist in modern media, from films (Dines, 2006; Guerrero, 1993) to Fascist propaganda posters (Difendila, 1944; United States Holocaust Memorial Museum, 2016). Interracial violence of this type induces seemingly disproportionate outrage, as in the prosecution of the (Black and Latino) Central Park Five who were wrongly accused of a rape and murder in New York City (Ammons, 1995), and the acquittal of two White men for the murder of Emmett Till, a Black 14-year-old killed in 1955 for reportedly whistling at a White woman (Wood, 2011). As Dylann Roof's rationalization attests, the myth of the "Big African Brute" (Hall, 1993, p. 112) persists in the $21^{\text {st }}$ century.

The stereotype of hypersexual minority men preying on White women is not confined to the United States, nor is it specific to Black men. During British colonial expansion in India, the threat of violence against White women represented the most dangerous form of native insubordination (Ware, 2015). Here as in the American South, White womanhood emblematized the purity of the White race and the domination of White men over others (Evans, 1979) and they required protection. This trope is also frequently seen when rationalizing fears of immigration. In the mid- $19^{\text {th }}$ century, concerns about the influx of Chinese immigrants gave rise to the "Yellow Peril" (Lee, 2007, p. 537), which was fueled by depictions in media of Chinese men either raping or seducing White women with opium (Allen, 2015; Marchetti, 1994; Tchen \& Yeats, 2014). The stereotype also implicated Japanese men during WWII as warmongering rapists (Miles, 2012). Similarly, Latino men are characterized as oversexed and seductive 
(Allen, 2015). Politicians and right-wing media have asserted the need for stricter control

of the U.S. southern border in order to ensure the safety of American women (Edwards, 2014; Garcia, 2014; Hee Lee, 2015). A similar discourse is occurring in Europe where, in 2015 alone, over one million migrants and refugees (mostly from the Middle East and Northern Africa) entered the European Union (BBC News, 2016). Arab men have long been represented in Western media as violent kidnappers and rapists of White women (Arab American National Museum, 2011; Mickalak, 1988), and anti-refugee fervor and policies in the region have intensified (Angerer, 2016; Yardley, 2016).

This is not to say that no White woman has ever been assaulted by a Black, Latino, Asian, or Arab man. Rather, this archetype is a fixture in historical and contemporary imaginations which vastly over-represents its frequency. Calls to defend White women from minority men occur disproportionate to the rate at which such interracial crimes happen (Becker, 2007; Ware, 2015) and far exceed calls to similarly protect or avenge minority women (Ammons, 1995; Young, 1986). This relationship between racial bias and BS may be consciously exploited to gain or maintain power, as in propaganda or protests (Angerer, 2016; Difendila, 1944), or it may be an unconscious psychological process prone to situational factors (as we explore in Study 2).

\section{Racism and Sexism: Social Psychological Perspectives}

Building on these historical associations, social psychology has empirically examined the relationship between these two forms of prejudice. People who endorse racist ideologies also tend to hold more sexist attitudes (Glick \& Fiske, 1996; Sidanius, 1993; Sidanius \& Pratto, 1999; Swim, Aikin, Hall, \& Hunter, 1995). Both racism and 
sexism have grown less overt in recent decades, as modern expressions of these biases tend to eschew public declarations of the relative inferiority of women and racial minorities in favor of antagonism toward demands for equality and a denial of gender- or race-based discrimination (McConahay, 1986; Swim et al., 1995).

Other research has examined the ways in which racial discrimination is gendered. Although Women of Color also experience discrimination (Bertrand \& Mullainathan, 2003; Krieger et al., 2006; National Women's Law Center, 2016b), it is men, not women, who are the assumed targets of racial prejudice (Goff \& Kahn, 2013). According to the subordinate male target hypothesis (Sidanius \& Veniegas, 2000), men from a racial or ethnic minority group experience a stronger degree of discrimination than their female counterparts, from employment (Carlsson \& Rooth, 2007) and education (Gordon, Piana, \& Keleher, 2000) to violent hate crimes (Sidanius \& Pratto, 1999). Racial minority men are also seen as more dangerous than are racial minority women (Plant, Goplen, \& Kunstman, 2011; Quillian \& Pager, 2001). As a consequence, the group in a position of power (i.e., White men) view men belonging to an outgroup, such as a racial minority, as more of a sexual danger to ingroup (e.g., White) women than are other ingroup (i.e., White) men (Nagel, 2001; Navarette, McDonald, Molia, \& Sidanius, 2010).

This recurring pattern suggests and provides evidence for the current studies' suggested link between benevolent sexism (specifically, protective paternalism) and racial bias. It further supports the idea that racial stereotypes characterize minority men as threats to the virtue and safety of White women, assigning these men to the role of the perceived "evil others" (Young, 2003, p. 13) from whom the masculine protector must 
defend his loved ones. This in turn suggests that protective paternalism, rather than solely a stable attitude, may also be influenced by perceptions of threat or danger.

\section{Overview of Studies}

The present studies seek to elucidate how protective paternalism is related to both racial bias and threat. Study 1 uses survey data to examine the relation between protective paternalism and subtle anti-minority racial attitudes. Study 2 experimentally manipulates threat to test for increases in protective paternalism and corresponding anti-minority racial attitudes, while considering the moderating roles of gender and majority racial group (i.e., White) status. In doing so, two bodies of literature are connected: BS as a response to threat as well as the relation between protective paternalism and racial bias.

\section{Study 1}

To our knowledge, the protective paternalism subscale has not been singled out as a facet of BS that has been directly correlated to anti-minority attitudes. Although prior studies have demonstrated the importance of examining the various subscales of BS in isolation (Burn \& Busso, 2005; Sarrasin, Fasel, Green, \& Helbling, 2015), here we focus on protective paternalism with its emphasis on men's duty to self-sacrifice and women's need to be cherished and protected. Study 1 sought to complement the previously described historical evidence linking paternalism and racism with empirical data. Further, we suspected, given the historical linkages between paternalism and the protection of White women from minority men, that the relation between paternalism and racism would be stronger for Whites than for racial minorities.

This initial study makes use of a pre-existing dataset collected at a mid-sized 
public U.S. university. The four items from the Ambivalent Sexism Inventory (Glick \& Fiske, 1996) assessing protective paternalism were included in this dataset, along with the Modern Racism Scale (McConahay, 1986) and items designed to measure attitudes about various contemporary issues in policing in the United States, including the use of body cameras; armed campus security; and the shooting death of Michael Brown in Ferguson, MO, along with the ensuing Black Lives Matter (BLM) movement. This data collection presented an opportunity to test our hypothesis using not only a popular, standardized measure of racism (McConahay, 1986) but also questions that tapped current relevant social issues related to race. Therefore, Study 1 involved an investigation of the relation between protective paternalism and various subtle measures of anti-Black bias, including modern racism (McConahay, 1986), support for BLM, and attributions of blame in the shooting death of African American teenager Michael Brown by White police officer Darren Wilson. We hypothesized that, for White participants in particular, stronger endorsement of protective paternalism would be correlated with higher modern racism, more blame directed at Michael Brown for his death, and less support for the BLM movement.

\section{Methods}

Participants and design. Fully 474 participants (162, 34\%, men; 289, 61\%, women; $23,5 \%$, other/declined to state) were recruited from a midsized public university to complete an online study about security on college campuses and policing in the United States. A majority (289, 61\%) identified as White, 50 (11\%) as Asian, 52 (11\%) as Latinx, $11(2 \%)$ as Middle Eastern, $10(2 \%)$ as Black, 45 (10\%) as multiracial, $6(1 \%)$ 
as Native, $11(2 \%)$ as Other; their average age was 26.05 years-old $(S D=8.33$, range $=$ 18-67). Participants were offered either extra credit in a course or the chance to win a gift card. Our study used a non-experimental, correlational design.

Measures. Of the measures in this pre-existing dataset, four were of interest to the present study: items measuring protective paternalism and three indices of anti-Black bias. The following measures are described in the order in which they appeared to participants. Interspersed between these measures were questions about other social groups (e.g., feeling thermometers for Latinos, Asians, police, etc.), attitudes (e.g., just world beliefs), and activities (e.g., social media usage), which likely helped to decrease response bias in our study.

Blame for Michael Brown. As part of this larger survey, participants were asked to recall the shooting death of Michael Brown, an unarmed Black teenager in Ferguson, MO, by a White police officer named Darren Wilson. A seven-item scale was created to assess the belief that Michael Brown (rather than Officer Darren Wilson) was ultimately to blame for the outcome of this incident. Items include: “Michael Brown's behavior led to the outcome of this incident," "Officer Darren Wilson was justified in the amount of force used in this incident," "Michael Brown was to blame for the amount of force that was used," "Officer Darren Wilson was responsible for any injuries Michael Brown obtained" (reverse-coded), "Officer Darren Wilson acted in an unbiased manner during this incident," "I support Officer Darren Wilson's actions in this incident," and "This incident was the fault of Officer Darren Wilson" (reverse-coded.) Agreement with each statement was rated on a scale from 1 (strongly disagree) to 7 (strongly agree). 
Participants who indicated on a previous question that they remembered "nothing at all" about this incident $(n=20)$ were excluded from subsequent analyses that use this scale. Internal consistency of the seven averaged items was very high $(\alpha=.91)$.

Support for BLM movement. Participants also indicated their support for Black Lives Matter, a grassroots movement that raises awareness of the deaths of unarmed African Americans by police. Six items were rated on a scale called Support for BLM Movement from 1 (strongly disagree) to 7 (strongly agree), with higher scores indicating stronger support for the Black Lives Matter movement. Items include: "The BLM movement is necessary," "I support the goals of the BLM movement," "The BLM movement is effective in increasing awareness of systemic racial bias," "The BLM movement is promoting unlawful behavior," (reverse-coded) "The BLM movement is justified," and "The BLM movement unnecessarily increases racial tensions in society" (reverse-coded). Internal consistency of the averaged items was robust $(\alpha=.92)$.

Modern racism. Attitudes about African Americans were assessed using the Modern Racism Scale (McConahay, 1986), which measures a less overt form of prejudice characterized by beliefs that racism is no longer problem and that Blacks are too "demanding." Participants rated their agreement with six statements (e.g., "Blacks should not push themselves where they are not wanted") on a 5-point Likert scale from 1 (strongly disagree) to 5 (strongly agree), $(\alpha=.90)$. Item responses were averaged so that higher scores indicate stronger endorsement of modern racist attitudes.

Protective paternalism. Participants completed the protective paternalism subscale of the Ambivalent Sexism Inventory (Glick \& Fiske, 1996), consisting of four 
items $(\alpha=.77)$ rated on a 6-point Likert scale from 0 (strongly disagree) to 5 (strongly agree), with higher average scores indicating greater endorsement of protective paternalism Sample items include: "A good woman should be set on a pedestal by her man" and "Women should be cherished and protected by men."

Measurement properties. An exploratory factor analysis with direct oblimin rotation was used to examine the Blame for Michael Brown and Support for BLM items. The EFA yielded two factors with a simple structure, which accounted for $69.5 \%$ of the variance. The seven Blame for Michael Brown items loaded onto the first factor (all loadings greater than .54), and the six Support for BLM items loaded onto the second factor (all loadings greater than .46), with no cross-loadings. The two factors were strongly correlated at -.76 , suggesting that these are two related yet empirically distinct constructs.

\section{Results}

Only participants who answered every question on each of the four measures were included in the analyses; those with missing items were excluded. Results of Little's MCAR for each measure suggest that item responses are missing at random (all $p \mathrm{~s}>.46$ ). This stringent exclusion criterion led to the loss of between 41-56 participants (depending on the variable). When the composite variables were adjusted to include participants who completed all but one of the items for any given measure, between 2123 participants were added, and all the patterns of results described in the following held.

Next, bivariate correlations between the four measures were computed separately for White and racial minority participants (see Table 1a). For White participants only, 
protective paternalism was positively correlated with Modern Racism and the conviction that Michael Brown's actions directly led to his death, and negatively related to support for the BLM movement. Protective paternalism was not correlated with any measures of anti-Black bias among minority participants.

We further examined whether participant race $(0=$ White, $1=$ racial minority $)$ moderated these relationships using the Hayes' PROCESS macro model 1 (Hayes, 2013), which used 1,000 bias-corrected bootstrapped samples to estimate confidence intervals for conditional effects at each level of the moderator (see Table 2). Participants' race moderated all three relationships (all $p \mathrm{~s}<.03$ ), such that for White participants only, protective paternalism was positively related to modern racism and blame for Michael Brown, as well as negatively related to support for BLM. For participants who were not White, protective paternalism was not related to any of the racial bias measures (all conditional effect $p s>.28)$. Furthermore, participants' gender $(0=$ female, $1=$ male $)$ did not moderate the relation between protective paternalism and any of the three measures of racial bias (all $p \mathrm{~s}>.10)$.

\section{Discussion}

The purpose of our first study was to provide initial evidence demonstrating the association between protective paternalism and anti-minority racial attitudes. In a preexisting dataset, we found that protective paternalism was correlated with measures of subtle anti-Black bias, but only for Whites. Specifically, White participants who endorsed protective paternalism more strongly also scored higher on modern racism, were more likely to believe that African American police-shooting victim Michael Brown was 
responsible for his own death, and showed less support for the Black Lives Matter movement. Participants' gender did not moderate these effects. Although these data are correlational, they provide initial evidence of the potentially insidious relationship between protective paternalism and racism. Although the correlation between sexism and racism is well established (Glick \& Fiske, 1996; Sidanius \& Pratto, 1999), the present study clarifies that (a) it also extends to protective paternalism, a sub-component of BS; (b) it can be found using more specific measures of subtle racism that reflect a current social issue (e.g., racial bias in policing), and (c) when the sexist attitude in question concerns the protection of women, the correlation with racial bias is present only for Whites. Our finding is also consistent with evidence that the BS subscale may have different psychometric properties for racial minority respondents (Hayes \& Swim, 2013).

\section{Study 2}

The results from Study 1 suggest that, for Whites, protective paternalism is related to negative attitudes about African Americans. Study 2 examines a potentially unconscious psychological process by which protective paternalism increases racial bias as a response to danger.

\section{Benevolent Sexism as a Response to Threat}

A wealth of research has established that fear and threat enhance various expressions of political conservatism (Jost, Glaser, Kruglanski, \& Sulloway, 2003). This relationship can be understood through a motivated social-cognitive approach, which highlights the situational as well as dispositional factors that lead to the adoption of conservative ideologies to satisfy psychological needs (Jost et al., 2003). BS, which is 
rooted in conservative beliefs (Christopher \& Mull, 2006; Sibley, Wilson, \& Duckitt, 2007), may too be a motivated response to threat.

Earlier investigations examined threats to women's group-level esteem. In their survey of 19 countries, Glick et al. (2000) found that in nations where men's HS was highest, women's endorsement of BS was as high or higher, suggesting that where men's attitudes about women are more negative, women may be motivated to affirm the positive qualities of their gender depicted by BS. Indeed, women who were told that men held negative attitudes about women reported higher levels of BS than those told that men had positive attitudes or a control group (Fischer, 2006), implying that some of women's BS might be a reaction to cues that their gender is perceived negatively by men. For both men and women, reading reports of a local crime has been shown to increase BS, but not HS (Phelan, Sanchez, \& Broccoli, 2010). Others have found that only sexual threats increase women's endorsement of BS (Espinoza Ornelas, Moya, \& Willis, 2015).

Although their specific findings differ, this pair of studies (Glick et al., 2000; Phelan et al., 2010) suggests that in response to some types of threat, BS may be a form of motivated social cognition. Women who feel physically threatened may increase their endorsement of sexist ideologies that promise them a safe haven. This may provide security in the immediate context, but it is contingent on them remaining dependent on and subordinate to men because only traditional, chaste women are "good" enough to receive men's adulation and protection (Glick et al., 1997; Sibley \& Wilson, 2004). This reasoning would also be consistent with the idea of BS as a legitimizing myth that serves to reinforce the status quo (Jost \& Kay, 2005). Men's response to hearing about crime 
with a heightened desire to defend women (Phelan et al., 2010) is in keeping with the logic of masculinist protection, whereby "good men can only appear in their goodness if...lurking outside the warm familial walls are aggressors who wish to attack them" (Young, 2003, p. 4). If outside threats make the role of the masculine protector salient and increase the desire to defend women from attackers, this may also activate the antiminority attitudes that have long been associated with protective paternalism, especially for Whites (as seen in our Study 1.)

Prior research has shown that reading about crime increases endorsement of BS, but protective paternalism has not been singled out for analysis and women's responses have been inconsistent, depending on the type of crime to which they are experimentally exposed (Espinoza Ornelas et al., 2015; Phelan et al., 2010). Study 2 examines the relationship between threat and protective paternalism with gender as a moderator, and it tests for corresponding increases in anti-minority attitudes, particularly for Whites.

\section{The Present Study}

Study 2 was designed to address both limitations from Study 1 and several new goals. First, we wanted to conceptually replicate the link between protective paternalism and racism. We diversified the range of anti-minority attitudes by including items related to immigrants and a new scale that measured beliefs that race is a factor in policing outcomes. We anticipated that, consistent with Study 1, protective paternalism would be related to a variety of anti-minority attitudes, including less support for policies that benefit racial minority groups, a negative view of immigration, and denying that race plays a role in policing outcomes, especially for White participants. 
Second, we investigated the causal role of threat in increasing protective paternalism. We prime global feelings of threat by having participants read about the recent increase in violent crime across the United States because we believed this exposure should both prime the role of the masculine protector for men (Young, 2003) and increase the desire for protection for women (Phelan et al., 2010). We predicted that those in the threat condition would report higher endorsement of protective paternalism than those in the control. Given that women have not consistently responded to all types of threat with increased BS (Espinoza Ornelas et al., 2015; Phelan et al., 2010), we also tested gender as a moderator of the relationship between global threats of violent crime and paternalism.

Third, our second study further examines the process and relationship among threat, protective paternalism, and racism in a mediation model. If being threatened increases protective paternalism, and protective paternalism is correlated with anti-Black attitudes (as suggested in Study 1), then this increase in sexism might cause an increase in racism. In other words, protective paternalism might mediate the relation between threat and anti-minority bias.

Fourth, we tested the moderating role of participants' race. As we discussed, the stated goal of protecting White women, and thus the White race as a whole (Wood, 2001), is a common pretext for racial bias and aggression, suggesting that the relation between protective paternalism and anti-minority attitudes should be stronger for Whites. Our results from Study 1 support this prediction. We therefore tested whether participants' racial group status (White vs. racial minority) moderated the relation between protective 
paternalism and our various measures of anti-minority bias. Finally, our experiment controlled for participants' endorsement of hostile sexism. The pre-existing dataset used in Study 1 did not include the 11-item HS subscale, so we were unable to control for HS to isolate the effects of BS (Glick \& Fiske, 1996; Glick et al., 1997).

In summary, we predicted that experimentally priming threat would increase protective paternalism, and we tested whether participants' gender moderated this effect. We further hypothesized that this increased protective paternalism would lead to stronger anti-minority attitudes, particularly for Whites, consistent with data from Study 1.

\section{Methods}

Participants and design. Fully 244 participants were recruited from Amazon Mechanical Turk and participated in the study hosted on Qualtrics. Participants who did not summarize the article as part of the manipulation check $(n=2)$ were excluded from subsequent analyses, leaving a final sample of 242 participants (116, 48\%, men; 126 , $52 \%$, women). Of these participants, $178(74 \%)$ identified as White, $18(7 \%)$ as Asian, $16(7 \%)$ as Latinx, $19(8 \%)$ as Black; $10(4 \%)$ as multiracial or other, $1(.4 \%)$ was missing. The present study used an experimental design with random assignment. Composite variables of the average score were only calculated for participants with no missing data.

Procedure and measures. After providing informed consent and demographic information, participants were randomly assigned to either a threat or no threat condition and completed subsequent questionnaires. The experimental manipulation and measures are described in the following in the order in which they were presented to participants. 
Threat manipulation. Participants were told that they were taking part in a study about news media. One of two news articles was presented, each drawn from a real online publication and made to look copied from the Washington Post's newspaper website. In order to make threat and danger salient in the threat condition, participants read that violent crimes were increasing in the United States ("FBI: Murders and other violent crimes increased last year"). The article informed them that "the numbers of murders, rapes, assaults and robberies were all up over the first six months" of the year, with the FBI reporting that "violent crime increased in most regions of the country" and criminologists stating "it was not clear what was happening and counsel[ling] patience." In the control condition, participants read about traffic congestion ("The U.S. is choking on its traffic and it's going to get worse."). This article described how "congestion is the worst it has ever been" due to "more people driving more vehicles more miles on about the same-sized road system as existed 30 years ago." The articles were of similar length (about 300 words) and included a related image below the headline (yellow crime scene tape and a crowded freeway, respectively). The first is similar to the reports of crime that have been previously used as manipulations (Ornelas Espinoza et al., 2015; Phelan et al., 2010). As a manipulation check, participants were asked to summarize the content of the article. (See online supplemental material for full text of articles.)

Protective paternalism. Immediately following the experimental manipulation, participants completed the full Ambivalent Sexism Inventory (Glick \& Fiske, 1996). This 22-item measure assesses both hostile $(\alpha=.93 ; 11$ items $)$ and benevolent $(\alpha=.89 ; 11$ items) sexism, and it includes the protective paternalism subscale $(\alpha=.76 ; 4$ items). The 
hostile sexism subscale includes items such as, "Women are too easily offended" and "Women seek to gain power by getting control over men." The response scale and scoring was identical to Study 1, with higher average scores indicating stronger endorsement of each type of sexism.

Racial bias in policing. A six-item measure was created to assess the belief that racial bias is an issue in contemporary policing $(\alpha=.91)$. Items include: "Police treat people differently based on the color of their skin," "Bias against racial minorities is not a problem in police departments today" (reverse-coded), "Police often use excessive force when dealing with minority suspects," "The police, in general, are not racist" (reversecoded), "Race is often a factor in how police treat a suspect," and "Police have been unfairly blamed for targeting racial minorities recently" (reverse-coded). These statements were rated on a Likert scale of 1 (strongly disagree) to 7 (strongly agree) and averaged, with a higher score indicating stronger beliefs that racial bias is an issue in policing. An EFA demonstrated that all items loaded on to a single factor that accounted for $69.79 \%$ of the variance, with all factor loadings above .69 .

Immigration negative. Three items were adapted from the General Social Survey (Smith et al., 2015) to measure negative attitudes about immigration. Participants rated on a scale from 1 (extremely unlikely) to 7 (extremely likely) how likely it would be that more immigrants coming to the United States would result in "higher crime rates," "making it harder to keep the country united," and "people born in the U.S. losing their jobs." Higher average scores indicated stronger beliefs that continued immigration to the United States would have negative consequences. The items had a high degree of internal 
consistency $(\alpha=.88)$ and loaded onto a single factor, with all factor loadings above .82 and explaining $81 \%$ of the variance.

Minority policy support. Embedded in a list of 12 local and national policies (e.g., raising the minimum wage, the Clean Air Act) were three policies that would specifically benefit racial minority populations in the United States: (a) affirmative action, (b)

allowing Syrian refugees into the United States, and (c) building a wall on the Mexican border (reverse-coded). Participants indicated how much they agreed with (supported) each policy on a scale from 1 (strongly disagree) to 7 (strongly agree). These three policy items were averaged to create a measure of Minority Policy Support $(\alpha=.78)$, with higher scores indicating greater support. An EFA showed that the items, each with a loading above .61, loaded onto a single factor that explained $70 \%$ of the variance.

\section{Results}

Conceptual replication of Study 1. First, bivariate correlations between protective paternalism and the three anti-minority attitudes measures were tested for White and racial minority participants (see Table 1b). As seen in Study 1, significant correlations emerged among White participants only, with protective paternalism being positively associated with anti-immigrant attitudes and negatively associated with beliefs about racial bias in policing and support for policies benefiting racial minorities. Protective paternalism was not correlated with any of the three anti-minority attitudes measures for racial minority participants. These preliminary findings, consistent with Study 1, further support the need to consider the moderating role of participants' race when examining the relationship between sexism and racism. Next, we incorporated the 
experience of threat, as well as the potential moderating role of gender, into a conditional process model to better understand when and for whom this relationship emerges.

Hayes' PROCESS macro (Hayes, 2013) was used to test the proposed moderated mediations for conditional indirect effects. For each dependent variable (Bias in Policing, Immigration, and Policy Support), we utilized PROCESS model 21, with the threat manipulation $(0=$ control, $1=$ experimental $)$ as the independent variable, protective paternalism as the mediator, participants' gender $(0=$ female, $1=$ male $)$ as the moderator of the relation between threat and paternalism (path $a$ in the model), and participants' racial group membership $(0=$ White, $1=$ racial minority $)$ as the moderator of the relation between paternalism and the dependent variables of anti-minority attitudes (path $b$ in the model). Hostile sexism was controlled as a covariate in each model. Full results for each moderated mediation can be found in Table 3 .

Racial bias in policing. The relationships between threat, paternalism, and the belief that race is a factor in policing (see Table $3 \mathrm{a}$ and Figure 1) were tested using Model 21. The full model was significant $\left(R^{2}=.30\right), F(5,236)=20.53, p<.001$. As expected, gender moderated the effect of threat on paternalism, with only men experiencing an increase in protective paternalism after reading about violent crime. Moreover, race moderated the relationship between paternalism and beliefs about racism in policing, such that higher paternalism was associated with diminished belief in racist policing outcomes, but only for Whites. Bias-corrected bootstrap samples revealed a conditional indirect effect for White men only, indicating that threat increased men's desire to protect women, which in turn decreased their belief that race is an important factor in policing 
outcomes, but only when they themselves where White.

Immigration negative. When this dependent variable was tested using Model 21, participants' race did not moderate path $b$; therefore Model 7 was used, which included the gender moderator on path $a$ but no moderator on path $b$ (see Figure 2). The full model was significant $\left(R^{2}=.24\right), F(3,238)=25.42, p<.0001$. A bias-corrected bootstrap confidence interval revealed a conditional indirect effect for men, but not for women, indicating that protective paternalism mediated the relation between the threat manipulation and negative attitudes about immigrants, but only for male participants (see Table 3b). Men, but not women, who read about violent crime experienced an increase in the desire to protect women, which in turn led to more negative beliefs about immigration in America.

Minority policy support. The relationships among threat, paternalism, and support for policies that benefit minorities (see Table 3c and Figure 3) were tested using Model 21, which tests the conditional indirect effects of threat on policy support through protective paternalism as moderated by participants' gender on the $a$ path and participants' race on the $b$ path. The full model was significant $\left(R^{2}=.33\right), F(5,234)=23.43, p<.0001$. As expected, gender moderated the effect of danger on paternalism, with only men experiencing an increase in protective paternalism after reading about violent crime. Moreover, race moderated the relationship between paternalism and policy support. The result is a conditional indirect effect for White men only. In other words, reading about violence increased men's desire to protect women, which was then associated with less support for policies that benefit minorities, but only for White men. 
Alternative models. The proposed causal sequence necessitates the testing of additional models to assess feasible alternatives (that threat increases racial bias, which increases paternalism). In order to test the hypothesis that threat increases protective paternalism through racial bias, three alternative models were tested in which the racial bias measures (racial bias in policing, immigration negative, and minority policy support) were used as mediators, while protective paternalism was the outcome. For all three models, the relationships between paternalism and racism remained, but no significant indirect effects emerged, suggesting that threat increases racial bias through protective paternalism and not the other way around. (Table 1s for these alternative models is available as an online supplement.)

Every model was also retested using BS (rather than protective paternalism alone) as the mediator, but all failed to yield significant indirect effects. This highlights the importance of examining individual subcomponents of BS while simultaneously controlling for the endorsement of HS. It should be noted that participants' gender did not moderate any of the other paths (PROCESS models 8, 58, and 59), nor was the relationship between participants' gender and the crime manipulation itself moderated by participants' race (PROCESS model 11).

\section{Discussion}

Study 2 experimentally manipulated threat to test for increases in protective paternalism and its corresponding effect on three anti-minority outcomes. Across three dependent variables measuring anti-minority attitudes, experimentally manipulated threat bolstered protective paternalism for men, which was in turn associated with stronger 
racial bias, including less support for policies that benefit minorities, believing that allowing more immigrants into United States will have negative consequences, and denying that racial bias plays any role in policing contexts. Unlike men, reading about violent crime did not result in increased paternalism or anti-minority attitudes for female participants. Furthermore, alternative models in which racial bias was a mediator and protective paternalism was the outcome contained no significant conditional indirect effects, implicating protective paternalism as the mediator between perceptions of threat and racial bias.

For two of these three outcomes (i.e., minority policy support, denial of racial bias in policing), the experimentally increased protective paternalism was only associated with stronger racial bias when the participant was a White man. Both White and racial minority men responded to increased protective paternalism with stronger beliefs that more immigrants coming to the United States would bring negative consequences. One potential explanation for this different pattern is that this particular outcome was not explicitly racialized; unlike the other two dependent variables, which are specifically about how police and the law should treat racial minority groups, this variable asks about immigrants in general. As a result of this wording, race may have been a less salient social category than that of nationality for this specific measure, making non-Americans the outgroup against whom women require protection, which our all-American sample of White and racial minority men could both endorse. Indeed, both White and racial minority Americans oppose immigration when they perceive a threat to their national ingroup (Wilson, 2001); however, the similar responses by White and racial minority 
men regarding immigration will require further exploration.

Reading about violent crime (rather than traffic) increased men's endorsement of protective paternalism, but not women's endorsement. That the female participants did not respond to threats of violent crime with increased paternalism is consistent with Espinoza Ornelas et al.'s (2015) finding that only the threat of sexual assault in particular, but not other crime (i.e., carjacking), led to greater BS for women. It is, however, inconsistent with Phelan et al.'s (2010) finding that reading about armed robbery increases BS for both men and women. It may be that women's motivated endorsement of protective paternalism is more susceptible to threats of sexual assault in particular, whereas men may experience an increase in their desire to protect and cherish women in response to more types of threats, but this will require additional experimentation in which a variety of threats (e.g., sexual assault, physical assault, robbery, murder) are carefully tested.

Our second study expanded on the findings of Study 1 in important ways. Because we were not relying on a pre-existing dataset, we were able to control for hostile sexism when examining the relations among threat, paternalism, and racism in order to better isolate the effects of protective paternalism. We also utilized a variety of subtle anti-minority attitudes, spanning several racial groups and domains. These included beliefs about the role of suspect race in police officers' decision making; support for policies that target Latinos, African Americans, and Middle Eastern refugees; and beliefs about the negative consequences of continued immigration to the United States. In both studies, anti-minority attitudes were only correlated with protective paternalism for White 
participants. Further, in none of the moderated mediations was benevolent sexism in general, rather than protective paternalism in particular, a significant mediator.

\section{General Discussion}

The need to protect White women has long served as a justification for racial enmity. We sought to examine the relationships between protective paternalism (a subcomponent of benevolent sexism) and anti-minority attitudes, particularly under conditions of threat. Two studies demonstrated a link between protective paternalism and anti-minority bias, particularly for Whites. In the first study, which utilized a pre-existing dataset, correlations were found, for White participants only, between protective paternalism and three measures of subtle racial bias against African Americans: modern racism, support for the Black Lives Matter movement, and attributions of blame for the death of police-shooting victim Michael Brown. In the second study, using a non-student sample and controlling for hostile sexism, feelings of threat were experimentally manipulated and then tested for corresponding increases in protective paternalism and anti-minority bias, while further examining the moderating roles of participants' gender and race. Protective paternalism acted as a mediator between experiencing threat and anti-minority attitudes, particularly for White men. For men only, the threat manipulation bolstered their endorsement of protective paternalism. This heightened desire to safeguard women was then associated with three different subtle expressions of racial bias, including stronger beliefs that more immigrants will have negative consequences for the United States. For White men in particular, threat was indirectly (through protective paternalism) associated with lower beliefs that suspect race plays a role in policing 
outcomes and less support for policies that benefit minorities. In this way, benevolent sexism contributes to racial inequality.

To our knowledge, ours is the first study to (a) test how protective paternalism (rather than BS in general) is affected by threats and (b) tie experimentally manipulated increases in paternalism with anti-minority attitudes, ultimately demonstrating that (c) protective paternalism acts as a mediator between experiencing threat and anti-minority attitudes. In doing so, protective paternalism is implicated in the maintenance of both patriarchal and White hegemony. These studies bridge two related sets of findings within the domain of ambivalent sexism: a heightened endorsement of BS as a response to threat (Espinosa Ornelas et al., 2015; Fisher, 2006; Glick et al., 2000; Phelan et al., 2010) and the long-standing link between protecting White women and racism (Davis, 1981; Hall, 1993; Ware, 2015). In doing so, we elucidated a path through which threats can prompt more conservative outcomes (Jost et al., 2003).

These results are consistent with the logic of masculinist protection (Young, 2003) in which "good men" have a sacred duty to protect their women from "bad men." Male participants who read that violent crimes such as murder, rape, and assault were increasing across the country showed an increase in their endorsement of protective paternalism relative to the control group, suggesting that the salience of these "evil others" (Young, 2003, p. 13) motivated their desire to safeguard women. The moderated mediation models are also consistent with the motivated social cognition perspective in which people embrace conservative ideals in order to assuage their fear or anxiety (Jost et al., 2003). 


\section{Limitations and Future Research Directions}

Our findings are not without limitations. As a secondary analysis of pre-existing data, Study 1 was not able to control for HS and relied heavily on outcomes that assessed anti-Black prejudice in particular rather than anti-minority attitudes in general. Both studies had majority White samples (61\% and 74\%, respectively), reflecting both the university and MTurk in general (Huff \& Tingley, 2015); a more thorough understanding of how different groups react to threats will require a larger, more diverse sample. Given our focus on attitude change, we cannot yet predict for whom and under what circumstances threat would motivate overt discrimination in the form of hate speech, protest, or racist violence.

Future studies will want to examine the conditions under which women's perceptions of threat lead to increases in protective paternalism given existing mixed findings (Espinoza Ornelas et al., 2015; Phelan et al., 2010). Our study used a more global manipulation of threat (a rise in all types of violent crimes across the U.S.) and found no increase in protective paternalism for female participants. Understanding when and how women are situationally encouraged to endorse a sexist ideology for their own protection, despite its demonstrated consequences for their well-being and gender equality, will be crucial in informing steps to mitigate this process. Future research will also want to further elucidate the relationship between protective paternalism and racism. It is not yet known whether paternalism and racism are bi-directionally associated (i.e., does priming protective paternalism also prime racism and vice versa). Others might investigate whether the mere presence of an outgroup man is enough to increase 
protective paternalism and how this varies based on the man's race and the presence of an ingroup woman.

\section{Practice Implications}

Because the experience of threat is inevitable, understanding responses to it is essential. The men in our study, after reading about an increase in violent crime, responded in a way that, on the surface, seems generally positive: a stronger motivation to protect and cherish the women in their lives. However, with this benevolent desire came a corresponding increase in anti-minority biases. Although these outcomes are not explicitly violent, they suggest the denigration or disempowerment of racial minorities. This potential linkage carries implications for how men in particular may respond to rhetoric that invokes feelings of fear or threat, whether from their immediate environment or the news. Such news, whether informational or tactical, may fuel both sexist and racist reactions, especially upon repeated exposure. Our threat manipulation utilized a nonpartisan source with more objective language, but a more sensationalized delivery may exacerbate these effects.

Understanding this psychological process will be crucial to counteracting it. Because the link between protective paternalism and racism has a long history of being used to gain power or reinforce institutionalized racism (Angerer, 2016; Difendila, 1944; United States Holocaust Memorial Museum, 2016), an awareness of this relationship may help to guard against it. Interventions can be designed that disrupt this psychological process, thereby inoculating people against those who would exploit it. Policymakers should be aware that the framing of a new bill or policy might have unintended 
consequences for their constituents. Policy justifications centered on safety concerns (e.g. "tough on crime") or that feature protective language about women might also make salient various anti-minority attitudes, with implications for the safety and well-being of People of Color. Following highly publicized threats to national security or public safety, efforts can be made by organizations serving minority populations to buffer against the hostilities that might result.

\section{Conclusion}

Although the desire to protect a loved one from harm is not inherently sexist or racist, beliefs about the fragility of White women are entwined with racial prejudices, whether directly espoused by White supremacists (Wade, 2015) or unconsciously activated by salient threats (as seen here). Benevolent sexism, for all its seemingly good intentions, contributes not only to gender inequality but to racial inequality as well. Social psychology must continue to explore how these systems of oppression mutually reinforce each other in order to achieve a more intersectional understanding of prejudice in a world of unavoidable threats. 
Table 1.0. Descriptive Statistics and Correlations for Study Variables, Studies 1 and 2

\begin{tabular}{|c|c|c|c|c|c|c|}
\hline \multirow[b]{2}{*}{ Variables } & \multirow{2}{*}{$\begin{array}{c}\text { White } \\
M(S D)\end{array}$} & \multirow{2}{*}{$\begin{array}{c}\text { Minority } \\
M(S D)\end{array}$} & \multicolumn{4}{|c|}{ Correlations } \\
\hline & & & 1 & 2 & 3 & 4 \\
\hline \multicolumn{7}{|c|}{ (a) Study 1} \\
\hline 1. Protective Paternalism & $\begin{array}{c}2.97 \\
(1.07)\end{array}$ & $\begin{array}{c}3.55 \\
(1.14)\end{array}$ & -- & $.35^{*}$ & $.39 *$ & $-.36^{*}$ \\
\hline 2. Modern Racism & $\begin{array}{c}1.56 \\
(0.67)\end{array}$ & $\begin{array}{c}1.88 \\
(0.76)\end{array}$ & .09 & -- & $.72 *$ & $-.66^{*}$ \\
\hline 3. Blame for Michael Brown & $\begin{array}{c}2.98 \\
(1.47)\end{array}$ & $\begin{array}{c}3.05 \\
(1.25)\end{array}$ & -.01 & $.57 *$ & -- & $-.79 *$ \\
\hline 4. Support for BLM & $\begin{array}{c}5.17 \\
(1.51) \\
\end{array}$ & $\begin{array}{c}4.96 \\
(1.14) \\
\end{array}$ & -.07 & $-.51 *$ & $-.59 *$ & -- \\
\hline \multicolumn{7}{|c|}{ (b) Study 2} \\
\hline 1. Protective Paternalism & $\begin{array}{c}3.27 \\
(1.16)\end{array}$ & $\begin{array}{c}3.49 \\
(1.16)\end{array}$ & -- & $-.45^{*}$ & $.36^{*}$ & $-.37 *$ \\
\hline 2. Racial Bias in Policing & $\begin{array}{c}4.32 \\
(1.49)\end{array}$ & $\begin{array}{c}4.62 \\
(1.49)\end{array}$ & .06 & -- & $-.56^{*}$ & $.72 *$ \\
\hline 3. Immigration Negative & $\begin{array}{c}4.36 \\
(1.64)\end{array}$ & $\begin{array}{c}3.99 \\
(1.37)\end{array}$ & .21 & $-.35 *$ & -- & $-.74 *$ \\
\hline 4. Minority Policy Support & $\begin{array}{c}4.29 \\
(1.74)\end{array}$ & $\begin{array}{c}4.71 \\
(1.38)\end{array}$ & -.09 & $.57 *$ & $-.54 *$ & -- \\
\hline
\end{tabular}

Note. Correlations above the diagonal are for White participants; below the diagonal, for racial minority participants.

$* p<.01$ 
Table 1.1. Moderation by Participants' Race and Gender for the Relation between Protective Paternalism and Three Racial Bias Outcomes, Study 1

\begin{tabular}{|c|c|c|c|c|c|}
\hline $\begin{array}{c}\text { Moderation } \\
\text { Effects }\end{array}$ & $b$ & $S E$ & $t$ & $p$ & $95 \% \mathrm{CI}$ \\
\hline \multicolumn{6}{|c|}{ (a) Modern Racism } \\
\hline \multicolumn{6}{|c|}{ Moderation by Participants' Gender } \\
\hline Protective Paternalism (PP) & .17 & .04 & 3.90 & $.0001 * * *$ & {$[.08, .25]$} \\
\hline Gender & .20 & .23 & .84 & .401 & {$[-.26, .65]$} \\
\hline PP*Gender & -.02 & .07 & -.31 & .756 & {$[-.15, .11]$} \\
\hline \multicolumn{6}{|l|}{ Moderation by Participants' Race } \\
\hline Protective Paternalism (PP) & .22 & .04 & 5.50 & $<.0001 * * *$ & {$[.14, .29]$} \\
\hline Race & .76 & .25 & 3.08 & $.002 * *$ & {$[.27,1.24]$} \\
\hline PP*Race & -.15 & .07 & -2.20 & $.028 *$ & {$[-.29,-.02]$} \\
\hline \multicolumn{6}{|l|}{ Conditional effect: } \\
\hline White Participants & .22 & .04 & 5.50 & $<.0001 * * *$ & {$[.14, .29]^{*}$} \\
\hline Minority Participants & .06 & .06 & 1.09 & .277 & {$[-.05, .17]$} \\
\hline
\end{tabular}

Moderation by Participants' Gender

\section{(b) Blame for Michael Brown}

$\begin{array}{lccccc}\text { Protective Paternalism (PP) } & .27 & .09 & 3.13 & .002 * * & {[.01, .44]} \\ \text { Gender } & 1.06 & .46 & 2.29 & .022^{*} & {[.15,1.97]} \\ \text { PP*Gender } & -.18 & .13 & -1.36 & .175 & {[-.43, .08]} \\ \begin{array}{l}\text { oderation by Participants' Race } \\ \text { Protective Paternalism (PP) }\end{array} & .41 & .08 & 5.16 & <.0001 * * * & {[.25, .57]} \\ \text { Race } & 1.34 & .50 & 2.66 & .008^{* *} & {[.35,2.32]} \\ \text { PP*Race } & -.43 & .14 & -3.02 & .003 * * & {[-.70,-.15]} \\ \text { Conditional effect: } & & & & & \\ \quad \text { White Participants } & .41 & .08 & 5.16 & <.0001 * * * & {[.25, .57]^{*}} \\ \quad \text { Minority Participants } & -.01 & .12 & -.13 & .899 & {[-.24, .21]}\end{array}$

(c) Support for Black Lives Matter

Moderation by Participants' Gender

$\left.\begin{array}{llllll}\text { Protective Paternalism (PP) } \quad .35 & .09 & -4.05 & .0001 * * * & {[-.51,-.18}\end{array}\right]$

$\begin{array}{llllll}\text { Gender } & -.88 & .46 & -1.92 & .056 & {[-1.79, .02]}\end{array}$

$\begin{array}{llllll}\text { PP*Gender } & .22 & .13 & 1.66 & .098 & {[-.04, .47]}\end{array}$

Moderation by Participants' Race

$\begin{array}{lccccc}\text { Protective Paternalism (PP) } & -.39 & .08 & -4.92 & <.0001 * * * & {[-.55,-.24]} \\ \text { Race } & -1.15 & .51 & -2.27 & .024 * & {[-2.15,-.15]} \\ \text { PP*Race } & .32 & .14 & 2.28 & .024 * & {[.04, .60]}\end{array}$

Conditional effect:

White Participants $\quad-.39 \quad .08 \quad-4.92 \quad<.0001 * * * \quad[-.55,-.24]^{*}$

$\begin{array}{llllll}\text { Minority Participants } & -.07 & .12 & -.59 & .559 & {[-.30, .16]}\end{array}$

Note: Using PROCESS model 1 , participants' gender $(0=$ female, $1=$ male $)$ and race $(0$ $=$ White, $1=$ racial minority) were tested as moderators of the relation between protective paternalism (PP) and three racial bias outcomes.

$* p<.05 . * * p<.01 . * * * p<.001$ 
Table 1.2. Moderated Mediation Results, Study 2

\begin{tabular}{|c|c|c|c|c|c|}
\hline Pathways & $b$ & $S E$ & $t$ & $p$ & $95 \% \mathrm{CI}$ \\
\hline \multicolumn{6}{|c|}{ (a) $\mathrm{Y}=$ Bias in Policing } \\
\hline$X \rightarrow M(a)$ & -.21 & .19 & -1.09 & 277 & {$[-.59, .17]$} \\
\hline$M \rightarrow Y(b)$ & -.38 & .09 & -4.43 & $<.001 * * *$ & {$[-.55,-.21]$} \\
\hline$X \rightarrow Y(c)$ & -.12 & .13 & -0.72 & .471 & {$[-.46, .21]$} \\
\hline$X \rightarrow Y\left(c^{\prime}\right)$ & -.13 & .16 & -0.82 & .414 & {$[-.45, .19]$} \\
\hline $\mathrm{X} * \mathrm{~W} \rightarrow \mathrm{M}$ & .58 & .27 & 2.08 & $.039 *$ & {$[.03,1.13]$} \\
\hline $\mathrm{M}^{*} \mathrm{~V} \rightarrow \mathrm{Y}$ & .63 & .16 & 3.91 & $.001 * * *$ & {$[.31, .94]$} \\
\hline \multicolumn{6}{|l|}{ Conditional effect: } \\
\hline White women & .08 & .09 & & & {$[-.06, .28]$} \\
\hline Minority women & -.05 & .07 & & & {$[-.27, .03]$} \\
\hline White men & .14 & .09 & & & {$[-.34,-.004]^{*}$} \\
\hline Minority men & .09 & .09 & & & {$[-.02, .36]$} \\
\hline \multicolumn{6}{|c|}{ (b) $\mathrm{Y}=$ Immigration } \\
\hline$X \rightarrow M(a)$ & -.21 & .19 & -1.09 & 277 & {$[-.59, .17]$} \\
\hline$M \rightarrow Y(b)$ & .22 & .08 & 2.72 & $.007 * *$ & {$[.06, .39]$} \\
\hline$X \rightarrow Y(c)$ & .34 & .18 & 1.89 & .060 & {$[-.01, .70]$} \\
\hline$X \rightarrow Y\left(c^{\prime}\right)$ & .31 & .18 & 1.72 & .086 & {$[-.04, .66]$} \\
\hline $\mathrm{X} * \mathrm{~W} \rightarrow \mathrm{M}$ & .58 & .27 & 2.08 & $.039 *$ & {$[.03,1.13]$} \\
\hline \multicolumn{6}{|l|}{ Conditional effect: } \\
\hline Men & .08 & .05 & & & {$[.003, .22]^{*}$} \\
\hline Women & -.05 & .05 & & & {$[-.18, .03]$} \\
\hline Index of Moderated Mediation & .13 & .08 & & & {$[.01, .33]^{*}$} \\
\hline \multicolumn{6}{|c|}{$\begin{array}{r}\text { (c) } Y=\text { Policy Support } \\
\end{array}$} \\
\hline$X \rightarrow M(a)$ & -.18 & .19 & -0.95 & .344 & {$[-.57, .20]$} \\
\hline$M \rightarrow Y(b)$ & -.30 & .09 & -3.21 & $<.002 * *$ & {$[-.49,-.12]$} \\
\hline$X \rightarrow Y(c)$ & -.16 & .18 & -0.89 & .373 & {$[-.52, .20]$} \\
\hline$X \rightarrow Y\left(c^{\prime}\right)$ & -.16 & .18 & -0.89 & .373 & {$[-.51, .19]$} \\
\hline $\mathrm{X} * \mathrm{~W} \rightarrow \mathrm{M}$ & .56 & .28 & 2.01 & $.045^{*}$ & {$[.01,1.11]$} \\
\hline $\mathrm{M}^{*} \mathrm{~V} \rightarrow \mathrm{Y}$ & .41 & .18 & 2.32 & $.021 *$ & {$[.06, .76]$} \\
\hline \multicolumn{6}{|l|}{ Conditional effect: } \\
\hline White women & .06 & .07 & & & {$[-.05, .23]$} \\
\hline Minority women & -.02 & .05 & & & {$[-.22, .02]$} \\
\hline White men & -.11 & .07 & & & {$[-.29,-.006]^{*}$} \\
\hline Minority men & .04 & .07 & & & {$[-.05, .26]$} \\
\hline
\end{tabular}

Note. For all models, hostile sexism was used as a covariate; $\mathrm{X}=$ manipulation, $\mathrm{M}=$ protective paternalism [mediator], $\mathrm{W}=$ participants' gender (moderator of path a), $\mathrm{V}=$ participants' race (moderator of path b), $\mathrm{Y}=$ Bias in Policing, Policy Support, and Immigration (tested separately using PROCESS models 21,7 , and 21, respectively). $\mathrm{C}=$ total effect, $\mathrm{C}^{\prime}=$ direct effect. ${ }^{*} p<.05 .{ }^{* *} p<.01 .{ }^{* * *} p<.001$ 
Figure 2.0. Study 2 moderated mediation describing relations between threat, protective paternalism, and beliefs that racial bias is a problem in policing (PROCESS model 21).

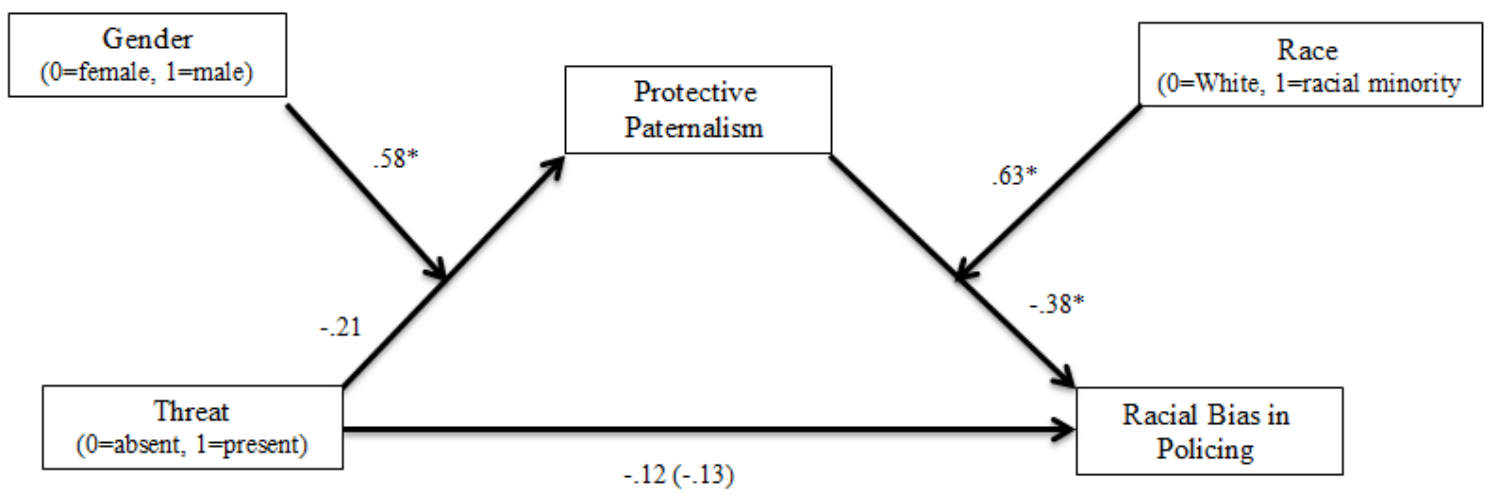

Note: Values represent unstandardized regression coefficients. The direct effect of threat on beliefs about racial bias in policing ( $\left.\mathrm{c}^{\prime}\right)$ is in parentheses. There is a conditional indirect effect for White men only, $b=.14,95 \%$ CI [-.34, -.01].

$* \mathrm{p}<.05$

Figure 2.1. Study 2 moderated mediation describing relations between threat, protective paternalism, and beliefs that immigration will have negative consequences for America (PROCESS model 7).

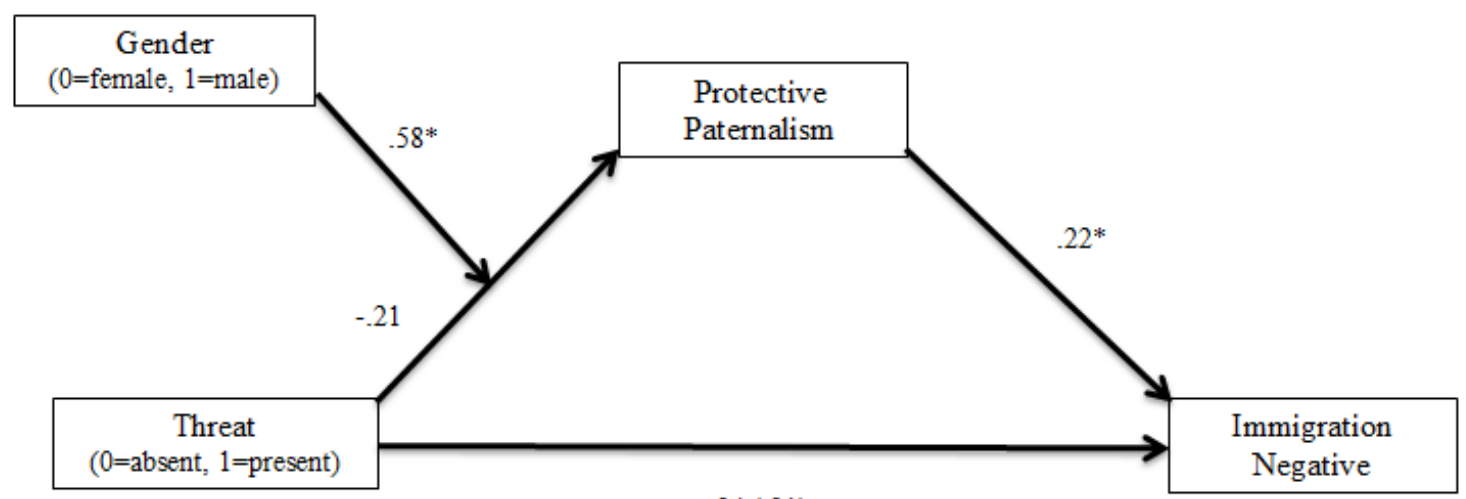

$.34(.31)$

Note: Values represent unstandardized regression coefficients. The direct effect of threat on negative attitudes about immigration (c') is in parentheses. There is a conditional indirect effect for men only, $\mathrm{b}=.08,95 \%$ CI $[.01, .22]$.

$* \mathrm{p}<.05$ 
Figure 2.2. Study 2 moderated mediation describing relations between threat, protective paternalism, and support for policies that target racial minorities (PROCESS model 21).

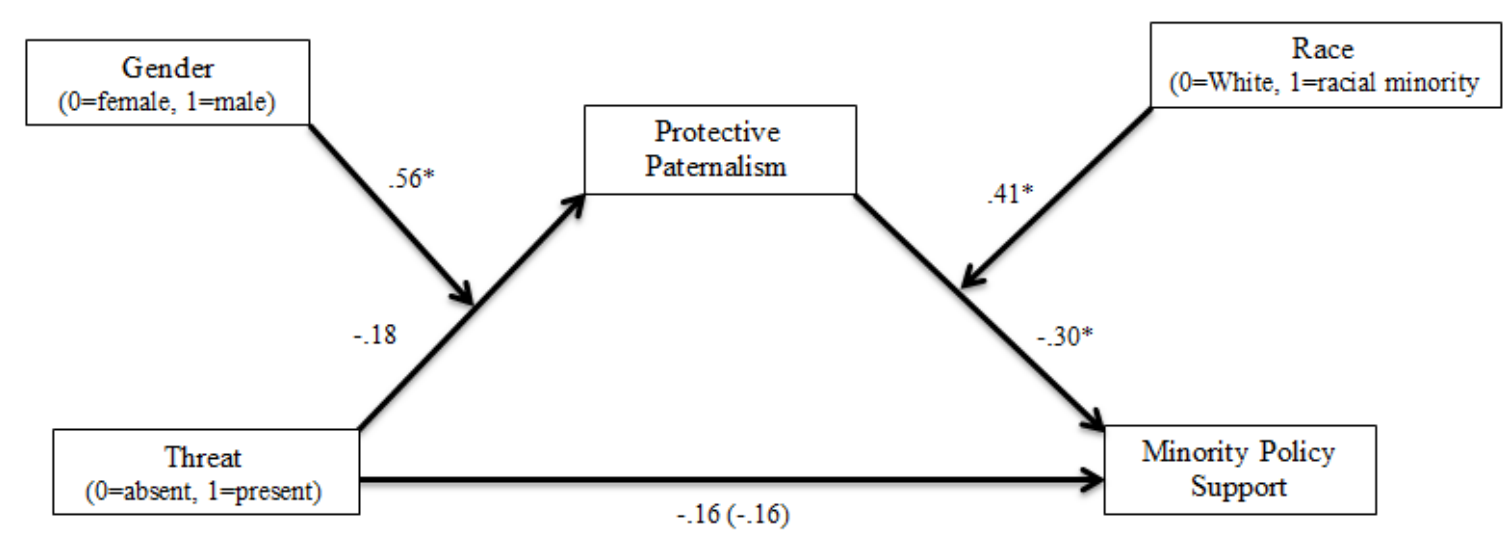

Note: Values represent unstandardized regression coefficients. The direct effect of threat on minority policy support (c') is in parentheses. There is a conditional indirect effect for White men only, $\mathrm{b}=-.11,95 \%$ CI $[-.29,-.006]$.

$* \mathrm{p}<.05$ 


\title{
CHAPTER IV. MANUSCRIPT III. TO PROTECT AND SERVE: POLICE RESPONSES TO BLACK AND WHITE FEMALE VICTIMS OF INTIMATE PARTNER VIOLENCE
}

\begin{abstract}
This study examines real-world consequences of the intersection of benevolent sexism (BS) and racial stereotypes. BS, an ideology depicting women as pure and defenseless, favors White women over Black (McMahon \& Kahn, 2016; chapter II) and has been used to justify racial bias (McMahon \& Kahn, 2017; chapter III). When police respond to intimate partner violence (IPV), racial stereotypes about victimhood and sexist prescriptions for helping may impact their treatment of victims, favoring White women. Incident $(\mathrm{N}=512)$, supplemental and narrative reports $(\mathrm{N}=342)$ of police responding to IPV where the victim was a Black or White woman were examined for treatment differences from a local police department. Controlling for available relevant variables, results indicate that police were more likely to file the supplemental form when the victim was White than when she was Black (the odds of filing were nearly four times greater for White women; relative risk of missing form 1.17 times higher for Black women). Officers were especially likely to file the supplemental form ( $93 \%$ probability) when encountering a Black suspect with a White victim. White victims were also written about with a greater "risk focus" in officers' first-person narrative accounts than Black victims. For the supplemental forms that were filed, rates of officers' additional helping behavior (e.g. giving informational resources, offering advocates) and missing data (e.g. in incident details and victim interviews) did not differ. Implications for victim outcomes and officer training are discussed.
\end{abstract}




\section{Introduction}

"I feel like if it was a White lady...I think she probably would have been treated better...I've never been asked the question, 'are you OK? Do you need anything?' I don't think a cop has ever asked me if I was OK, ever.” (Potter, 2010, p. 234)

Approximately 1 in 3 women will be victims of some form of physical violence by an intimate partner (IPV) in her lifetime (Black, et al., 2011). For women suffering abuse by a loved one, police are often the first point of contact in the criminal justice system (Buzawa \& Buzawa, 2003). While the arrest of an IPV suspect may be mandated by law depending on jurisdiction (Gelles, 1993), there are additional, more discretionary helping behaviors that officers can also enact at the scene that benefit victims, such as providing resources, transportation, or referrals, or demonstrating concern (Gondolf \& McFerron, 1989; Potter, 2010). However, there is some question as to whether this help is extended equally to all IPV victims. As illustrated in the quote above, interviews with victims have suggested that officers' discretionary helping behaviors favor White women (Few, 2005; Gillis et al., 2006; Potter, 2010; Yegidis \& Renzy, 1994). Indeed, the stereotypical victim of IPV is a White woman (MadDowell, 2013), while stereotypes of Black women depict them in ways inconsistent with victimhood (Ammons, 1995).

While racial differences in police responses to IPV have been previously examined, disparities in the treatment of White and Black female victims of IPV may be explained, at least partially, by racial differences in the application of benevolent sexism (McMahon \& Kahn, 2016, chapter II) and paternalistic protections (McMahon \& Kahn, 2017, chapter III). If more benevolent sexism is directed at White women (McMahon \& Kahn, 2016; chapter II), then this might impact police responses to IPV at the first step of 
the official legal process, when police answer IPV calls and fill out the correspondingand essential—case paperwork.

\section{Intimate Partner Violence}

\section{History and Scope}

Every minute in the United States, 20 people are physically abused by an intimate partner, equating to over 10 million people per year (Black et al., 2011). The majority $(85 \%)$ of these victims are women, and it is crucial to take a more intersectional approach to consider how additional identities such as race and class impact women's experiences of IPV (Williams, Oliver, \& Pope, 2008). African American men and women are victimized by intimate partners at a rate $35 \%$ higher than people of other races (Rennison \& Welchans, 2000), with nearly one-third of African American women experiencing IPV compared to one-fourth of White women (Tjaden \& Thoennes, 2000). The violence perpetrated against Black women also tends to be more severe than for their White counterparts (Hampton \& Gelles, 1994). However, the most significant risk factor for IPV is economic distress combined with being in a socially disadvantaged neighborhood (Benson \& Fox, 2004). Indeed, lower-SES Blacks and Whites have similar rates of IPV; the higher rate overall for Blacks is due, in large part, to their disproportionate experience of economic deprivation and disadvantaged neighborhoods (Benson \& Fox, 2004).

The role that police should play in responding to domestic violence has long been a topic of debate. For much of the twentieth century, domestic violence was considered a private dispute between husband and wife, and therefore an unproductive waste of time for police officers (Buzawa \& Buzawa, 1993), who are more likely to view their role as 
law-enforcers than helpers (Berk, 1980). With the rise of the feminist movement in the 1970s came greater visibility of the problem, eventually leading to the criminalization of IPV and the adoption of many mandatory and presumptive arrest policies (Gelles, 1993). The efficacy of these arrest policies and rates of actual arrest have been major focal points of study for those examining police responses to IPV (Melton, 1999; Jordan, 2004), yet the decision to arrest a suspect is only one of the actions that officers can take at the scene. For women who report their abuse by an intimate partner, this encounter with the criminal justice system usually begins with an interaction with the police (Buzawa \& Buzawa, 2003). These interactions thus represent an initial point at which officers can intervene on the behalf of victims, demonstrating societal disapproval of IPV to suspects (Holder, 2001) while also laying the groundwork for potential prosecution by collecting evidence.

In a just and equitable society, these initial interactions, given similar incidents and contexts, would be identical for all victims of IPV. However, when police responses to victims of IPV have been studied, racial disparities have sometimes emerged regarding the treatment of Black and White women victims. Importantly, "disparities" describe numerical differences in outcomes between groups; they do not prove that intentional discrimination by police has taken place, as this would require the measuring of officers' attitudes and the refutation of many alternative explanations. Below, the variety of behaviors police can enact at the scene and evidence of racial disparities are examined. Police Responses to IPV

Arrests. The most common outcome examined by researchers studying police 
responses to IPV is whether an arrest was made on behalf of IPV victims. Here, the evidence for racial disparities on arrests made is mixed. In some analyses, police responses seem to favor White women, with racial minority victims having lower rates of arrests made on their behalf than White victims (Avakame \& Fyfe, 2001; Ferraro, 1989; Hirschel, Buzawa, Pattavina, Faggiani, \& Reuland, 2007; Smith, 1987). Factors that increase the likelihood of police arrest in cases with White women (e.g. the presence of children, drug use) oppositely predict less police involvement for Black women (Robinson \& Chandek, 2000), making Black women more vulnerable to future violence. In an examination of felonious assault cases, police consistently failed to make an arrest on behalf of Black victims unless the victim insisted on prosecution (LaFavre, 1965), suggesting that police often "fail to come to the rescue of poor, urban, Black women...inadvertently sending the message that Black women are fair game for abusers" (Avakame \& Fyfe, 2001, p. 38). The race of the suspect is also predictive of arrest, with a greater likelihood of arrest when the offender is a Black male (Avakame \& Fyfe, 2001) and in cases where Black men assault Black women (Bachman \& Coker, 1995). In other empirical examinations, however, the race of the victim and offender do not predict arrest (Berk \& Loseke, 1981; Ho, 2003; Jasinski, 2003; Shernock \& Russel, 2012; Tatum \& Pence, 2015), especially when the socio-economic status of the couple is taken into account (Klein \& Smith, 1984) or when mandatory arrest policies are in place (Eitle, 2005).

Many police departments in the United States have mandatory arrest policies that require the alleged assailant or primary aggressor to be taken into custody (Hirschel, 
2008). However, compliance with these policies is not guaranteed, especially after first adoption; in one department, arrest rates were as low as $18 \%$ following the implementation of state-wide mandatory arrest policy one month later (Ferraro, 1989). In areas where arrest is preferred rather than mandated, the rate of arrest may be only $5 \%$ higher (i.e. about $50 \%$ of the time) than in non-arrest areas (Eitle, 2005). Officers can still exercise discretion in how they respond in pro-arrest areas, such as by issuing a citation instead, arresting the suspect for a separate offense, or choosing whether to charge the suspect with aggravated or simple assault (Shernock \& Russel, 2012).

Discretionary assistance. Responding to a call for service is a basic job requirement for police officers, but providing supplemental services to victims takes extra time and effort. In addition to arresting a suspect, which may or may not be required of them by law, there are a host of other discretionary behaviors police officers can do that focus primarily on assisting the victim. Police are often trained to provide victims with resources (e.g. hotline numbers, referrals to helping agencies), but such behaviors are rare when police interact with IPV victims (Belknap \& McCall, 1994; Brown, 1984; Ferraro, 1989; Oppenlander, 1982). Officers are more likely to advise victims of their rights or inform them about restraining orders than they are to help them find counseling or make referrals (Apsler, Cummins, \& Carl, 2003; Gondolf \& McFerron, 1989), though sometimes they fail to provide either one (Yegidis \& Renzy, 1994). Officers' personal treatment of female victims also varies, with some officers being insensitive, impersonal, and dismissive, while others can be helpful and patient (Gillis et al., 2006). It should be noted that officers are often overworked and stressed (Stotland \& Pendleton, 1989); 
providing additional services to victims requires time that they may not have to spare. Thus, despite wanting to provide additional services, they may be unable to do so because of time constraints, staff shortages, and other job demands.

Few empirical examinations of racial disparities in officers' discretionary helping behaviors at the scene make use of official police records, which the current study uses. One exception is Eitle (2005), who demonstrated that in areas where there is no mandatory arrest policy in place, the victim's race is more likely to play a role in whether an arrest is made on her behalf. This finding demonstrates that officer arrest decisions are influenced partially by a victim's race when the decision to arrest is left to his or her discretion rather than required by law; the current study tested whether the same is true of other discretionary helping behaviors in a mandatory arrest context. Other investigations have relied on observers of officer-citizen interactions and concluded that more time and energy may be spent settling disputes among White couples than Black couples (Black, 1980); the current study expands on this by examining different types of discretionary efforts.

Victim reports. Most studies that examine the experiences of victims with police have utilized interviews and focus groups and have revealed a variety of ways in which police may respond to victims, again with mixed findings. Some women who have dealt with police following an incident of IPV report dissatisfaction when talking to officers, sensing a lack of interest, having their concerns minimized, and not being believed (Erez \& Balknap, 1998; Meyer, 2011; Stephens \& Sinden, 2000). Officers may provide encouraging comments during the interaction, but they may also try to convince victims 
to drop complaints, fail to collect evidence, or discourage victims from filing charges (Erez \& Balknap, 1998). In some samples, Black women report getting less help from police (e.g. information about injunctions or shelter recommendations) than White women (Few, 2005; Yegidis \& Renzy, 1994) and rarely report positive experiences (Gillis et al., 2006; Potter, 2010). In other studies, the female victim's race is unrelated to helpfulness ratings of police by the women they serve (Apsler et al., 2003). Conversely, being a Black female victim (rather than White) may predict a greater likelihood that police go beyond "papering the incident" (Bachman \& Coker, 1995) by searching the scene, taking evidence, and promising to investigate (though this may be confounded with the higher likelihood of arrest for Black men in this majority intraracial sample).

These findings demonstrate how officers' treatment of suspects, including their decisions to arrest in accordance with pro- or mandatory-arrest policies, does not necessarily translate into equitable outcomes for Black and White victims. Police are instead often viewed as simultaneously devaluing Black women's complaints while overzealously arresting Black men (Rasche, 1988). Black women have reported feeling like victims of racial discrimination by police when they call for help (Few, 2005), with some suspecting that they would be treated better if they were White (Potter, 2010). Guidebooks for dealing with IPV have advised Black women to make sure officers see their injuries and explain to them that their bruises would not be as pronounced as those on White skin (White, 1985), suggesting that Black women may have to take additional steps to ensure that they are taken seriously. Officers may not be as responsive to Black women, even when they have suffered obvious injuries (Ferraro, 1989). 
Officer impact. Beyond concerns for fairness, what police do in this context has consequences for victims. The criminal justice system as a whole, and police in particular, play a role in whether women leave or stay with abusive partners (Barnett, 2000). When officers are unhelpful, particularly if they side with the offender, women may be less likely to leave their abusive partners (Hamilton \& Coates, 1993). Even though officers are sometimes required to complete supplemental forms as part of their job when responding to IPV (usually involving additional questions about the incident and the relationship between the suspect and victim), this only happened for $35 \%$ of the cases in one sample (Robinson \& Chandek, 2000), meaning that whatever additional information was contained in these forms went undocumented and was not available for future use by advocates or attorneys. Women have noted officers' reluctance to deal with filing reports on their behalf, making them feel like a waste of time (Meyer, 2011). Officers may be especially unlikely to take action against suspects or deal with the additional administrative paperwork that accompanies a proper IPV investigation when they think the victim is hesitant to press charges (Crime \& Misconduct Commission, 2005). Over two-thirds of one sample reported that officers tried to get them to drop their complaints and failed to collect any evidence, making it impossible for them to prosecute their cases later (Erez \& Belknap, 1998). In other cases, officers made errors or omissions at the scene that caused women to lose their case in court (Gillis et al., 2006). Women who experience poor treatment by police report less trust in them (Stephens \& Sinden, 2000), more self-blame (Brown, 1984), and say they are less likely to use the legal system again, even in the face of future violence (Gillis et al., 2006). The greater the unmet 
expectations that victims have for the officers they call for help (e.g. not getting referrals, information, or transportation), the greater their PTSD symptomology later (Srinivas \& DePrince, 2015), suggesting poorer mental health outcomes when officers fail to provide victims with what they need.

While officer neglect has the potential for negative consequences, officers also have a lot of power at the scene to take actions that benefit victims. Police encouragement (Fischer \& Rose, 1995) and information about legal rights (Brown, 1984) can motivate some women to obtain restraining orders, and victims provided outside help or resources are more likely to have their cases prosecuted (Dawson \& Dinovitzer, 2001). Positive police responses also increase victims' satisfaction with police and willingness to call them to report future incidents (Apsler et al., 2003; Brandl \& Horvath, 1991).

Summary. IPV presents a situation in which officers are confronted with (often, but not always) a woman who has experienced physical intimidation and violence at the hands of a male partner. Regardless of whether the suspect is arrested or not, there are various additionally supportive behaviors that officers can enact, which require extra effort on their part, that provide assistance to victims. Existing evidence suggests that these additional helping behaviors may not be equally offered to Black and White women. The present study suggests the intersection of racial stereotypes and benevolent sexism as one way to understand differences in helping behaviors that may emerge in the context of intimate partner violence. In the next section, these relevant literatures from the field of social psychology are reviewed. 


\section{Social Psychology, Police, and IPV}

Ambivalent Sexism Theory

Ambivalent sexism (Glick \& Fiske, 1996) describes prejudice against women as having both hostile and benevolent components. Benevolent sexism (BS) characterizes women as inherently moral, defenseless, pure, and good, while hostile sexism (HS) depicts women as manipulative, easily offended, and unappreciative. BS is directed at women who adhere to traditional gender roles by being chaste, housewives, or mothers, while HS targets those who reject these roles by being career-oriented, promiscuous, or feminists (Glick, Diebold, Bailey-Werner, \& Zhu, 1997; Sibley \& Wilson, 2004). The two ideologies thus work in tandem to maintain the status quo by rewarding women who uphold it and punishing women who challenge it (Glick \& Fiske, 2001a).

Benevolent sexism has three subcomponents: heterosexual intimacy, complementary gender differentiation, and protective paternalism (Glick \& Fiske, 1996). The latter describes women's inherent fragility and need for men's authority and protection, and is particularly relevant for a policing context. Officers routinely encounter women who need assistance, and beliefs or stereotypes about what "types" of women are "worthy" of protection may factor, however unintentionally, into the application of the law. In a rare examination of BS in this context, officers who endorsed BS more strongly also showed a preference for conditional law enforcement, i.e. depending on the willingness of the victim to press charges against the offender (Lila, Garcia, \& Garcia, 2013), suggesting a link between BS and tolerance for IPV among officers. BS is primarily concerned with adherence to traditional gender roles, but when this information 
is lacking, race offers a cue by which women are judged. Racial stereotypes depict White women in ways that align with BS ideals (e.g. fragility, domesticity); as a result, White women receive more BS than Black women (McMahon \& Kahn, 2016).

\section{Racial Stereotypes}

Though not always using the explicit language of benevolent sexism, the idea that female victims and offenders may be treated differently by the criminal justice system is already well-established. Attempts to compare the treatment of men and women by police have yielded contradictory results, with women sometimes being treated more harshly, more leniently (the "chivalry hypothesis"), or no different compared to men (Young \& Adams-Fuller, 2006). This discrepancy supports the need to not think of women as a homogenous group, but rather to take an intersectional stance that considers the joint effects of gender and race, which is largely lacking in the literature on police offers' discretionary helping behaviors.

Men are expected to respond protectively when women are in peril (Hernshaw, 1935; Hurd, 1762). However, White women are generally considered worthier of protection from interpersonal and social harm (Belknap, 2007; Madriz, 1997). The ideal

image of upper class White women has long informed the definition of which "types" of women are good (chaste, passive, emotional, fragile) and which are bad (deceitful, aggressive, calculating, masculine) (Klein \& Kress, 1976; Young, 1986). While White women are considered good as long as they stay in their prescribed roles, Black women are not afforded that presumption (Ammons, 1995) and are consequently not afforded chivalrous treatment by the criminal justice system (Chesney-Lind \& Pasko, 2012; 
Gabbidon, Higgins, \& Potter, 2010). Instead, the stereotypical or "ideal" victim is female, White, middle-class, passive, and weak (Ammons, 1995; MacDowell, 2013).

Because both historical and modern stereotypes of Black women contradict this characterization, it is harder for Black women to be seen as victims of IPV (Ammons, 1995; Young, 1986). The Sapphire (Bond \& Perry, 1970) who nags and emasculates men is seen as provoking violence, while the immoral and depraved Jezebel (Jewell, 1993) is a deserving, willing participant. Even more "positive" stereotypes of Black women fail to paint them as possible legitimate victims, with the long-suffering Mammy's (Gilkes, 1981) abuse seen as unlikely or unimportant, while the "strong black matriarch" is domineering, masculine, and capable of enduring hardship, thereby requiring no extra protection (Bond \& Perry, 1970; Gilkes, 1981). These stereotypes, antithetical to victimhood, could also account for the disproportionate media attention given to missing (Min \& Feaster, 2010) and trafficked (IMADR, 2006) White women and girls, and the disproportionate number of laws that memorialize White victims of violent crime (Kulig \& Cullen, 2016).

If White women are treated more favorably than minority women in the crimeprocessing system at least partially due to deeply entrenched racist ideals of womanhood (Young \& Adams-Fuller, 2006), it may likely begin with their treatment by the police officers that respond to IPV calls on their behalf. Black women may be perceived as more culpable for the violence perpetuated against them than White women, with violence seen as even more justified when she provoked it (Esqueda \& Harrison, 2005), suggesting Black women's complaints may not be taken as seriously. If Black women are seen as 
provoking violence, as the Sapphire stereotype suggests (Bond \& Perry, 1970), that perception may make them seem less deserving of help (Lerner, 1970; 1980). Indeed, officers were more likely to endorse high involvement in responding to IPV (e.g. filling out a report, making an arrest) when they felt a high sense of personal responsibility and the situation was severe (Garcia, Garcia, \& Lila, 2008). An officer's sense of personal responsibility to intervene may be lessened when the victim appears to have invited the violence on herself (Buzawa \& Buzawa, 1996), consistent with the Sapphire stereotype (Bond \& Perry, 1970). Further, perceptions of the severity of the situation may be impacted by differences in the presentation of bruising on Black and White skin (Potter, 2010; Rasche, 1988; White, 1985) and beliefs about Black women's ability to endure physical hardships that White women could not (Bond \& Perry, 1970). This would be consistent with Black women's reported experiences of not being given resources by police or treated as deserving of help (Few, 2005; Gillis et al., 2006; Potter, 2010; Yegidis \& Renzy, 1994).

In addition, officers' judgments of the level of risk to the victim predict whether they take action and apply for an intervention order at the scene (Trujillo \& Ross, 2008), suggesting that officers' perceptions of the victims' vulnerability to future violence help determine whether they will intervene on her behalf. While this study utilized incident attributes, such as level of fear expressed by the victim and features of the incident (e.g. presence of drugs, incident progression, and previous incidents) to predict officer perceptions of risk, the race of the suspect and victim may also have an influence. White women are traditionally seen as more fragile (Schloesser, 2002), while Black women are 
more antagonistic (Niemann, Jennings, Rozelle, Baxter, \& Sullivan, 1994) and able to withstand pain (Bond \& Perry, 1970), suggesting that White women could be perceived by police as being at greater risk in IPV situations and therefore worthier of intervention. This might help to explain the greater rates of arrests made of behalf of White victims than minority victims found in some studies (Avakame \& Fyfe, 2001; Ferraro, 1989; Hirschel, et al., 2007; Smith, 1987).

Importantly, racial stereotypes also apply to assailants, and Black men are more likely to be perceived as criminal and aggressive than White men (Devine, 1989; Eberhardt, Goff, Purdie, \& Davies, 2004), which may help account for the greater rates of arrest for Black men in this context found in other studies (Avakame \& Fyfe, 2001; Bachman \& Coker, 1995; Smith \& Visher, 1981). Perceptions of risk are likely informed by a combination of racial stereotypes as they apply to both the suspect and the victim. For instance, Ammons (1995) considered how a Black woman on trial for killing her abusive (Black) male partner did not necessarily "benefit" from the racial stereotypes depicting him as violent, because jurors did not simultaneously perceive her to be a helpless victim due to her race.

Research on implicit social cognition has demonstrated how racial stereotypes can influence perceptions and behavior even when they are not consciously endorsed. Stereotypes are automatically activated in the mind of the perceiver when in the presence of the attitude object, here a person (Devine, 1989; Eberhardt, Goff, Purdie, \& Davies, 2004). The stereotype then acts a lens through which the person is perceived, biasing the processing of subsequent information and potentially influencing judgments and 
reactions (Biernat, 2003; Devine, 1989; Fazio, 1986; Greenwald \& Banaji, 1995). This spontaneous process produces behaviors consistent with the stereotype, but it can be disrupted with conscious effort. The perceiver's motivation and opportunity to do so will determine whether automatic (spontaneous) or controlled (deliberative) processes occur (Fazio, 1986). In the context of IPV, racial stereotypes can bias officers' perceptions of victims and suspects even when they do not explicitly endorse those stereotypes. Given the time demands and job stressors experienced by officers, they may lack the opportunity to consciously override them.

Aversive Racism

These hypotheses regarding more help for White victims than Black victims of IPV are supported with other social psychological theories. One modern form of racial bias, aversive racism, occurs when individuals hold egalitarian beliefs yet still harbor unconscious negative feelings about Blacks, creating a tension that results in behavioral instability (Dovidio \& Gaertner, 1986). People are often unaware of their negative implicit attitudes, as they exist below conscious awareness (Greenwald \& Banaji, 1995) and result not from conscious feelings of hatred but from personal experiences and exposure to widespread cultural biases (Rudman, 2004). Aversive racists will not behave in a discriminatory way when such behaviors could clearly be labeled as racist by others or themselves; however, in ambiguous situations where there is no socially or morally "correct" response, or a negative response can be justified by a factor other than race, they are more likely to discriminate in line with racial stereotypes. Like other members of society, police can form negative implicit attitudes about African Americans (Kahn \& 
McMahon, 2015; Kahn \& Martin, 2016), even if they consciously and sincerely espouse egalitarian beliefs.

Mandatory arrest policies and basic procedural job requirements (i.e. submitting a report, providing basic details of the incident) remove some of the ambiguity around treatment of IPV suspects by police (Eitle, 2005), but not treatment of IPV victims. Instead, officers have a great deal of discretion at the scene in terms of whether they do nothing, mediate, make referrals, provide transportation, or advise victims of rights (Gondolf \& McFerron, 1989), offering opportunities for their own implicit attitudes to influence behavior. There are also a multitude of factors at the scene other than the race of victims, such as their SES, the presence of drugs/alcohol, witnesses, or warrants and restraining orders, upon which officers could attribute their own behaviors.

\section{Shifting Standards Theory}

Discretionary helping behaviors favoring White women would also be consistent with shifting standards theory (Biernat, Vescio, \& Manis, 1998), which suggests that zero sum behaviors, including the allocation of limited resources, favor individuals who belong to the group more strongly associated with that role, behavior, or position (Biernat, 2003). According to shifting standards theory, officers should spend their finite resources (their time and attention) on those victims that most closely align with stereotypes relevant to the setting; in this case, the stereotype that White women are more inherently worthy of benevolent protection (Belknap, 2007; Madriz, 1997; McMahon \& Kahn, 2016, chapter II). Officers are not working with unlimited resources, particularly when it comes to time; they may also sometimes not view IPV as a criminal incident worthy of their 
attention (Buzawa \& Buzawa, 1993) and may prefer to spend their time on other cases (Ferraro, 1989), especially in light of the additional paperwork these incidents incur (Crime \& Misconduct Commission, 2005; Meyer, 2011). In support of this, officers are less likely to arrest IPV suspects toward the end of their shifts, even in pro-arrest areas (Robinson \& Chandek, 2000), possibly due to the additional effort this would require at a time when their physical and cognitive resources are waning. In the city where the police bureau for the current study is located, police officers respond to over 200 IPV calls per week and are required to fill out additional supplemental reports for these cases before the end of their shifts ("DVU advanced academy training”, 2016). The department was also undergoing a staffing shortage, further increasing the time demands and stressors on officers, which may unintentionally produce disparities in discretionary helping. In light of these theories, I hypothesize that officers will be as likely to fulfill basic unambiguous reporting requirements when responding to White and Black female victims of IPV, consistent with aversive racism. However, their discretionary efforts at the scene should favor White victims, as predicted by aversive racism and shifting standards theory. Racial stereotypes may also color their perceptions of victims at the scene, with White women being described as more at risk and more paternalistically. Importantly, while this study searches for racial disparities in the treatment of Black and White female victims of IPV, it does not and cannot claim that these are caused by officers' racial biases or intentional discrimination. As I am unable to measure officers' attitudes directly and eliminate all alternative explanations, causal claims cannot be made. Instead, any significant findings could speak to the insidious power of stereotypes, which 
have the ability to alter perceptions, impact judgments, and sway behavior even when they are not consciously endorsed (Devine, 1989; Fazio, 1986).

\section{The Current Study}

I performed a cross-sectional analysis of police IPV records to compare the treatment of White and Black women. If White women receive more benevolent sexism than Black women (McMahon \& Kahn, 2016; chapter II) and are in a context in which help is needed (IPV), then this may result in White victims of IPV receiving more discretionary help from police.

\section{Study Development and Data Sources}

Police consultant. This study was designed in consultation with a police sergeant with over 20 years of experience. He had worked in the crime analysis unit and supervised the Domestic Violence Unit (DVU) for three years. All decisions regarding the applicability of police procedures to the variables of interest (e.g. which police behaviors were basic reporting requirements and which constituted an action requiring discretionary effort) were based on his expertise and the author's reviews of the academic literature.

Officer training materials. Proper procedural responses to IPV in the police department under study were informed by a police consultant and by training materials used by the police bureau ("DVU advanced academy training", 2016; "Lethality indicators", 2016). After police officers (at least two) are dispatched to the scene, they are required to make a thorough initial investigation of IPV by gathering details of the incident from the victim, suspect, and any witnesses ("DVU advanced academy training", 
2016). Once the primary aggressor in the incident has been determined (based on a comparison of the injuries, allegations, threats, etc.), the responding officers are required to make an arrest (or make a reasonable effort to locate a suspect who has fled) if they have probable cause to believe that the primary aggressor assaulted the other person or placed them in fear of serious injury. Both the victim and suspect must be informed of their legal rights. As an "investigative tip" (“DVU advanced academy training”, 2016), officers are told to collect as much evidence as possible (including photographs) and to "ask about/verify history of abuse" by interviewing the victim. Officers are encouraged to express their concern for the victim's safety, tell them about resources (i.e. helplines, shelters, how to get a restraining order) or page a DV advocate ("Lethality indicators", 2016). Officers have a notebook for recording their findings and actions, which is then referred to when (electronically) writing their reports, often hours later. The completion and submission of incident, supplemental, and narrative reports (described below) is required prior to the end of their shift. They may also follow-up and/or send their reports directly to the DVU.

Incident and supplemental reports. There are two types of report forms that can be filed for an IPV case: incident and supplemental forms. Both forms are often used to study police responses to IPV (Shernock \& Russel, 2012). The incident report provides basic information about the persons involved, including demographic variables such as age, race, and sex of the suspect and victim. This information was used in the current study to narrow the sample to only Black and White female victims. The supplemental form used by this department is the result of ongoing collaborative efforts, containing 
items drawn from various risk assessment scales and requested by local prosecution, and has been validated for predicting recidivism (Henning, 2014). Questions include the charges brought against the suspect and additional questions that responding officers are required to address in cases of domestic violence. These include the relationship between the victim and suspect (married/not married, intimate/blood relation, current/former partner), the presence of children, details about the specific incident, any injuries incurred, and a victim interview. This interview contains ten questions that help assess risk ("Lethality indicators", 2016), including access to firearms, escalating violence, suspect drug and alcohol abuse, a recent separation, and suspect unemployment. In this study, these reports are examined for indications of any discretionary effort an officer may provide during the initial investigation.

Narrative report. Narrative reports are an increasingly common methodology for examining police interactions with civilians (Hickman, Atherley, Lowery, \& Alpert, 2015; Kahn, Steele, McMahon, \& Stewart, 2017; Terrill, 2001). The incident report described above also contains a narrative component. In responding to IPV, officers are required to write a first-person narrative report in which they recount their involvement with the case, including what they saw, what occurred on the scene, and the interviews with victims and suspects. For this study, these narratives will be coded for three indications of additional effort and two control variables, described later.

I also examined these narrative reports for linguistic cues of officers' perceptions of danger or their desire to help. The words people use can provide clues as to their thought processes, emotions, and motivations (Pennebaker, Boyd, Jordan, \& Blackburn, 
2015). Linguistic Inquiry \& Word Count software (LIWC; Pennebaker et al., 2015) was designed to analyze such word use within a text using proprietary algorithms. LIWC scans documents and calculates the percentage of words in each LIWC category, which are made up of a carefully selected dictionary of words (Tausczik \& Pennebaker, 2010). In its most recent version, LIWC2015 (Pennebaker et al., 2015), over 90 output variables are possible, including word count, linguistic dimensions (e.g. pronouns, auxiliary verbs), summary language variables (e.g. emotional tone, analytical thinking), and psychological constructs (e.g. drives, affect). Hundreds of studies have linked the language categories in LIWC with various psychological processes in a variety of text formats (Tausczik \& Pennebaker, 2010), including negative emotion words in the writing of depressed patients (Rude, Gortner, \& Pennebaker, 2004), pronouns as predictors of relationship satisfaction in instant message transcripts (Slatcher, Vazire, \& Pennebaker, 2008), and changes in cognitive and social processing in blog posts immediately before and after the $9 / 11$ attacks (Cohn, Mehl, \& Pennebaker, 2004). LIWC2015 was used to analyze the narrative reports written by officers for indicators of perceived risk and paternalistic language.

\section{Operationalizations and Hypotheses}

A full list of the dependent variables and their operationalizations may be found in Table 2.0.

Basic reporting vs. discretionary effort hypotheses

Hypothesis 1: Basic reporting. First, I examined whether officers responding to IPV calls do the basic reporting requirements for Black and White victims. Given that racial biases are less likely to manifest when the correct response is unambiguous (as in 
the case of required reporting steps) (Dovidio \& Gaertner, 1986), I anticipated that officers are as likely to fulfill their basic reporting requirements when addressing Black and White female victims of IPV. Arguably the filing of the incident report constitutes a basic requirement in this context, but there is no way to examine the treatment of IPV victims if no record of the incident exists (indeed, the sample was drawn based on demographic information from incident reports.) To assess whether officers fulfilled their basic reporting requirements when responding to IPV calls, I chose to focus on two indicators:

1a) Filing the supplemental form. The inclusion of the required supplemental form along with the incident report. As this is an unambiguous job requirement, racial biases should be less likely to emerge (Dovidio \& Gaertner, 1986).

Hypothesis 1a: Officers will be as likely to file the supplemental form for White victims as for Black victims.

1b) Incident details. The completion of the five questions about the IPV incident contained in the supplemental form. Officers are required to collect basic information about the incident that occurred (as they would when responding to any call) by observing the scene and speaking with the suspect, victim, and witnesses to answer these five questions (e.g. was the victim strangled, did the suspect have a weapon). These questions constitute basic reporting because they help the officer determine which charges to make against the suspect. I recorded how many of the five questions about the IPV incident from this form were adequately answered.

Hypothesis 1b: Officers will gather the same amount of basic information about 
the IPV incident (by answering the five questions in the Incident section of the supplemental form) for Black and White female victims of IPV.

Hypothesis 2: Discretionary effort. Next, I investigated the degree of extra effort that officers put into responding to IPV calls for Black and White victims. Based on research suggesting that White women are seen as more worthy of protection (Belknap, 2007; Madriz, 1997), while Black women are perceived as antagonistic and culpable for violence (Esqueda \& Harrison, 2005), I anticipated that more initial effort will be put in to investigating IPV cases where the victim is White (compared to Black). Six indications that officers went above the basic reporting requirements and expended additional effort in responding to IPV calls were determined in consultation with a policing expert and from academic literature (Bachman \& Coker, 1995; Belknap \& McCall, 1994; Erez \& Balknap, 1998; Gondolf \& McFerron, 1989) and may be drawn from both the supplemental forms and the narrative reports:

2a) Victim Interview. There is a ten-question victim interview included in the supplemental form. It is completed electronically and utilizes dropdown menus with response options. These questions pertain to the relationship between the victim and suspect and are all indicators of lethality (signs of increased risk of serious injury or death to the victim). Officers are trained to recognize lethality indicators and perform thorough initial investigations so that lethality is properly assessed ("Lethality indicators", 2016). As corroborated by the police consultant, this process involves taking the victim aside and gathering additional information that may seem extraneous, as it is not immediately relevant to the current incident or to which charges are brought against the suspect (e.g. if 
their relationship recently ended, if the suspect tries to control the victim). The victim interview also contains twice as many questions as the Incident Details, requiring extra effort by officers to complete.

For each case, I recorded how many of the victim interview questions were adequately answered. Decisions about what constituted an "adequate answer" were made in consultation with a policing expert. All of the dropdown menu options were deemed acceptable responses, but special consideration was given to questions that were left blank or marked "unknown". It was determined whether "unknown" was a reasonable response or whether this likely indicated that the question was not asked. For example, the victim would reasonably know whether their relationship with the suspect had recently ended, but would not necessarily know whether the suspect had access to firearms or was currently employed (especially in the case of a former partner).

Hypothesis 2a: I predict that more of the victim interview questions will be answered when the victim is White than when she is Black.

2b) Narrative length. Officers are required to write a first-person narrative account of their investigation, including what they observed on the scene (description of injuries, emotional states), their interactions with the victim, suspect, and witnesses, and their actions (arresting the suspect, reading Miranda rights, offering medical attention, etc.) The narrative is submitted as part of the incident report.

Hypothesis 2b: I predict that these narratives will be longer (i.e. have a greater word count) when the victim is White than when she is Black.

2c) Photographic evidence. The supplemental form includes questions about whether 
photographs were taken as evidence of the victim or suspect's injuries. Officers are trained to take photos of the victim's injuries ("DVU advanced academy training", 2016) and must then manually enter the photos into DIMS (Digital Image Management System). For each case, I recorded whether any photographic evidence was collected.

Hypothesis 2c: I predict that officers are more likely to collect photographic evidence when the victim is White than when she is Black.

2d) Child interviews. Children are sometimes at the scene of IPV incidents. The supplemental form contains questions about the presence and handling of child witnesses. If any child over the age of five hears or sees the incident, officers have two options: a) interview the child themselves or b) make a referral to a local organization that specializes in child interviews. For each case involving witnesses between the ages of 518 , I noted whether the officer conducted the interviews themselves, as this would constitute extra effort when a referral would also suffice.

Hypothesis 2d: I anticipate that child witnesses (ages 5-18) are more likely to be interviewed by the officer (rather than ignored or referred elsewhere) when the victim is White than Black.

2e) Victim resources. Officers are encouraged to provide the victims with additional resources (e.g. their business card, contact information for the District Attorney or a local women's helpline, or steps for obtaining a restraining order) and then include this in their narrative reports ("Lethality indicators", 2016). For each case, I coded whether the officer wrote that they provided the victim with any of these additional resources in their narrative report. 
Hypothesis 2e: I anticipate that officers are more likely to provide additional resources for White victims than Black victims.

2f) $D V$ advocate. Finally, in severe cases, officers are encouraged to connect victims with a DV Advocate by either paging one or making a referral or sending the report directly to the DVU (with the victim's permission). Only four DV advocates are currently available to work with victims, and are assigned based on need and availability ("DVU advanced academy training", 2016). I coded whether the officer reported taking this action (or offering to) in their narrative reports.

Hypothesis 2f: I predict that officers are more likely to attempt to set up DV advocates for White victims than Black victims.

\section{Linguistic hypotheses of police incident narrative report}

Hypothesis 3: Risk. While the case files include more direct measures of the seriousness of the incident (e.g. a misdemeanor vs. felony charge) or the danger posed to the victim (e.g. the victim's self-reported likelihood of being assaulted by the suspect in the next year on a scale from 1-10), I wanted to examine how officers perceive the danger the victims are in, when controlling for other actual risk factors. Since it is not possible to ask the officers outright, I utilized more indirect measures by using the narrative reports to test for subtle linguistic cues or word choices that might be indicative of officers' perceptions of the risk or danger of the victim's situation. Risk was assessed using the "risk focus" dictionary in LIWC2015, which consists of 103 references to dangers, concerns, and things to avoid (e.g. danger, doubt, safety, concern). A risk focus score was generated for each narrative, indicating the percentage of total words that match items 
from the risk focus dictionary. After controlling for objective risk factors, any differences found here will be in the officers' perceptions of the scene. This research question had no specific hypothesis, as two outcomes are equally plausible:

Outcome \#3a: Given that benevolent sexism is more strongly attributed to White women (McMahon \& Kahn, 2016; chapter II), while Black women are stereotyped as antagonistic (Niemann et al., 1994) and resilient (Bond \& Perry, 1970), one might anticipate that White women in an IPV context will be perceived as being in 'more danger' than their Black counterparts. As a result, the officers' narrative report would be written with a stronger "risk focus" (i.e. a greater percentage of risk words) when the victim is White than when she is Black.

Outcome \#3b: Alternatively, given stereotypes of Black men as dangerous and criminal (Devine, 1989; Eberhardt et al., 2004), it is also possible that the dangerousness of the situation for the victim is more strongly determined by the race of her partner than her own race. As a result, narratives describing Black male suspects would be written with a stronger "risk focus" (i.e. a greater percentage of risk words) than those written about White male suspects.

Hypothesis 4: Protective paternalism. Another aim of this study will be to test for the presence of words suggestive of protective paternalism, the subcomponent of benevolent sexism that characterizes women as defenseless and worthy of protection and help (Glick \& Fiske, 1996). Given the association between benevolent sexism and White women (McMahon \& Kahn, 2016), words indicative of this construct (e.g. protect, rescue, help) may be more present in the officers' narrative reports for White victims. This 
construct is normally measured with four questions from the Ambivalent Sexism Inventory (Glick \& Fiske, 1996). Again, since testing the officers directly is beyond the scope of this study, I focused on word choices in the narrative reports that might indicate the desire to help victims. A dictionary capturing the construct of protective paternalism was created and programmed into LIWC (see Appendix C and D).

Hypothesis \#4: A greater percentage of words suggesting protective paternalism will be used when writing about White victims than Black victims.

Hypothesis 5: Risk-Paternalism Mediation. Finally, this study will explore the mediating relationship between these two linguistic indicators. The desire to protect women is bolstered by situational threats (McMahon \& Kahn, 2017); therefore one might expect a positive correlation between risk and protective paternalism (as measured by LIWC), suggesting that the perception of a more dangerous situation is associated with a stronger desire to cherish and defend women from harm. Further, since perceptions of risk might be affected by the race of the victim or the suspect (see Hypothesis \#3), I will test whether risk mediates the relation between race and paternalism.

Outcome \#5a: If the risk focus is higher for White victims than Black victims (Outcome \#3a is supported), then risk will mediate the relation between victim race and paternalism, such that higher levels of risk focus for White victims will lead to more paternalism words in the narrative reports.

Outcome \#5b: If the risk focus is higher for Black suspects than White suspects (Outcome \#3b is supported), then risk will mediate the relation between suspect race and paternalism, such that higher levels of risk focus for Black suspects will lead to more 
paternalism words in the narrative reports.

\section{Methods}

\section{Sample}

Official police records were gathered from a medium-to-large sized urban police department in a mandatory arrest jurisdiction. Cases were available from June 1, 2015 through August 31, 2016. A new electronic record management system was implemented a few weeks before the start date, giving officers time to adjust to the new system, while the end date represents the last full month at the time the data was pulled. During the 15month period in which data was available, all DV related aggravated and simple assault cases were pulled for victims who were female and Black or White. This resulted in 1,652 cases. This sample was further restricted to ones with a Black or White male arrestee (no dual arrests), yielding 680 reports.

The reasons for this sampling are both procedural and practical. First, the quality of the initial investigation is likely affected by whether a (mandatory) arrest was made or not. The police consultant advised that the largest predictor of arrest was whether the suspect remained on the scene, which means that any racial differences in who remains at the scene could affect the quality of the investigation. Restricting the sample to only ones in which an arrest was made allows for testing whether officers are doing a better investigation because of the victim's race or because an arrest was made. Second, if a suspect is not found and verified within a set number of days they become marked as a "subject", which presents a classification issue when trying to pull those cases. Third, this decision represents a conscious departure from previous studies that have focused 
primarily on the decision to arrest (Jordan, 2004; Melton, 1999; Robinson \& Chandek, 2000). By using only cases in which the suspects were apprehended, I could explore whether, even when arrests are made in a mandatory arrest state, there are still differences in the treatment of victims or the overall handling of an investigation.

Next, I eliminated cases that involved the same suspect and/or victim more than once to ensure independence of errors $(\mathrm{N}=155)$ or pertained to $\mathrm{DV}$ incidents that were not IPV (e.g. violence between blood relations; $\mathrm{N}=13$ ). The result was a sample of 512 incident reports, with 135 Black female victims and 377 White female victims. Of the couples in the sample, 123 were two Black partners, 312 were two White partners, 65 had a Black male and a White female, and 12 had a White male and a Black female, making the sample $85 \%(\mathrm{~N}=435)$ intraracial couples. Of those 512 incident reports, 342 had the supplemental forms attached ( $26 \%$ Black victims). This number is consistent with similar studies of police IPV records, which have utilized between 200-500 cases (Buzawa et al., 2000; Rauma, 1984; Robinson \& Chandek, 2000; Trujillo \& Ross, 2008; Worrall et al., 2006). The narrative reports were pulled for every case that had a supplemental form $(\mathrm{N}=342)$.

\section{Data preparation and coding}

The case files were not stored in an extractable format; therefore, each file was printed, read for relevant independent, dependent, and control variables, and manually entered into a dataset. The narrative reports were converted from PDFs to Word documents and manually de-identified for coding and processing through LIWC. This process involved replacing the names of people in the narrative report with signifiers (e.g. 
suspect-X, victim-V, witness-W), eliminating all locations (e.g. substituting a home address, intersection, business, or the name of the police bureau with "[location]") and redacting any identifying information (e.g. replacing license plate or officer badge numbers with "[redacted]"). The 342 narrative reports were then coded for four variables: two control variables (whether the victim 1) was uncooperative or 2) called/requested police intervention) and two dependent variables (whether the officer 1) provided the victim with informational resources or 2) attempted to set up a DV advocate). Narrative coding was completed with the help of a research assistant. After being trained in the coding procedure (see Appendix A), the research assistant and I coded the same set of 20 narratives in order to assess inter-rater reliability. The resulting kappas were in the "good" to "very good" range (Altman, 1991) for all variables: advocate (kappa=.86), resources (kappa=.64), uncooperative $(\mathrm{kappa}=1)$ and caller $(\mathrm{kappa}=.70)$. Disagreements were then discussed and resolved before coding was resumed and completed. Examples of coded narratives may be found in Appendix B.

\section{Control variables}

I gathered data on eleven necessary control variables (indicated in italics below) from these same three sources. A full list of the control variables, their source, and how they are coded can be found in Table 2.1. The suspect age and victim age (in years) and suspect race $(0=$ Black, $1=$ White $)$ were drawn from the incident reports and served as control variables. Other variables that have been shown to affect arrest decisions and discretionary behaviors were also used as controls, including the charge, i.e. a felony vs. a misdemeanor charge (Black, 1971; Ferraro, 1989), found in the supplemental form 
( $\operatorname{coded} 0=$ Misdemeanor, $1=$ Felony). Others include whether the victim had visible injuries $(0=\mathrm{No}, 1=$ Yes $)$, whether the couples are married $(0=$ Not married, $1=$ Married $)$ (Bachman \& Coker, 1995), and whether there were children present at the scene ( $0=$ Absent, $1=$ Present) (Robinson \& Chandek, 2000), all from the supplemental form. Because the presence of missing data is likely impacted by the willingness of the victim to cooperate and answer questions, I controlled for this as well. As a measure of officer's subjective perceptions of victim cooperativeness, narrative reports were coded for any indication by the officer that the victim was being uncooperative with their investigation ( $0=$ Cooperative, $1=$ Uncooperative), i.e. if the officer explicitly stated that the victim is "uncooperative" or described uncooperative behavior that interfered with reporting (e.g. will not answer victim interview questions, allow them to speak to children, photograph injuries). As a more objective measure of victim cooperation, the narrative reports were coded for whether the victim called police themselves or requested police intervention $(0=$ No, $1=$ Yes $)$.

Two additional indicators of incident severity and risk that are unique to the supplemental form used at this police department were also used as controls. The first was a self-report scale of victim pain level from 1 (mild) to 10 (severe). The victim's physical pain may a) signal to officers that the victim is suffering and in greater need of help or b) increase perceptions of the severity of the crime (such as a felony vs. misdemeanor charge). Since officers support a higher level of police involvement in IPV cases when they perceive the incident as more severe (Garcia et al., 2008), controlling for the victim's pain helps to remove this potential confounding effect. The report also asks 
victims their likelihood of future assault by the suspect in the next year on a scale from 1 (low) to 10 (high), which was used to control for the victims' own perceived risk for future violence.

Unfortunately, neither officer variables (e.g. sex, race, and tenure) nor socioeconomic information about the suspect and victim were available in this data set. However, I am able to control for the precinct (A, B, and C) in which the incident occurred to account for some of the potential differences in climate, workload and neighborhood characteristics. This variable was dummy coded, with Precinct A as the reference group (coded 0,0$)$ and Precincts B (coded 1,0$)$ and C $(0,1)$ entered as controls.

\section{Paternalism Dictionary}

In order to test Hypothesis 4, a custom dictionary that captured the construct of "protective paternalism" was created using the same basic steps as Frimer, Schaefer, \& Oakes (2014). First, I assembled descriptions of paternalism from Glick and Fiske (1996) and other ambivalent sexism publications and wrote instructions for each phase (see Appendix C). During Phase 1, two research assistants and myself generated a list of probable words based off the descriptions given, resulting in a total of 268 unique words. In Phase 2, three new research assistants reviewed the list and rated each word for "goodness of fit" with the construct (e.g. "does this word match: yes or no?"). Majority rule was required for inclusion, resulting in 18 words and word stems such as defend, help, provide and support. The full paternalism dictionary, as it was programmed into LIWC, is available in Appendix D. 


\section{Results}

\section{Pre-analysis Screening}

Prior to hypothesis testing, data were examined for outliers, missingness, and all assumptions of multiple and logistic regression.

Missing data. I began by checking for the presence of missing data. Two of the control variables were found to have extremely high rates of missingness: the victim's self-reported pain level (43\% missing) and the victim's estimation of how likely the suspect is to assault her in the next year (30\% missing). Results of Little's MCAR test

suggest that these data are not missing completely at random, $\chi^{2}(29)=187.29, p<.001$. The decision was made to drop these two control variables from subsequent analyses, as the missing values were concentrated here (there was no more than one missing value on any other variable) and they are not critical to the hypotheses (Tabachnik \& Fidell, 2013) ${ }^{1}$.

Regression assumptions. Normality, linearity, and homoscedasticity assumptions were assessed using residual scatterplots, skew, P-P plots, and Q-Q plots. Distributions for word count, risk focus, and paternalism in the narrative reports demonstrated positive skew, while the number of incident and victim interview questions answered were negatively skewed. Normality was achieved by applying a log transformation to the word count outcome, an inverse transformation to the risk and paternalism outcomes, and squaring the victim interview outcome. Upon discovering that all five of the incident detail questions were answered in $90 \%$ of cases, producing a degree of skew impervious to linear transformation, this outcome was dichotomized to reflect an incomplete (coded 0) or completed (coded 1) interview, as suggested by Tabachnik and Fidell (2013). 
Tolerance and VIF statistics were examined for evidence of multicollinearity. For one outcome only (child interviews), two of the predictors (Precinct B and Precinct C) exhibited possible signs of multicollinearity (VIF $>5$ ); the dummy variable for Precinct B was dropped from subsequent analyses to eliminate this issue. ${ }^{2}$ The linearity assumption for logistic regression was assessed using the Box-Tidwell approach, in which interactions between each continuous predictor and its natural log are added to the equation. Linearity assumptions were met for each dichotomous outcome, with the exception of whether the supplemental form was filed (Hypothesis 1a); for this variable only, the victim's age was squared in order to meet the assumption of linearity. The Durbin-Watson test for independence of errors was also generated for each continuous outcome; all test statistics fell around 2, suggesting no autocorrelation among residuals.

Outliers. Multivariate outliers were identified using Cook's Distance, a measure of influence that identifies unusual combinations of two or more variables. The cutoff of any Cook's D value greater than 4/N (Bollen \& Jackman, 1985) was used, suggesting the need to eliminate between 3-37 cases (average $=18$ ) for each dependent variable. Outliers detected on variables that have already undergone linear transformations (i.e. word count, risk focus, paternalism, and victim interview) are considered "truly multivariate" and are usually deleted, as they "may distort results in almost any direction" (Tabachnik \& Fidell, 2013, p. 77). All hypotheses were tested using both a) the full sample, with no outliers cut, and b) the sample with between 3-37 multivariate outliers excluded (depending on the dependent variable). When the full sample was used for hypothesis testing, the models explained less variance and had lower statistical power. The same general pattern of 
results emerged, only weaker, resulting in the loss of two significant effects. The decision was made to use the sample without any outliers, on the principle that "a good model for most of our data is better than a poor model for all of our data" (McClelland, 2000, p. 409). Exploratory tests of the outliers that precluded significant findings can be found in the Additional Analyses section below.

\section{Descriptives}

The final sample included 512 incident reports, with 342 corresponding supplemental forms and narrative reports. Descriptive frequencies and statistics for all control and outcome variables may be found in Table 2.2 and 2.3, respectively. The average age of suspects was 37.89 years $(S D=11.41$, range $=18-67)$ and 36.82 years $(\mathrm{SD}=12.23$, range $=18-87)$ for victims. All other sample demographics were pulled from the supplemental forms. The majority of the couples were unmarried (73\%), with children present at the scene in only $14 \%$ of cases. Of the charges brought against the suspects, $68 \%$ were misdemeanors and $32 \%$ were felonies. Victims were likely to be visibly injured ( $66 \%$ of reports), rarely described as uncooperative (10\% of reports), and slightly more likely to have called police themselves or requested police intervention than not (56\% of reports). Importantly, there were no racial differences in the likelihood of victims being described as uncooperative $\left.\left[\chi^{2}(1, \mathrm{~N}=342)=1.32, p=.25\right)\right]$ or calling/requesting police intervention $\left.\left[\chi^{2}(1, \mathrm{~N}=342)=.02, p=.88\right)\right]$.

On average, officers completed the majority of the Incident Details $(M=4.88$, $S D=.41$, range $=1-5)$ and Victim Interview $(M=8.41, S D=2.01$, range $=1-10)$ questions . The length of the narrative reports varied considerably, with an average word count of 
728 and a standard deviation of 395 (range $=153-2896)$, while the risk focus $(M=0.38$, $S D=0.29$, range $=0-1.57)$ and protective paternalism $(M=0.19, S D=0.21$, range $=0-1.31)$ in the narratives was relatively low on average, though these rates are not inconsistent with similar LIWC studies (e.g. Faasee et al., 2016).

\section{Basic Reporting Hypotheses}

Supplemental Form. Hypothesis la predicted that officers would be as likely to file the supplemental form for White victims as for Black victims. Sequential logistic regression was used to test this prediction, with the limited control variables ${ }^{3}$ available for the full sample of incident reports (suspect age, victim age squared to meet the linearity assumption, and suspect race) in Step 1 and victim race in Step 2 (Table 2.4). The model in Step 1 was significant, $\chi^{2}(3, \mathrm{~N}=492)=30.84, p<.001$, Nagelkerke $\mathrm{R}^{2}=.09$, as was the model in Step 2, $\chi^{2}(1, \mathrm{~N}=492)=14.01, p<.001$, Nagelkerke $\mathrm{R}^{2}=.12$. Observed power was adequate for this test, power $\leq .97$. The likelihood ratio test indicated that the inclusion of victim race in Step 2 significantly improved the model, $\chi^{2}(1)=14.01, p<.001$, suggesting that, contrary to the hypothesis that predicted similar filing rates for Black and White victims, officers were more likely to file the supplemental form when the victim was White than when she was Black, $B=1.35, S E=.39$, Wald=12.34, $p<.001$. The odds ratio of 3.86 for this variable indicates that the odds of officers filing the supplemental form are almost 4 times greater for White victims than Black victims, controlling for age and suspect race. Put another way, the relative risk of having a missing supplemental form for Black victims is 1.17 times higher than for White victims (or the risk of having the supplemental form filed is 1.08 times higher for White victims than for Black 
victims). Furthermore, the supplemental form was more likely to be filed when the suspect was a Black male than a White male, $B=-1.29, S E=.37$, Wald=12.02, $p=.001$, with an odds ratio of 0.28 indicating that approximately 3 White suspects had the supplemental form filed for every 10 Black suspects. The relative risk of having a missing supplemental form for White suspects is 1.32 times higher than for Black suspects (or the risk of having the supplemental form filed for Black suspects is 1.13 times higher than for White suspects. Even though officers had arrested the suspect (because the sample is limited to all arrests), their decision to file supplementary paperwork was influenced by the race of the victim and suspect.

In order to investigate this finding further, I conducted a second sequential logistic regression in which the race and age variables for the suspect and victim were entered in Step 1 and the interaction between victim and suspect race was entered in Step 2 (Table 2.5). The model in Step 1 was significant, $\chi^{2}(4, \mathrm{~N}=492)=44.85, p<.001$, Nagelkerke $\mathrm{R}^{2}=.12$ and was marginally improved upon the inclusion of the race interaction term in Step 2, $\chi^{2}(1)=3.53, p=.06$. Hayes's PROCESS macro (Hayes, 2013) was used to test the interaction of victim and suspect race on the likelihood of filing the supplemental form when controlling for the ages of the victim and suspect. Model 1 was used, in which victim race was the predictor, filing the supplemental form was the outcome, and suspect race was the moderator (Table 2.6). There was a marginally significant interaction between victim and suspect race $[B=-1.56, S E=.86, p=.07]$, such that when the suspect was Black, the supplemental form was more likely to be filed for White victims (93\% probability) than for Black victims (66\% probability), $B=1.96$, 
$S E=.56, p<.001$. Intraracial White couples shared a similar outcome (68\% probability), while those with a Black victim and White suspect had the lowest probability of having the supplemental form filed (59\%). Relative risk ratios were calculated to compare couples with a White victim and Black suspect to the other three possible combinations (intraracial Black, intraracial White, and a Black victim with a White suspect.) The risk of having the supplemental form missing for the three other types of couples was 4.71 times higher than for couples with a White victim and a Black suspect (alternatively, the risk of the form being filed for a couple with a White victim and a Black suspect is 1.39 times higher than for types of couples in this sample.) Therefore, while a significant outcome, Hypothesis 1a is not supported.

Incident details. Hypothesis $1 \mathrm{~b}$ posited that officers would gather the same amount of basic information about an IPV incident, regardless of the victim's race. As described above, high rates of completeness on this outcome ( $90 \%$ of cases) prompted a switch to a dichotomous dependent variable. For this outcome only, the full sample (with no multivariate outliers eliminated) was used, as otherwise the small number of cases in which all of the incident questions were not answered $(\mathrm{N}=34)$ were eliminated as multivariate outliers and the analyses could not be conducted. After this adjustment, sequential logistic regression was used to test whether victim race predicted the completion of the five incident questions in the supplemental form (Table 2.7.). The control variables in Step 1 did not produce a significant model, $\chi^{2}(11, N=341)=14.78$, $p=.19$, Nagelkerke $\mathrm{R}^{2}=.09$. The inclusion of victim race in Step 2 did not improve the model, as the likelihood ratio test indicated that there was no significant difference 
between Step 1 and Step 2, $\chi^{2}(1)=.91, p=.34$, suggesting that victim race does not predict officers asking all the incident detail questions. Instead, only the victim calling or requesting police intervention marginally predicted this outcome $[B=.70, S E=.41$, Wald $=2.96, p=.09]$. However, observed power was inadequate for this test, power $\leq .41$. Due to the non-significant overall model, low power, and small effect size preclude my ability to call Hypothesis $1 \mathrm{~b}$ supported.

\section{Discretionary Effort Hypotheses}

Victim interview. Hypothesis $2 \mathrm{a}$ anticipated that more of the victim interview questions would be asked when the victim was White rather than Black. Due to high rates of completeness (44\%) and skew, this variable was tested as both a continuous outcome (with the number of victim interview questions squared to improve skew) and a dichotomous one (indicating a completed or unfinished interview). Sequential multiple regression was used to test whether victim race improved the prediction of the number of victim interview questions answered once the control variables were accounted for (Table 2.8). After the control variables were entered in Step 1, the model was significant, $F(11$, $306)=7.39, p<.001, \mathrm{R}^{2}=.21$. The inclusion of victim race in Step 2 did not improve prediction of the model, $\Delta F(1,305)=.17, p=.68$, nor was victim race a significant predictor of the number of (squared) victim interview questions, $B=-1.68, S E=4.08, p=.68$. Observed power was very high for this test, power $=.99$. The only significant predictor of the number of (squared) victim interview questions was a cooperative victim, $B=-$ 41.39, $S E=4.94, p<.001$.

Additionally, sequential logistic regression was used to determine whether victim 
race predicted a completed victim interview (Table 2.9). The control variables in Step 1 produced a significant model, $\chi^{2}(11, \mathrm{~N}=338)=35.50, p<.001$, Nagelkerke $\mathrm{R}^{2}=.14$, but after including victim race in Step 2, the likelihood ratio test indicated that there was no significant difference between Step 1 and Step 2, $\chi^{2}(1)=.77, p=.38$, suggesting that victim race does not contribute to the prediction of a completed victim interview. As before, only victim cooperation predicted a finished victim interview $[B=-3.55, S E=1.04$, Wald $=11.78, p=.001]$. However, the observed power for this test was inadequate, power $\leq .13$. Therefore, Hypothesis $2 \mathrm{a}$ is not supported.

Narrative length. Hypothesis $2 \mathrm{~b}$ predicted longer narrative reports (in word count) for White victims than Black ones. Sequential multiple regression was used to determine whether victim race improved prediction of $(\log )$ word count after accounting for the eleven control variables (Table 2.10). After the control variables were entered in Step 1 , the model was significant, $F(11,309)=7.76, p<.001, \mathrm{R}^{2}=.22$. However, adding the victim race predictor in Step 2 did not result in a significant increase in $\mathrm{R}^{2}, \Delta F(1$, $308)=.73, p=.40$, nor was victim race a significant predictor of $(\log )$ word count, $B=-.03$, $S E=.03, p=.40$. Observed power was very high for this test, power $=.99$. Instead, officers wrote longer narratives when the suspect was younger $[B=-.003, S E=.001, p=.01]$ and charged with felony assault $[B=.13, S E=.02, p<.001]$ and the victim was visibly injured $[B=.04, S E=.03, p=.08]$ and cooperative $[B=-.14, S E=.03, p<.001]$. Thus, Hypothesis $2 \mathrm{~b}$ was not supported.

Photographic evidence. Hypothesis 2c predicted a greater likelihood of officers gathering photographic evidence when the case involved a White victim than a Black 
victim. The control variables in Step 1 (Table 2.11) resulted in a well-fitting model, $\chi^{2}(11$, $\mathrm{N}=305)=268.90, p<.001$, Nagelkerke $\mathrm{R}^{2}=.84$, but after adding victim race in Step 2, the likelihood ratio test demonstrated no difference between the models, $\chi^{2}(1)=.002, p=.96$. Thus, victim race did not predict photographic evidence, and Hypothesis 2c is rejected. Note that observed power was inadequate for this test, power $\leq .05$. Instead, officers were more likely to take photographs when the victim was visibly injured $[B=-7.14, S E=.89$, Wald $=63.92, p<.001]$ and the suspect was Black $[B=-1.76, S E=.92$, Wald $=3.66, p=.06]$.

Child interviews. Hypothesis $2 \mathrm{~d}$ anticipated that officers were more likely to interview child witnesses themselves when the victim was White. For this outcome only, the sample size was reduced to $\mathrm{N}=44$ (as there were only 47 cases where a child was present to be interviewed, minus 3 outliers) and the "presence of children" control variable was removed from Step 1 of the sequential logistic regression (Table 2.12). The control variables in Step 1 produced a significant, well-fitting model, $\chi^{2}(9, N=44)=20.54$, $p=.02$, Nagelkerke $\mathrm{R}^{2}=.53$, but after including victim race in Step 2, the likelihood ratio test indicated that there was no significant difference between Step 1 and Step 2, $\chi^{2}(1)=.49, p=.49$. Therefore, victim race did not predict whether officers interviewed child witnesses, so Hypothesis $2 \mathrm{~d}$ is rejected. Observed power was inadequate for this test, power $\leq .48$. Officers were marginally more likely to interview children if the victim and suspect were unmarried, $[B=-2.79, S E=1.53$, Wald $=3.34, p=.07]$.

Victim resources. Hypothesis 2e predicted that officers were more likely to offer informational resources to victims who were White. During the first round of testing, the "uncooperative victim" control variable exhibited an inflated standard error 
( $\mathrm{SE}=6,859.71)$, an improbably high odds ratio $(\mathrm{OR}=150,813,074.20)$ and the model failed to converge, suggesting too few cases relative to the number of predictor variables (only 36 victims were described as uncooperative). This control variable was excluded from subsequent analyses, as suggested by Tabachnik and Fidell (2013).

The control variables in Step 1 (Table 2.13) significantly accounted for variance in the giving of resources, $\chi^{2}(10, \mathrm{~N}=314)=34.81, p<.001$, Nagelkerke $\mathrm{R}^{2}=.23$, but the likelihood ratio test indicated no difference between Step 1 and the full model including victim race in Step $2, \chi^{2}(1)=.50, p=.48$. Thus, officers were just as likely to provide White and Black victims with additional helping resources, and Hypothesis 2e is rejected. However, observed power was inadequate for this test, power $\leq .41$. Instead, officers were more likely to give additional resources to the victim when the suspect was Black $[B=-2.46, S E=.96$, Wald $=6.62, p=.01]$, the victim was not visibly injured $[B=-1.29$, $S E=.53$, Wald $=5.91 p=.02]$, and someone else called the police $[B=-1.46, S E=.50$, Wald $=8.57, p=.003]$.

DV advocate. Finally, Hypothesis $2 \mathrm{f}$ predicted that officers were more likely to attempt to set up a DV advocate for White victims than Black ones. While the control variables in Step 1 (Table 2.14) resulted in a significant model, $\chi^{2}(11, \mathrm{~N}=331)=40.87$, $p<.001$, Nagelkerke $\mathrm{R}^{2}=.18$, the inclusion of race in Step 2 resulted in no significant change, $\chi^{2}(1)=.62, p=.43$. This suggests that officers were as likely to attempt to set up response advocates for Black and White victims, though observed power was inadequate for this test, power $\leq .13$. Hypothesis $2 \mathrm{f}$ is not supported. Instead, officers were more likely to set up an advocate in Precinct B $[B=-.62, S E=.38$, Wald=2.71, $p=.10]$, when the 
suspect was older $[B=.06, S E=.02$, Wald $=9.69, p=.002]$, the victim was younger $[B=-.06$, $S E=.02$, Wald $=8.52, p=.004]$, there were children at the scene $[B=1.06, S E=.36$, Wald $=8.92, p=.003]$, and the victim was visibly injured $[B=.55, S E=.31$, Wald $=3.31$, $p=.07]$ and cooperative $[B=-1.48, S E=.69$, Wald $=4.66, p=.03]$.

\section{Linguistic Hypotheses}

Risk. Hypothesis 3 predicted two plausible outcomes: that the narrative reports would be written with a stronger risk focus when the victim was a White woman and/or when the suspect was a Black man. Multiple linear regression was used to test the control variables and two race predictors simultaneously (Table 2.15). The full model was significant, $F(12,309)=1.94, p=.03, \mathrm{R}^{2}=.07$, with high observed power, power $=.99$. Consistent with the hypothesis, the victim race predictor was significant, indicating a stronger (inverse of) risk focus for White victims, $B=.05, S E=.02, p=.04$. That is, officers wrote their narrative reports with a stronger "risk focus", indicating greater perceptions of danger, when the victim was a White woman (compared to a Black woman). Suspect race did not predict risk focus, $B=-.02, S E=.02, p=.33$, while the incident taking place in Precinct B did, $B=.06, S E=.02, p=.002$. Thus, Hypothesis 3 was supported.

Paternalism. Hypothesis 4 posited more words indicative of protective paternalism in narrative reports written about White victims than Black victims. Sequential regression was used to determine whether victim race improved prediction of paternalistic words after accounting for the eleven control variables (Table 2.16). After the control variables were entered in Step 1, the model was marginally significant, $F(11$, $315)=1.57, p=.11, \mathrm{R}^{2}=.05$, with high observed power, power $=.99$. The inclusion of 
the victim race predictor in Step 2 did not result in a significant increase in $\mathrm{R}^{2}, \Delta F(1$, $314)=.15, p=.70$, nor was victim race a significant predictor of (inverse) paternalism, $B=-.01, S E=.02, p=.70$. Instead, the presence of visible injuries $[B=.03, S E=.01, p=.04]$ and the absence of children $[B=-.04, S E=.02, p=.03]$ were associated with greater (inverse) protective paternalism in the narratives, though caution should be taken when interpreting significant coefficients in a non-significant model. Therefore, Hypothesis 4 was not supported.

Risk-Paternalism Mediation. Hypothesis 5 explored the mediating relation between race, risk, and paternalism. As victim race (not suspect race) predicted risk focus (Hypothesis 3), a mediation model was tested in which victim race predicted paternalism, mediated by risk. Hayes's PROCESS macro (Hayes, 2013) Model 4 was used to test whether risk mediated the relation between victim race and paternalism, with the same set of eleven control variables as covariates (Figure 3.0). While there was no direct effect of victim race on paternalism, $B=-.01, S E=.02, p=.66$, consistent with the results of Hypothesis 4, a significant indirect effect was found, $B=.01, S E=.01$, CI [.0003, .0212], indicating that when the victim was White, officers wrote their narrative reports with a marginally stronger risk focus $[B=.04, S E=.02, p=.07]$, which was then associated with the use of more paternalism words $[B=.19, S E=.05, p<.0001]$. Put another way, officers used an average of 4.59 risk focus words when writing about Black victims and 7.25 risk focus words when writing about White victims, and every risk focus word used was then associated with an additional 1.47 paternalism words in the narrative report. This comes out to an average of 6.75 paternalism words for Black victims and 10.66 paternalism 
words for White victims.

An alternate model in which paternalism mediated the relation between victim race and risk did not produce a significant interaction effect, suggesting that victim race impacted perceptions of danger, which then increased paternalism. ${ }^{4}$

\section{Additional Analyses}

After testing the proposed hypotheses, several supplemental analyses were conducted. Of particular interest was using victim race to predict each of the following six indicators of officer effort: giving informational resources, taking photographs, assigning advocates, finishing the victim interview, number of victim interview questions

answered, and a new measure called the Discretionary Behavior Scale, with both risk and paternalism tested as mediators. ${ }^{5}$ Observed power was also calculated for all outcomes, and the outliers for the filing the supplemental form (H1a) and risk focus (H3) outcomes were further explored.

Post-hoc Power Analyses. As seen in the results above, observed statistical power was calculated for each test. This information was computed automatically by SPSS for each continuous outcome (i.e. number of victim interview questions, word count, risk focus, and paternalism words), with the resulting observed power always exceeding the desired 0.8 . For the dichotomous outcomes, observed power was calculated using $\mathrm{G}^{*}$ Power. For each analyses, the following information was imputed: the odds ratio for the victim race predictor, alpha level (.05), the sample size, the proportion of cases where $\mathrm{X}=1$ (i.e. the proportion of the sample that was White victims), and the squared multiple correlation coefficient between the main predictor variable (victim race) and all 
other covariates. The test also required the probability of $Y=1$ for $X=1$ (e.g. the probability of officers collecting photographic evidence for White victims). Given the challenges in estimating this number from the existing literature, 0.5 was used for this parameter. Doing so provided the maximum observed power possible for these parameters. Note that (except for the filing of the supplemental form), the observed power does not exceed .38 for the dichotomous outcomes (i.e. gathering all incident details, finishing the victim interview, taking photographs, conducting interviews with child witnesses, giving informational resources, and assigning advocates), which is well below the standard cutoff. In summation, five of the outcomes had adequate observed power (filing the supplemental form, number of victim interview questions, word count, risk focus, and paternalism words), and five has inadequate observed power (completing incident detail questions, taking photographs, conducting interviews with child witnesses, giving informational resources, and assigning advocates). Observed power could not be calculated for the PROCESS mediation models.

Discretionary Behaviors Scale. Due to low statistical power found for the outcomes tested with logistic regression, I combined the individual discretionary behaviors tested in Hypothesis 2 into a continuous scale reflecting the number of discretionary behaviors officers enacted at the scene. The "child interviews" outcome was excluded, as it requires a child witness to be present ( $\mathrm{N}=47$ cases) and therefore does not apply to all incidents, as was the "finish victim interview" dichotomous outcome, as the effort to complete this item (asking all 10 victim interview questions) is qualitatively different than providing informational resources to victims (e.g. handing them a business 
card.) ${ }^{6}$ The resulting scale included 3 items: assigning an advocate, taking photographic evidence, and providing informational resources.

Though describing count data, the resulting scale displayed a Normal, rather than Poisson, distribution $(M=1.78, S D=.78$, range $=0-3$, skew=-.15). All assumptions of multiple regression were met (good standardized residual, Q-Q, and P-P plots indicating normality, linearity, and homoscedasticity; VIF $<3$ suggesting no multicollinearity; Durbin-Watson=1.99 indicating independence of errors; 18 outliers with Cook's Distance $>4 / \mathrm{N})$. Sequential multiple regression was then used to test whether victim race improved the prediction of the number of discretionary behaviors officers enacted at the scene once the control variables were accounted for (Table 2.17). After the control variables were entered in Step 1, the model was significant, $F(11,309)=12.64, p<.001$, $\mathrm{R}^{2}=.31$; however, the inclusion of victim race in Step 2 did not improve the model, $\Delta F(1$, $308)=.22, p=.64$, Power $=.99$. Instead, officers enacted more discretionary behaviors when the suspect was older $[B=.01, S E=.01, p=.02]$ and Black [ $B=-.34, S E=.10, p=.001]$, children are present $[B=.25, S E=.09, p=.007]$, and the victim is visibly injured $[B=.72$, $S E=.08, p<.001]$ and cooperative $[B=-.21, S E=.12, p=.09]$.

Models. A variety of supplementary moderation, mediation, and moderated mediation models were fit to the data to try to better understand the relations between race, officers' perceptions of risk and paternalism, and discretionary behaviors at the scene. None of these models produced any significant findings of note; see Appendix E for a depiction of each of the models tested.

First, a simple mediation (PROCESS Model 4) was tested in which risk mediated 
the relation between victim race and each of the six outcomes (giving informational resources, taking photographs, assigning advocates, finishing the victim interview, number of victim interview questions answered, and the Discretionary Behavior Scale), with all control variables included as covariates. No significant indirect effects emerged, suggesting that while officers' risk focus was greater for White victims (Hypothesis 3), this did not correspond to an increase in any of the six effort outcomes tested.

Next, I tested whether suspect race moderated any of the pathways in the above mediation (PROCESS Model 59). That is, whether risk mediated the relation between victim race and the six effort indicators, and whether suspect race moderated Path A, B, or C. Again, there was no significant indirect effect of risk focus, nor did suspect race significantly moderate any of the pathways.

As there was a greater amount of risk focus in narrative reports written about White victims, I also wanted to test whether suspect race interacted with victim race to produce different levels of risk focus. PROCESS Model 1 indicated that suspect race did not moderate the relation between victim race and risk focus, indicating that, controlling for other risk factors, while officers perceived White women as being in more danger than Black women, this perception was not impacted by the race of her assailant.

While victim race did not predict paternalism (Hypothesis 4), I also tested the above mediation models with paternalism instead of risk. That is, I tested whether paternalism mediated the relation between victim race and each of the six discretionary effort outcomes (giving informational resources, taking photographs, assigning advocates, finishing the victim interview, number of victim interview questions answered, and the 
Discretionary Behavior Scale), with all control variables included as covariates. No indirect effects emerged, likely due to a floor effect for paternalism words in the narrative reports.

Outliers. When the full sample was used (rather than one in which multivariate outliers had been eliminated), two of the above effects weakened to the point of nonsignificance: the interaction between victim and suspect race on the filing of the supplemental form, and the greater percentage of risk focus words in narrative reports about White victims (rather than Black). The outliers that precluded these significant findings were further scrutinized.

First, I examined the 20 cases that were cut for the filing of the supplemental form outcome. Logistic regression was used to see whether the five predictor variables (the age and race of the victim and suspect, and the interaction of victim and suspect race) predicted whether a case was cut. The full model was significant, $\chi^{2}(3, N=512)=66.16$, $p<.001$, Nagelkerke $\mathrm{R}=.43$. A case was more likely to be a multivariate outlier, and thus eliminated, when the victim was White $[B=3.14, S E=.82$, Wald=14.56, $p<.001]$, when the suspect was older $[B=.16, S E=.03$, Wald $=28.37, p<.001]$, and the victim was younger $[B=-.17, S E=.04$, Wald $=21.40, p<.001]$. The race interaction was also significant $[B=-$ 4.73, $S E=1.62$, Wald $=8.55, p=.003]$, indicating that, for White victims, a case was more likely to be cut when the suspect was Black $[B=3.14 S E=.82, p<.001]$ than when the suspect was White $[B=-1.59 S E=1.36, p=.24]$. That is, not only did the cases cut tend to have older suspects and younger victims, but these cases were disproportionally those with a White victim and a Black suspect $(\mathrm{N}=11)$. The sample used for the reported 
analysis contained 54 cases with a White victim and a Black suspect (50 had the supplemental form filed, 4 did not). These 11 cases in which the supplemental form was not filed, but which were then eliminated as multivariate outliers (Cook's D $>4 / \mathrm{N}$ ), were therefore responsible for suppressing the significant race interaction for Hypothesis 1a. There were no significant differences in the average age of the White victims $[t(13)=1.22$, $p=.25]$ or Black suspects $[t(13)=-.82, p=.43]$ that were eliminated or kept.

Next, standard multiple regression was used to examine the 16 cases that were cut for the risk focus outcome. The twelve predictor variables (i.e. race, age, charge, precinct, etc.) produced a significant model, $F(12,326)=2.75, p<.001, \mathrm{R}^{2}=.09$, indicating that a case was more likely to be an outlier, and thus eliminated, when the victim was uncooperative [ $B=.18, S E=.04, p<.001]$ or the couple was married [ $B=.05, S E=.03, p=.08]$. Interactions between victim race and marriage status, victim race and cooperation, and marriage status and cooperation were added into the model to try to better understand how these outliers could have reduced effects of victim race on risk focus, but all the interactions were $n s$ (all $p \mathrm{~s}>.12$ ). Note that this model only accounted for $11 \%$ of the variance in whether a case was cut or not, so larger combinations of $2+$ variables were likely detected by Cook's D.

\section{Discussion}

The current study applied social psychological theories of sexism and racism to the domain of police responses to victims of intimate partner violence. When police respond to an IPV call, they encounter (usually, but not always) women experiencing intimidation and violence. These women have requested and/or require help, making this 
a relevant context in which BS can impact behavior. Mandatory arrest laws reduce ambiguity around the treatment of IPV suspects, but not the treatment of IPV victims. As police investigate the incident, interact with the victim, and file the paperwork, stereotypes about which "types" of women are believable victims who deserve help may subtly influence behavior even when those stereotypes are not consciously endorsed, potentially producing real-world consequences of the intersection of benevolent sexism and racial stereotypes. This study examined the extent to which racial disparities in the treatment of Black and White victims were evident in a sample of police IPV records in which mandatory arrests had been made. I differentiated between unambiguous basic reporting requirements, which I predicted would not exhibit racial disparities, and discretionary efforts and helping behaviors, which should favor White victims due to the differential application of benevolent sexism to White women (McMahon \& Kahn, 2016, chapter II). I also examined officers' first-person narrative accounts of the scene to measure their perceptions of risk and feelings of protective paternalism. To my knowledge, this study was the first to use the theoretical framework of benevolent sexism to consider how racial differences might emerge in how police respond to victims of IPV. I also expanded upon previous investigations of police responses to IPV by utilizing new indicators of officer "effort" at the scene, testing for the presence of missing data (i.e. missing supplemental forms, missing interview questions) rather than only using cases without any, analyzing linguistic choices in officers' first-person narrative accounts, and relying on official documentation rather than victim accounts.

Results indicated that, contrary to the hypotheses, police actions favored White 
women at the level of basic reporting rather than discretionary behaviors. However, once officers decided to file the supplemental form, no racial disparities were found on any of the outcome variables contained therein.

The required supplemental form was only filed for $67 \%$ of the incident reports, and the odds of filing were nearly four times greater when the victim was White than when she was Black (controlling for the race of the suspect and the ages of both parties). Put another way, Black victims were 1.17 times more likely than White victims to have the supplemental form missing. Furthermore, suspect race also influenced this behavior, such that officers were more likely to file the supplemental form when the suspect was Black (controlling for victim race and ages), and marginally more likely to file the supplemental form when the victim was a White woman assaulted by a Black man (controlling for the independent effects of race and age). Rather than finding a ceiling effect of officers fulfilling this basic reporting requirement when responding to IPV, officers were attuned to both the race of the victim and the suspect. If Hypothesis 1a had been supported, and filing the supplemental form was truly an unambiguous job requirement (and therefore less susceptible to biases), rates of filing would have approached $100 \%$. Instead, this form was only filed for 2 out of every 3 IPV investigations, and was more likely to be missing when the victim was a Black woman. This suggests that officers may have perceived the supplemental form as optional rather than required, putting these results in line with my predictions regarding racial disparities in discretionary behavior.

Importantly, once officers decided to file to supplemental form, no differences 
were observed between the treatment of White and Black female victims. Officers were as likely to provide informational resources, take photographic evidence, attempt to set up DV advocates, and interview child witnesses; they also collected details about the incident, asked the victim interview questions, and wrote narrative reports of similar lengths. In other words, once the decision was made to file the supplemental form, officers produced similar quality investigations for Black and White victims of IPV.

A linguistic analysis of the narrative reports revealed that officers had a greater risk focus when writing about White victims than Black victims, but the attempts to capture paternalistic language did not result in a significant model. Further examination of these linguistic variables revealed that risk mediated the relation between victim race and paternalism, suggesting that officers perceived White victims as being in more danger than Black ones (i.e. they wrote with a stronger risk focus), which then led them to use more paternalistic language in their narrative reports, possibly indicating a greater desire to help these victims. Though these LIWC measures are new, imprecise, and failed to predict officers' behavior (see the Additional Analyses above), they do hint at officers' perceptions of victims at the scene, which are both 1) consistent with racial stereotypes of Black and White women, and 2) have the potential to impact other readers of these narrative reports (described further below).

While the results largely contradict the original hypotheses, they do have empirical and theoretical support in line with my initial reasoning. I had predicted that, since filing the supplemental form is an unambiguous job requirement, there would be no difference between outcomes for Black and White women, as even if officers had 
unconscious negative feelings about African Americans, they should be less likely to discriminate when the "correct" response in a given situation is clear (Dovidio \& Gaertner, 1986). In this sample of IPV cases, in which the suspect had been arrested in accordance with the state's mandatory arrest policy, officers only filed the supplemental form $67 \%$ of the time, indicating that they perceived this paperwork as discretionary rather than required or they foresaw no professional consequences for omitting it. This behavior would be consistent with previous studies that have revealed officer reluctance and frustration at dealing with additional IPV paperwork (Crime \& Misconduct Commission, 2005; Gila et al., 2008; Meyer, 2011), as well as studies where the rates of filing supplemental paperwork are low (e.g. Robinson \& Chandek, 2000) or missing data in these files are high (e.g. Worrall et al., 2006). The operationalization of "filing the supplemental form" as a basic job requirement rather than a discretionary behavior was informed by official police training materials, state statutes, and a police consultant; focus groups or surveys with the police officers who responded to these IPV incidents may have revealed this behavior was in fact perceived as discretionary. Given that most studies utilizing police reports only include cases with no missing data (or files) rather than samples of the population from a specific time period (Shernock \& Russell, 2012), this disparity in filing supplemental IPV reports, which may be used later for case planning, risk assessment, and prosecution, is a novel contribution to the literature. The sample used here only included cases in which suspects had been arrested, but the presence of missing supplemental forms indicates that 1) proper handling of suspects in accordance with mandatory arrest policies does not necessarily predict proper treatment 
of victims or a complete IPV investigation, and 2) future investigation or prosecution of IPV cases involving Black female victims may be hindered by missing information contained in the forms.

Officers filing the supplemental form (and therefore, properly investigating the IPV incident rather than solely arresting the primary aggressor) at a higher rate for White victims is also theoretically consistent with previous social psychological research showing that benevolent sexism is directed more at White women than Black women (McMahon \& Kahn, 2016, chapter II). That is, police may be influenced by stereotypes that White women are more inherently fragile and worthy of benevolent protection (Belknap, 2007; Madriz, 1997; McMahon \& Kahn, 2016, chapter II) than Black women. With more time and effort spent on cases involving White victims, results demonstrate how stereotypes can govern the allocation of zero-sum resources, as predicted by shifting standards theory (Biernat, 2003).

Another unpredicted finding was the marginally significant interaction between victim and suspect race in predicting the rates of filing the supplemental form. Rather than the anticipated ceiling effect, the supplemental form was most likely to be filed when the incident involved a White victim and a Black suspect (93\% probability). Rates of filing were similar for intraracial White $(68 \%)$ and Black (66\%) couples, and lowest for couples with a White suspect and Black victim (59\%); the risk of a missing supplemental form for these three types of couples (intraracial or White suspect and Black victim) was 4.71 times higher than for couples with a White victim and a Black suspect. Research into police responses to IPV among inter- and intra-racial couples is 
essentially nonexistent, but these results can be understood through a social psychological lens.

First, this finding is consistent with my work demonstrating that the protective paternalism component of BS bolsters attitudes that denigrate racial minorities (McMahon \& Kahn, 2017; chapter III). Here the extra attention paid to incidents in which Black men assaulted White women may demonstrate an increased desire to defend White women from a dangerous minority male, particularly if the responding officer is a White male himself (McMahon \& Kahn, 2017; chapter III). As explored in chapter III of this dissertation, White men (as the dominant group) perceive racial minority men, rather than White men, as a greater threat to White women (Nagel, 2001; Navarette, McDonald, Molia, \& Sidanius, 2010). White men under threat (as an officer may be when responding to IPV) show a greater desire to protect women, which then bolsters their anti-racial minority attitudes (McMahon \& Kahn, 2017). Here, a White male officer, upon seeing a White woman assaulted by a Black man, may experience an increase in protective paternalism, which then may activate the negative racial stereotypes that have long painted minority men as abusers of White women (see chapter III), leading to the high rates of filing seen for these incidents of interracial violence.

Second, the higher probability of filing for Black suspects with White victims (93\%) compared to White suspects with White victims (68\%) is not dissimilar from other criminal justice outcomes. For example, Black men are more likely to receive a death sentence than White men, particularly when their victim was White (Baldus, Woodworth, Zuckerman, \& Weiner, 1998) and when they themselves were more phenotypically Black 
(i.e. darker skin, fuller lips) (Eberhardt, Davies, Purdie-Vaughns, \& Johnson, 2006). Racial disparities in the treatment of Black and White suspects may reflect not just antiBlack implicit bias, but also pro-White biases that benefit White individuals (Kahn, Goff, Lee, \& Motamed, 2016). Police, like other members of society, may form anti-Black and/or pro-White implicit biases as a result of their personal experiences and upbringing in a culture where such stereotypes have a long history of automatic activation and reinforcement (Kahn \& McMahon, 2015; Kahn \& Martin, 2016; Rudman, 2004). Lower use of force by police has been found for suspects that have higher White phenotypic racial stereotypicality; that is, the "more White" they appear (blonde hair, pale skin, blue eyes), the less force is used on them compared to White suspects who appear "less White" (Kahn, et al., 2016). In this study, a combination of unconscious pro-White and antiBlack biases could help produce different treatment for Black and White suspects who commit similar crimes. However, the inability to actually measure officers' attitudes and use them to predict behavior in this study precludes any definitive causal claims about officer bias.

Third, the treatment of intraracial couples may be marked by conflicting motivations and stereotypes. In a Black couple, the man is stereotyped as dangerous and criminal (Devine, 1989; Eberhardt et al., 2004) and the woman as antagonistic and culpable for violence (Esqueda \& Harrison, 2005; Niemann et al., 1994). For this reason, police may devalue Black women's suffering even as they are arresting Black men (Rasche, 1988). In a White couple, beliefs about the purity of (traditional) White women (Morton, 1991) may clash with ingroup favoritism toward White men by White male 
officers (Tajfel \& Turner, 1986). In these cases, other variables, such as the presence of children, drugs, or witnesses (Robinson \& Chandek, 2000), previous IPV incidents (Trujillo \& Ross, 2008), and officers' beliefs and assumptions (e.g. Edwards, 1996; Stewart \& Maddren, 1997) should help predict officers' responses. In the case of White suspects and Black victims, the pairing of pro-White biases with negative stereotypes of Black women could have helped produce these lowest rates of filing (59\%).

Importantly, here were no differences between White and Black victims in the rate at which the various behaviors we operationalized as discretionary (i.e. "extra effort") took place, either individually or when combined into a Discretionary Behavior Scale (with adequate statistical power). It appears that once officers in this sample decided to do the supplemental form (where racial disparities are present), the discretionary effort they expended was not impacted by the race of the victim. This study tested eight hypotheses (1a-b and 2a-f) concerning officers' behaviors at the scene (i.e. asking questions, taking photos). Unfortunately, few of the outcomes had adequate observed power (filing the supplemental form, number of victim interview questions, word count), while most had inadequate observed power (completing incident detail questions, taking photographs, conducting interviews with child witnesses, giving informational resources, and assigning advocates). Notably, evidence for bias or disparities here is limited, as statistically significant results were only found for one of these outcomes (the filing of the supplemental form; Table 2.18.) While this could be attributed to the low observed power, the lack of significant victim race effects for the continuous Discretionary Behavior Scale (a combination of taking photos, giving 
resources, and setting up DV advocates, with power $=.99)$ support these null results. Instead, one may infer that once officers decide to file the supplemental form, they are producing similar quality investigations for White and Black victims.

Instead, these discretionary helping behaviors are predicted by other variables, including the race of the suspect. Specifically, officers were more likely to collect photographic evidence and provide the victim with informational resources when the suspect was Black. These findings suggest that once a Black suspect of IPV is apprehended, police enact more behaviors that will assist in their prosecution, as photographs are used as evidence in court and informational resources given to victims included the number for the District Attorney's office and how to file a restraining order. That these efforts are spent more on Black suspects than White ones hints at the potential influence of anti-Black biases that condemn Black men, pro-White biases that exonerate White men for the same crimes, or a pernicious combination of the two. The presence of visible injuries to the victim also predicted several discretionary behaviors, including taking pictures and offering a DV advocate, though, interestingly, this was associated with a lower likelihood of giving informational resources (possibly because the assaults had escalated and victims had these resources from a prior call to police). Women whose injuries are not visible, either because they're internal, they waited too long to report the incident, or they have darker skin (White, 1985), may not have their cases treated as seriously by police. The victim's cooperation, unsurprisingly, predicted several of the discretionary helping behaviors, including asking victim interview questions, writing longer narrative reports, and assigning advocates. The presence of children was also 
associated with a greater likelihood of police assigning a DV advocate.

Importantly, potential evidence of the impact of racial stereotypes can be seen in the narrative reports, where the only significant predictor of a higher risk focus (aside from the precinct dummy control variables) was the race of the victim. Officers were more likely to use words like "danger", "doubt", and "safety" when they wrote about White victims, suggesting they perceived these women to be at greater risk. That White victims were viewed as being in more danger, even though other potential risk factors (i.e. the charge, the presence of visible injuries) had been statistically controlled for, which then bolstered feelings of protective paternalism toward the victim, suggests the influence of racial stereotypes on officers' perceptions and the alignment of White women with BS ideals of fragility and defenselessness (McMahon \& Kahn, 2016). I had also hypothesized that officers would write with a higher risk focus when the suspect was Black, but found no evidence of this (nor was there an interaction between suspect and victim race). This is both consistent with my findings that BS is more closely associated with White women than Black women (McMahon \& Kahn, 2016) and inconsistent with evidence that outgroup males (here, Black men) are seen as more of a danger to ingroup (i.e. White) women than White men (Navarette, McDonald, Molia, \& Sidanius, 2010; see also chapter III of this dissertation). Whether risk focus in the narratives has any predictive validity for future behaviors of other officers, advocates, or attorneys who read the reports will require additional study.

Victim race was, contrary to the hypothesis, not a significant predictor of paternalistic language in the narrative reports, nor did the model reach significance. As 
the dictionary of paternalism words was created for this study, it does not have the same history of validation as similar LIWC dictionaries. However, even if its construct validity was beyond question, the low rate of occurrence of these words in the narratives (an average of $0.19 \%$ of the text per report) suggests a floor effect. Unlike other first-person narrative accounts written by police (e.g. use of force reports), the narratives here are not introspective; they are meant to objectively chronicle what the officer saw, heard, and did, not to explain the officer's thought process in order to justify their actions later. For example, a narrative report in this sample was more likely to read, "I gave her my business card and asked if she wanted a DV advocate to call her" than "she seemed defenseless and I wanted to help her." Further, several of the words in the paternalism dictionary, while undoubtedly matching the construct, would be unlikely to turn up in any police report (e.g. breadwinner, chivalry, pedestal), so while this LIWC dictionary might have been able to capture paternalism words other contexts (e.g. poetry, a romance novel, a rom-com script), police narratives were likely not a viable source.

In summation, this cross-sectional examination of police records uncovered racial disparities in the rates of filing supplemental paperwork and the use of risk focus words when writing about victims, but not in other helping behaviors such as providing informational resources or offering DV advocates. It appears that once officers decided to file the supplemental form, Black and White victims received similar amounts of help. One possible explanation for the initial disparity in filing is the influence of racial stereotypes, whether or not they are explicitly endorsed. Merely viewing a member of a stereotyped group is enough to automatically activate the stereotypes associated with that 
group in the minds of both high and low prejudiced individuals (Devine, 1989). Whether the stereotype will then bias perceptions and treatment of the target depends on the perceiver's motivation and opportunity to respond in a non-biased way (Fazio, 1986).

In the context of IPV, victims and suspects, each possessing of a race and gender, automatically activate race and gender stereotypes in the minds of responding officers. These stereotypes may then influence officers' perceptions and behaviors (i.e. perceiving White women as being in more danger than Black women, given racial stereotypes of White women as defenseless and Black women as tough), unless officers consciously override them. Even if officers are highly motivated to be egalitarian in this context, and are sincerely egalitarian in their day-to-day lives, they may lack the opportunity for such controlled processing. Police are often overworked and under great stress, with multiple demands on their time and finite resources. The police department studied here was also undergoing a staffing shortage, further exasperating demands on individual officers. While it is possible that some officers may have lacked the motivation to treat victims equally (i.e. those who are explicitly racist), the disparities seen here are more likely impacted by officers' lack of opportunity for the sort of deliberative, controlled processing that would have suppressed racial stereotypes to produce nonbiased outcomes. A similar trend can be seen in the domain of healthcare, where racial disparities have sometimes emerged in the treatment of Black patients. Physicians are less likely to prescribe analgesics (Dominick et al., 2004) and antibiotics (Mayr et al., 2010) to Black patients, and less likely to recommend breast cancer screening (McCarthy et al., 2016) and cardiovascular procedures (Kressin et al., 2004; Schulman et al., 1999). Implicit pro- 
White biases (and not explicit racial attitudes) have predicted the likelihood of physicians treating White patients and not Black ones with thrombolysis (Green et al., 2007). In the same way that quantitative disparities in the treatment of Black and White women experiencing IPV (e.g. Avakame \& Fyfe, 2001; Robinson \& Chandek, 2000) have been supported by qualitative data from victims (Few, 2005; Gillis et al., 2006; Potter, 2010), African Americans in focus groups have reported having their symptoms dismissed by doctors and needing to reassert themselves to receive fair treatment (Cuevas, O'Brien, \& Saha, 2016). Doctors, like police officers, are often overworked and under great stress, with multiple demands on their time and finite resources. Racial disparities may be partially explained by the influence of automatically activated racial stereotypes to color doctors' perceptions of their patients and impact decision-making, especially when time demands and limited resources impede controlled processing (Fazio, 1986) or the correct behavior (e.g. whether or not to prescribe a drug or recommend a test) is ambiguous (Gaertner \& Dovidio, 1986).

It is crucial to note that the precise cause of the disparities seen here cannot be determined by the present data. The presence of racial differences in the likelihood that officers filed the supplemental form and the percentage of risk focus words used in the narrative reports does not definitively prove that intentional officer discrimination took place or that officers' racial biases played a role. The inability to distinguish disparity from discrimination is one of the challenges of studying racial bias in policing (Goff \& Kahn, 2012). Disparities (i.e. numerical differences between groups) can arise from a variety of factors, and these alternative explanations must be considered. For one, the 
missing supplemental forms in the dataset may not be truly missing due to sampling error. As different precincts transitioned from a paper to an electronic system, hard copies of supplemental forms may have been filed, yet were not able to be found later when the sample was being pulled electronically. These files would thus be missing from the electronic database, but would not be truly missing, meaning that disparities in rates of filing here might be overestimated. There are also other factors about the suspects that could not be controlled for, such as their criminal history. This information may have been available to the officer doing the arresting, but was not available for the present study. A criminal history may have impacted perceptions of danger at the scene, accounting for some of the variance in risk focus words in the narrative reports. While the current sample included only cases with no duplicate suspects or victims in order to meet the independent errors assumption for regression, repeat offenses may also influence officers' behavior. Police may be more willing to file supplemental paperwork for a first time offense, but become reluctant to handle burdensome paperwork for the same couple again and again, as this could signal that the victim is unwilling to press charges (Crime \& Misconduct Commission, 2005; Gila et al., 2008; Lila et al., 2013). To the extent that Black women are more likely to experience repeat offenses, they may be more likely to have missing paperwork for their IPV incidents for this reason. The elimination of cases with duplicate victims or suspects in this sample does reduce the influence of this factor on the present findings, but it does not eliminate it entirely, as there may have been incidents prior to the sample's start date (June 2015) that the responding officer knew about. Additional factors which may have affected these findings but which were not 
controlled for (e.g. officer race) due to restricted access at the police department are further described in the Limitations section.

\section{Implications}

The primary finding of this study was that supplemental paperwork was (1.17 times) more likely to be missing for Black female victims of IPV compared to White ones. Whether this finding has legal ramifications for real victims of IPV depends on the degree to which these supplemental forms are actually utilized. In theory, the purpose of this supplemental form is to collect information that may not be available later for risk assessment and case planning. Victim advocates, probation and parole officers, city prosecutors, and officers in the DVU can all use information from these forms to make decisions that can impact victims. For instance, answers from the victim interview questions are used to assess lethality; for every question left unanswered, the assessment of risk becomes less accurate. The victim's self-reported likelihood of future assault question also helps predict recidivism (Henning, 2014). Without the supplemental form, lethality and recidivism cannot be assessed and vital evidence may go undocumented. Omissions in similar IPV reports have made cases impossible to prosecute (Erez \& Belknap, 1998) or caused the victims to ultimately lose their cases in court (Gillis et al., 2006). It is possible that the missing supplemental paperwork seen in this study could have similar consequences for victims whose cases are eventually brought to trial.

As poor experiences in court have led victims to vow to never use the legal system again (Gillis et al., 2006), losing a case due to insufficient paperwork filed by police could shatter a victim's trust in the system and put her at risk for future violence. Missing 
paperwork may also signal to the courts that those incidents were less severe or important, possibly impacting perceptions of the situation and subsequent decision-making. Probation or parole officers, if they lack a complete record of a suspect's abusive relationship with his victim (as captured by the incident detail and victim interview questions in the supplemental form), may under-supervise offenders or make recommendations that put the victim in further danger. In practice, notably, it is unclear how often the supplemental forms are actually read by other officers in this police department or used by prosecutors and the courts. That is, while the forms may be useful, they are not necessarily being used. To the degree that they are used, the Black women in this sample will have less documentation of the violence perpetrated against them, with possible ramifications for assessments of lethality, predictions of recidivism, parole decisions, and evidence to prosecute (Erez \& Belknap, 1998; Gillis et al., 2006) Additionally, missing data poses a challenge for other researchers who wish to study IPV in this setting. A secondary analysis of pre-existing records is impossible if those records do not exist. Missing data also introduces numerous statistical difficulties requiring imputation, casewise deletion, or the elimination of variables (Tabachnik \& Fidell, 2013). Many studies therefore only use complete records (Shernock \& Russel, 2012), even if it means reducing a sample size by over 60\% (Robinson \& Chandek, 2000), neglecting (sometimes by necessity) those cases where supplemental paperwork was not filed. Any descriptive or inferential analyses of this data will then only include those IPV cases where officers were able or compelled to file additional forms. This introduces a coverage bias, meaning there may be unaccounted for differences between the final 
sample and those IPV incidents not captured by the sampling frame (pulling complete IPV case files).

However, even if the police department does not use the supplemental forms, officers choosing to do the form (i.e. conducting the victim interview and taking photos) can still be beneficial for the victim. In focus groups, Black victims have sometimes reported that officers minimize their concerns or appear uninterested (Potter, 2010). Officers who are taking the time to ask questions and collect evidence may appear to take the case more seriously. To the extent that officers doing the forms at the scene is perceived by victims as proper treatment, this should lead to lower PTSD symptomology (Srinivas \& DePrince, 2015) and more trust in law enforcement (Stephens \& Sinden, 2000), which in turn increases willingness to report future IPV incidents (Apsler et al., 2003; Brandl \& Horvath, 1991). From a procedural justice perspective, officers choosing to do these supplemental forms at the scene may communicate dignity, respect, and fair and neutral treatment for the victim, which enhances perceptions of police legitimacy, willingness to cooperate with police, and satisfaction with police in general (Mazerolle, Antrobus, Bennett, \& Tyler, 2013). There is also the possibility that as officers go through the interview the victim may, upon hearing her own repeated affirmative responses to questions about choking, escalating violence, controlling behavior, etc., become more aware that she is in an abusive relationship. This awareness, when combined with high perceived social support and self-efficacy, enhances a victim's degree of readiness to change her situation (Cluss et al., 2006). In short, even if the supplemental forms are never used by the department or in court, "a little bit of being 
nice goes a long way" (Mazerolle, et al., 2013, p. 55.)

Officers do not complete the form at the scene; they use a small card with the incident detail (Hypothesis 1b) and victim interview (Hypothesis 2a) questions to gather information in their notes, which are later entered into an electronic form. Given that these incident detail and victim interview questions were answered at similar rates for Black and White victims, and officers performed similar numbers of "extra effort behaviors" (as measured by the Discretionary Behavior Scale), the decision to take out and begin reading off this card represents a crucial point that interventions can target.

If the police department wants officers to more consistently file these supplemental forms, there are several things they can do. First, trainings by the DVU should frame the supplemental form as an explicit, completely unambiguous job requirement, as this would reduce the impact of negative implicit biases or automatically activated stereotypes (Gaertner \& Dovidio, 1986) by removing the need for controlled processing (Fazio, 1986) to decide whether to do the form. Current trainings may be too vague, saying "officers are required by [department redacted] directive to make a thorough initial investigation including interviews of witnesses and the collection of evidence" and that under Mandatory Reporting [number redacted] "a police report will be written and submitted prior to the end of the shift" ("DVU advanced academy training", 2016). However, it is not explicitly written on the slides (though it may be said aloud by the instructor) that the supplemental form is part of Mandatory Reporting or is tantamount to the "collection of evidence." Instead, instructions to "collect as much evidence as possible (PHOTOS)" and to "verify history of abuse" are listed on a slide 
titled "DV Investigative Tips", suggesting a small but useful piece of practical advice rather than a crucial component of one's job. According to a [state redacted] Revised Statue cited in this same training, officers are required to identify the primary aggressor by considering, among other things, "the history of DV between the persons involved" and "the potential for future assaults." Both these pieces of information are found in supplemental paperwork via the victim interview (Hypothesis 2a) and the "likelihood of future assault" question; the former is more likely to be missing for Black victims (since their forms are less likely to be filed), and the latter question was missing $30 \%$ of the time. Police are instructed to be attuned to these risk factors, but this information is not necessary being documented. Explaining to officers in these DV trainings how the various parts of the supplemental form relate to state statues and department directives will help cement the impression that this is an unambiguous job requirement.

Second, officers are unlikely to increase their rates of filing the supplemental form if they do not foresee any penalties for not doing so. Even if the form is required, if it is little used by the department or the courts, it may be perceived as useless, and therefore a burdensome task they can avoid. Further, if officers never find themselves in a situation where, for example, a form was requested and found to be missing, leading to negative consequences for the victim or a verbal reprimand from their supervisor, the impression of the supplemental form as "required, but pointless" is unlikely to change. Additionally, officers could be taught about procedural justice, which holds that if the public views police as being fair in their decision-making, they will view police as legitimate and be more willing to cooperate with law enforcement (Sunshine \& Tyler, 
2003). Taking the time to talk with the victim and go through the elements of the supplemental form can make victims feel heard and supported, and being treated with dignity and respect should increase victims' trust in and cooperation with police (Mazerolle et al., 2013). If officers learn that taking the time to do the form with victims can help women in vulnerable communities trust police more, they may be more encouraged to do so.

Finally, while paperwork can never be made glamorous, but it can be made easier. Any efforts to increase the ease of filing this form should be considered. Record Management Systems and the electronic forms should be as user-friendly as possible. If the resources were ever available, electronic handheld versions of the form could be completed and filed in real-time at the scene, meaning officers would only have to go through the questions once (and not again, hours later, as they file the form using their handwritten notes). Though requiring gargantuan effort, various forms could be overhauled and streamlined to reduce the overall burden of paperwork on police. And finally, since the opportunity for controlled processing helps produce more egalitarian outcomes (Fazio, 1986), interventions that alleviate the considerable time demands and stress on police or reductions in the current staffing shortage could also be beneficial for reducing disparities in filing.

Note that these proposed interventions focus on police training and procedural changes, not on somehow increasing the benevolent sexism directed at Black women so that they are treated more like White women. Arguably, the White women in this sample experiencing IPV received help, so benevolent sexism may be considered "good." The 
following points are submitted in opposition to this argument. First, while benevolent treatment in this context might produce a tangible benefit in the moment (greater documentation of IPV incidents), the negative impact of exposure to benevolently sexist ideologies on female targets has been consistently demonstrated (Lee, Fiske, \& Glick, 2010), shown to undermine cognitive performance (Dardenne, Dumont, \& Bollier, 2007; Dardenne et al., 2013) and social activism (Becker \& Wright, 2011), decrease condom use (Fitz \& Zucker, 2014), increase body shame (Shepherd et al., 2011), and even reduce help-seeking for fear of confirming dependency stereotypes (Wakefield, Hopkins, \& Greenwood, 2012). Second, this preferential treatment of White women is further likely limited to those that most fit the stereotype of the "ideal" victim, who is female and White, but also middle-class, passive, and weak (Ammons, 1995; MacDowell, 2013). This definition would also exclude non-traditional women (e.g. feminists, sexually promiscuous, career-oriented) who, in challenging gender norms, are seen as unworthy of benevolent protections (Glick \& Fiske, 1996). In other words, the group of people who could be said to tangibly benefit from BS and racial stereotypes in this context is a small one indeed. Third, increasing benevolent sexism toward Black women, particularly by White Americans, would necessitate the unlearning of centuries-old racist stereotypes (Bond \& Perry, 1970; Jewell, 1993) that paint them in opposition to the ideals of BS. There is little hope that this could be achieved quickly. One of the oldest representations of Africans, the Negro-Ape metaphor, can still be activated in the minds of twenty-first century students, irrespective of their implicit or explicit anti-Black biases, many decades after it disappeared from media (Goff, Eberhardt, Williams, \& Jackson, 2008). Though 
not part of the contemporary cultural landscape, the Black-ape association has been shown to increase support for violence against Black suspects and the likelihood of real Black defendants receiving the death penalty (Goff et al., 2008). The undoing of similarly dehumanizing stereotypes about Black women in order that they might qualify for benevolent protections, which historically are themselves used to uphold White hegemony (McMahon \& Kahn, 2017), is therefore an untenable solution. Fourth, if police departments are concerned with procedural justice, they will want to ensure that officers are treating victims of IPV in accordance with state statutes and department directives, as these more explicit, unambiguous job requirements are less likely to produce racial disparities (Gaertner \& Dovidio, 1986). The ideal solution, therefore, is not achieving equal benevolent sexism for all races of women, as this would by definition still exclude non-traditional subtypes of women (Glick \& Fiske, 1996), who also deserve police intervention for violence committed against them. Instead, interventions should attempt to remediate the possible influence of racial stereotypes and pro-White/anti-Black biases so that Black and White women are treated more equally. This can be achieved by emphasizing the job requirements of thorough initial investigations and mandatory reporting ("DVU advanced academy training", 2016) and the rights of victims, including the right "to be treated with dignity and respect, to fair and impartial treatment, and to reasonable protection from the offender" (Victims' rights guide, n.d.).

The current study also found a greater percentage of "risk focus" words used when writing about White victims than Black ones, suggesting officers perceived them to be in more danger, even after more objective risk factors were controlled for. It is 
possible that an officer writing with a greater risk focus for White victims may influence perceptions of that victim to future readers, as the language used to describe violence has been shown to affect perceptions of the crime (Henley, Miller, \& Beazley, 1995; Pierce \& Harris, 1993). In this way, officers' perceptions of the victim will be passed on to others who read and use the form, including officers, attorneys, or advocates, which may affect how they subsequently handle the case or treat the victim. If the case ever goes to court, these impressions may be passed on to judges and jurors, potentially influencing their legal decisions. Importantly, this finding represents a minor shift in language and is not terribly robust (see the outliers section), yet it can be considered as part of the constellation of studies that demonstrate subtle differential perceptions of and treatment for White and Black Americans (e.g. Ainscough \& Motley, 2000; Bertrand \& Mullainathan, 2003; Devine, 1989; Goddard, Kahn, \& Adkins, 2015).

\section{Limitations}

The primary limitations of this study result from a lack of unrestrained access to police records. Importantly, narrative reports were only pulled for those cases that had a supplemental form. That is, the policing consultant (who served as gatekeeper) provided the supplemental forms and narrative reports as a pair. Climate shifts in the police department that restricted civilian access, disruptions in the immediate aftermath of the 2016 presidential election, and our gatekeeper's transitioning into a new division with limited access to the needed files all conspired to keep our sample fixed at 512 incident reports and 342 supplemental forms and narrative reports. This means that I cannot account for the content of the 170 narrative reports attached to incident reports in which 
officers did not file the supplemental form. This means that the two control variables coded from the narrative reports (i.e. whether the victim requested police intervention or was uncooperative) are unavailable for these 170 cases. Specifically, the possibility that supplemental forms were not filed because victims refused to cooperate with police cannot be ruled out.

Had this cooperation variable been included in the prediction of the filing of the supplemental form (Hypothesis 1a) as a control, different results may have emerged. As officers who believe victims will pursue criminal charges are more willing to handle additional IPV paperwork (Crime \& Misconduct Commission, 2005; Gila et al., 2008), one can predict that officers were less likely to file the supplemental form when they encountered an uncooperative (or even hesitant) victim. Some studies have found Black women more reluctant to involve police in IPV (Rasche, 1988; Smith \& Klein, 1984), while others have found Black women are more likely to call police in response to IPV than White women (Jasinski, 2003; Jordan, 2004). To the extent that Black victims are more reluctant to cooperate with police investigations, this "uncooperative victim" variable is an unfortunate confound in the analyses. However, officers' perceptions of cooperation may also be informed by racial stereotypes of Black women as antagonistic (Niemann et al., 1994), stubborn (Weitz \& Gordon, 1993) and more culpable for violence (Esqueda \& Harrison, 2005). If so, the same behavior (e.g. reluctance to answer questions) could be interpreted as uncooperative from a Black woman and as a natural reaction to trauma requiring police encouragement from a White woman, making it possible that depictions of Black victims as uncooperative in the narrative reports are 
inflated. Testing this hypothesis would require verifying degrees of victim cooperation at the scene using body camera footage, which is nonexistent for this data. Importantly, no differences were found in the rates at which Black and White women in the present sample called police or cooperated with them (though again, these variables were pulled from the narrative reports, which were only available for cases in which a supplemental form was filed.)

Another consequence of this restricted sample is impaired statistical power. While observed power was high ( $>.95)$ for all continuous outcomes (risk, paternalism, word count, number of victim interview questions) and for the prediction of filing the supplemental form, most of the sequential logistic regressions suffered from low power, which is common for this test when sample sizes are too small and there are many control variables (Tabachnik \& Fidell, 2013). The low statistical power estimated for the analyses with dichotomous outcomes (i.e. gathering all incident details, finishing the victim interview, taking photographs, conducting interviews with child witnesses, giving informational resources, and assigning advocates) indicates that a larger sample size might have been needed to find the independent effects of victim race on each discretionary police behavior outcome (if indeed those effects are there to find.)

Further, I was unable to control for several variables that may have impacted these results, such as the possible effects of the couple's economic or social class. In some examinations of officers' responses to IPV, income did not predict the likelihood of arrest (Jasinski, 2003) or whether officers did more than "paper the incident" (Bachman \& Coker, 1995). In others, more officer interventions on behalf of wealthier victims were 
found, with arrests being more likely when the IPV victim has a higher household income (Avakame \& Fyfe, 2001). Supportive assistance from police, such as providing legal assistance and information and showing concern, also favor wealthier, less-disadvantaged victims of IPV, regardless of their racial minority status (Sun, 2007; Sun \& Payne, 2004). These findings suggest that effects of the female victim's race on predicting officers' filing of the supplemental form may have weakened if household income were controlled for, with officers instead more likely to properly file supplemental (yet required) paperwork when responding to higher income women, regardless of their race. Officers' risk focus may have diminished for higher SES women, who could be seen as having the financial and social resources to leave abusive partners; alternatively, risk focus might have been unaffected by SES, due to the higher attributions of benevolent sexism for White women (McMahon \& Kahn, 2016, chapter II) and racial stereotypes that still depict White women as more inherently fragile (Schloesser, 2002) and Black women as able to withstand pain (Bond \& Perry, 1970). Unfortunately, many studies (e.g. Bachman $\&$ Coker, 1995; Sun, 2007; Sun \& Payne, 2004) that examine victim characteristics as predictors of officer behavior do not test how the variables interact with each other; a more intersectional understanding of how race and class impact how police respond to female victims of IPV will require that these variables are not only measured, but considered jointly.

Furthermore, I was not granted access to any information about the responding officers, nor was I permitted to denote which incidents the same officer responded to, making any examinations of intra-individual variation impossible. For example, some of 
the variance in risk focus, paternalism words, and word count could likely be accounted for by differences in officers' writing styles (though this should be equally distributed across victim race, limiting this issue). The race and gender of the officers may also have been influential. While the police department examined here is comprised of mostly White male officers, the present sample only includes cases where arrests were made; here, the effects of officer race are often mixed. Sometimes officer race does not predict arrest (Walker, Spohn, \& DeLone, 1996) or "control" actions such as verbal threats, interrogation, restraint and arrest (Sun, 2007); other times, Black officers are more likely to respond with commands and verbal threats than White officers (Sun \& Payne, 2004) or White officers are likely to make arrests than Black officers (Robinson \& Chandek, 2000). Further, Black officers may be more likely than White officers to conduct supportive activities (e.g. telling victims to sign a formal complaint, use legal system or seek out a service agency, providing comfort and information) in predominantly Black neighborhoods, while there is no difference between White and Black officers in initiating support in more racially diverse communities (Sun \& Payne, 2004), suggesting that filing of the supplemental form may be more likely for Black victims when they live in a predominantly Black neighborhood and the responding officer is also Black. This study was able to control for the precinct in which the incident took place, so some of the neighborhood racial demographics and the corresponding potential differences in supportive actions by White and Black officers seen in Sun and Payne (2004) are accounted for here.

Considering officer gender, evidence is also mixed. Female officers may be less 
likely to make arrests (Morash \& Greene, 1986), to endorse higher police involvement in IPV (Homant \& Kennedy, 1985), and to recommend shelters (Finn \& Stalans, 1995) than male officers, or there may be no gender differences found in arrests (Robinson \& Chandek, 2000), having a pro-intervention response to IPV (Feder, 1997), or referrals to shelters and mental health treatment (Finn \& Stalans, 1995). Findings that female officers are more likely to provide supportive actions (which here include "filing incident report" and "acting on citizens' behalf") to victims than male officers in one study (Sun, 2007) have been nullified in other studies that include more situational variables (Sun \& Payne, 2004; Sun, Payne, \& Wu, 2008). Even when officer gender predicted supportive, noncoercive behavior by police, the minority status of the victim did not (Sun, 2007). Therefore, it is possible that officer gender would not have predicted different outcomes for Black and White victims in this study, particularly with the inclusion of situational control variables (e.g. visible injuries, children present, marriage status, cooperative victim, etc.) Alternatively, (White) males, who make up the majority of officers in this department, may be less helpful toward Black victims, given that men consistently endorse hostile sexism more than women (Glick et al., 2000), which has been linked with lower benevolent sexism toward a negatively-subtyped Black female target (McMahon \& Kahn, 2016; chapter II). That is, male officers (who are more likely to strongly endorse HS than female officers) should be particularly unlikely to offer help (or even file the correct paperwork) when responding to a Black woman they deem promiscuous (e.g. if the couple is unmarried). As White men have been shown to react to salient danger by increasing their desire to protect women, which subsequently bolsters anti-racial minority 
attitudes (McMahon \& Kahn, 2017; chapter III), the especially high rate (93\%) of filing supplemental forms for White women assaulted by Black men is likely driven by the White male officers in this sample.

It is important to note that all cases of IPV examined involved heterosexual couples with a male suspect and a female victim; therefore, these results cannot generalize these findings to cases with LGBT couples. Others have investigated how police respond to IPV among same-sex couples and found dual arrests to be more likely than for heterosexual couples (Hirschel, Buzawa, Pattavina, Faggiani, \& Reuland, 2007), perhaps because police are unable to rely on gender to help them distinguish the primary aggressor from the victim (Hirschel \& Buzawa, 2002). Lesbians who have called police following an incident of IPV describe unhelpful behaviors such as minimizing the problem, misclassifying it as a "mutual fight", or failing to intervene (Hodges, 2000; Ristock, 2002). Since BS and HS presuppose a female target, these constructs have less relevance to situations where police are responding to male same-sex couples. However, lesbians belong to an "unattractive" or "deviant" sexual subtype (Glick et al., 1997) due to their rejection of traditional gender norms, so one might expect them to be targets of HS rather than BS. Further, since violence between two women may not evoke in male officers the same role of the masculine protector (Young, 2003) whose job is to protect "good women" from "bad men" (chapter III of this dissertation), officers would not be expected to respond in a particularly benevolently sexist way. This may manifest as officers responding to a lesbian couple being less likely to engage in the discretionary helping behaviors seen in this study (e.g. less likely to give resources or offer an 
advocate) or file the supplemental form (particularly if IPV between two women is misclassified by the officer as a fight between roommates or friends.)

Other limitations include the inability to verify the accuracy of these police records, particularly the details contained in the narrative reports. As this is a secondary analysis of existing reports and the interactions were not directly observed, there is no way to confirm from this data whether officers actually offered informational resources or advocates to the victims, or if victims were truly being uncooperative to the point of obstructing the investigation. However, given that providing victims with resources and advocates is recommended but non-verifiable, such behaviors are likely over-reported rather than under-reported, making this a conservative test of my hypotheses. Additionally, LIWC software cannot recognize the context of a word, such that the two phrases, "I told her I was worried for her safety" and "they did not seem concerned or in danger" would code equally for the risk focus category, making this measure somewhat imprecise.

\section{Future Directions}

Future studies with police may want to measure how an officer's personal endorsement of hostile and benevolent sexism impacts their behavior on the job. Only two studies have considered HS and BS in a sample of police regarding IPV (Garcia, Garcia, \& Lila, 2011; Lila, et al. 2013), but only to predict preferences for conditional or unconditional law enforcement in hypothetical situations. While endorsement of HS and BS has been shown to predict HS and BS behaviors in a laboratory setting (De Oliveira Laux, Ksenofontov, \& Becker, 2015), this has not yet been translated into a real-world 
policing context. As endorsement of HS has been shown to not only correlate with attitudes that legitimize IPV (Glick, Sakall1-Ugurlu, Ferreira, \& Aguiar de Souza, 2002; Sakalh, 2001) but actually predict IPV perpetration (Makin-Byrd \& Azar, 2011; Lisco, Parrott, \& Tharp, 2012), understanding how these attitudes also affect the policing of IPV is critical. While there is some evidence that high HS may inhibit empathetic responses to IPV victims by police (Lila et al., 2013), this was in response to a hypothetical scenario; future studies could utilize behavioral indicators of empathy from police records (e.g. offering an advocate or transportation) or linguistic cues from narrative reports.

Relatedly, the first-person narrative accounts written by officers should be further explored. LIWC, with its $90+$ output variables, could be utilized to test a variety of hypotheses. For instance, LIWC's "emotional tone" summary language variable could be used to infer officer's personal reactions at the scene, e.g. some IPV cases may be written about in a more negative tone than others. Racial disparities in the use of "negative emotion" words (e.g. anxiety, sadness) when describing victims may emerge. It will also be essential to test whether experimentally manipulated risk focus in the narratives actually produces stronger perceptions of danger to the victim in a sample of police officers, advocates, or attorneys, and whether this subsequently predicts different outcomes for the handling of these cases, such as shifts in demeanor, the allocation of resources, decisions to prosecute, or effort.

The narratives also offer the opportunity to code for a variety of meaningful linguistic markers. There may be differences in the use of active versus passive voice when describing assaults. Passive voice places the victim in the causal role of the 
sentence (i.e. "she was attacked" vs. "he attacked her"), producing lower attributions of harm to the victim and responsibility of the perpetrator (Henley, Miller, \& Beazley, 1995). To the extent that Black women are seen as more culpable for violence (Esqueda \& Harrison, 2005), a greater ratio of passive-to-active voice when describing IPV perpetrated against Black women, relative to White, might be found. Evidence of the linguistic expectancy bias may also be found when describing IPV suspects. Stereotypeconsistent behavior is described at a higher level of abstraction, while stereotypeinconsistent behavior is described more concretely (Wigboldus, Semin, \& Spears, 2000), resulting in the subtle transmission of stereotypes. For instance, given the stereotype of Black men as violent, their IPV perpetration may be depicted abstractly (e.g. "Tyrone was violent") while a White suspect's may be described in more concrete terms (e.g. "John hit her.") Other more explicit language that blames the victim may be present as well, and should be found to negatively correlate with the use of paternalistic language. Importantly, this study demonstrated that supplemental paperwork was more likely to be missing for Black female IPV victims than White ones, but many potentially important variables (e.g. the charge, visible injuries, children) were not factored into this equation because they were contained in the missing supplemental paperwork itself. Other researchers interested in predicting the filing of supplemental paperwork would be wise to do so in a department with required body cameras. This footage would reveal many contextual factors that might influence the decision to file supplemental forms (e.g. the victim's cooperativeness and emotional state, the severity of visible injuries, the presence of children, etc.), improving on the present study's preliminary efforts to predict 
missing data with an incomplete dataset. Footage from body cameras could also be examined for racial disparities in respectful language (e.g. Voigt et al., 2017), officer tone and demeanor, and victim cooperation.

Other researchers looking to study how the intersection of BS and racial stereotypes plays out in a real-world context may wish to utilize other situations in which women appear in need of assistance. This could take the form of chivalrous helping (e.g. moving something heavy, providing directions, offering rides), paternalistic language (e.g. when women are pregnant or in labor), or preferential treatment (e.g. applications for emergency housing, granting political asylum, online fundraising for medical expenses, reimbursing health insurance claims, triaging patients, performing medical procedures) for White women seeking help. Those wishing to further explore discretionary efforts by police may want to conduct focus groups or surveys with officers to learn which behaviors are seen as optional, rather than relying on official guidelines.

\section{Conclusion}

Benevolent sexism (McMahon \& Kahn, 2016; chapter II) and paternalistic protections (McMahon \& Kahn, 2017; chapter III) favor White women. The current study searched for signs of this disparity in an applied context where women are in need of assistance. Results indicated that police officers responding to IPV might be impacted by a combination of racial stereotypes and benevolent sexism, as evidence of racial disparities was discovered in the filing of supplementary paperwork and in officers' perceptions of risk at the scene, which favored White women. Importantly, no racial disparities were seen in the quality of the IPV investigations once officers decided to file 
the supplemental form, making this a point at which trainings and policies can intervene. This study helps to expand the current understanding of police responses to IPV and contributes to my dissertation work by investigating a context in which the intersection of benevolent sexism and racial stereotypes might have real-world consequences for Black and White women. 


\section{Footnotes}

${ }^{1}$ When these two control variables (victim pain and likelihood of future assault) were included in the analyses, several of the logistic regressions failed to run due to missing data in the covariance matrices. It was also impossible to calculate Cook's Distance values for cases with missing data. Further, the two were not missing completely at random. Officers who did not answer the "victim pain" question also 1) asked fewer victim interview questions ( $M=7.6$ questions vs. $M=9.0$ questions) $[t(236)=6.5, p<.001]$ and 2) wrote shorter narrative reports ( $M=674$ words vs. 770 words) $[t(335)=2.3, p=.02]$. Officers who did not ask the "likely assault" question also 1) asked fewer of the incident detail questions ( $M=4.8$ questions vs. 4.9 questions) $[t(123)=2.1, p=.04]$ and fewer victim interview questions $(M=6.27$ questions vs. 9.3 questions) $[t(120)=13.6 p<.001]$.

${ }^{2}$ When the two precinct dummy control variables were included in the analyses, the model failed to converge and they both had inflated standard errors ( $\mathrm{SE}=22,712.69)$. Alternative solutions to multicollinearity resulted in weaker models: excluding the Precinct $C$ dummy code (rather than Precinct B) produced a marginal model $\left[\chi^{2}(9\right.$, $\mathrm{N}=44)=15.33, p=.08$, Nagelkerke $\mathrm{R}^{2}=.43$ ], while eliminating both dummy codes resulted in a non-significant model $\left[\chi^{2}(8, \mathrm{~N}=44)=9.37, p=.31\right.$, Nagelkerke $\left.\mathrm{R}^{2}=.27\right]$. Regardless of which strategy for multicollinearity was employed, victim race was never a significant predictor of officers conducting a child interview and the overall pattern of results was consistent.

${ }^{3}$ The full set of eleven control variables was not available for this test, as the majority of them were drawn from the supplemental form, and this logistic regression was specifically testing for the presence of the supplemental form.

${ }^{4}$ I also tested whether suspect race moderated Path A of this mediation model. Given the differences in the rates of filing of the supplemental form when the victim was White and the suspect was Black, perceptions of risk at the scene may be influenced by the race of both the suspect and the victim. However, the interaction between suspect and victim race was $n s, B=.04, S E=.06, p=.57$.

${ }^{5}$ Ideally I would have tested whether the relation between victim race and the filing of the supplemental form (Hypothesis 1a) was mediated by risk focus or paternalism. One might expect the higher risk focus for White victims to then predict a greater likelihood of filing the supplemental form. Unfortunately, the risk focus and paternalism variables are drawn directly from the narrative reports, and the narrative reports were only pulled for those cases that had a corresponding supplemental form attached, so I am unable to test these hypotheses.

${ }^{6}$ When "finishing victim interview" was included in the Discretionary Behaviors Scale, the same pattern of results emerged, but with a model explaining less overall variance $\left(\mathrm{R}^{2}=.25\right)$. 
Table 2.0. Dependent variables.

\begin{tabular}{|c|c|c|c|}
\hline Variable & Operationalization & Data Source & Coded/Measured \\
\hline \multirow[t]{2}{*}{$\begin{array}{l}\text { Basic } \\
\text { reporting }\end{array}$} & $\begin{array}{l}\text { Was the supplemental form } \\
\text { included with the Incident } \\
\text { Report? }\end{array}$ & $\begin{array}{l}\text { Presence vs. } \\
\text { absence of the } \\
\text { supplemental } \\
\text { form }\end{array}$ & $\begin{array}{l}\text { By Sergeant's search } \\
\text { through database } \\
\text { records. } \\
0=\text { No, } 1=\text { Yes. }\end{array}$ \\
\hline & $\begin{array}{l}\text { How many of the } 5 \text { questions } \\
\text { about the incident were } \\
\text { adequately answered? }\end{array}$ & $\begin{array}{l}\text { Supplemental } \\
\text { form }\end{array}$ & $\begin{array}{l}\text { Manually, by researcher. } \\
0-5 \text { scale. }\end{array}$ \\
\hline \multirow[t]{6}{*}{$\begin{array}{l}\text { Discretionary } \\
\text { Effort }\end{array}$} & $\begin{array}{l}\text { How many of the Victim } \\
\text { Interview questions were } \\
\text { adequately answered? }\end{array}$ & $\begin{array}{l}\text { Supplemental } \\
\text { form }\end{array}$ & $\begin{array}{l}\text { Manually, by researcher. } \\
0-10 \text { scale. }\end{array}$ \\
\hline & $\begin{array}{l}\text { How long was the officer's } \\
\text { Narrative Report? }\end{array}$ & $\begin{array}{l}\text { Narrative } \\
\text { Report }\end{array}$ & $\begin{array}{l}\text { LIWC } 2015 . \\
\text { Word count. }\end{array}$ \\
\hline & $\begin{array}{l}\text { Were pictures taken at the } \\
\text { scene? }\end{array}$ & $\begin{array}{l}\text { Supplemental } \\
\text { form }\end{array}$ & $\begin{array}{l}\text { Manually, by researcher. } \\
0=\text { No, } 1=\text { Yes. }\end{array}$ \\
\hline & $\begin{array}{l}\text { Were child witnesses } \\
\text { appropriately handled? }\end{array}$ & $\begin{array}{l}\text { Supplemental } \\
\text { form }\end{array}$ & $\begin{array}{l}\text { Manually, by researcher. } \\
0=\text { No, } 1=\text { Yes. }\end{array}$ \\
\hline & $\begin{array}{l}\text { Did the officer provide any } \\
\text { additional resources to the } \\
\text { victim? }\end{array}$ & $\begin{array}{l}\text { Narrative } \\
\text { Report }\end{array}$ & $\begin{array}{l}\text { Manually, by researcher. } \\
0=\text { No, } 1=\text { Yes. }\end{array}$ \\
\hline & $\begin{array}{l}\text { Did the officer (try to) } \\
\text { connect victim with DV } \\
\text { Response Advocate? }\end{array}$ & $\begin{array}{l}\text { Narrative } \\
\text { Report }\end{array}$ & $\begin{array}{l}\text { Manually, by researcher. } \\
0=\text { No, } 1=\text { Yes. }\end{array}$ \\
\hline Risk & $\begin{array}{l}\text { How much danger does the } \\
\text { officer think the victim is in? }\end{array}$ & $\begin{array}{l}\text { Narrative } \\
\text { Report }\end{array}$ & $\begin{array}{l}\text { LIWC 2015. Percentage } \\
\text { of words in "risk focus" } \\
\text { category. }\end{array}$ \\
\hline $\begin{array}{l}\text { Protective } \\
\text { Paternalism }\end{array}$ & $\begin{array}{l}\text { How much does the officer } \\
\text { want to help the victim? }\end{array}$ & $\begin{array}{l}\text { Narrative } \\
\text { Report }\end{array}$ & $\begin{array}{l}\text { LIWC } 2015 . \\
\text { Percentage of words in } \\
\text { new dictionary }\end{array}$ \\
\hline
\end{tabular}


Table 2.1. Control and independent variables

\begin{tabular}{|c|c|c|}
\hline & Coded & Source \\
\hline \multicolumn{3}{|l|}{$\begin{array}{l}\text { Step } 1 \text { of Sequential Regression } \\
\text { (control variables) }\end{array}$} \\
\hline Suspect race & $\begin{array}{l}0=\text { Black } \\
1=\text { White }\end{array}$ & Incident report \\
\hline Suspect age & (in years) & Incident report \\
\hline Victim age & (in years) & Incident report \\
\hline Charge against suspect & $\begin{array}{l}0=\text { Misdemeanor } \\
1=\text { Felony }\end{array}$ & $\begin{array}{l}\text { Supplemental } \\
\text { form }\end{array}$ \\
\hline Visible injury to victim & $\begin{array}{l}0=\mathrm{No} \\
1=\mathrm{Yes}\end{array}$ & $\begin{array}{l}\text { Supplemental } \\
\text { form }\end{array}$ \\
\hline Marital status & $\begin{array}{l}0=\text { Not married } \\
1=\text { Married }\end{array}$ & $\begin{array}{l}\text { Supplemental } \\
\text { form }\end{array}$ \\
\hline Presence of children & $\begin{array}{l}0=\text { Absent } \\
1=\text { Present }\end{array}$ & $\begin{array}{l}\text { Supplemental } \\
\text { form }\end{array}$ \\
\hline Victim cooperation & $\begin{array}{l}0=\text { Cooperative } \\
1=\text { Uncooperative }\end{array}$ & $\begin{array}{l}\text { Narrative } \\
\text { Report }\end{array}$ \\
\hline Victim called & $\begin{array}{l}0=\mathrm{No} \\
1=\mathrm{Yes}\end{array}$ & $\begin{array}{l}\text { Narrative } \\
\text { Report }\end{array}$ \\
\hline Victim's pain level & 1 (mild) to 10 (severe) & $\begin{array}{l}\text { Supplemental } \\
\text { form }\end{array}$ \\
\hline Likelihood of future assault & 1 (low) to 10 (high) & $\begin{array}{l}\text { Supplemental } \\
\text { form }\end{array}$ \\
\hline Precinct & $\begin{array}{l}A=0,0 \\
B=1,0 \\
C=0,1\end{array}$ & $\begin{array}{l}\text { Supplemental } \\
\text { form }\end{array}$ \\
\hline \multicolumn{3}{|l|}{$\begin{array}{l}\text { Step } 2 \text { of Sequential } \\
\text { Regression (IV of int }\end{array}$} \\
\hline Victim race & $\begin{array}{l}0=\text { Black } \\
1=\text { White }\end{array}$ & Incident report \\
\hline
\end{tabular}


Table 2.2. Descriptive frequencies for control and outcome variables

\begin{tabular}{|c|c|c|c|c|c|}
\hline & Freq. & $\%$ & & Freq. & $\%$ \\
\hline \multicolumn{3}{|l|}{ Control Variables } & \multicolumn{3}{|l|}{ Outcomes } \\
\hline \multicolumn{3}{|c|}{ From Incident Reports $(N=512)$ : } & \multicolumn{3}{|l|}{ Supplemental Form } \\
\hline Suspect Race & & & Not filed & 170 & $33 \%$ \\
\hline Black & 188 & $37 \%$ & Filed & 342 & $67 \%$ \\
\hline White & 324 & $63 \%$ & & & \\
\hline \multicolumn{3}{|l|}{ Victim Race } & \multicolumn{3}{|c|}{ From Supplemental Forms $(N=342)$ : } \\
\hline Black & 135 & $26 \%$ & & & \\
\hline \multirow[t]{2}{*}{ White } & 377 & $74 \%$ & Incident details & & \\
\hline & & & Incomplete & 34 & $10 \%$ \\
\hline \multicolumn{3}{|c|}{ From Supplemental Forms $(N=342)$ : } & Complete & 308 & $90 \%$ \\
\hline \multicolumn{3}{|c|}{ Charge } & \multicolumn{3}{|l|}{ Victim Interview } \\
\hline Misdemeanor & 232 & $68 \%$ & Incomplete & 192 & $56 \%$ \\
\hline Felony & 110 & $32 \%$ & Complete & 150 & $44 \%$ \\
\hline \multicolumn{3}{|l|}{ Precinct } & \multicolumn{3}{|l|}{ Photos } \\
\hline A & 71 & $21 \%$ & No & 112 & $33 \%$ \\
\hline B & 154 & $46 \%$ & Yes & 227 & $66 \%$ \\
\hline $\mathrm{C}$ & 110 & $33 \%$ & \multicolumn{3}{|l|}{ Child Interviews } \\
\hline \multicolumn{3}{|l|}{ Marriage status } & No & 15 & $32 \%$ \\
\hline Not married & 249 & $73 \%$ & Yes & 32 & $68 \%$ \\
\hline Married & 93 & $27 \%$ & Resources & & \\
\hline \multicolumn{3}{|l|}{ Children Present } & No & 59 & $17 \%$ \\
\hline No & 295 & $86 \%$ & Yes & 283 & $83 \%$ \\
\hline Yes & 47 & $14 \%$ & Advocate & & \\
\hline \multicolumn{3}{|l|}{ Visible Injuries } & No & 251 & $73 \%$ \\
\hline No & 112 & $33 \%$ & Yes & 91 & $27 \%$ \\
\hline Yes & 227 & $66 \%$ & & & \\
\hline \multicolumn{6}{|l|}{ Uncooperative } \\
\hline No & 306 & $90 \%$ & & & \\
\hline Yes & 36 & $10 \%$ & & & \\
\hline \multicolumn{6}{|l|}{ Victim Called } \\
\hline No & 151 & $44 \%$ & & & \\
\hline Yes & 191 & $56 \%$ & & & \\
\hline
\end{tabular}


Table 2.3. Descriptive statistics for control and outcome variables.

\begin{tabular}{lcccc}
\hline & $M$ & $S D$ & Min & Max \\
\hline Controls & & & & \\
Suspect age & 37.89 & 11.41 & 18 & 67 \\
Victim age & 36.82 & 12.23 & 18 & 87 \\
Outcomes & & & & \\
Incident details & 4.88 & .41 & 2 & 5 \\
Victim interview & 8.41 & 2.01 & 0 & 10 \\
Word count & 728.23 & 395.49 & 153 & 2896 \\
Risk focus & .38 & .29 & 0 & 1.57 \\
Paternalism & .19 & .21 & 0 & 1.31 \\
\hline
\end{tabular}

Note: The values for the Risk focus and Paternalism outcomes represent the percentage of words (not the raw number of words) in the narrative reports that match words found in the Risk focus and Paternalism dictionaries. 
Table 2.4. Results of sequential logistic regression predicting filing of the supplemental form (Hypothesis 1a)

\begin{tabular}{lcccccccc}
\hline & \multicolumn{3}{c}{ Step 1 } & \multicolumn{5}{c}{ Step 2 } \\
\hline Constant & B & SE & Wald & OR & B & SE & Wald & OR \\
Suspect & .36 & .38 & .90 & 1.43 & -.02 & .39 & $<.01$ & .98 \\
Race & & .22 & 2.34 & .72 & $-1.29^{* * *}$ & .37 & 12.02 & .28 \\
Suspect Age & $.04^{* * *}$ & .01 & 14.23 & 1.05 & $.05^{* * *}$ & .01 & 15.53 & 1.05 \\
Victim Age & $<-.01^{* * *}$ & $<.001$ & 22.70 & 1.00 & $-.001^{* * *}$ & $<.001$ & 24.62 & 1.00 \\
Victim Race & & & & & $1.35^{* * *}$ & .39 & 12.34 & 3.86 \\
\hline Omnibus $\chi^{2}$ & $30.84^{* * *}$ & & & & $14.01^{* * *}$ & & & \\
Nagelkerke & .09 & & & & .12 & & & \\
$\mathrm{R}^{2}$ & & & & & & & & \\
$-2 \mathrm{LL}$ & 574.26 & & & & 560.25 & & & \\
\hline
\end{tabular}

$+p<.10, * p<.05, * * p<.01, * * * p<.001$

Table 2.5. Exploratory results of sequential logistic regression predicting filing of the supplemental form.

\begin{tabular}{|c|c|c|c|c|c|c|c|c|}
\hline & \multicolumn{4}{|c|}{ Step 1} & \multicolumn{4}{|c|}{ Step 2} \\
\hline & B & SE & Wald & OR & B & SE & Wald & OR \\
\hline Constant & -.02 & .39 & $<.01$ & .98 & -.12 & .40 & .09 & .89 \\
\hline $\begin{array}{l}\text { Suspect } \\
\text { Race }\end{array}$ & $-1.29 * * *$ & .37 & 12.02 & .82 & -.29 & .67 & .19 & .75 \\
\hline Victim Race & $1.35^{* * *}$ & .39 & 12.34 & 3.86 & $1.97 * * *$ & .57 & 12.11 & 7.13 \\
\hline Suspect Age & $.05 * * *$ & .01 & 15.53 & 1.05 & $.05 * * *$ & .01 & 15.20 & 1.05 \\
\hline Victim Age & $<-.01 * * *$ & $<.001$ & 24.62 & 1.00 & $\begin{array}{c}<- \\
.01 * * *\end{array}$ & $<.001$ & 23.85 & 1.00 \\
\hline Race*Race & & & & & $-.12+$ & .40 & .09 & .21 \\
\hline Omnibus $\chi^{2}$ & $44.85^{* * *}$ & & & & $3.53+$ & & & \\
\hline $\begin{array}{l}\text { Nagelkerke } \\
\mathrm{R}^{2}\end{array}$ & .12 & & & & .13 & & & \\
\hline$-2 \mathrm{LL}$ & 560.25 & & & & 556.72 & & & \\
\hline
\end{tabular}

$+p<.10, * p<.05, * * p<.01, * * * p<.001$ 
Table 2.6. Testing the moderating effect of suspect race on the relation between victim race and filing the supplemental form.

\begin{tabular}{lccc}
\hline & $\mathrm{b}$ & $\mathrm{SE}$ & $\mathrm{z}$ \\
\hline Suspect Race & -.29 & .67 & -.44 \\
Victim Race & $1.96^{* * *}$ & .56 & 3.48 \\
Suspect Age & $.05^{* * *}$ & .01 & 3.90 \\
Victim Age & $<.001^{* * *}$ & $<.001$ & -4.88 \\
Race*Race & $-1.56+$ & .86 & -1.81 \\
Conditional effect: & & & \\
$\quad$ Black suspect & $1.96 * * *$ & .56 & 3.48 \\
$\quad$ White suspect & .41 & .65 & .62 \\
\hline
\end{tabular}

$+p<.10, * p<.05, * * p<.01, * * * p<.001$

Table 2.7. Results of sequential logistic regression predicting completed incident details (Hypothesis 1b)

\begin{tabular}{lcccccccc}
\hline & \multicolumn{4}{c}{ Step 1 } & \multicolumn{5}{c}{ Step 2 } \\
\hline & B & SE & Wald & OR & B & SE & Wald & OR \\
\hline Constant & $2.42^{* *}$ & .90 & 7.18 & 11.25 & $2.71^{* *}$ & .95 & 8.90 & 15.00 \\
Suspect Race & -.08 & .41 & .03 & .93 & .29 & .51 & .32 & 1.33 \\
Suspect Age & $<.001$ & .03 & .02 & 1.00 & $<.001$ & .03 & $<.001$ & 1.00 \\
Victim Age & -.01 & .03 & .18 & .99 & -.01 & .03 & .05 & .99 \\
Charge & -.30 & .43 & .48 & .74 & -.33 & .44 & .58 & .72 \\
Precinct B & -.68 & .50 & 1.89 & .51 & -.69 & .50 & 1.91 & .50 \\
Precinct C & .51 & .64 & .64 & .43 & .49 & .64 & .58 & 1.62 \\
Married & -.30 & .43 & .47 & .49 & -.33 & .43 & .59 & .72 \\
Children Present & .49 & .49 & .97 & 1.63 & .48 & .50 & .95 & 1.62 \\
Visible Injury & .26 & .39 & .46 & .50 & .31 & .40 & .62 & 1.36 \\
Uncooperative & -.75 & .53 & 2.02 & .47 & -.84 & .54 & 2.43 & .43 \\
Victim Called & .60 & .40 & 2.27 & 1.82 & .60 & .40 & 2.27 & 1.83 \\
Victim Race & & & & & -.67 & .60 & 1.22 & .51 \\
\hline Omnibus $\chi^{2}$ & 13.86 & & & & 1.25 & & & \\
Nagelkerke R ${ }^{2}$ & .09 & & & & .09 & & & \\
-2LL & 202.57 & & & & 201.31 & & & \\
\hline
\end{tabular}

$+p<.10, * p<.05, * * p<.01, * * * p<.001$ 
Table 2.8. Results of sequential multiple regression predicting number of victim interview questions answered (Hypothesis 2a)

\begin{tabular}{|c|c|c|c|c|c|c|c|c|}
\hline & \multicolumn{4}{|c|}{ Step 1} & \multicolumn{4}{|c|}{ Step 2} \\
\hline & B & $\mathrm{SE}$ & $\beta$ & $\mathrm{t}$ & $\mathrm{B}$ & SE & $\beta$ & $\mathbf{t}$ \\
\hline Constant & $73.00 * * *$ & 6.55 & & 11.15 & $73.55 * * *$ & 6.69 & & 10.99 \\
\hline Suspect Race & 2.77 & 2.82 & .05 & .98 & 3.77 & 3.72 & .07 & 1.01 \\
\hline Suspect Age & -.01 & .18 & $<-.01$ & -.04 & -.01 & .18 & $<-.01$ & -.06 \\
\hline Victim Age & .16 & .18 & .07 & .87 & .17 & .19 & .07 & .90 \\
\hline Charge & -.07 & 3.18 & $<-.01$ & -.02 & -.19 & 3.20 & $<-.01$ & -.06 \\
\hline Precinct B & -4.03 & 3.54 & -.08 & -1.14 & -4.06 & 3.55 & -.08 & -1.14 \\
\hline Precinct $\mathrm{C}$ & 4.08 & 3.82 & .08 & 1.07 & 4.02 & 3.83 & .08 & 1.05 \\
\hline Married & -.81 & 3.19 & -.01 & -.25 & -.87 & 3.20 & -.02 & -.27 \\
\hline Children Present & 1.60 & 3.42 & .03 & .47 & 1.62 & 3.42 & .03 & .47 \\
\hline Visible Injury & 2.35 & 2.78 & .04 & .85 & 2.49 & 2.81 & .05 & .89 \\
\hline Uncooperative & $-41.08 * * *$ & 4.87 & -.44 & -8.43 & $-41.39 * * *$ & 4.94 & -.45 & -8.38 \\
\hline Victim Called & -1.04 & 2.80 & -.02 & -.37 & -1.00 & 2.80 & -.02 & -.36 \\
\hline Victim Race & & & & & -1.68 & 4.08 & -.03 & -.41 \\
\hline Total $\mathrm{R}^{2}$ & .21 & & & & .21 & & & \\
\hline$\Delta \mathrm{R}^{2}$ & .21 & & & & .00 & & & \\
\hline$\Delta F$ & $7.40 * * *$ & & & & .17 & & & \\
\hline
\end{tabular}

Table 2.9. Results of sequential logistic regression predicting a completed victim interview (Hypothesis 2a)

\begin{tabular}{|c|c|c|c|c|c|c|c|c|}
\hline & \multicolumn{4}{|c|}{ Step 1} & \multicolumn{4}{|c|}{ Step 2} \\
\hline & B & SE & Wald & OR & $\mathrm{B}$ & SE & Wald & OR \\
\hline Constant & -.54 & .58 & .90 & .58 & -.42 & .59 & .52 & .66 \\
\hline Suspect Race & .03 & .25 & .02 & 1.04 & .21 & .32 & .44 & 1.24 \\
\hline Suspect Age & .01 & .02 & .21 & 1.01 & .01 & .02 & .16 & 1.01 \\
\hline Victim Age & $<-.01$ & .02 & .06 & 1.00 & $<.01$ & .02 & .03 & 1.00 \\
\hline Charge & -.10 & .28 & .12 & .91 & -.12 & .28 & .19 & .89 \\
\hline Precinct B & .12 & .31 & .14 & 1.12 & .12 & .31 & .14 & 1.12 \\
\hline Precinct $\mathrm{C}$ & .51 & .33 & 2.29 & 1.66 & .50 & .33 & 2.21 & 1.64 \\
\hline Married & -.08 & .28 & .07 & .93 & -.09 & .28 & .10 & .92 \\
\hline Children Present & .33 & .30 & 1.19 & 1.38 & .32 & .30 & 1.18 & 1.38 \\
\hline Visible Injury & .25 & .24 & 1.11 & 1.29 & .28 & .24 & 1.32 & 1.32 \\
\hline Uncooperative & $-3.49 * * *$ & 1.03 & 11.45 & .03 & $-3.55 * * *$ & 1.04 & 11.78 & .03 \\
\hline Victim Called & -.26 & .24 & 1.13 & .77 & -.25 & .24 & 1.10 & .78 \\
\hline Victim Race & & & & & -.31 & .36 & .76 & .73 \\
\hline Omnibus $\chi^{2}$ & $35.50 * * *$ & & & & .77 & & & \\
\hline Nagelkerke $\mathrm{R}^{2}$ & .14 & & & & .14 & & & \\
\hline$-2 \mathrm{LL}$ & 422.84 & & & & 422.08 & & & \\
\hline
\end{tabular}


Table 2.10. Results of sequential multiple regression predicting narrative length (in word count) (Hypothesis 2b)

\begin{tabular}{|c|c|c|c|c|c|c|c|c|}
\hline & \multicolumn{4}{|c|}{ Step 1} & \multicolumn{4}{|c|}{ Step 2} \\
\hline & $\mathrm{B}$ & SE & $\beta$ & $\mathrm{t}$ & $\mathrm{B}$ & SE & $\beta$ & $\mathrm{t}$ \\
\hline Constant & $2.88 * * *$ & .05 & & 59.61 & $2.88 * * *$ & .05 & & 58.70 \\
\hline Suspect Race & .03 & .02 & .07 & 1.35 & .05 & .03 & .11 & 1.57 \\
\hline Suspect Age & $<-.01 *$ & $<-.01$ & -.19 & -2.52 & $<-.01 *$ & $<.01$ & -.20 & -2.54 \\
\hline Victim Age & $<-.001$ & $<-.01$ & -.01 & -.09 & $<-.001$ & $<.01$ & $<-.001$ & -.04 \\
\hline Charge & $.13^{* * *}$ & .02 & .32 & 5.64 & $.13 * * *$ & .02 & .31 & 5.54 \\
\hline Precinct B & -.02 & .03 & -.05 & -.68 & -.02 & .03 & -.05 & -.68 \\
\hline Precinct C & .02 & .03 & .04 & .61 & .02 & .03 & .04 & .58 \\
\hline Married & $<.01$ & .02 & -.01 & -.12 & $<.-.01$ & .02 & -.01 & -.18 \\
\hline Children Present & .01 & .03 & .02 & .40 & .01 & .03 & .03 & .41 \\
\hline Visible Injury & $.03+$ & .02 & .09 & 1.67 & $.04+$ & .02 & .09 & 1.75 \\
\hline Uncooperative & $-.13 * * *$ & .03 & -.21 & -3.97 & $-.15 * * *$ & .03 & -.21 & -4.04 \\
\hline Victim Called & -.01 & .02 & -.03 & -.62 & -.01 & .02 & -.03 & -.58 \\
\hline Victim Race & & & & & -.03 & .03 & -.06 & -.85 \\
\hline Total $\mathrm{R}^{2}$ & .22 & & & & .22 & & & \\
\hline$\Delta \mathrm{R}^{2}$ & .22 & & & & $<.01$ & & & \\
\hline$\Delta F$ & $7.76^{* * *}$ & & & & .73 & & & \\
\hline
\end{tabular}

Table 2.11. Results of sequential logistic regression predicting officers taking photographic evidence (Hypothesis 2c)

\begin{tabular}{|c|c|c|c|c|c|c|c|c|}
\hline & \multicolumn{4}{|c|}{ Step 1} & \multicolumn{4}{|c|}{ Step 2} \\
\hline & B & $\mathrm{SE}$ & Wald & OR & B & $\mathrm{SE}$ & Wald & OR \\
\hline Constant & -.72 & 1.43 & .25 & .49 & .73 & 1.45 & .25 & .48 \\
\hline Suspect Race & $-1.73 * *$ & .65 & 7.17 & .12 & $-1.76+$ & .92 & 3.66 & .17 \\
\hline Suspect Age & .02 & .04 & .19 & .66 & .02 & .04 & .19 & 1.02 \\
\hline Victim Age & -.05 & .04 & 1.34 & .95 & -.05 & .04 & 1.34 & .95 \\
\hline Charge & -.20 & .66 & .10 & .82 & -.21 & .66 & .10 & .81 \\
\hline Precinct B & 1.06 & .81 & 1.69 & 2.87 & 1.06 & .81 & 1.69 & 2.88 \\
\hline Precinct $\mathrm{C}$ & -1.18 & .89 & 1.74 & .31 & -1.18 & .89 & 1.73 & .31 \\
\hline Married & -.69 & .74 & .87 & .50 & -.68 & .74 & .84 & .51 \\
\hline Children Present & .48 & .69 & .50 & 1.62 & .48 & .69 & .49 & 1.62 \\
\hline Visible Injury & $7.14 * * *$ & .89 & 64.28 & 1265.09 & $7.14 * * *$ & .89 & 63.92 & 1261.37 \\
\hline Uncooperative & .54 & 1.59 & .12 & 1.72 & .55 & 1.59 & .12 & 1.73 \\
\hline Victim Called & .68 & .60 & 1.26 & 1.97 & .68 & .61 & 1.25 & 1.97 \\
\hline Victim Race & & & & & .04 & .92 & $<.01$ & 1.04 \\
\hline Omnibus $\chi^{2}$ & $\begin{array}{c}268.90^{*} \\
* *\end{array}$ & & & & $<.01$ & & & \\
\hline Nagelkerke $\mathrm{R}^{2}$ & .84 & & & & .84 & & & \\
\hline$-2 \mathrm{LL}$ & 93.75 & & & & 93.75 & & & \\
\hline
\end{tabular}

$+p<.10, * p<.05, * * p<.01, * * * p<.001$ 
Table 2.12. Results of sequential logistic regression predicting child interview (Hypothesis 2d)

\begin{tabular}{|c|c|c|c|c|c|c|c|c|}
\hline & \multicolumn{4}{|c|}{ Step 1} & \multicolumn{4}{|c|}{ Step 2} \\
\hline & $\mathrm{B}$ & SE & Wald & OR & $\mathrm{B}$ & $\mathrm{SE}$ & Wald & OR \\
\hline Constant & 3.08 & 2.49 & 2.34 & 45.02 & 3.72 & 2.50 & 2.22 & 41.38 \\
\hline Suspect Race & -.23 & 1.13 & .04 & .79 & 1.16 & 2.30 & .25 & 3.19 \\
\hline Suspect Age & -.12 & .11 & 1.18 & .88 & -.14 & .12 & 1.36 & .89 \\
\hline Victim Age & .16 & .12 & 1.63 & 1.17 & .18 & .13 & 1.87 & 1.20 \\
\hline Charge & -.98 & 1.30 & .57 & .38 & -.64 & 1.39 & .21 & .53 \\
\hline Precinct C & $-3.56^{* *}$ & 1.42 & 6.30 & .03 & $-3.50 * *$ & 1.43 & 5.99 & .03 \\
\hline Married & $-2.79+$ & 1.53 & 3.34 & .06 & $-3.01+$ & 1.59 & 3.57 & .05 \\
\hline Visible Injury & .93 & 1.27 & .53 & 2.52 & .68 & 1.37 & .25 & 1.98 \\
\hline Uncooperative & .58 & 1.80 & .11 & 1.79 & .22 & 1.91 & .01 & 1.25 \\
\hline Victim Called & -.37 & .97 & .15 & .69 & -.15 & 1.03 & .02 & .86 \\
\hline Victim Race & & & & & -1.56 & 2.27 & .47 & .21 \\
\hline Omnibus $\chi^{2}$ & $20.54 * *$ & & & & .48 & & & \\
\hline Nagelkerke $\mathrm{R}^{2}$ & .53 & & & & .54 & & & \\
\hline$-2 L L$ & 32.88 & & & & 32.39 & & & \\
\hline
\end{tabular}

Table 2.13. Results of sequential logistic regression predicting the giving of informational resources to the victim (Hypothesis 2e)

\begin{tabular}{|c|c|c|c|c|c|c|c|c|}
\hline & \multicolumn{4}{|c|}{ Step 1} & \multicolumn{4}{|c|}{ Step 2} \\
\hline & B & SE & Wald & OR & B & SE & Wald & OR \\
\hline Constant & $3.85^{* * *}$ & 1.20 & 10.25 & 46.82 & $3.61 * *$ & 1.23 & 8.60 & 37.10 \\
\hline Suspect Race & $-2.02 * *$ & .65 & 9.69 & .13 & $-2.46^{* *}$ & .96 & 6.62 & .09 \\
\hline Suspect Age & .03 & .03 & .74 & 1.03 & .03 & .03 & .80 & 1.03 \\
\hline Victim Age & .03 & .03 & .79 & 1.03 & .03 & .03 & .70 & 1.03 \\
\hline Charge & -.05 & .50 & .01 & .95 & -.01 & .50 & $<.01$ & .99 \\
\hline Precinct B & -.24 & .55 & .19 & .79 & -.21 & .56 & .15 & .81 \\
\hline Precinct C & -.33 & .58 & .33 & .72 & -.32 & .58 & .31 & .73 \\
\hline Married & -.16 & .52 & .09 & .86 & -.18 & .52 & .12 & .83 \\
\hline Children Present & .35 & .55 & .41 & 1.42 & .34 & .55 & .38 & 1.41 \\
\hline Visible Injury & $-1.26^{*}$ & .53 & 5.66 & .29 & $-1.29 *$ & .53 & 5.93 & .28 \\
\hline Victim Called & $-1.47 * *$ & .50 & 8.60 & .23 & $-1.46^{* *}$ & .50 & 8.57 & .23 \\
\hline Victim Race & & & & & .70 & 1.00 & .49 & 2.02 \\
\hline Omnibus $\chi^{2}$ & $34.81 * * *$ & & & & .50 & & & \\
\hline Nagelkerke $\mathrm{R}^{2}$ & .23 & & & & .23 & & & \\
\hline$-2 L L$ & 162.52 & & & & 162.01 & & & \\
\hline
\end{tabular}


Table 2.14. Results of sequential logistic regression predicting the offering of a DV advocate (Hypothesis 2f)

\begin{tabular}{lcccccccc}
\hline & \multicolumn{4}{c}{ Step 1 } & \multicolumn{5}{c}{ Step 2 } \\
\hline Constant & B & SE & Wald & OR & B & SE & Wald & OR \\
Suspect Race & $-1.26+$ & .72 & 3.07 & .28 & $-1.39+$ & .74 & 3.53 & .25 \\
Suspect Age & -.42 & .29 & 2.05 & .66 & -.60 & .37 & 2.62 & .55 \\
Victim Age & $-.06^{* *}$ & .02 & 9.42 & 1.06 & $.06^{* *}$ & .02 & 9.69 & 1.06 \\
Charge & .39 & .02 & 8.29 & .94 & $-.06^{* *}$ & .02 & 8.52 & .94 \\
Precinct B & -.61 & .38 & 1.52 & 1.47 & .41 & .32 & 1.67 & 1.51 \\
Precinct C & -.15 & .39 & .16 & .86 & -.14 & .39 & .13 & .87 \\
Married & -.44 & .35 & 1.58 & .64 & -.43 & .35 & 1.49 & .65 \\
Children Present & $1.05 * *$ & .35 & 8.76 & 2.85 & $1.06 * *$ & .36 & 8.92 & 2.90 \\
Visible Injury & $.58+$ & .30 & 3.63 & 1.78 & $.55+$ & .31 & 3.31 & 1.74 \\
Uncooperative & $-1.53^{*}$ & .68 & 5.02 & .22 & $-1.48^{*}$ & .69 & 4.66 & .23 \\
Victim Called & -.43 & .29 & 2.13 & .65 & -.45 & .30 & 2.29 & .64 \\
Victim Race & & & & & .32 & .41 & .62 & 1.38 \\
\hline Omnibus $\chi^{2}$ & $40.87 * * *$ & & & & .62 & & & \\
Nagelkerke R & .18 & & & & .19 & & & \\
-2 LL & 321.29 & & & & 320.66 & & &
\end{tabular}

Table 2.15. Results of multiple linear regression predicting risk focus in the narrative reports (Hypothesis 3)

\begin{tabular}{|c|c|c|c|c|}
\hline & B & SE & $\beta$ & $t$ \\
\hline Constant & .67 & .03 & & 17.63 \\
\hline Suspect Race & -.02 & .02 & -.07 & -.98 \\
\hline Victim Race & $.05^{*}$ & .02 & .15 & 2.04 \\
\hline Suspect Age & $<.01$ & $<.01$ & $<.01$ & .01 \\
\hline Victim Age & $<.01$ & $<.01$ & .01 & .15 \\
\hline Charge & -.01 & .02 & -.02 & -.27 \\
\hline Precinct B & $.06 * *$ & .02 & .22 & 3.06 \\
\hline Precinct C & .04 & .02 & .12 & 1.64 \\
\hline Married & .02 & .02 & .06 & 1.05 \\
\hline Children Present & -.02 & .02 & -.07 & -1.10 \\
\hline Visible Injury & .02 & .02 & .08 & 1.44 \\
\hline Uncooperative & -.02 & .03 & -.04 & -.63 \\
\hline Victim Called & .03 & .02 & .09 & 1.57 \\
\hline
\end{tabular}


Table 2.16. Results of sequential multiple regression predicting protective paternalism in the narrative reports (Hypothesis 4)

\begin{tabular}{|c|c|c|c|c|c|c|c|c|}
\hline & \multicolumn{4}{|c|}{ Step 1} & \multicolumn{4}{|c|}{ Step 2} \\
\hline & $\mathrm{B}$ & $\mathrm{SE}$ & $\beta$ & $\mathrm{t}$ & $\mathrm{B}$ & SE & $\beta$ & $\mathrm{t}$ \\
\hline Constant & .91 & .03 & & 28.33 & .92 & .03 & & 27.70 \\
\hline Suspect Race & -.01 & .01 & -.03 & -.57 & $<-.01$ & .02 & -.01 & -.19 \\
\hline Suspect Age & $<-.01$ & $<.01$ & -.07 & -.93 & $<-.01$ & $<.01$ & -.08 & -.96 \\
\hline Victim Age & $<.001$ & $<.01$ & .01 & .06 & $<.001$ & $<.01$ & .01 & .10 \\
\hline Charge & $<-.01$ & .02 & $<-.01$ & -.07 & $<-.01$ & .02 & $<-.01$ & -.11 \\
\hline Precinct B & -.02 & .02 & -.07 & -.98 & -.02 & .02 & -.07 & -.98 \\
\hline Precinct C & -.01 & .02 & -.04 & -.50 & -.01 & .02 & -.04 & -.51 \\
\hline Married & .01 & .02 & .03 & .43 & .01 & .02 & .02 & .41 \\
\hline Children Present & $-.04 *$ & .02 & -.15 & -2.28 & $-.04 *$ & .02 & -.15 & -2.27 \\
\hline Visible Injury & $.03 *$ & .01 & .12 & 2.06 & $.03 *$ & .01 & .12 & 2.08 \\
\hline Uncooperative & .02 & .02 & .06 & 1.01 & .02 & .02 & .06 & .97 \\
\hline Victim Called & -.01 & .01 & -.05 & -.83 & -.01 & .01 & -.05 & -.82 \\
\hline Victim Race & & & & & -.01 & .02 & -.03 & -.38 \\
\hline Total $\mathrm{R}^{2}$ & .05 & & & & .05 & & & \\
\hline$\Delta \mathrm{R}^{2}$ & .05 & & & & $<.01$ & & & \\
\hline$\Delta F$ & 1.57 & & & & .15 & & & \\
\hline
\end{tabular}

Table 2.17. Results of supplemental sequential multiple regression predicting number of discretionary behaviors at the scene

\begin{tabular}{lcccccccc}
\hline & \multicolumn{3}{c}{ Step 1 } & \multicolumn{5}{c}{ Step 2 } \\
\hline & $\mathrm{B}$ & $\mathrm{SE}$ & $\beta$ & $\mathrm{t}$ & $\mathrm{B}$ & $\mathrm{SE}$ & $\beta$ & $\mathrm{t}$ \\
\hline Constant & $1.44^{* * *}$ & .17 & & 8.33 & $1.44^{* * *}$ & .18 & & 7.96 \\
Suspect Race & $-.30^{* * *}$ & .08 & -.19 & -3.93 & $-.33^{* * *}$ & .10 & -.21 & -3.34 \\
Suspect Age & $.01^{*}$ & .01 & .16 & 2.29 & $.01 *$ & .01 & .16 & 2.32 \\
Victim Age & -.01 & .01 & -.11 & -1.06 & -.01 & .01 & -.11 & -1.63 \\
Charge & -.02 & .08 & -.01 & -.18 & -.01 & .08 & -.01 & -.14 \\
Precinct B & -.04 & .09 & -.03 & -.46 & -.04 & .09 & -.03 & -.45 \\
Precinct C & -.09 & .10 & -.06 & -.88 & -.09 & .10 & -.06 & -.85 \\
Married & -.11 & .08 & -.07 & -1.34 & -.11 & .08 & -.07 & -1.32 \\
Children Present & $.25 * *$ & .09 & .16 & 2.69 & $.25 * *$ & .09 & .16 & 2.69 \\
Visible Injury & $.73 * * *$ & .08 & .47 & 9.69 & $.72 * * *$ & .08 & .46 & 9.55 \\
Uncooperative & -.22 & .12 & -.09 & -1.79 & -.21 & .12 & -.09 & -1.72 \\
Victim Called & -.12 & .07 & -.08 & -1.60 & -.12 & .07 & -.08 & -1.62 \\
Victim Race & & & & & .05 & .11 & .03 & .47 \\
\hline Total R ${ }^{2}$ & .31 & & & & .31 & & & \\
$\Delta \mathrm{R}^{2}$ & .31 & & & & $<.01$ & & & \\
$\Delta F$ & 12.64 & & & & .22 & & & \\
\hline$+p<.10, * p<.05, * *$ & $*<.01, * * * p<.001$ & & & & & &
\end{tabular}


Table 2.18. Result summary

\begin{tabular}{rlc}
\hline Hypothesis & Supported & Finding \\
\hline Basic reporting hypotheses & \\
\hline
\end{tabular}

1a: Officers will be as likely to file the supplemental form for White victims as for Black victims.

$\mathrm{X}$

Odds of filing increased nearly 4 times when the victim was White; relative risk for Black women 1.17 times higher than White. Filing most likely when suspect also Black (93\% probability). Power $\leq .97$.

1b: Officers will gather the same amount of basic information about the IPV incident (by answering the five incident questions on the supplemental form) for Black and White female victims of IPV.

X Model $n s$. Victim race $n s$.

Power $\leq .41$.

Discretionary effort hypotheses

2a: More of the victim interview questions will be answered when the victim is White than when she is Black.

$\mathrm{X} \quad$ Victim race $n s$. Power $=.99$.

2b: Narratives will be longer (i.e. have a greater word count) when the victim is White than when she is Black.

$\mathrm{X} \quad$ Victim race $n s$. Power $=.99$.

2c: Officers are more likely to collect photographic evidence when the victim is White than when she is Black.

$\mathrm{X} \quad$ Victim race $n s$. Power $\leq .05$.

2d: Child witnesses (ages 5-18) are more likely to be interviewed by the officer (rather than ignored or referred elsewhere) $\mathrm{X} \quad$ Victim race $n s$. Power $\leq .35$. when the victim is White than Black.

2e: Officers are more likely to provide additional resources for White victims than Black victims.

$\mathrm{X} \quad$ Victim race $n s$. Power $\leq .38$.

2f: Officers are more likely to attempt to set up DV Response Advocates for White victims than Black victims.

$\mathrm{X} \quad$ Victim race $n s$. Power $\leq .13$. 
Table 2.18. Result summary cont.

\section{Linguistic hypotheses}

3: Narrative reports will be written with a stronger "risk focus" when a) the victim is White and/or b) the suspect is Black

4: A greater number of words suggesting protective paternalism will be used when writing about White victims than Black victims.

5: "Risk focus" will mediate the relation between a) victim race or b) suspect race and paternalism. $\checkmark \quad$ Narratives written with a stronger "risk focus" when the victim was White.

Power $=.99$.

X Model $n s$. Victim race $n s$. Power $=.99$.

When the victim was White, officers wrote with a stronger risk focus, which then predicted greater paternalism. 
Figure 3.0. Mediation model (Hypothesis 5)

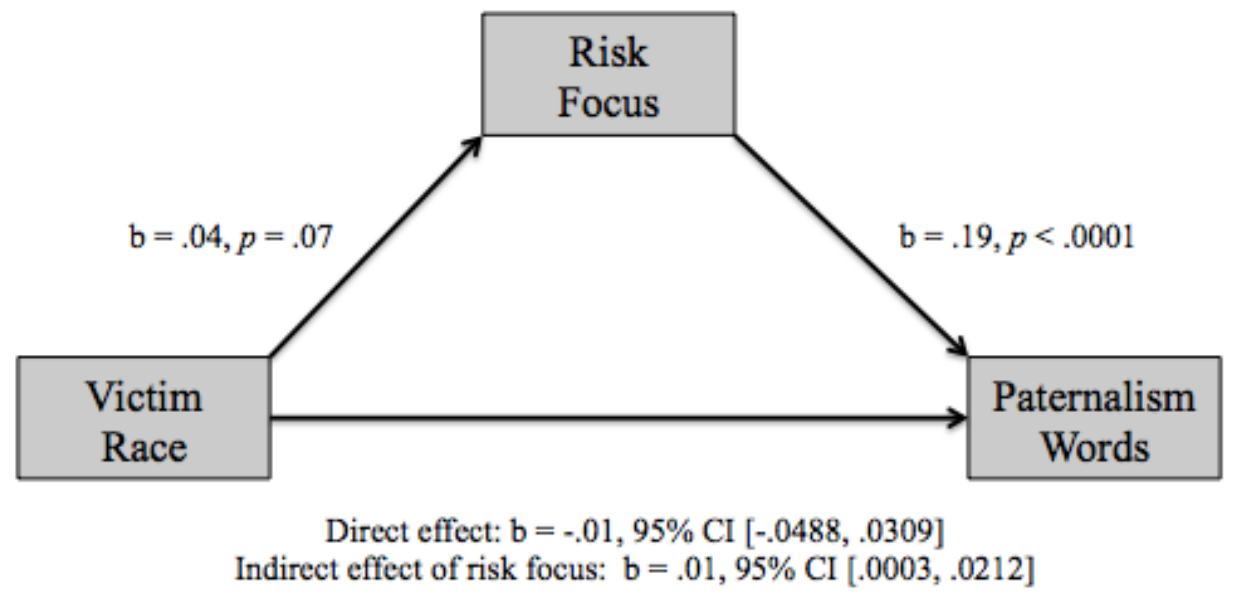

Note: Based on 5000 bootstrap samples. Covariates include suspect age, suspect race, victim age, charge, children present, precinct $B$, precinct $C$, married, visible injury, uncooperative, and victim called. $\mathrm{R}^{2}=.10$. 


\section{CHAPTER V. DISCUSSION}

This dissertation investigated how racial stereotypes inform the targets, function, and consequences of benevolent sexism. Across three manuscripts and five studies, race was integrated into ambivalent sexism theory for the first time (to my knowledge), demonstrating how benevolent sexism, a seemingly positive ideology depicting women as pure and defenseless, is also racialized. Findings from these three manuscripts demonstrate how research regarding ambivalent sexism benefits from simultaneously considering multiple categories of social identity, both in laboratory studies and in the field, which will hopefully inspire future research on intersectional prejudice.

\section{Contributions}

Prejudice is most commonly understood as an antipathy toward some social group (Allport, 1954), yet women as a whole are simultaneously adored and condemned. Glick and Fiske (1996) developed ambivalent sexism theory to explain how sexism is instead a "special case of prejudice marked by a deep ambivalence" (p. 491) with both hostile and benevolent components. While a successful framework for understanding gender bias (Glick, et al., 2000), this theory has relied on women's traditional versus non-traditional behavior to inform whether they are treated with HS or BS, largely neglecting how other social identities interact with gender to produce different outcomes for women. The primary contribution of this dissertation was to introduce race into this framework, thereby producing a more intersectional understanding of prejudice.

This dissertation began by asking how race impacts who is a target of benevolent sexism at the interpersonal level. It has long been established that BS is directed at 
women who conform to traditional norms of their gender by being homemakers, wives, and mothers (Glick, Diebold, Baily-Werner, \& Zhu, 1997) or chaste (Sibley \& Wilson, 2004), yet in the absence of behavior cues to elicit subtyping, racial stereotypes of White and Black women were found to influence perceptions of female targets. Across two experiments (McMahon \& Kahn, 2016; chapter II), I determined that BS is more strongly associated with White women than Black women, suggesting White women are the primary targets of benevolent sexism, when devoid of other information.

At the societal level, the function of BS is to encourage women to remain in subordinate positions (relative to men) by offering rewards such as male affection, security, and approval (Glick \& Fiske, 2001). In the second part of this dissertation (McMahon \& Kahn, 2017; chapter III), I focused on how the protective paternalism subcomponent of BS was related to racial bias, given that the stated goal of protecting White women from racial minority men is a common pretext for violence. Not only was paternalism correlated with several measures of anti-Black prejudice among White participants (study 1), but when men were threatened, they increased their endorsement of paternalism, which then bolstered anti-racial minority attitudes, particularly when they were White (study 2). This indicates that another function of BS at the societal level is to promote and perpetuate racial inequality.

Finally, in an effort to bring these findings out of the lab and into a naturalistic setting, I tested for possible consequences of the differential application of BS to White and Black women (seen in chapter II) and racialized paternalistic protections of women (found in chapter III) in a real world applied context where women require help—when 
police are responding to an IPV incident involving a female victim and a male perpetrator. The independent effects of victim race were tested, controlling for all available and relevant variables (e.g. age, suspect race, marriage status, the presence of children, visible injuries, etc.) While unable to measure BS directly, behaviors at the scene were consistent with my previous work, with the odds of police properly investigating IPV incidents involving White female victims (by filing supplemental paperwork) nearly four times greater than Black ones (with missing forms 1.17 times more likely for Black women), particularly when her assailant was a Black man. Officers also wrote about White women with a stronger risk focus in their narrative reports, suggesting they were perceived as being in more danger. Results from this cross-sectional analysis of official police records suggest that one possible consequence of the intersection of benevolent sexism and racial stereotypes is that violence (here, IPV) against White women is treated as more worthy of police time and attention (i.e. is more thoroughly investigated), especially when caused by a racial minority male, while violence against Black women may be more disregarded, with the missing paperwork having potential negative consequences for future investigation, advocacy, and prosecution.

The paternalism dictionary I created for the third study represents the first time (to my knowledge) that a linguistic analysis of BS has utilized a new dictionary of terms to capture this construct. Using LIWC, others have demonstrated that men higher in BS use more positive words when interacting with women (Goh \& Hall, 2015); this dictionary allowed for the measurement of the protective paternalism subcomponent in particular. While police reports might not have the highest incidents of such words (producing the 
floor effect seen in Study 3), this new dictionary may be of use to others exploring verbal expressions of benevolent sexism. Of primary interest will be further establishing the construct validity of this measure. Using three raters to judge whether each word proposed during Phase 1 matched the construct during Phase 2 supports the content validity of this new measure (see Appendix C). Convergent validity was also demonstrated by the paternalism dictionary's positive correlation with the LIWC risk focus dictionary, as these two constructs (a perception of danger and a desire to help) should theoretically be related. Additional steps should be taken to further support this measure's construct validity. Convergent validity could be further established by correlating an individuals' endorsement of protective paternalism (as measured by the four items in the Ambivalent Sexism Inventory) with the frequency of paternalism words used in their writings about women. Substantive evidence could come from the comparison of theoretically distinct groups: just as professors should score higher than blue-collar workers on a Need for Cognition scale, so too should a greater percentage of paternalism words be seen in speeches by conservative politicians than liberal ones, or in romance novels than in cookbooks. The use of paternalism words will then want to be correlated with perceptions of the speaker and subsequent behaviors, as paternalistic justifications can lead women, especially those already high in BS, to accept restrictions on their behavior (Moya, Glick, Esposito, de Lemus, \& Hart, 2007).

Another contribution is the way in which this dissertation utilizes the full-cycle model (Mortenson \& Cialdini, 2010). This model advocates moving cyclically and bidirectionally between naturalistic observation, theory, and experimentation to promote 
valid research. The methodological strengths of each step compensate for the weaknesses in others, when combined into a coherent overall line of research. Validity is never the achievement of a single research project, but rather the product of systematic testing and application. In the first study (chapter II), observations from purity culture (Valenti, 2009) and Black feminist thought (Davis, 1983; hooks, 1981; Hull, Bell Scott, \& Smith, 1982) were viewed through an ambivalent sexism lens, leading to the testing of differential applications of BS and HS to White and Black targets. These two experiments were designed to corroborate theory and determine causality, establishing internal validity. Similarly, countless examples of the historical link between racism and protecting White women prompted an experiment to better understand these causal, mediating, and moderating processes (chapter III). Here, ecological validity was promoted through the use of a straightforward manipulation of a news article, while "anti-racial minority attitudes" were operationalized six different ways, bolstering construct validity. From there, these findings were verified in an applied setting with realworld consequences (chapter IV), demonstrating ecological validity. In following the full-cycle model, basic theory is advanced, pressing social concerns are addressed, and our doctoral program's goal of utilizing psychological theory and empirical methods to build understanding and address societal problems is met.

That benevolent sexism is a positively-valenced attitude that serves a negative (i.e. prejudicial, hierarchy-enhancing) function is already well established within the social psychological literature. Similarly, while this dissertation claims that BS is more associated with White women, it does not take the position that this is a good thing. 
This stance may seem to contradict the conclusions of Study 3 (chapter IV of this dissertation), in which the intersection of benevolent sexism and racial stereotypes may have contributed to police filing supplemental paperwork at higher rates for White victims of IPV than Black ones. However, help that is contingent on the victim aligning with positive racist and sexist stereotypes is not in keeping with the letter of the law nor the rights of victims to equitable treatment (victims' rights guide, n.d.) Proper handling of IPV victims will come not from extensions of benevolent protections to all races of women, which will still by definition exclude those non-traditional subtypes (i.e. feminists) whose behavior undermines the gender hierarchy, but by consciously remediating those influences so that both may be treated equally (see Study 3). The present findings also suggest that White women (compared to Black women) will be exposed to more benevolent sexism, thereby increasing the likelihood that they will experience its negative effects (see the Applied Implications section below). Of course, this is not to say that Black women are 'spared' from benevolent sexism and therefore encounter less bias than White women. Relative to their White counterparts, Black women experience greater discrimination in hiring (Bertrand \& Mullianathan, 2003) and wages (National Women's Law Center, 2016b). In McMahon and Kahn (2016), attributions of hostile sexism to Black (but not White) women did not differ depending on their traditional behaviors, and the same benevolent sexism that may have prompted officers to more fully investigate IPV against White women (study 3 of this dissertation) did not help Black victims. The conclusion of these studies is ultimately not that White women receive more bias than Black women, but rather that sexism interacts with racial 
stereotypes to produce different outcomes for White and Black women.

\section{Patterns of Significance}

Each manuscript presented here contributes to our understanding of how racial stereotypes inform the targets, function, and consequences of benevolent sexism. Several patterns of significance across studies are worth exploring, including the alignment of benevolent sexism with White femininity, how this pro-White bias protects individuals, and how this produces negative outcomes for racial minorities.

First, results from studies one and three suggest that benevolent sexism favors White women over Black women, both in terms of benevolent attributions (McMahon \& Kahn, 2016; chapter II) and protective treatment and perception (chapter IV). This is a divergence from previous ambivalent sexism research, which relied on women's gendernormative behaviors rather than other social identities to inform whether they are targets of HS or BS, yet is consistent with scholarship from other disciplines (e.g. women's studies, colonial history, law) that better consider how race shapes perceptions and treatment of women (e.g. Ammons, 1995; Davis, 1983; Hull, et al., 1982; Morton, 1991; Ware, 2015). This pattern of results therefore confirms previous findings using a social psychological framework.

These studies further illuminate how Whiteness serves a protective function. That is, while non-White individuals face worse outcomes and treatment as a result of pervasive anti-non-White attitudes, White individuals also benefit from pro-White biases (Kahn, Goff, Lee, \& Motamed, 2016; Kahn, Thompson, \& McMahon, 2017; Kahn, Steele, McMahon, \& Stewart, 2017). This is most evident in study three, with officers 
filing required supplemental paperwork more often when the victim was White (rather than Black), yet the odds of filing decreased when the suspect was White (rather than Black). In the context of an IPV investigation, White women are "protected" by their Whiteness, in that police are more likely to properly investigate the incident. This is especially true when their assailant is Black, possibly due to officers being less eager to investigate crimes committed by White men (illustrating how Whiteness also protects men in this context), the desire to defend White women activating racial biases (McMahon \& Kahn, 2017; chapter II), or a pernicious combination of the two. Similarly, the theoretical basis of study two is that the inherent fragility of White women requires protection by male relatives and partners, justifying violence against dangerous racial minority men. Whiteness also protects the female targets from study one (McMahon \& Kahn, 2016; chapter II), where participants who more strongly endorsed HS directed less BS at promiscuous Black women but not promiscuous White women. This suggests that even when White women violate prescribed norms of sexual behavior (here, by "enjoying casual flings"), they do not necessary "lose" benevolent evaluations, as their Black counterparts do.

Importantly, results from studies two and three indicate that the association between BS and White women comes at a cost to others. This is seen in study two (McMahon \& Kahn, 2017; chapter III) where White men's protective paternalism increased their racial biases (and not the other way around), suggesting that the seemingly noble desire to protect women activates the racial animosity that has historically been justified by protective paternalism. This finding is partially conceptually replicated in 
study three, with the most complete initial investigation of IPV happening when a Black man assaults a White woman. Results from study two suggest that this outcome should be especially likely for White male officers, though unfortunately I am not able to test this hypothesis. Greater BS for White women (and less for Black women) as seen in study one may also contribute to the disparity in IPV investigations, where violence against Black women is less likely to be thoroughly investigated by responding officers. Previous work has established that BS, while seeming subjectively positive, can have negative consequences for targets (e.g. Bosson, Pinel, \& Vandello, 2010; Dardenne, et al., 2007; Shepherd, et al., 2011). Here I demonstrate how the differential application of BS to White women can produce negative effects for unrelated others, from shifting attitudes about racial minorities in general (study two) to greater tolerance of violence against Black women (study three).

\section{Theoretical Implications}

This dissertation sought to expand ambivalent sexism theory by incorporating race; in doing so, I also drew upon shifting standards theory and the motivated social cognition model. Each of these theories are supported and further refined by the results.

The primary theoretical implication from this dissertation is a new understanding regarding how women are subtyped by perceivers within ambivalent sexism theory. It had been previously determined that, rather than being judged as a whole group, women are separated into subtypes based on their adherence to prescribed gender roles, with the traditional ones (e.g. mother, chaste) receiving BS and the non-traditional ones (e.g. feminist, promiscuous) being punished with HS. I diverge from and extend the 
established model by demonstrating how race alone can act as a subtype to elicit benevolent sexism (McMahon \& Kahn, 2016; chapter II). Previous research had primarily focused on behavioral subtypes rather than immutable social identities; here, I provided preliminary evidence that women can also be subtyped by race, with racial stereotypes then influencing perceivers' benevolent attributions of female targets in the absence of behavioral information. Furthermore, racial subtypes then interact with behavioral subtypes, producing divergent outcomes. Determining responses to different racial subtypes and testing how each interacts with traditional and non-traditional behavioral subtypes will be a crucial next step.

Interestingly, my findings regarding the intersection of racial subtypes with hostile sexism (rather than BS) follow a different pattern. In the first pair of studies (chapter II), BS favored the White woman subtype, then the chaste Black woman subtype (consistent with shifting standards theory). Conversely, attributions of HS did not differ between the Black and White woman subtypes, and favored the promiscuous subtypes, regardless of race. However, there was no difference in the amount of HS directed at Black women when they were chaste or promiscuous. Hostile sexism should be higher for promiscuous women than chaste women (Sibley \& Wilson, 2004); that this pattern did not replicate when the woman in question was Black further suggests the influence of racial stereotypes and the number of other findings within the ambivalent sexism literature that might be qualified by target race.

The first manuscript also utilized shifting standards theory (Biernat, 2003) to explain why BS would favor chaste Black women. This model posits that when 
expectations of a stereotyped group are low (i.e. evidentiary standards are low), those that exceed them are rewarded with positively-valenced non-zero sum behaviors (i.e. limitless, like expressions of praise). Because expectations for Black women's sexual behavior are more negative, an individual Black woman described as chaste was "rewarded" for this stereotype-inconsistent behavior with praise in the form of BS. In predicting that promiscuous White women (who are violating the purity expectations of both their gender and their race) would receive more HS than promiscuous Black women (who are stereotype-congruent), I was testing whether when expectations of a group are high, those who fail to achieve them (when it's stereotype-congruent) are more punished with negatively-valenced non-zero sum behaviors (e.g. contempt, HS). This would be analogous to an Asian student receiving more ridicule than a White student for failing a math test, due to this behavior being stereotype-incongruent. Instead, hostile evaluations did not appear to "shift" as the benevolent ones did, indicating support for the current model of shifting standards (i.e. praise for exceeding low evidentiary standards), with no evidence to support extending the model for the reverse pattern (i.e. contempt for failing to meet high evidentiary standards).

Findings from study two also support benevolent sexism as a form of motivated social cognition (McMahon \& Kahn, 2017; chapter III). This model describes how environmental stimuli eliciting uncertainty or fear provoke an interrelated set of epistemic, existential, and ideological motives that predict the holding of conservative ideologies (Jost, Glaser, Kruglanski, \& Sulloway, 2003). Finding that participants in the threat condition increased their endorsement of protective paternalism builds on previous 
research that has shown $\mathrm{BS}$ to increase as a response to situational threats to group-level esteem (e.g. Fischer, 2006; Glick et al., 2000) and physical safety (Espinoza Ornelas, Moya, \& Willis, 2015; Phelan, Sanchez, \& Broccoli, 2010). Moreover, I exposed one path through which situational threats increase racial bias (i.e. with protective paternalism as the mediator). Notably, the female participants in this study did not respond to threat with higher endorsement of protective paternalism while male participants did, consistent with some previous work (Espinoza Ornelas, et al., 2015) while contradicting others (Phelan et al., 2010). Research should continue to explore the role of gender in predicting responses to uncertainty and threat, particularly as it pertains to women's endorsement of a sexist ideology that promises them protection conditional on subordination.

\section{Applied Implications}

In addition to contributing to the theoretical literature on ambivalent sexism, the results of this dissertation may have a number of applied implications for women outside the lab in a variety of real world contexts.

In the first manuscript, BS was directed more at White targets when no other information about traditional behavior was present, showing how race can act as a subtype to elicit BS. This suggests that White women in the real world, relative to Black women, might be exposed to more benevolent sexism, in the form of sexist statements and paternalistic treatment, from others. To the extent that exposure to BS elicits negative emotions (Bosson, et al., 2010; Shepherd et al., 2011), reduces cognitive performance Dardenne, et al., 2007; Dardenne et al., 2013) and bolsters endorsement for the status quo (Jost \& Kay, 2005), White women may experience these consequences more often. 
Consistent exposure may lead to the transmission and internalization of BS (Montañés, et al., 2012), which has been shown to predict women's future endorsement of HS (Sibley, Overall, \& Duckitt, 2007). If White women are the principal targets of BS (study 1), then they may both more often suffer the immediate negative consequences of BS exposure and over time come to more strongly endorse both hostile and benevolent sexism, thereby perpetuating these ideologies. While these outcomes may occur more for White women, this does not diminish the experiences of Black women who, as previously stated, encounter different forms of discrimination and bias.

Consistent with shifting standards theory, the chaste Black target in the first manuscript received more BS than the chaste White target, suggesting patronizing surprise at stereotype-inconsistent behavior. This finding may have consequences for real Black women, insofar as it could produce differential treatment in the form of microaggressions, which are commonplace verbal or behavioral slights that communicate negative perceptions of a person or their group (Sue, 2010). For example, a Black teenager dressing modestly or delaying sexual intercourse might receive increased praise for these actions in ways that communicate to her that she was not expected to behave this way because of her racial identity. These microaggressions build on each other over time, producing high stress, feelings of powerlessness, and loss of integrity (Sue, Capodilupo, \& Holder, 2008). Additionally, non-zero sum rewards, such as praise, do not necessarily translate into zero sum rewards like a promotion or a raise (Biernat, 2003), further illuminating how these positively valenced expressions of bias lack tangible benefits for targets. 
In the second manuscript (McMahon \& Kahn, 2017), men, in response to threat, increased their desire to defend women from harm, which then for White men activated the anti-racial minority biases that have long been associated with protective paternalism. This suggests a process that can unfold in times of heightened security concerns, from rising crime rates to a terrorist attack, where paternalistic reactions bolster attitudes that denigrate racial minorities. People of color should be aware that in times of intensified threats they may be treated with more hostility via this indirect process, while White men wishing to be more egalitarian should be made aware of this potentially unconscious psychological process, including its historical exploitation by jingoists and fascists, in an effort to guard against it.

Finally, the third manuscript in this dissertation found disparities in the filing of supplemental forms for White and Black female victims of IPV by police officers, implying that in this particular real-world context, violence against White women may be more properly investigated. The applied implication of this finding is not that Black victims should better advocate for themselves in this context, but rather the onus should be on departments to ensure that the policing of IPV is governed by state ordinances and directives requiring arrests of the primary aggressor and thorough initial investigations, rather than cultural stereotypes that favor some victims over others. Similar disparities may be seen in other policing contexts where women require help, such as welfare checks, other forms of domestic violence, or missing persons.

\section{Limitations and Future Directions}

There are a number of methodological limitations within this dissertation that, 
while reducing internal and external validity in particular studies, also provide directions for future research. First and foremost, while this research attempted to incorporate race into a social psychological theory of sexism, race was operationalized somewhat inconsistently, either by restricting race to a comparison between White and Black women (studies 1 and 3 of this dissertation) or grouping all racial minorities into a single category (study 2). Reasons for this were both theoretical and practical, and highlight some of the challenges of intersectional research, including sampling requirements, difficulties in theoretical interpretation, and appropriate operational definitions (Goff \& Kahn, 2013).

As previously described, racial stereotypes depict White women and Black women in diametrically opposing ways. If femininity is associated with Whiteness (Hull, et al., 1982), and stereotypes of Black women directly contradict the idealized femininity espoused by BS (see chapter II of this dissertation), then beginning a program of research into the different targets of BS by comparing White and Black women is reasonable. In order to examine causal relationships, I then relied on basic experiments in which race (Black vs. White) and additionally sexual subtype (promiscuous vs. chaste) were manipulated (McMahon \& Kahn, 2016; chapter II); had additional racial groups been incorporated, the required sample size for adequate statistical power would have doubled (at least) and the results may have been less interpretable (Goff \& Kahn, 2013). The scope of intersectionality in study 1 was therefore restricted to minimize required sample size and to maximize ease of interpretation of this nascent research. However, this omission does present an opportunity for future researchers to consider how other racial 
stereotypes (e.g. of Native American, Asian, or Latina women) impact the targets of BS and their subsequent treatment, with the ultimate goal of fully integrating race into ambivalent sexism theory. For instance, stereotypes of submissiveness (Ghavami \& Peplau, 2013) should afford Asian women a high degree of benevolent sexism, while the stereotype of Asian hyper-intelligence may imply competence and competition that, along with in-group favoritism (Tajfel \& Turner, 1986), might produce relatively less BS for Asian women compared to White women (for White perceivers).

While studies 1 and 3 tested race in a Black/White dichotomy, study 2 operationalized race more broadly, comparing White versus racial minority participants and examining "anti-racial minority attitudes" in general (McMahon \& Kahn, 2017, chapter III). The grouping of all non-White participants into the category of "racial minority" was done to compensate for the low statistical power in this sample of students to test for racial differences, as $61 \%$ of participants were White. Importantly, the dominant group (i.e. White men) has used protecting White women as a pretext for violence against whichever racial minority group is contextually relevant, e.g. Japanese men during WWII (Miles, 2012), Arab men during the European migrant crisis (Yardlley, 2016), Indian men during British colonial expansion (Ware, 2015), Black men since Reconstruction (Davis, 1981). This historical pattern suggests that even with a sufficiently large, diverse sample, effects would have emerged for White participants more so than other racial minority groups tested separately. That is, because the link between paternalism and racism is consistently used to reinforce White supremacy in majority White societal contexts, racial minority participants (Black, Latinx, Native, etc.) 
should behave more similarly to each other than to White participants. However, the similar responses between racial minority and White male participants regarding increased paternalism predicting more negative views of immigrants (the second study in McMahon \& Kahn, 2017) suggests that responses by racial minority groups might come to differ depending on which outgroup is made salient. For example, negative perceptions of Islam following the terrorist attacks on September 11, 2011 were seen in both White and non-White American citizens (Nisbet, Ostman, \& Shanahan, 2004), so making that particular threat salient in study 2 might have produced increased paternalism and antiArab bias in a sample of non-Arab racial minorities compared to Arab racial minorities. As the qualitative experiences of the numerous racial minority groups in America are profoundly different, they should not be expected to respond identically; future research will want to further explore if and how protective paternalism bolsters racial biases among various racial minority groups, especially if this pattern has the ironic effect of upholding White hegemony (McMahon \& Kahn, 2017).

Additionally, the anti-minority attitude dependent variables written for study 2 were designed to both minimize participant reactivity and be purposefully broad. Modern forms of prejudice are characterized by hostility toward demands for equality and denial of discrimination (McConahay, 1986; Swim, Aikin, Hall, \& Hunter, 1995); as such, I predicted participants would be less reactive (i.e. prone to social desirability concerns) when, for example, denying that racial bias is an issue in contemporary policing rather than something more overt (e.g. being asked, "how dangerous do you find Black men?"). Having a more diversified operationalization of anti-minority attitudes that moved 
beyond the Black/White dichotomy allowed me to capture the uniquely broad relationship between BS and racism.

While studies 1 and 2 used a combination of experimental methods and nonstudent samples (from Amazon Mechanical Turk), thereby enhancing the strength of the causal claims and generalizability of the findings, study 3 (chapter IV) took place in an applied context with unique constraints, comparatively diminishing its internal and external validity. My assessment of police records for White and Black victims of IPV used a cross-sectional, rather than experimental, design; the ability to say that the victim's race caused officers to file supplemental forms is hindered by a lack of direct manipulation and experimental control over other confounding factors, such as victim cooperation or officer race and gender. I also used police data from a city that is majority White, restricting generalizability to other police departments in more diverse locations. However, the use of real-world data in study 3 produces high ecological validity, which was more limited in studies 1 and 2. This mixed-method approach therefore utilized strengths of different designs to compensate for weaknesses in others.

The link between biased attitudes and behavior is an important, yet elusive, one. This dissertation examined both, although not simultaneously. The first two studies measured attitudes: Study 1 assessed BS and HS evaluations of Black and White female targets, and Study 2 examined how situationally-increased endorsement of protective paternalism bolstered negative views of immigrants, denial of racial bias in policing, and decreased policy support. In contrast, Study 3 primarily focused on officers' behavior when responding to IPV. While this is an improvement on many studies, which often 
neglect discriminatory behavior in favor of attitudes (Fiske, 2000), I was not able to measure officers' racial biases or ambivalent sexism, and so cannot predict their behaviors from their attitudes. While officers did behave in ways consistent with the intersection of racial stereotypes with BS found in Study 1 (chapter II) and the increased paternalistic protections for White women assaulted by minority men from Study 2 (chapter III), the cause of this behavior will need to be explicitly measured (e.g. de Oliveira Laux, Ksenofontov, \& Becker, 2015).

Another limitation is the inconsistency with which I assess participant gender throughout these studies: Study 1 (chapter II) examined several attitudinal moderators, but neglected gender, and the gender of the officer responding to the IPV incident was not available in Study 3 (chapter IV). Study 2 (chapter III) was the only one that explicitly tested how the gender of the participant affected their response to threat and subsequent endorsement of protective paternalism and racial bias. Gender was tested as a moderator in this experiment due to previous findings regarding how BS may be amplified by situational threats (Espinoza Ornelas, et al., 2015; Phelan, et al., 2010). That is, I had theoretical bases for predicting why participant gender should matter in the context of physical threat: for women, because BS promises them safety, contingent on traditional behavior (Glick, et al., 1997), and for men, because the role of the "masculine protector" would be made salient (Young, 2003). I did not anticipate any gender differences in Study 1 (chapter II); instead, participants' endorsement of HS, BS, and modern racism were examined as moderators of the HS and BS they directed at female targets. Benevolent sexism, with its positive tone, tends to be endorsed by both men and 
women, while HS is consistently higher among men (Glick, et al., 2000), as is modern racism (Aosved \& Long, 2006). Using gender as a proxy for these attitudes would have been more imprecise than measuring them directly; however, as participants' endorsement of modern racism and hostile sexism did moderate the application of HS and BS to Black (but not White) faces, and these tend to be higher for men, it is possible that participant gender could have also been a significant moderator here. Future examinations of how hostile and benevolent sexism are directed at particular women (rather than women at the global level) may want to more thoroughly consider the gender of the perceiver.

Finally, this research attempted to make ambivalent sexism theory more intersectional by incorporating race, yet this is but one social identity that can intersect with gender to affect how women are perceived and treated. In order for ambivalent sexism theory to be made fully intersectional, multiple categories of social group membership will need to be considered (Crenshaw, 1989), including class, sexual orientation, age, nationality, ability, religion, etc. From there, intragroup differences, in addition to intergroup differences, can be explored; within-group differences (e.g. phenotypic racial stereotypicality, physical femininity) affect the accessibility of relevant stereotypes (e.g. Kahn \& Davies, 2011), which should impact hostile and benevolent attributions and subsequent treatment. Future research in this area will similarly benefit from the utilizing the full-cycle model (Mortensen \& Cialdini, 2010), wherein theory (social psychological theories of prejudice, shaped by sociological perspectives) is used to inform experiments later corroborated by naturalistic observation. 


\section{Conclusion}

In closing, this dissertation attempted to incorporate race into ambivalent sexism theory using a combination of experimental and non-experimental methods in laboratory and applied contexts. Specifically, I examined how racial stereotypes inform the targets, functions, and consequences of benevolent sexism. In doing so, I revealed how BS is more strongly associated with White women than Black women, with potential realworld consequences in the context of intimate partner violence, and a process through which BS promotes the denigration of racial minorities in general. This intersectional perspective is vital to understanding how systems of oppression (i.e. racism and sexism) interact to stall human progress toward equality. 


\section{Terminal References}

Abrams, D., Becker, J. C., \& Wright, S. C. (2011). Yet another dark side of chivalry: Benevolent sexism undermines and hostile sexism motivates collective action for social change. Journal of Personality and Social Psychology, 101, 62-78. doi:10.1037/0022-3514.84.1.111.

Abrams, D., Tendayi Viki, G., Masser, B. M., \& Bohner, G. (2003). Perceptions of stranger and acquaintance rape: The role of benevolent and hostile sexism in victim blame and rape proclivity. Journal of Personality and Social Psychology, 84, 111-125. doi: 10.1037/0022-3514.84.1.111.

Ainscough, T. L., \& Motley, C. M. (2000). Will you help me please? The effects of race, gender and manner of dress on retail service. Marketing Letters, 11, 129-136. doi: 10.1023/A:1008138722964.

Allen, S. A. (2015). Sexual stereotypes about ethnic minorities in the United States. In The International Encyclopedia of Human Sexuality. (Vol. \#3, p.1115-1354). Hoboken, NJ: John Wiley \& Sons, Ltd. doi: 10.1002/9781118896877.wbiehs460

Allport, G. W. (1954) The Nature of Prejudice. Reading, MA: Addison-Wesley.

Ammons, L. L. (1995). Mules, madonnas, babies, bathwater, racial imagery and stereotypes: The African-American woman and the battered woman syndrome. Wisconsin Law Review, 5, 1003-1080.

Angerer, C. (2016). "Cologne sex attacks 'good for us', anti-refugee protesters say." $N B C$ News. Retrieved from http://www.nbcnews.com/storyline/europes-bordercrisis/cologne-sex-attacks-good-us-anti-refugee-protesters-say-n497376

Aosved, A. C., \& Long, P. J. (2006). Co-occurrence of rape myth acceptance, sexism, racism, homophobia, ageism, classism, and religious intolerance. Sex Roles, 55, 481-492.

Apel, D. (2004). Imagery of lynching: Black men, white women, and the mob. Rutgers University Press.

Apsler, R., Cummins, M. R., \& Carl, S. (2003). Perceptions of the police by female victims of domestic partner violence. Violence Against Women, 9, 1318-1335. doi: $10.1177 / 1077801203255554$

Arab American National Museum. (2011). Reclaiming identity: Dismantling Arab stereotypes. Retrieved from http://www.arabstereotypes.org/whystereotypes/what-orientalism/sheiks-terrorists

Avakame, E. F., \& Fyfe, J. J. (2001). Differential police treatment of male-on-female spousal violence additional evidence on the leniency thesis. Violence Against Women, 7(1), 22-45. doi: 10.1177/10778010122182280

Ayres, I., \& Siegelman, P. (1995). Race and gender discrimination in bargaining for a new car. American Economic Review, 85, 304-321.

Bachman, R., \& Coker, A. L. (1995). Police involvement in domestic violence: The interactive effects of victim injury, offender's history of violence, and race. Violence and Victims, 10(2), 91-106.

Bakeman, R. (2000). Behavioral observation and coding. In Reis, H. T., \& Judd, C. M. (Eds.). Handbook of research methods in social and personality psychology, 138159. Cambridge, U.K.: Cambridge University Press. 
Baldus, D. C., Woodworth, G., Zuckerman, D., \& Weiner, N. A. (1997). Racial discrimination and the death penalty in the post-Furman era: An empirical and legal overview with recent findings from Philadelphia. Cornell Law Review, 83, 1638-1770.

Barnett, O. W. (2000). Why battered women do not leave, Part 1: External inhibiting factors within society. Trauma, Violence, \& Abuse, 1(4), 343-372. doi: $10.1177 / 1524838000001004003$

Barreto, M., \& Ellemers, N. (2005). The burden of benevolent sexism: How it contributes to the maintenance of gender inequalities. European Journal of Social Psychology, 35, 633-642. doi: 10.1002/ejsp.270.

BBC News. (2016, March 4). Migrant crisis: Migration to Europe explained in seven charts. Retrieved from http://www.bbc.com/news/world-europe-34131911

Becker, S. (2007). Race and violent offender propensity: Does the intraracial nature of violent crime persist on the local level? Justice Research and Policy, 9, 53-86. doi: 10.3818/JRP.9.2.2007.53

Becker, J. C., Glick, P., Ilic, M., \& Bohner, G. (2011). Damned if she does, damned if she doesn't: Consequences of accepting versus confronting patronizing help for the female target and male actor. European Journal of Social Psychology, 41(6), 761-773. doi: 10.1002/ejsp.823

Becker, J. C., \& Wright, S. C. (2011). Yet another dark side of chivalry: Benevolent sexism undermines and hostile sexism motivates collective action for social change. Journal of Personality and Social Psychology, 101, 62-78. doi: $10.1037 / \mathrm{a} 0022615$.

Belknap, J. (2007). The invisible woman, gender, crime, and justice (3rd ed.). Belmont, CA, Wadsworth.

Belknap, J., \& McCall, K. D. (1994). Woman battering and police referrals. Journal of Criminal Justice, 22, 223-236. doi: 10.1016/0047-2352(94)90019-1

Benson, M. L., Wooldredge, J., Thistlethwaite, A. B., \& Fox, G. L. (2004). The correlation between race and domestic violence is confounded with community context. Social Problems, 51(3), 326-342. doi: 10.1525/sp.2004.51.3.326

Berk, R. (1980). Bringing the cops back in: A study of efforts to make the criminal justice system more responsive to incidents of family violence. Social Science Research, 9, 195-215. doi: 10.1016/0049-089X(80)90011-3

Berk, S. \& Loseke, D. (1981). Handling family violence: Situational determinants of police arrest in domestic disturbances. Law and Society Review, 15, 317-344. doi: $10.2307 / 3053608$

Bertrand, M., \& Mullainathan, S. (2003). Are Emily and Greg more employable than Lakisha and Jamal? A field experiment on labor market discrimination. American Economic Review, 94, 991-1013. doi: 10.3386/w9873

Biernat, M. (2003). Toward a broader view of social stereotyping. American Psychologist, 58, 1019-1027. doi: 10.1037/0003-066X.58.12.1019.

Biernat, M., \& Kobrynowicz, D. (1997). Gender- and race-based standards of competence: Lower minimum standards but higher ability standards for devalued groups. Journal of Personality and Social Psychology, 72, 544-557. doi: 10.1037/0022-3514.72.3.544. 
Biernat, M., Manis, M., \& Nelson, T. F. (1991). Comparison and expectancy processes in human judgment. Journal of Personality and Social Psychology, 61, 203-211. doi: 10.1037/0022-3514.61.2.203.

Biernat, M., \& Vescio, T. K. (2002). She swings, she hits, she's great, she's benched: Implications of gender-based shifting standards for judgment and behavior. Personality and Social Psychology Bulletin, 28, 66 -77. doi: 10.1177/0146167202281006.

Biernat, M., Vescio, T. K., \& Manis, M. (1998). Judging and behaving toward members of stereotyped groups: A shifting standards perspective. Intergroup Cognition and Intergroup Behavior, 151-175.

Black, D. J. (1971). The social organization of arrest. Stanford Law Review, 23, 10871111. doi: $10.2307 / 1227728$

Black, D. (1980). The manners and customs of police. New York: Academic Press.

Black, M.C., Basile, K.C., Breiding, M.J., Smith, S.G., Walters, M.L., Merrick, M.T., Chen, J., \& Stevens, M.R. (2011). The National Intimate Partner and Sexual Violence Survey (NISVS): 2010 Summary Report. Atlanta, GA: National Center for Injury Prevention and Control, Centers for Disease Control and Prevention.

Blee, K. M. (2002). Inside organized racism: Women in the hate movement. Berkeley, CA: University of California Press.

Bollen, K. A., \& Jackman, R. W. (1985). Regression diagnostics: An expository treatment of outliers and influential cases. Sociological Methods \& Research, 13(4), 510-542. doi: 10.1177/0049124185013004004

Bond, J. C. \& Perry. P. (1974) Is the black male castrated? in The Black Woman, an Anthology. Toni Cade (ed.) New American Library: New York, pp. 113-119.

Bosson, J. K., Pinel, E. C., \& Vandello, J. A. (2010). The emotional impact of ambivalent sexism: Forecasts versus real experiences. Sex Roles, 62, 520-531. doi: 10.1007/s11199-009-9664-y

Brandl, S., \& Horvath, F. (1991). Crime victim evaluation of police investigative performance. Journal of Criminal Justice, 19, 293-305. doi: 10.1016/00472352(91)90008-J

Brown, S. E. (1984). Police responses to wife beating: Neglect of a crime of violence. Journal of Criminal Justice, 12, 277-288. doi: 10.1016/0047-2352(84)90074-6

Buchanan, N. T., Settles, I. H., \& Woods, K. C. (2008). Comparing sexual harassment subtypes among Black and White women by military rank: Double jeopardy, the jezebel, and the cult of true womanhood. Psychology of Women Quarterly, 32, 347-361. doi: 10.1111/j.1471-6402.2008.00450.x.

Bump, P. (2016). Maine governor says out-of-state drug dealers are impregnating 'young, white girl[s]', kind of apologizes. The Washington Post. Retrieved from https://www.washingtonpost.com/news/the-fix/wp/2016/01/07/maine-gov-paullepage-drug-traffickers-are-guys-named-d-money-who-impregnate-young-whitegirls/.

Bureau of Labor Statistics. (2008). Married parents; use of time summary [press release]. Retrieved from https://www.bls.gov/news.release/atus2.nr0.htm

Burn, S. M., \& Busso, J. (2005). Ambivalent sexism, scriptural literalism, and religiosity. Psychology of Women Quarterly, 29(4), 412-418. doi: 10.1111/j.1471- 
6402.2005.00241.x

Buzawa, E. S., \& Buzawa, C. G. (2003). Domestic violence: The criminal justice response. Thousand Oaks, CA: Sage.

Buzawa, E. S., \& Buzawa, C. G. (Eds.). (1996). Do arrests and restraining orders work?. Sage Publications.

Buzawa, E. S., \& Buzawa, C. G. (1993). The impact of arrest on domestic violence. The American Behavioral Scientist, 36, 558-574. doi: 10.1177/0002764293036005002

Carlsson, M., \& Rooth, D. O. (2007). Evidence of ethnic discrimination in the Swedish labor market using experimental data. Labour Economics, 14, 716-729. doi: 10.1016/j.labeco.2007.05.001

Chesney-Lind, M., \& Pasko, L. (Eds.). (2012). Girls, women, and crime: selected readings. Sage Publications.

Christopher, A. N., \& Mull, M. S. (2006). Conservative ideology and ambivalent sexism. Psychology of Women Quarterly, 30, 223-230. doi: 10.1111/j.147 6402.2006.00284.x.

Cluss, P. A., Chang, J. C., Hawker, L., Scholle, S. H., Dado, D., Buranosky, R., \& Goldstrohm, S. (2006). The process of change for victims of intimate partner violence: support for a psychosocial readiness model. Women's Health Issues, 16(5), 262-274. doi: 10.1016/j.whi.2006.06.006

Cohen, J. (1988). Statistical power analysis for the behavioral sciences (2nd ed.). Mahwah, NJ: Erlbaum.

Cohn, M., Mehl, M., \& Pennebaker, J. (2004). Linguistic markers of psychological change surrounding September 11, 2001. Psychological Science, 15, 687-693. doi: 10.1111/j.0956-7976.2004.00741.x

Cole, E. R. (2009). Intersectionality and research in psychology. American Psychologist, 64, 170-180. doi: 10.1037/a0014564.

Cozier, Y., Palmer, J. R., Horton, N. J., Fredman, L., Wise, L. A., \& Rosenberg, L. (2006). Racial discrimination and the incidence of hypertension in US black women. Annals of Epidemiology, 16, 681-687. doi: 10.1016/j.annepidem.2005.11.008.

Cozier, Y. C., Yu, J., Coogan, P. F., Bethea, T. N., Rosenberg, L., \& Palmer, J. R. (2014). Racism, segregation, and risk of obesity in the Black women's health study. American Journal of Epidemiology, 179, 875-883. doi: 10.1093/aje/kwu004.

Crenshaw, K. (1989). Demarginalizing the intersection of race and sex: A Black feminist critique of antidiscrimination doctrine, feminist theory and antiracist politics. University of Chicago Legal Forum, 1989, 139-167.

Crime and Misconduct Commission. (2005). Policing domestic violence in Queensland: Meeting the challenges. Brisbane, Queensland, Australia.

Cuddy, A. J., Fiske, S. T., \& Glick, P. (2008). Warmth and competence as universal dimensions of social perception: The stereotype content model and the BIAS map. Advances in Experimental Social Psychology, 40, 61-149. doi:10.1016/S0065-2601(07)00002-0

Cuevas, A. G., O'Brien, K., \& Saha, S. (2016). African American experiences in healthcare: "I always feel like I'm getting skipped over". Health

Psychology, 35(9), 987-995. doi:10.1037/hea0000368 
Daniel, J. E. \& Daniel J. L. (1998). Preschool children's selection of race-related personal names. Journal of Black Studies, 28, 471-490. doi:10.1177/002193479802800403.

Dardenne, B., Dumont, M., \& Bollier, T. (2007). Insidious dangers of benevolent sexism: Consequences for women's performance. Journal of Personality and Social Psychology, 93, 764-779. doi: 10.1037/0022-3514.93.5.764.

Dardenne, B., Dumont, M., Sarlet, M., Phillips, C., Balteau, E., Degueldre, C., ... \& Collette, F. (2013). Benevolent sexism alters executive brain responses. NeuroReport, 24(10), 572-577. doi: 10.1097/WNR.0b013e3283625b5b

Davis, A. Y. (1981). Women, race, and class. New York: Vintage.

Davis, G. L., \& Cross, H. J. (1979). Sexual stereotyping of Black males in interracial sex. Archives of Sexual Behavior, 8, 269-279. doi: 10.1007/BF01541243.

Dawson, M., \& Dinovitzer, R. (2001). Victim cooperation and the prosecution of domestic violence in a specialized court. Justice Quarterly, 18, 593-622. doi: 10.1080/07418820100095031

de Oliveira Laux, S. H., Ksenofontov, I., \& Becker, J. C. (2015). Explicit but not implicit sexist beliefs predict benevolent and hostile sexist behavior. European Journal of Social Psychology, 45(6), 702-715. doi: 10.1002/ejsp.2128

Devine, P. G. (1989). Stereotypes and prejudice: Their automatic and controlled components. Journal of Personality and Social Psychology, 56, 5-18. doi: 10.1037/0022-3514.56.1.5

Devine, P. G., \& Baker, S. M. (1991). Measurement of racial stereotype subtyping. Personality and Social Psychology Bulletin, 17, 44-50. doi: 10.1177/0146167291171007.

Difendila! [Online image]. (1944). Retrieved Sept. 5, 2016 from http://www.ww2incolor.com/homefront/manifesto_difendila.html

Dines, G. (2006). White man's burden: Gonzo pornography and the construction of Black masculinity. Yale Journal of Law \& Feminism, 18, 283-297.

Dominick, K. L., Bosworth, H. B., Dudley, T. K., Waters, S. J., Campbell, L. C., \& Keefe, F. J. (2004). Patterns of opioid analgesic prescription among patients with osteoarthritis. Journal of Pain \& Palliative Care Pharmacotherapy, 18, 31-46. doi: 10.1080/J354v18n01_03

DVU advanced academy training. [PowerPoint slides]. (2016) Provided by police consultant.

Eagly, A. H., Ashmore, R. D., Makhijani, M. G., \& Longo, L. C. (1991). What is beautiful is good, but...: A meta-analytic review of research on the physical attractiveness stereotype. Psychological bulletin, 110, 109-128. doi: 10.1037/0033-2909.110.1.109.

Eagly, A. H., \& Crowley, M. (1986). Gender and helping behavior: A meta-analytic view of the social psychological literature. Psychological Bulletin, 100, 283-308. doi: 10.1037/0033-2909.100.3.283

Eberhardt, J. L., Davies, P. G., Purdie-Vaughns, V. J., \& Johnson, S. L. (2006). Looking deathworthy: Perceived stereotypicality of Black defendants predicts capitalsentencing outcomes. Psychological Science, 17(5), 383-386. doi: 10.1111/j.1467-9280.2006.01716.x

Eberhardt, J. L., Goff, P. A., Purdie, V. J., \& Davies, P. G. (2004). Seeing black: race, 
crime, and visual processing. Journal of Personality and Social Psychology, 87, 876-893. doi: 10.1037/0022-3514.87.6.876

Edwards, S. S. M. (1996). Sex and gender in the legal process. London: Blackstone.

Edwards, D. (2014). “Louie Gohmert: Obama don't 'defend women' from 'hundreds of thousands' of immigrant rapists." Raw Story. Retrieved from http://www.rawstory.com/2014/07/louie-gohmert-obama-wont-defend-womenfrom-hundreds-of-thousands-of-immigrant-rapists/.

Ehrenreich, B., \& English, D. (1978). For her own good: One hundred and fifty years of the experts' advice to women. Garden City, NY: Anchor/Doubleday.

Eitle, D. (2005). The influence of mandatory arrest policies, police organizational characteristics, and situational variables on the probability of arrest in domestic violence cases. Crime \& Delinquency, 51, 573-597. doi: $10.1177 / 0011128705277784$

Ekehammar, B., Akrami, N., Gylje, M., \& Zakrisson, I. (2004). What matters most to prejudice: big five personality, social dominance orientation, or right-wing authoritarianism? European Journal of Personality, 18(6), 463-482. doi: $10.1002 /$ per.526

Erez, E., \& Belknap, J. (1998). In their own words: Battered women's assessment of the criminal processing system's responses. Violence and Victims, 13, 251-268.

Espinoza Ornelas, R., Moya, M., \& Willis, G. B. (2015). The relationship between fear of rape and benevolent sexism in a sample of women from Ciudad Juarez (Mexico). Suma Psicológica, 22, 71-77. doi: 10.1016/j.sumpsi.2015.09.001

Esqueda, C. W., \& Harrison, L. A. (2005). The influence of gender role stereotypes, the woman's race, and level of provocation and resistance on domestic violence Culpability attributions. Sex Roles, 53, 821-834. doi: 10.1007/11199s-005-8295-1.

Evans, S. (1979). Personal politics: The roots of women's liberation in the civil rights movements and the new left (Vol. 228). New York, NY: Vintage.

Faasse, K., Chatman, C. J., \& Martin, L. R. (2016). A comparison of language use in proand anti-vaccination comments in response to a high profile Facebook post. Vaccine, 34(47), 5808-5814. doi: 10.1016/j.vaccine.2016.09.029

Faul, F., Erdfelder, E., Buchner, A., \& Lang, A.-G. (2009). Statistical power analyses using $\mathrm{G}^{*}$ Power 3.1: Tests for correlation and regression analyses. Behavior Research Methods, 41, 1149-1160. doi: 10.3758/BRM.41.4.1149

Fazio, R. H. (1986). How do attitudes guide behavior. In R.M. Sorrentino \& E.T. Higgins (Eds.), Handbook of motivation and cognition: Foundations of Social Behavior, (pp. 204-243). New York: Guilford Press.

Ferraro, K. J. (1989). Policing woman battering. Social Problems, 36, 61-74. doi: $10.2307 / 800550$.

Few, A.L. (2005). The voices of black and white rural battered women in domestic violence shelters. Family Relations, 54, 488-500. doi: 10.1111/j.17413729.2005.00335.x

Figea, L. (2016). Machine learning for affect analysis on white supremacy forums. Unpublished manuscript, Department of Information Technology, Uppsala University, Uppsala, Sweden.

Fischer, A. R. (2006). Women's benevolent sexism as reaction to hostility. Psychology of 
Women Quarterly, 30, 410-416. doi: 10.1111/j.1471-6402.2006.00316.x

Fischer, K., \& Rose, M. (1995). When "enough is enough": Battered women's decision making around court orders of protection. Crime \& Delinquency, 41, 414-429. doi: $10.1177 / 0011128795041004003$

Fiske, S. T. (2000). Stereotyping, prejudice, and discrimination at the seam between the centuries: Evolution, culture, mind, and brain. European Journal of Social Psychology, 30(3), 299-322. doi: 10.1002/(SICI)1099 0992(200005/06)30:3<299::AID-EJSP2>3.0.CO;2-F

Fiske, S. T., Cuddy, A. J., Glick, P., \& Xu, J. (2002). A model of (often mixed) stereotype content: competence and warmth respectively follow from perceived status and competition. Journal of Personality and Social Psychology, 82(6), 878. doi: 10.1037/0022-3514.82.6.878

Fitz, C. C., \& Zucker, A. N. (2014). Feminist with benefits: College women's feminist beliefsbuffer sexual well-being amid hostile (not benevolent) sexism. Psychology of Women Quarterly, 38, 7-19. doi: 10.1177/0361684313504736.

Forbes, G. B., Adams-Curtis, L. E., Hamm, N. R., \& White, K. B. (2003). Perceptions of the woman who breastfeeds: The role of erotophobia, sexism, and attitudinal variables. Sex Roles, 49, 379-388. doi: 10.1023/A:1025116305434.

Frimer, J. A., Schaefer, N. K., \& Oakes, H. (2014). Moral actor, selfish agent. Journal of Personality and Social Psychology, 106(5), 790-802. doi: 10.1037/a0036040.

Gabbidon, S. L., Higgins, G. E., \& Potter, H. (2011). Race, gender, and the perception of recently experiencing unfair treatment by the police: Exploratory results from an all-black sample. Criminal Justice Review, 36, 5-21. doi: 10.1177/0734016810379904.

Gaertner, S. L., \& Dovidio, J. F. (1986). The aversive form of racism. Academic Press.

Garcia, A. (2014). Michelle Bachmann calls immigrant children 'invaders' and compares them to rapists. Raw Story. Retrieved from http://www.rawstory.com/2014/07/michele-bachmann-calls-immigrant-childreninvaders-and-compares-them-to-rapists/\#.U8XUB5_1MI8.twitter

Garcia, E., Garcia, F., \& Lila, M. (2008). Police involvement in cases of intimate partner violence against women: The influence of perceived severity and personal responsibility. Violence Against Women, 14, 697-714. doi: $10.1177 / 1077801208317288$

Gelles, R.J. (1993). Constraints against family violence: How well do they work. American Behavioral Scientist, 36, 757-585. doi: 10.1177/0002764293036005003

Ghavami, N., \& Peplau, L. A. (2013). An intersectional analysis of gender and ethnic stereotypes: Testing three hypotheses. Psychology of Women Quarterly, 37(1), 113-127. doi : 10.1177/0361684312464203

Gibbons, J. L., Hamby, B. A., \& Dennis, W. D. (1997). Researching gender role ideologies internationally and cross-culturally. Psychology of Women Quarterly, 21, 151-170. doi: 10.1111/j.1471-6402.1997.tb00106.x

Gilkes, C. T. (1983). From slavery to social welfare: Racism and the control of black women. Class, race, and sex: The dynamics of control. Amy Sherdlow and Hanna Leesinger (eds.). Barnard College Women's Center, G.K. Hall \& Co.: Boston: 288-300. 
Gillis, J. R., Diamond, S. L., Jebely, P., Orekhovsky, V., Ostovich, E. M., MacIsaac, K., ... \& Mandell, D. (2006). Systemic obstacles to battered women's participation in the judicial system: When will the status quo Change? Violence Against Women, 12(12), 1150-1168. doi: 10.1177/1077801206293500

Glick, P., Diebold, J., Bailey-Werner, B., \& Zhu, L. (1997). The two faces of Adam: Ambivalent sexism and polarized attitudes toward women. Personality and Social Psychology Bulletin, 23, 1323-1334. doi: 10.1177/01461672972312009

Glick, P., \& Fiske, S. T. (1996). The ambivalent sexism inventory: Differentiating hostile and benevolent sexism. Journal of Personality and Social Psychology, 70(3), 491512. doi: 10.1037/0022-3514.70.3.491.

Glick, P., \& Fiske, S. T. (2001). An ambivalent alliance: Hostile and benevolent sexism as complementary justifications for gender inequality. American Psychologist, 56, 109-118. doi: 10.1037/0003-066X.56.2.109

Glick, P., \& Fiske, S. T. (2011). Ambivalent sexism revisited. Psychology of Women Quarterly, 35(3), 530-535. doi: 10.1177/0361684311414832

Glick, P., Fiske, S. T., Mladinic, A., Saiz, J. L., Abrams, D., Masser, B., ... Lopez, W. (2000). Beyond prejudice as simple antipathy: Hostile and benevolent sexism across cultures. Journal of Personality and Social Psychology, 79, 763-775. doi: 10.1037/0022-3514.79.5.763

Glick, P., Sakalli-Ugurlu, N., Ferreira, M. C., \& de Souza, M. A. (2002). Ambivalent sexism and attitudes toward wife abuse in Turkey and Brazil. Psychology of Women Quarterly, 26, 292-297. doi: 10.1111/1471-6402.t01-1-00068

Gloor, D., \& Meier, H. (2013). Clouds darkening the blue marital sky. In Framing Sexual and Domestic Violence through Language (pp. 57-85). Palgrave Macmillan US. doi: 10.1057/9781137340092_4

Goddard, T., Kahn, K. B., \& Adkins, A. (2015). Racial bias in driver yielding behavior at crosswalks. Transportation research part F: Traffic psychology and behaviour, 33, 1-6. doi: 10.1016/j.trf.2015.06.002

Goff, P. A., Eberhardt, J. L.,Williams, M. J., \& Jackson, M. C. (2008b). Not yet human: Historical dehumanization and contemporary consequences. Journal of Personality and Social Psychology, 94, 292-306. doi: 10.1037/00223514.94.2.292.

Goff, P. A., \& Kahn, K. B. (2012). Racial bias in policing: Why we know less than we should. Social Issues and Policy Review, 6(1), 177-210. doi: 10.1111/j.17512409.2011.01039.x

Goff, P. A., \& Kahn, K. B. (2013). How psychological science impedes intersectional thinking. Du Bois Review: Social Science Research on Race, 10, 365-384. doi: 10.1017/S1742058X13000313

Goff, P. A., Thomas, M. A., \& Jackson, M. C. (2008a). “Ain't I a woman?”: Towards an intersectional approach to person perception and group-based harms. Sex Roles, 59, 392-403. doi: 10.1007/s11199-008-9505-4.

Goldin, C., \& Rouse, C. (2000). Orchestrating impartiality: The impact of" blind" auditions on female musicians. American Economic Review, 90(4), 715-741. doi: 10.1257/aer.90.4.715

Gondolf, E. W., \& McFerron, J. R. (1989). Handling battering men: Police action in wife 
abuse cases. Criminal Justice and Behavior, 16, 429-439. doi:

$10.1177 / 0093854889016004003$

Gordon, R., Piana, L. D., \& Keleher, T. (2000). Facing the consequences: An examination of racial discrimination in U.S. public schools. Oakland, CA: Applied Research Center.

Green, A. R., Carney, D. R., Pallin, D. J., Ngo, L. H., Raymond, K. L., Iezzoni, L. I., \& Banaji, M. R. (2007). Implicit bias among physicians and its prediction of thrombolysis decisions for black and white patients. Journal of General Internal Medicine, 22(9), 1231-1238. doi: 10.1007/s11606-007-0258-5

Greenwald, A. G., \& Banaji, M. R. (1995). Implicit social cognition: Attitudes, selfesteem, and stereotypes. Psychological Review, 102, 4-27. doi: 10.1037/0033295X.102.1.4

Greenwald, A. G., McGhee, D. E., \& Schwartz, J. L. K. (1998). Measuring individual differences in implicit cognition: the implicit association test. Journal of Personality and Social Psychology, 74, 1464-1480. doi: 10.1037/00223514.74.6.1464.

Guerrero, E. (1993). Framing blackness: the African American image in film. Philadelphia, PA: Temper University Press.

Gupta, N., Jenkins, G. D., Jr., \& Beehr, T. A. (1983). Employee gender, gender similarity, and supervisor-subordinate cross-evaluations. Psychology of Women Quarterly, 8, 174-184. doi: 10.1111/j.1471-6402.1984.tb00627.x.

Guttentag, M., \& Secord, P. (1983). Too many women? Beverly Hills, CA: Sage.

Hall, R.E. (1995). Dark skin and the cultural ideal of masculinity. Journal of African American Men, 1, 37-62. doi: 10.1007/BF02692070.

Hall, J. D. (1993). Revolt against chivalry: Jessie Daniel Ames and the women's campaign against lynching. New York City, NY: Columbia University Press.

Hamilton, B., \& Coates, J. (1993). Perceived helpfulness and use of professional services by abused women. Journal of Family Violence, 8(4), 313-324

Hamptom, R. L., \& Gelles, R. J. (1994). Violence toward Black women in a nationally representative sample of Black families. Journal of Comparative Family Studies, 25, 105-119.

Harris, M. (1991). Cultural anthropology (3rd ed.). New York: HarperCollins.

Hayes, A. F. (2013). Introduction to mediation, moderation, and conditional process analysis: A regression-based approach. New York, NY: Guilford Press.

Hayes, E. R., \& Swim, J. K. (2013). African, Asian, Latina/o, and European Americans' responses to popular measures of sexist beliefs: Some cautionary notes. Psychology of Women Quarterly, 37, 155-166. doi: $10.1177 / 0361684313480044$.

Hearnshaw, F. J. C. (1935). Chivalry. In E. Seligman (Ed.) Encyclopedia of the Social Sciences (436-440). New York: Macmillan.

Hee Lee, M. Y. (2015). "Donald Trump's false comments connecting Mexican immigrants and crime. The Washington Post. Retrieved from https://www.washingtonpost.com/news/fact-checker/wp/2015/07/08/donaldtrumps-false-comments-connecting-mexican-immigrants-and-crime/

Henley, N. M., Miller, M., \& Beazley, J. A. (1995). Syntax, semantics, and sexual 
violence agency and the passive voice. Journal of Language and Social Psychology, 14(1-2), 60-84. doi: 10.1177/0261927X95141004

Henning, K. (2014). 2014 Revalidation of DVU risk screen. [PowerPoint slides].

Hickman, M. J., Atherley, L. T., Lowery, P. G., \& Alpert, G. P. (2015). Reliability of the force factor method in police use-of-force research. Police Quarterly, 18(4), 368396. doi: $10.1177 / 1098611115586175$

Hirschel, D. (2008). Domestic violence cases: What research shows about arrest and dual arrest rates. Washington, DC: National Institute of Justice.

Hirschel, D., \& Buzawa, E. (2002). Understanding the context of dual arrest with directions for future research. Violence Against Women, 8, 1449-1473. doi: $10.1177 / 107780102237965$

Hirschel, D., Buzawa, E., Pattavina, A., Faggiani, D., \& Reuland, M. (2007). Explaining the prevalence, context, and consequences of dual arrest in intimate partner cases-final report submitted to the U.S. Department of Justice. Washington, DC: U.S. Department of Justice.

Ho, T. (2003). The influence of suspect gender in domestic violence arrests [dagger]. American Journal of Criminal Justice, 27, 183-195. doi: 10.1007/BF02885693

Hodes, M. (1993). The sexualization of reconstruction politics: white women and black men in the South after the Civil War. Journal of the History of Sexuality, 3, 402417. doi:1043-4070/93/0303-0003.

Hodges, K. M. (2000). A review of lesbian, gay, bisexual and transgender issues. Law and Sexuality, 9, 1-22.

Holder, R. (2001). Domestic and family violence: Criminal justice interventions (Issues Paper No. 3). Sydney: Australian Domestic and Family Violence Clearinghouse hooks, b. (1981). Ain't I a woman: Black women and feminism. New York: South End.

Howell, D. C. (2012). Statistical methods for psychology. Belmont, CA: Cengage Learning.

Huang, Y., Osborne, D., Sibley, C. G., \& Davies, P. G. (2014). The precious vessel: Ambivalent sexism and opposition to elective and traumatic abortion. Sex Roles, 71(11-12), 436-449. doi:10.1007/s11199-014-0423-3

Huff, C., \& Tingley, D. (2015). "Who are these people?" Evaluating the demographic characteristics and political preferences of MTurk survey respondents. Research \& Politics, 2(3), 1-12. doi: 10.1177/2053168015604648

Hull, G. T., Bell Scott, P., \& Smith, B. (1982). But some of us are brave: All the women are White, all the Blacks are men: Black women's studies. New York: Feminist.

Hurd, R. (1762). Letters on Chivalry and Romance. A. Millar, W. Thurlbourn, and J. Woodyer.

International Movement against All Forms of Discrimination and Racism (IMADR). (2006). Human trafficking and racism: Exploring the links between marginalization and exploitive migration. New York: IMADR.

Jackman, M. R. (1994). Velvet Glove: Paternalism and Conflict in Gender, Class, and Race Relations. University of California Press.

Jasinski, J. L. (2003). Police involvement in incidents of physical assault: Analysis of the redesigned National Crime Victimization Survey. Journal of Family

Violence, 18(3), 143-150. doi: 10.1023/A:1023512420703 
Jewell, K. S. (1993). From mammy to Miss America and beyond: Cultural images and the shaping of U.S. social policy. New York: Routledge.

Jordan, C. E. (2004). Intimate partner violence and the justice system: An examination of the interface. Journal of Interpersonal Violence, 19(12), 1412-1434. doi: $10.1177 / 0886260504269697$

Jost, J. T., Glaser, J., Kruglanski, A. W., \& Sulloway, F. J. (2003). Political conservatism as motivated social cognition. Psychological Bulletin, 129(3), 339-375. doi: 10.1037/0033-2909.129.3.339

Jost, J. T., \& Kay, A. C. (2005). Exposure to benevolent sexism and complementary gender stereotypes: Consequences for specific and diffuse forms of system justification. Journal of Personality and Social Psychology, 88, 498-509. doi: 10.1037/0022-3514.88.3.498

Kahn, K.B., Barreto, M., \& Kaiser, C. (2012). Stay silent or shout out? How benevolent sexism modifies attitudes towards females who confront sexism. Poster presented at Group Processes and Intergroup Relations, San Diego, CA.

Kahn, K. B., \& Davies, P. G. (2011). Differentially dangerous? Phenotypic racial stereotypicality increases implicit bias among ingroup and outgroup members. Group Processes \& Intergroup Relations, 14(4), 569-580. doi: $10.1177 / 1368430210374609$

Kahn, K. B., Goff, P. A., Lee, J. K., \& Motamed, D. (2016). Protecting whiteness: White phenotypic racial stereotypicality reduces police use of force. Social Psychological and Personality Science, 7(5), 403-411. doi: 10.1177/1948550616633505

Kahn, K. B., \& Martin, K. D. (2016). Policing and race: Disparate treatment, perceptions, and policy responses. Social Issues and Policy Review, 10(1), 82-121. doi: 10.1111/sipr.12019

Kahn, K. B., \& McMahon, J. M. (2015). Shooting deaths of unarmed racial minorities: Understanding the role of racial stereotypes on decisions to shoot. Translational Issues in Psychological Science, 1(4), 310-320. doi: 10.1037/tps0000047

Kahn, K. B., Steele, J. S., McMahon, J. M., \& Stewart, G. (2017). How suspect race affects police use of force in an interaction over time. Law and Human Behavior, 41(2), 117-126. doi: 10.1037/lhb0000218

Kahn, K. B., Thompson, M., \& McMahon, J. M. (2017). Privileged protection? Effects of suspect race and mental illness status on public perceptions of police use of force. Journal of Experimental Criminology, 13(2), 171-191. doi: 10.1007/s11292-016-9280-0

Kilianski, S. E., \& Rudman, L. A. (1998). Wanting it both ways: Do women approve of benevolent sexism? Sex Roles, 39, 333-352. doi: 10.1023/A:1018814924402.

King, D. K. (1988). Multiple jeopardy, multiple consciousnesses: The context of a Black feminist ideology. Signs, 14, 42-72. doi: 10.1086/494491.

King, E. B., Botsford, W., Hebl, M. R., Kazama, S., Dawson, J. F., \& Perkins, A. (2012). Benevolent sexism at work gender differences in the distribution of challenging developmental experiences. Journal of Management, 38(6), 1835-1866. doi:10.1177/0149206310365902

Klein, D., \& Kress, J. (1976). Any woman's blues: A critical overview of women, crime 
and the criminal justice system. Crime and Social Justice, 5, 34-49.

Kressin, N. R., Chang, B. H., Whittle, J., Peterson, E. D., Clark, J. A., Rosen, A. K., ... \& Petersen, L. A. (2004). Racial differences in cardiac catheterization as a function of patients' beliefs. American Journal of Public Health, 94(12), 2091-2097. doi: 10.2105/AJPH.94.12.2091

Krieger, N., Waterman, P. D., Hartman, C., Bates, L. M., Stoddard, A. M., Quinn, M. M., ... \& Barbeau, E. M. (2006). Social hazards on the job: workplace abuse, sexual harassment, and racial discrimination--a study of Black, Latino, and White lowincome women and men workers in the United States. International Journal of Health Services, 36, 51-85.

Kulig, T. C., \& Cullen, F. T. (2016). Where is Latisha's Law? Black Invisibility in the Social Construction of Victimhood. Justice Quarterly, 1-36. doi: 10.1080/07418825.2016.1244284

LaFavre, W. (1965) Arrest: The decision to take a suspect into custody. Boston: Little, Brown and Company.

Lamy, L., Fischer-Lokou, J., \& Guéguen, N. (2009). Induced reminiscence of love and chivalrous helping. Current Psychology, 28, 202-209. doi: 10.1007/s12144-0099059-9

Lee, E. (2007). The "Yellow Peril" and Asian Exclusion in the Americas. Pacific Historical Review, 76(4), 537-562. doi:10.1525/phr.2007.76.4.537

Lee, T. L., Fiske, S. T., \& Glick, P. (2010). Next gen ambivalent sexism: Converging correlates, causality in context, and converse causality, an introduction to the special issue. Sex Roles, 62, 395-404. doi: 10.1007/s11199-010-9747-9

Lerner, M. J. (1970). The desire for justice and reactions to victims. In J. Macaulay \& L. Berkowitz (Eds.), Altruism and helping behavior (pp. 205-229). New York: Academic Press.

Lerner, M. J. (1980). The belief in a just world: A fundamental delusion. New York: Plenum. doi: 10.1007/978-1-4899-0448-5

Lethality indicators. [PowerPoint slides]. (2016) Provided by police consultant.

Lila, M., Gracia, E., \& García, F. (2013). Ambivalent sexism, empathy and law enforcement attitudes towards partner violence against women among male police officers. Psychology, Crime \& Law, 19, 907-919. doi: 10.1080/1068316X.2012.719619

Lisco, C. G., Parrott, D. J., \& Tharp, A. T. (2012). The role of heavy episodic drinking and hostile sexism in men's sexual aggression toward female intimate partners. Addictive Behaviors, 37(11), 1264-1270. doi: 10.1016/j.addbeh.2012.06.010

Lyness, K. S., \& Heilman, M. E. (2006). When fit is fundamental: performance evaluations and promotions of upper-level female and male managers. Journal of Applied Psychology, 91(4), 777. doi: 10.1037/0021-9010.91.4.777

MacDowell, E. L. (2013). Theorizing from particularity: Perpetrators and intersectional theory on domestic violence. Journal of Gender, Race and Justice, 16, 531-576.

Madon, S., Guyll, M., Aboufadel, K., Montiel, E., Smith, A., Palumbo, P., \& Jussim, L. (2001). Ethnic and national stereotypes: The Princeton trilogy revisited and revised. Personality and Social Psychology Bulletin, 27, 996-1010. doi: 
$10.1177 / 0146167201278007$.

Madriz, E. (1997). Nothing bad happens to good girls: Fear of crime in women's lives. Univ of California Press.

Makin-Byrd, K., \& Azar, S. T. (2011). Beliefs and attributions of partner violence perpetrators: The physical and psychological violence of adolescent males. Violence and Victims, 26(2), 177-190. doi: 10.1891/0886-6708.26.2.177

Marable, M. (2004). Racism and sexism. In P.S. Rothenberg (6th Eds.), Race, class, and gender in the United States: An integrated study, 160-164. Worth Publishers: New York, NY.

Marchetti, G. (1994). Romance and the "Yellow Peril": Race, sex, and discursive strategies in Hollywood fiction. Berkley, CA: University of California Press.

Mayr, F. B., Yende, S., D’Angelo, G., Barnato, A. E., Kellum, J. A., Weissfeld, L., ... Angus, D. C. (2010). Do hospitals provide lower quality of care to black patients for pneumonia? Critical Care Medicine, 38(3), 759-765. doi: 10.1097/CCM.0b013e3181c8fd58

Mazerolle, L., Antrobus, E., Bennett, S., \& Tyler, T. R. (2013). Shaping citizen perceptions of police legitimacy: A randomized field trial of procedural justice. Criminology, 51(1), 33-63. doi: 10.1111/j.1745-9125.2012.00289.x

McCarthy, A. M., Bristol, M., Domchek, S. M., Groeneveld, P. W., Kim, Y., Motanya, U. N., ... \& Armstrong, K. (2016). Health care segregation, physician recommendation, and racial disparities in BRCA1/2 testing among women with breast cancer. Journal of Clinical Oncology, 34(22), 2610-2618. doi: 10.1200/JCO.2015.66.0019

McClelland, G. H. (2000). Nasty data: Unruly, ill-mannered observations can ruin your analysis. In H. T. Reis, \& C. M. Judd (Eds.), Handbook of research methods in social and personality psychology (pp. 393-411). New York, NY: Cambridge University Press.

McConahay, J. B. (1986). Modern racism, ambivalence, and the modern racism scale. In J. D. Dovidio \& S. L. Gaertner (Eds.), Prejudice, discrimination, and racism (pp. 91-125). Orlando, FL: Academic Press.

McMahon, J. M., \& Kahn, K. B. (2016). Benevolent racism? The impact of target race on ambivalent sexism. Group Processes \& Intergroup Relations, 19, 169-183. doi: $10.1177 / 1368430215583153$

McMahon, J.M. \& Kahn, K.B. (2017). When sexism leads to racism: Threat, protecting women, and racial bias. Sex Roles, 1-15. https://doiorg.proxy.lib.pdx.edu/10.1007/s11199-017-0828-x

Melton, H. C. (1999). Police response to domestic violence. Journal of Offender Rehabilitation, 29(1-2), 1-21. doi: 10.1300/J076v29n01_01

Meyer, S. (2011). Seeking help for intimate partner violence: Victims' experiences when approaching the criminal justice system for IPV-related support and protection in an Australian jurisdiction. Feminist Criminology, 6, 268-290. doi: $10.1177 / 1557085111414860$

Michalak, L. (1988). Cruel and unusual: Negative images of Arabs in American popular culture. ADC Issue Paper No. 15. Retrieved from http://files.eric.ed.gov/fulltext/ED363532.pdf 
Miles, H. (2012). WWII propaganda: The influence of racism. Artifacts, 6. Retrieved from https://artifactsjournal.missouri.edu/2012/03/wwii-propaganda-theinfluence-of-racism/

Min, S. J., \& Feaster, J. C. (2010). Missing children in national news coverage: Racial and gender representations of missing children cases. Communication Research Reports, 27, 207-216. doi: 10.1080/08824091003776289

Minear, M. \& Park, D.C. (2004). A lifespan database of adult facial stimuli. Behavior Research Methods, Instruments, \& Computers, 36, 630-633. doi: 10.3758/BF03206543.

Montañés, P., de Lemus, S., Bohner, G., Megías, J. L., Moya, M., \& Garcia-Retamero, R. (2012). Intergenerational transmission of benevolent sexism from mothers to daughters and its relation to daughters' academic performance and goals. Sex Roles, 66(7-8), 468-478. doi: 10.1007/s11199-011-0116-0

Mortensen, C. R., \& Cialdini, R. B. (2010). Full-cycle social psychology for theory and application. Social and Personality Psychology Compass, 4(1), 53-63. doi: 10.1111/j.1751-9004.2009.00239.x

Morton, D. (1991). Disfigured images: The historical assault on Afro-American women. Westport, CT: Greenwood Press.

Nagel, J. (2001). Racial, ethnic, and national boundaries: sexual intersections and symbolic interactions. Symbolic Interactions, 24, 123-139. doi:

10.1525/si.2001.24.2.123

National Women's Law Center. (2016a). Poverty rate falls but being a woman increases the odds of being poor in America [press release]. Retrieved from http://nwlc.org/press-releases/poverty-rate-falls-but-being-a-womanincreases-the-odds-of-being-poor-in-america-uninsurance-among-womendropped-by-nearly-one-third-under-the-aca-and-the-wage-gap-closes-by-just-onepenny-nwlc-ana/

National Women's Law Center (2016b). Equal pay for African American women. Retrieved from https://nwlc.org/resources/equal-pay-for-african-americanwomen/

Navarrete, C. D., McDonald, M. M., Molina, L. E., and Sidanius, J. (2010). Prejudice at the nexus of race and gender: an outgroup male target hypothesis. Journal of Personality and Social Psychology, 98, 933-945. doi: 10.1037/a0017931

Niemann, Y. F., Jennings, L., Rozelle, R. M., Baxter, J. C., \& Sullivan, E. (1994). Use of free responses and cluster analysis to determine stereotypes of eight groups. Personality and Social Psychology Bulletin, 20, 379-390. doi: 10.1177/0146167294204005.

Nisbet, E. C., Ostman, R., \& Shanahan, J. (2008). Public opinion toward Muslim Americans: Civil liberties and the role of religiosity, ideology, and media use. In A. Sinno (Ed.), Muslims in Western politics (pp. 161-199). Bloomington, IN: Indiana University Press.

Oppenlander, N. (1982). Coping or copping out. Criminology, 20, 449-465. doi: 10.1111/j.1745-9125.1982.tb00471.x

Osborne, D., \& Davies, P. G. (2012). When benevolence backfires: Benevolent sexists' opposition to elective and traumatic abortion. Journal of Applied Social 
Psychology, 42, 291-307. doi: 10.1111/j.1559-1816.2011.00890.x.

Ott, M. (2016). Tweet like a girl: A corpus analysis of gendered language in social media. Unpublished manuscript, Department of Linguistics, Yale University, New Haven, CT.

Patten, E. (2015, April 14). On equal pay day, key facts about the gender pay gap. Retrieved from http://www.pewresearch.org/fact-tank/2015/04/14/on-equal-payday-everything-you-need-to-know-about-the-gender-pay-gap/

Pennebaker, J.W., Boyd, R.L., Jordan, K., \& Blackburn, K. (2015). The development and psychometric properties of LIWC2015. Austin, TX: University of Texas at Austin.

Phelan, J. E., Sanchez, D. T., \& Broccoli, T. L. (2010). The danger in sexism: The links among fear of crime, benevolent sexism, and well-being. Sex Roles, 62, 35-47. doi: $10.1007 / \mathrm{s} 11199-009-9711-8$

Pierce, M. C., \& Harris, R. J. (1993). The effect of provocation, race, and injury description on men's and women's perceptions of a wife-battering incident. Journal of Applied Social Psychology, 23, 767-790. doi: 10.1111/j.15591816.1993.tb01006.x

Pilgrim, D. (2002). The jezebel stereotype. http://www.ferris.edu/news/jimcrow/menu.htl.

Plant, E. A., Goplen, J., \& Kunstman, J. W. (2011). Selective responses to threat: The roles of race and gender in decisions to shoot. Personality and Social Psychology Bulletin, 37, 1274-1281. doi: 10.1177/0146167211408617

Potter, H. (2010). 'I don't think a cop has ever asked me if I was ok': Battered women's experiences with police intervention. Female victims of crime: Reality reconsidered. Upper Saddle River, NJ: Pearson Education, pp. 219-242.

Prentice, D. A., \& Miller, D. T. (1992). When small effects are impressive. Psychological Bulletin, 112, 160-164. doi: 10.1037/0033-2909.112.1.160.

Purdie-Vaughns, V., \& Eibach, R. P. (2008). Intersectional invisibility: The distinctive advantages and disadvantages of multiple subordinate-group identities. Sex Roles, 59, 377-391. doi: 10.1007/s11199-008-9424-4.

Quillian, L., \& Pager, D. (2001). Black neighbors, higher crime? The role of racial stereotypes in evaluations of neighborhood crime. American Journal of Sociology, 107, 717-767. doi: $10.1086 / 338938$

Rasche, C. E. (1988). Minority women and domestic violence: The unique dilemmas of battered women of color. Journal of Contemporary Criminal Justice, 4, 150-171. doi: $10.1177 / 104398628800400304$

Rauma, D. (1984). Going for the gold: Prosecutorial decision making in cases of wife assault. Social Science Research, 13, 321-351. doi: 10.1016/0049089X(84)90008-5.

Rennison, C. M., \& Welchans, S. (2000). Intimate partner violence: Bureau of Justice statistics special report. Washington, DC: US Department of Justice. doi: 10.1037/e378132004-001

Reuben, E., Sapienza, P., \& Zingales, L. (2014). How stereotypes impair women's careers in science. Proceedings of the National Academy of Sciences, 111(12), 4403-4408.

Ristock, J. L. (2002). No more secrets: Violence in lesbian relationships. Psychology Press. Routledge: New York, NY. 
Robinson, A. L., \& Chandek, M. S. (2000). Differential police response to Black battered women. Women \& Criminal Justice, 12(2-3), 29-61. doi: 10.1300/J012v12n02_04

Rollero, C. Glick, P., \& Tartaglia, S. (2014). Psychometric properties of short versions of the ambivalent sexism inventory and ambivalence toward men inventory. TPM: Testing, Psychometrics, Methodology in Applied Psychology, 21(2), 149-159.

Rosenblatt, A., Greenberg, J., Solomon, S., Pyszczynski, T., \& Lyon, D. (1989). Evidence for terror management theory: I. The effects of mortality salience on reactions to those who violate or uphold cultural values. Journal of Personality and Social Psychology, 57, 681-690. doi: 10.1037/0022-3514.57.4.681.

Ross, L., Lepper, M., \& Ward, A. (2010). History of social psychology: Insights, challenges, and contributions to theory and application. In S.T. Fiske, D.T. Gilbert, \& G. Lindzey (Eds.), Handbook of social psychology, (pp. 3-50). 10.1002/9780470561119.socpsy001001

Rude, S., Gortner, E.M., \& Pennebaker, J.W. (2004). Language use of depressed and depression-vulnerable college students. Cognition \& Emotion, 18, 1121-1133. doi: 10.1080/02699930441000030

Rudman, L. A. (2004). Sources of implicit attitudes. Current Directions in Psychological Science, 13(2), 79-82. doi: 10.1111/j.0963-7214.2004.00279.x

Sakalh-Uğurlu, N., \& Glick, P. (2003). Ambivalent sexism and attitudes toward women who engage in premarital sex in Turkey. Journal of Sex Research, 40, 296-302. doi:10.1080/00224490309552194

Sarrasin, O., Fasel, N., Green, E. G. T., \& Helbling, M. (2015) When sexual threat cues shape attitudes toward immigrants: The role of insecurity and benevolent sexism. Frontiers in Psychology, 6, 1-13. doi: 10.3389/fpsyg.2015.01033

Schloesser, P. E. (2002). The fair sex: White women and racial patriarchy in the early American republic. New York, NY: NYU Press.

Schneider, M. E., Major, B., Luhtanen, R., \& Crocker, J. (1996). Social stigma and the potential costs of assumptive help. Personality and Social Psychology Bulletin, 22, 201-209. doi: 10.1177/0146167296222009

Schulman, K. A., Berlin, J. A., Harless, W., Kerner, J. F., Sistrunk, S., Gersh, B. J., ... \& Eisenberg, J. M. (1999). The effect of race and sex on physicians' recommendations for cardiac catheterization. New England Journal of Medicine, 340(8), 618-626. doi: 10.1056/NEJM199902253400806

Shepherd, M., Erchull, M. J., Rosner, A., Taubenberger, L., Queen, E. F., \& McKee, J. (2011). "I'll get that for you": The relationship between benevolent sexism and body self-perceptions. Sex Roles, 64, 1-8. doi: 10.1007/s11199-010-9859-2

Shernock, S., \& Russell, B. (2012). Gender and racial/ethnic differences in criminal justice decision making in intimate partner violence cases. Partner Abuse, 3(4), 501-530. doi: 10.1891/1946-6560.3.4.501.

Sibley, C. G., Overall, N. C., \& Duckitt, J. (2007). When women become more hostilely sexist toward their gender: The system-justifying effect of benevolent sexism. Sex Roles, 57, 743-754. doi: 10.1007/s11199-007-9306-1.

Sibley, C. G., \& Wilson, M. S. (2004). Differentiating hostile and benevolent sexist attitudes toward positive and negative sexual female subtypes. Sex Roles, 51, 687696. doi: 10.1007/s11199-004-0718-x 
Sibley, C. G., Wilson, M. S., \& Duckitt, J. (2007). Antecedents of men's hostile and benevolent sexism: The dual roles of social dominance orientation and right-wing authoritarianism. Personality and Social Psychology Bulletin, 33(2), 160-172. doi: $10.1177 / 0146167206294745$

Sidanius, J. (1993). The interface between racism and sexism. The Journal of Psychology, 127(3), 311-322. doi: 10.1080/00223980.1993.9915565

Sidanius, J., \& Pratto, F. (1999). Social dominance: An intergroup theory of social hierarchy and oppression. New York, NY: Cambridge University Press. doi: $10.1017 / \mathrm{CBO} 9781139175043$

Sidanius, J., \& Veniegas, R. C. (2000). Gender and race discrimination: The interactive nature of disadvantage. In S. Oskamp (Ed.), Reducing prejudice and discrimination: The Claremont Symposium on Applied Social Psychology (pp. 47-69). Mahwah, NJ: Erlbaum.

Slatcher, R.B. Vazire, S., \& Pennebaker, J.W. (2008). Am "I" more important than "we"? Couples' word usage in instant messages. Personal Relationships, 15, 407-424. doi: $10.1111 / \mathrm{j} .1475-6811.2008 .00207 . \mathrm{x}$

Smith, D. A. (1987). Police response to interpersonal violence: Defining the parameters of legal control. Social Forces, 65, 767-782. doi: 10.2307/2578527

Smith, D. A., \& Klein, J. R. (1984). Police control of interpersonal disputes. Social Problems, 31(4), 468-481. doi: 10.2307/800391

Smith, T. W., Marsden, P., Hout, M., \& Kim, J. (2015). General Social Surveys, $1972-$ 2012: Cumulative codebook. National Data Program for the Social Sciences Series, No. 22. Chicago: NORC at the University of Chicago.

Smith, D. A., \& Visher, C. A. (1981). Street-level justice: Situational determinants of police arrest decisions. Social Problems, 29, 167-177. doi: 10.2307/800422

Spence, J. T., Helmreich, R., \& Stapp, J. (1973). A short version of the Attitudes toward Women Scale (AWS). Bulletin of the Psychonomic Society, 2(4), 219-220. doi: 10.3758/BF03329252

Srinivas, T., \& DePrince, A. P. (2015). Links between the police response and women's psychological outcomes following intimate partner violence. Violence and Victims, 30, 32-48. doi: 10.1891/0886-6708.VV-D-13-00109

Stanton, E. C., Anthony, S. B., \& Gage, M. J. (Eds.) (1881). History of Woman Suffrage. New York: Fowler \& Wells.

Stephens, T. (1992). Review of disfigured images: The historical assault on AfroAmerican women. Explorations in Sights and Sounds, 12, 41-42.

Stephens, B. J., \& Sinden, P. G. (2000). Victims' voices domestic assault victims' perceptions of police demeanor. Journal of Interpersonal Violence, 15, 534-547. doi: $10.1177 / 088626000015005006$

Stewart, A., \& Maddren, K. (1997). Police officers judgments of blame in family violence: The impact of gender and alcohol. Sex Roles, 37(11/12), 921-933. doi: 10.1007/BF02936347

Stotland, E., \& Pendleton, M. (1989). Workload, stress, and strain among police officers. Behavioral Medicine, 15(1), 5-17. doi: 10.1080/08964289.1989.9935146

Sue, D. W. (2010). Microaggressions in everyday life: Race, gender, and sexual orientation. John Wiley \& Sons. 
Sue, D. W., Capodilupo, C. M., \& Holder, A. (2008). Racial microaggressions in the life experience of Black Americans. Professional Psychology: Research and Practice, 39, 329-336. doi: 10.1037/0735-7028.39.3.329

Sun, I.Y. (2007). Policing domestic violence: Does officer gender matter? Journal of Criminal Justice, 35, 581-595. doi: 10.1016/j.jcrimjus.2007.09.004

Sun, I. Y., \& Payne, B. K. (2004). Racial differences in resolving conflicts: A comparison between Black and White police officers. Crime \& Delinquency, 50(4), 516-541. doi: 10.1177/0011128703259298

Sun, I. Y., Payne, B. K., \& Wu, Y. (2008). The impact of situational factors, officer characteristics, and neighborhood context on police behavior: A multilevel analysis. Journal of Criminal Justice, 36(1), 22-32. doi: 10.1016/j.jcrimjus.2007.12.004

Sunshine, J., \& Tyler, T. R. (2003). The role of procedural justice and legitimacy in shaping public support for policing. Law \& Society Review, 37(3), 513-548. doi: 10.1111/1540-5893.3703002

Swim, J. K., Aikin, K. J., Hall, W. S., \& Hunter, B. A. (1995). Sexism and racism: Oldfashioned and modern prejudices. Journal of Personality and Social Psychology, 68(2), 199-214. doi: 10.1037/0022-3514.68.2.199

Swim, J. K., Hyers, L. L., Cohen, L. L., \& Ferguson, M. J. (2001). Everyday sexism: Evidence for its incidence, nature, and psychological impact from three daily diary studies. Journal of Social Issues, 57(1), 31-53. doi: 10.1111/00224537.00200.

Tabachnick, B. G. \& Fidell, L. S. (2013). Using multivariate statistics. Upper Saddle River, NJ: Pearson Education, Inc.

Tajfel, H. \& Turner, J. C. (1986). The social identity theory of intergroup behavior. In S. Worchol \& W. G. Austin (Eds.), Psychology of intergroup relations (2nd ed), (pp. 409-426). Chicago, IL: Nelson-Hall.

Tatum, K. M., \& Pence, R. (2015). Factors that affect the arrest decision in domestic violence cases. Policing: An International Journal of Police Strategies \& Management, 38(1), 56-70. doi: 10.1108/PIJPSM-07-2014-0075

Taube, A. (2014, September 23). 'Lean in' isn't enough: Women's process in leadership has stalled. Retrieved from http://www.businessinsider.com/why-women-arentgetting-more-c-suite-jobs-2014-9\#ixzz3jqzI7m2k

Tausczik, Y. R., \& Pennebaker, J. W. (2010). The psychological meaning of words: LIWC and computerized text analysis methods. Journal of Language and Social Psychology, 29, 24-54. doi: 10.1177/0261927X09351676

Tavris, C., \& Wade, C. (1984). The longest war: Sex differences in perspective (2nd ed.). San Diego, CA: Harcourt Brace Jovanovich.

Taylor, T. R., Williams, C. D., Makambi, K. H., Mouton, C., Harrell, J. P., Cozier, Y., ... \& Adams-Campbell, L. L. (2007). Racial discrimination and breast cancer incidence in US Black women: The Black women's health study. American Journal of Epidemiology, 166, 46-54. doi: 10.1093/aje/kwm056.

Tchen, J. K. W., \& Yeats, D. (Eds.). (2014). Yellow peril!: an archive of anti-Asian fear. New York, NY: Verso.

Tenenbaum, H. R., \& Leaper, C. (2002). Are parents' gender schemas related to their 
children's gender-related cognitions? A meta-analysis. Developmental Psychology, $38,615-630$.

Terrill, W. (2001). Police coercion: Application of the force continuum. New York, NY: LFB Scholarly Publishing.

Thompson, K. (2013, October 10). Essence: Black women still poorly depicted in media. The Washington Post. Retrieved from http://www.washingtonpost.com/blogs/shethe-people/wp/2013/10/10/essence-black-women-still-poorly-depicted-in-media/.

Tjaden, P., \& Thoennes, N. (2000). Prevalence and consequences of male-to-female and female-to-male intimate partner violence as measured by the National Violence Against Women Survey. Violence Against Women, 6(2), 142-161. doi: $10.1177 / 10778010022181769$

Trujillo, M. P., \& Ross, S. (2008). Police response to domestic violence making decisions about risk and risk management. Journal of Interpersonal Violence, 23, 454-473. doi: $10.1177 / 0886260507312943$

U.N. Women (2017, February 13). Take five: "in too many countries laws still discriminate against women". Retrieved from

U.N. Women (2016, August). Facts and figures: Leadership and political participation. Retrieved from http://www.unwomen.org/en/what-we-do/leadership-andpolitical-participation/facts-and-figures

U.S. Census Bureau. (2000). Genealogy Data: Frequently Occurring Surnames from Census 2000. Retrieved from http://www.census.gov/genealogy/www/data/2000surnames/index.html.

United States Holocaust Memorial Museum. (2016). Blacks during the Holocaust. Retrieved from https://www.ushmm.org/wlc/en/article.php?ModuleId=10005479.

Valenti, J. (2009). The purity myth: How America's obsession with virginity is hurting young women. Seal Press.

Victims' rights guide [Brochure]. (n.d.). Salem, OR: Department of Justice. Retrieved from https://www.doj.state.or.us/wpcontent/uploads/2017/03/victims_rights_guide-1.pdf

Viki, G. T., Massey, K., \& Masser, B. (2005). When chivalry backfires: Benevolent sexism and attitudes toward Myra Hindley. Legal and Criminological Psychology, 10, 109-120. doi: 10.1348/135532504X15277.

Visher, C.A. (1983). Gender, police arrest decisions, and notions of chivalry. Criminology, 21, 5-28. doi: 10.1111/j.1745-9125.1983.tb00248.x.

Voigt, R., Camp, N. P., Prabhakaran, V., Hamilton, W. L., Hetey, R. C., Griffiths, C. M., ... \& Eberhardt, J. L. (2017). Language from police body camera footage shows racial disparities in officer respect. Proceedings of the National Academy of Sciences, 11, 6521-6526. doi: 10.1073/pnas.1702413114

Wade, L. (2015). How 'benevolent sexism' drove Dylann Roof's racist massacre. The Washington Post. Retrieved from https://www.washingtonpost.com/posteverything/wp/2015/06/21/howbenevolent-sexism-drove-dylann-roofs-racist-massacre/?utm_term=.516ff7acac79

Wakefield, J. R., Hopkins, N., \& Greenwood, R. M. (2012). Thanks, but no thanks: Women's avoidance of help-seeking in the context of a dependency-related stereotype. Psychology of Women Quarterly, 36(4), 423-431. doi: 
$10.1177 / 0361684312457659$

Ware, V. (2015). Beyond the pale: White women, racism, and history. Brooklyn, NY:

Verso Books.

Weitz, R., \& Gordon, L. (1993). Images of black women among anglo college students. Sex Roles, 28, 19-34. doi: 10.1007/BF00289745.

White, E. C. (1985). Chain chain change: For black women dealing with physical and emotional abuse. Seattle, WA: The Seal Press.

Wigboldus, D. H., Semin, G. R., \& Spears, R. (2000). How do we communicate stereotypes? Linguistic bases and inferential consequences. Journal of Personality and Social Psychology, 78(1), 5-18. doi: 10.1037/0022-3514.78.1.5

Williams, O. J., Oliver, W., \& Pope, M. (2008). Domestic violence in the African American community. Journal of Aggression, Maltreatment \& Trauma, 16(3), 229-237. doi: 10.1080/10926770801925486

Wilson, T. C. (2001). Americans' views on immigration policy: Testing the role of threatened group interests. Sociological Perspectives, 44(4), 485-501. doi: $10.2307 / 1389655$

Wood, A. L. (2011). Lynching and spectacle: Witnessing racial violence in America, 1890-1940. Chapel Hill, NC: University of North Carolina Press.

Worrall, J., Ross, J., McCord, E. (2006). Modeling prosecutors' charging decisions in domestic violence cases. Crime and Delinquency, 52, 472-503. doi: $10.1177 / 0011128705282496$

Wyatt, J. (2008). Patricia Hill Collins's black sexual politics and the genealogy of the strong black woman. Studies in Gender and Sexuality, 9, 52-67. doi: 10.1080/15240650701759516.

Yamawaki, N., Ostenson, J., \& Brown, C. R. (2009). The functions of gender role traditionality, ambivalent sexism, injury, and frequency of assault on domestic violence perception: A study between Japanese and American college students. Violence Against Women, 15, 1126-1142. doi: $10.1177 / 1077801209340758$

Yardley, J. (2016). "Sexual attacks widen divisions in European migrant crisis. The New York Times. Retrieved from http://www.nytimes.com/2016/01/14/world/europe/aclimate-of-fear-widens-divisions-in-europes-migrant-crisis.html

Yegidis, B. L., \& Renzy, R. B. (1994). Battered women's experiences with a preferred arrest policy. Affilia, 9, 60-70. doi: 10.1177/088610999400900105

Young, I. M. (2003). The logic of masculinist protection: Reflections on the current security state. Signs: Journal of Women in Culture and Society, 29, 1-25. doi: 10.1086/375708

Young, V.D. (1986). Gender expectations and their impact on black female offenders and victims. Justice Quarterly, 3, 305-327. doi: 10.1080/07418828600088961. 


\section{APPENDIX A}

\section{Narrative Coding Instructions}

Person codes:

$\mathrm{V}$ - Victim (always female)

W - Witnesses

$\mathrm{X}$ - Suspect (always male)

$\mathrm{C}-$ Child witnesses

$\mathrm{O}$ - Officers on scene (often $\mathrm{O} 1, \mathrm{O} 2$, etc.)

$\mathrm{P}$ - Other persons listed in report

\section{1) Did the officer attempt to set up the victim with a DV Response Advocate?}

$$
\begin{aligned}
& 0=\text { No } \\
& 1=\text { Yes }
\end{aligned}
$$

It does not matter whether the victim accepts or declines the offer; only that the officer appears to bring it up. If no mention is made of DV Advocates, assume the officer didn't make the offer and code as a 0 .

Examples from text:

- A DV Advocate was requested to the scene.

- I informed her of...the availability of DV Advocates that could assist her.

- I requested a DV advocate respond to the location.

\section{2) Did the officer provide any additional informational resources to the victim?}

$$
\begin{aligned}
& 0=\text { No } \\
& 1=\text { Yes }
\end{aligned}
$$

Including, but not limited to, the officer's business card, information about how to get a restraining order, the case number, the phone number for DA's office, phone numbers for Women's Crisis Line or the Gateway Center

If the officer did not explicitly state in their report that they gave the victim any of the above resources, assume that they did not and code as a 0 .

Examples from text:

- I gave $\mathrm{V}$ my card with the assigned case number and information on how to obtain a restraining order.

- I made contact with $\mathrm{V}$ and provided her with information on how to apply for a restraining order as well as information for womens assistance.

- I provided her with the Abuse Prevention Sheet, DA Contact Info and the case number written on my business card. 


\section{3) Does the officer describe the victim as uncooperative?}

$$
\begin{gathered}
0=\text { No } \\
1=\text { Yes }
\end{gathered}
$$

If victims do not cooperate with the officer, then they will not be able to complete their reports, ask all their questions, or collect all the evidence.

We are looking for either:

a) Direct references to the victim being "uncooperative"

b) Descriptions of behavior that would directly interfere with the officers' reporting, e.g. if she refuses to answer any further questions or will not let them speak to her children or take photographs. The victim being too distraught to answer questions does NOT count as uncooperative unless the officer explicitly uses that word.

If the officer does NOT use the word "uncooperative" or describe uncooperative behaviors, assume that the victim did cooperate and code as a 0 .

Examples from text:

- As I continued talking with $\mathrm{V}$ about the details of the incident she started becoming uncooperative...She began...telling me how I needed to do my job, and not answering my questions.

- She did not want to answer further questions, and did not want any further help.

- V was not cooperative and stated that both she and the suspect are "not fans of law enforcement." It was difficult to get details about the incident as she refused to answer all questions.

\section{4) Who called the police?}

$$
\begin{gathered}
0=\text { someone else (a witness or child) or unknown } \\
1=\text { the victim }
\end{gathered}
$$

If the victim specifically asks for someone else to call police on her behalf, this counts as the victim making the call (because she is asking for police intervention.)

Examples from text:

- On [redacted] at $2036 \mathrm{hrs}$, dispatch advised of a disturbance at [location]. The caller stated that a male had beaten up a female and that they had the male restrained on the ground [code as 0 ]

- Dispatched to a domestic assault call. The female caller said her boyfriend had slammed her hand into a doorway. [code as 1] 


\section{APPENDIX B}

\section{$\underline{\text { Narrative Examples }}$}

\section{Example \#1}

I was dispatched to the area of [location] regarding a disturbance. Upon arrival I spoke with the caller $(V)$ who appeared to be crying. I asked $\mathrm{V}$ if she needed medical attention but $V$ did not respond. I told $V$ that she needed to calm down and I needed to know what had occurred.

$\mathrm{V}$ told she had an argument with her boyfriend of five years. At first V said she did not know why she the argument had started. $V$ then told me the argument started because her boyfriend, later identified as X, currently is unemployed and is having financial hardship. $\mathrm{V}$ explained that $\mathrm{X}$ is constantly asking $\mathrm{V}$ for money. $\mathrm{V}$ told me that it is difficult on her to support $X$, her daughter, and herself. V said she is the sole provider of the family. $\mathrm{V}$ explained that $\mathrm{X}$ does live at the location.

V told me X got really to close to her face and was yelling at her. V explained that when $\mathrm{X}$ was close to her $\mathrm{X}$ head-butted V. I was able to see $\mathrm{V}$ had a small bump on the top of her forehead. I asked $\mathrm{V}$ if she could rate her pain level from a scale of one to ten with ten being the worst pain she had ever felt. V said her pain level was a six. $V$ refuse any medical attention at the location.

$\mathrm{V}$ said she hit $\mathrm{X}$ back by slapping $\mathrm{X}$ to defend herself. $\mathrm{V}$ told me $\mathrm{X}$ continued to argue with V. V said X went to the kitchen and grabbed a handful of food and smothered it all over her face. This caused V to stop breathing for about a minute. I noticed that V's shirt that she was wearing was covered with food. V appeared to be upset and told she was tired of the situation that she was in.

I provided $V$ with information on how to obtain a restraining order and also provided $a$ $D V$ advocate to contact $V$. I provided $V$ a case number of this report along with my business card.

The victim called police (victim called $=1$ )

Victim is in emotional distress, but still eventually answers questions (uncooperative $=0$ ) Officer provides victim with informational resources (info $=1$ )

Officer sets up a DV advocate (advocate =1)

Paternalism words are in bold

Risk focus words are underlined

Note: The full dictionary of risk focus words is unknown (i.e. proprietary), so the underlined risk focus words here are non-exhaustive. 


\section{Example \#2}

$\mathrm{R} / \mathrm{C}$ to a suicide attempt at [location]. $V$ called 911 to report her husband, $\mathrm{X}$, was drunk and was threatening to kill himself with a knife. O1 arrived on scene and contacted $\mathrm{X}$ at the corner of [location]. X had walked out of the house prior to our arrival.

I arrived and contacted V who was outside of the house. V stated she had been assaulted and wanted $\mathrm{X}$ arrested. $\mathrm{V}$ told me $\mathrm{X}$ is a military veteran and suffers from PTSD. She stated $\mathrm{X}$ has threatened suicide multiple times in the past and has a problem with alcohol. $\mathrm{V}$ stated $\mathrm{X}$ has been trying to stay sober, but he started drinking today and threatened to kill himself. She stated X was intoxicated and they had an argument and he threatened to drive away. V said she took the keys to prevent him from leaving. V stated X grabbed the keys out of her hand and pinched her skin to make her drop the keys. V stated her son, C1, grabbed the keys out of her hand so X would not take them. V said X pushed $\mathrm{C} 1 \mathrm{during}$ the struggle for the keys. She stated $\mathrm{X}$ became very upset and started throwing things in the house and trying to remove property. She stated he threw the Xbox and pulled the TV cabinet away from the wall.

$\mathrm{V}$ told $\mathrm{X}$ to stop and she stated he pushed her three times. V said she almost fell down and she thought he was going to assault her. $X$ left the house and the police arrived thereafter. V stated she had no pain and did not need medical attention.

I spoke to $\mathrm{C} 1$ who told me he heard his dad yelling and he tried to get the keys away. $\mathrm{C} 1$ stated he did not really see his dad push his mother, but he stated his dad did push him a little bit when he was going for the keys.

I contacted $\mathrm{X}$ outside and noted he had a strong odor of alcoholic beverage coming from his breath. $\mathrm{X}$ told me to give him his ID and he was leaving. We placed X into custody without incident and I advised him of his Miranda rights to which he stated he understood, "yes." X said he wanted a lawyer so he was not questioned about the crime. I found nothing of value on his person and placed him into my patrol car without incident. $X$ told me he had prior injuries from his military service and so I double handcuffed him for more comfort. I provided $V$ with the DA complaint form with $R O$ information and the case number. $\mathrm{X}$ was transported and booked into [location] without incident.

The victim called police (victim called $=1$ )

Officer provides victim with informational resources (info $=1)$

No indication that victim was uncooperative (uncooperative $=0$ ) or that the officer attempted to set up a DV response advocate (advocate =0)

Paternalism words are in bold

Risk words are underlined 


\section{APPENDIX C \\ Paternalism Dictionary Instructions}

\section{Phase 1)}

The task: Help me to create a dictionary of words that capture the idea of "protective paternalism."

For example, if I asked you to come up with words that captured the idea of "school", you might say: homework, teacher, student, learn, study, graduate, test, etc.

Read through the text below a few times until you feel like you understand the concept. Using the description from the original study, the additional resources I've provided, and any dictionary/thesaurus of your choosing, list as many single words (not phrases) as you can think of that fit. You can type them directly into this document and email it back to me. We will narrow down the list later, but the first step is just to think of as many words as possible.

\section{What is protective paternalism? From the original study:}

"Paternalism literally means relating to others "in the manner of a father dealing with his children" (Random House College Dictionary, 1973)....This definition meshes well with the view that sexism is a form of ambivalence, for it includes connotations of both domination (dominative paternalism) as well as affection and protection (protective paternalism)...protective paternalism may coexist with its dominative counterpart because men are dependent on women (because of heterosexual reproduction) as wives, mothers, and romantic objects; thus, women are to be loved, cherished, and protected (their "weaknesses" require that men fulfill the protector-and-provider role)...Protective paternalism is evident in the traditional male gender role of provider and protector of the home, with the wife dependent on the husband to maintain her economic and social status"

Measured with these 4 items:

1. Men should be willing to sacrifice their own well being in order to provide financially for the women in their lives.

2. A good woman should be set on a pedestal by her man.

3. Women should be cherished and protected by men.

4. In a disaster, women ought not necessarily to be rescued before men.

\section{Other Resources:}

"Offering help, protection, advice, and caring might be seen as proof of intimacy that is congruent with romantic and intimate relationships but not with work relationships..." 
1. "Men are protective towards women"

2. "Men play the rescuers for women,"

3. "I expect a man to be protective towards me"

4. "I expect a man to be attentive to me,"

5. "Men should provide help to women for some tasks"

6. "Men should protect women"

"I would tell her that she cannot do this. I think it is a bad idea because it would not be safe for her and I think she would find it to be really stressful. Even if she thought she really wanted to do it, I would get her not to because I would be very worried about her safety and well-being in this situation. I am sure I could convince her."

"I don't think it's good for you to be exposed to people who have committed violent crimes. It seems like a stressful and dangerous situation that wouldn't be safe for you."

"Paternalism reflects views of women as underdeveloped adults, providing justification for men to be authoritative and monitor, protect, and make decisions on women's behalf."

\section{Phase 2)}

Instructions:

Help me to create a dictionary of words that capture the idea of "protective paternalism." In Phase 1, three different people contributed words that they thought would fit. Now, in Phase 2, I need you to tell me whether you think each word belongs in the dictionary or not.

Here's the tricky part: the words have to fit "protective paternalism" without being so broad as to also describe too many other things.

For example, if I asked you to come up with words that captured the idea of "school": Good words: homework, teacher, student, learn, study, graduate, test, exam, semester (very specific to school)

Bad words: people, building, place, time, kids, work (too broad)

Steps:

1) Read thoroughly through the descriptions on the Protective Paternalism tab until you understand the construct

2) Look at each word in the Words tab

3) If you think the word fits the construct of "protective paternalism", mark the column to the right with an asterisk *

4) If you think the word does NOT fit, leave the space next to it blank 


\section{APPENDIX D}

\section{Paternalism Dictionary Words}

breadwinner*
cherish*
chivalr*
defend*
defenseless
dote*
doting
gentleman*
help*
paternal
patriarch*
pedestal
protect*
provide*
rescue*
safe*
security
support*

Note: the use of an asterisk at the end of a word or word stem signals LIWC to ignore all subsequent letters. 
APPENDIX E

\section{Supplementary Models}

Model 4:
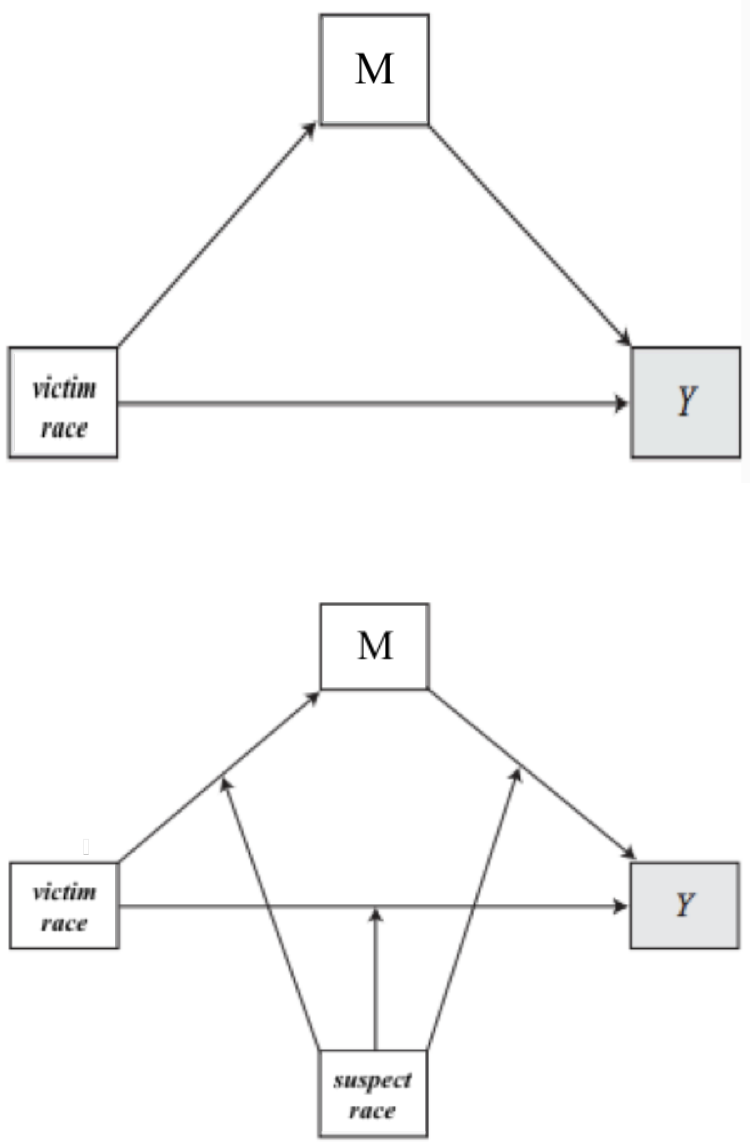

Model 59:

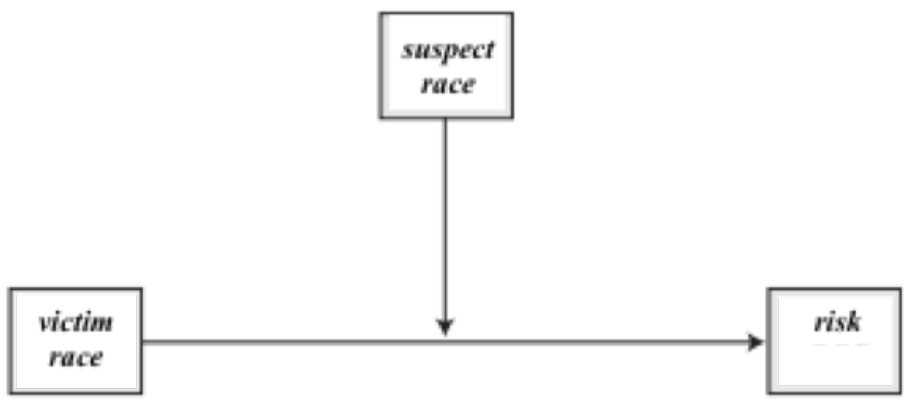

Model 1:

$\mathrm{M}=$ risk focus and paternalism, tested separately. $\mathrm{Y}=$ giving informational resources, taking photographs, assigning advocates, victim interview questions, finishing victim interview, discretionary helping scale (tested separately). All control variables were included as covariates. 